Göttinger Klassiker der Strömungsmechanik Bd. 1 herausgegeben von Andreas Dillmann

Johanna Vogel-Prandtl

Ludwig Prandtl Ein Lebensbild Erinnerungen, Dokumente

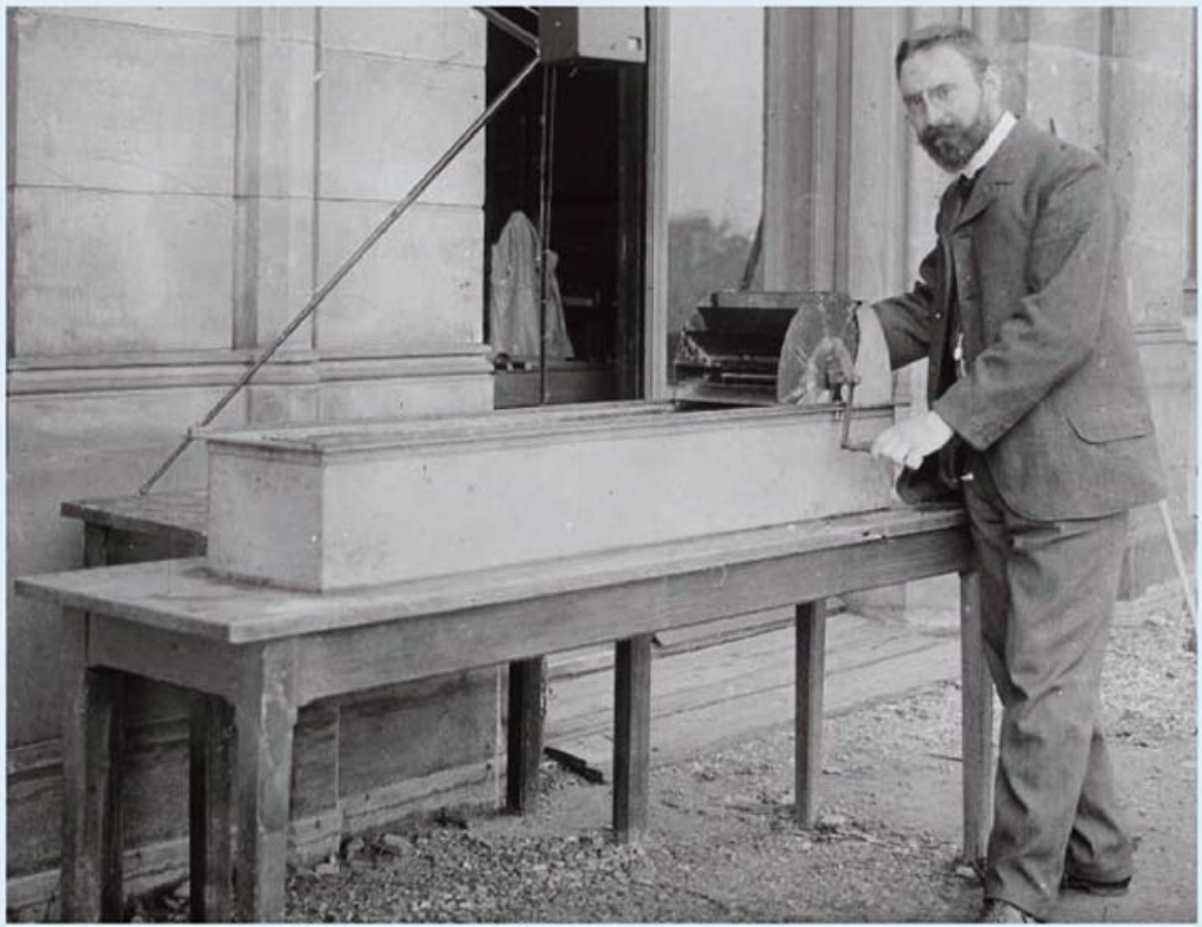

\title{
Universitätsverlag Göttingen
}





\section{Johanna Vogel-Prandtl \\ Ludwig Prandtl}

This work is licensed under the Creative Commons License 3.0 "by-nd", allowing you to download, distribute and print the document in a few copies for private or educational use, given that the document stays unchanged and the creator is mentioned.

You are not allowed to sell copies of the free version.

$$
\text { (c) }
$$

SORAERIGHIS RESERVED 
erschienen als Band 1 in der Reihe „Göttinger Klassiker der Strömungsmechanik“ im Universitätsverlag Göttingen 2005 


\section{Johanna Vogel-Prandtl \\ Ludwig Prandtl}

Ein Lebenbild

Erinnerungen, Dokumente

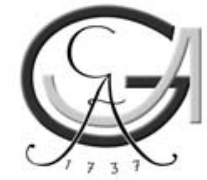

Universitätsverlag Göttingen 2005 
Bibliografische Information der Deutschen Bibliothek

Die Deutsche Bibliothek verzeichnet diese Publikation in der

Deutschen Nationalbibliographie; detaillierte bibliografische Daten sind im Internet über $<$ http://dnb.ddb.de $>$ abrufbar.

Herausgeber der Reihe „Göttinger Klassiker der Strömungsmechanik“"

Prof. Dr. rer.nat. Dr.-Ing.habil. Andreas Dillmann

(Georg-August-Universität Göttingen und

Deutsches Zentrum für Luft- und Raumfahrt)

Schriftleitung der Reibe „Göttinger Klassiker der Strömungsmechanik“"

PD Dr. rer. nat. Martin Rein

(Georg-August-Universität Göttingen und

Deutsches Zentrum für Luft- und Raumfahrt)

Ursprünglich erschienen in den „,Mitteilungen aus dem Max-Planck-Institut für Strömungsforschung“", Nr. 107, herausgegeben von E.-A. Müller, Selbstverlag: Max-Planck-Institut für Strömungsforschung, Göttingen 1993

Titelabbildung

Ludwig Prandtl an einem Wasserkanal. Fotografie aus Privatbesitz

(C) 2005 Universitätsverlag Göttingen

ISBN 3-938616-34-2 


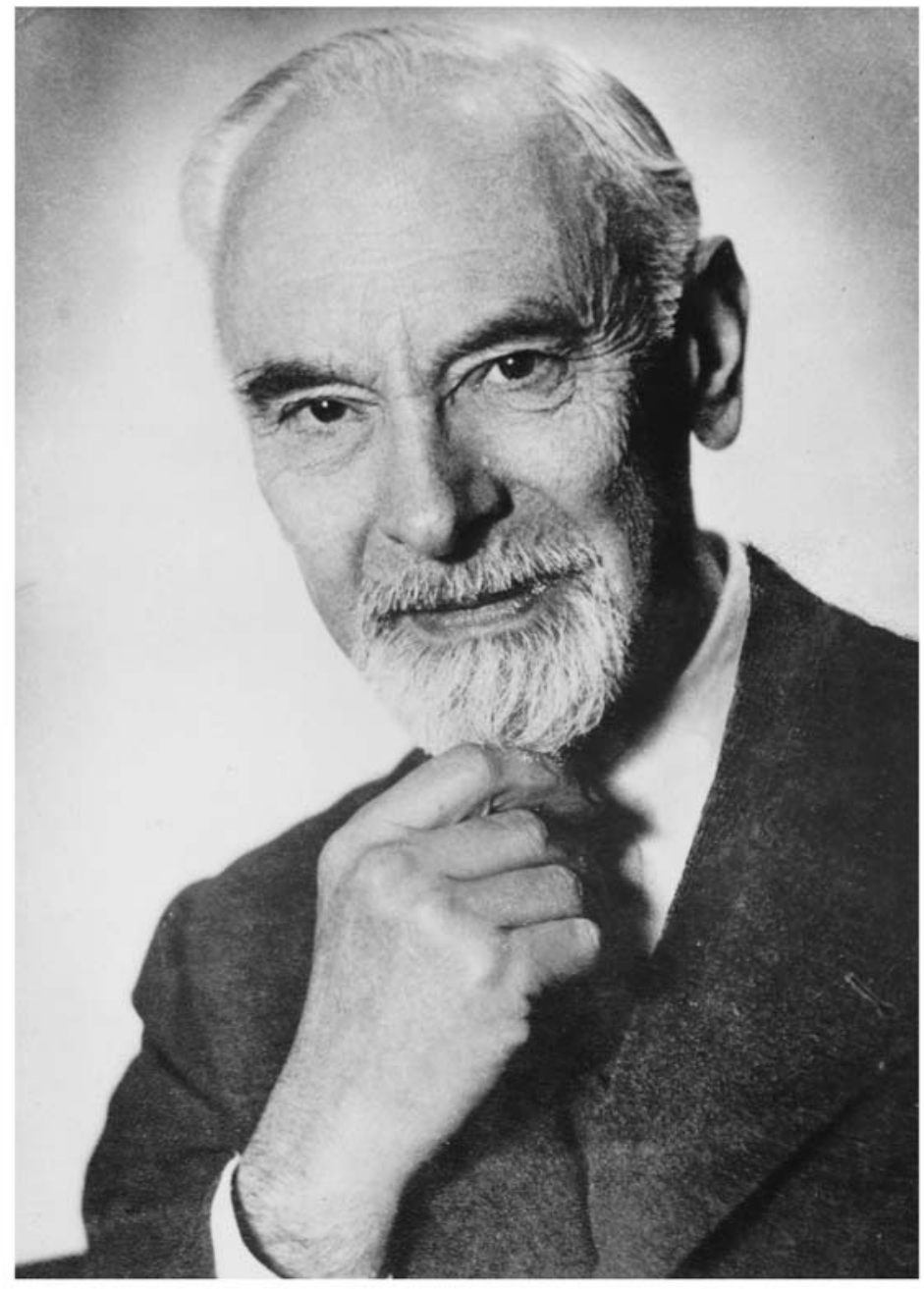

Ludwig Prandtl

4.2.1875 - 15.8.1953 



\section{Zum Geleit}

Ludwig Prandtl hat mit grundlegenden Beiträgen zur angewandten Mechanik, Hydro-, Aero- und Gasdynamik die Entwicklung auf diesen Gebieten in der ersten Hälfte unseres Jahrhunderts entscheidend vorangebracht. Durch die Herausgabe seiner gesammelten Werke, die wenige Jahre nach seinem Tode in drei Bänden erfolgte, sind seine Veröffentlichungen der Nachwelt umfassend zugänglich geworden. Diese schriftliche Hinterlassenschaft ist aber nur ein Teil der Lebensarbeit, die die Wissenschaft dem genialen Gelehrten verdankt. Auch zu den Arbeiten seiner zahlreichen Schüler und Mitarbeiter sowie vieler Fachkollegen aus der ganzen Welt hat er mit seinen Anregungen Wesentliches beigetragen.

Das Bildnis von der Forscherpersönlichkeit Ludwig Prandtls wäre unvollkommen, wenn man neben dem wissenschaftlichen Wirken nicht seine hohen menschlichen Qualitäten würdigen würde. Einige ehemalige Mitarbeiter haben bei Anlässen des Gedenkens ihre Erlebnisse aus dem Umgang mit ihrem Lehrer geschildert und so versucht, die Erinnerung an sein ausstrahlendes und vorbildliches Wesen wachzuhalten. Da die Aufsätze mit den Erinnerungen im Schrifttum weit verstreut sind, besteht die Gefahr, daß sie im Laufe der Zeit in Vergessenheit geraten. So wurde auch befürchtet, daß eine Biographie von Ludwig Prandtl niemals geschrieben würde. Diese Lücke soll das vorliegende Buch ausfüllen, das seine Tochter Frau Johanna Vogel-Prandtl verfaßt hat. Mit ihren Erinnerungen und Materialien möchte sie dem Leser vor allem den "Menschen" Ludwig Prandtl näherbringen.

Im Jahre 1904 erhielt Prandtl den Ruf an die Universität Göttingen, womit ein Forscherleben begann, das in der ganzen Welt Beachtung und Anerkennung fand. Da sein Wirken der jüngeren Generation vielleicht nicht mehr so präsent ist, soll es in dem nachstehenden Abriß kurz vorgestellt werden.

Er begründete die Grenzschichttheorie und die Tragflügeltheorie, er hatte grundlegende Ideen zur Strömung kompressibler Medien und zur turbulenten Flüssigkeitsbewegung, er wandte die Strömungsphysik in der Meteorologie an, aber auch seine Beiträge zu Problemen der Elastizität, Plastizität und Rheologie sollten erwähnt werden. 
Er gründete in Göttingen zwei bedeutende Forschungsanstalten: im Jahre 1907 die Aerodynamische Versuchsanstalt (zuerst unter dem Namen Modellversuchsanstalt), im Jahre 1925 das Kaiser-Wilhelm-Institut für Strömungsforschung. Im letzteren konnte er, von äußeren Anforderungen entlastet, intensiv Grundlagenforschung treiben. Besonders erfolgreich war er bei der Verbindung von Theorie und Experiment: neben den oben genannten Theorien (sie tragen beide seinen Namen) entwickelte er für seine Versuche Windkanäle und Meßgeräte (z.B. Prandtl-Rohr; Prandtl-Manometer) und erwies sich so als umfassender Gelehrter.

Unter seiner Anleitung als Hochschullehrer entstanden 83 Dissertationen. Er gehörte zu den aktiven Mitgründern zweier angesehener wissenschaftlicher Gesellschaften, der im Jahre 1912 gegründeten "Wissenschaftlichen Gesellschaft für Luftfahrt" (heute "Deutsche Gesellschaft für Luft- und Raumfahrt") und der im Jahre 1922 gegründeten "Gesellschaft für Angewandte Mathematik und Mechanik" (GAMM), deren Präsident er vom Gründungsjahr bis 1945 war.

Ludwig Prandtl wurde mit Ehrungen und Auszeichnungen überschüttet. An Ehrenpromotionen sind zu nennen: TH Danzig, TH Zürich, TH Prag, TH Trondheim, Universität Cambridge (England), Universität Bukarest und Universität Istanbul. Etwa zwanzig Akademien oder andere wissenschaftliche Institutionen haben ihn zu ihrem Mitglied bzw. Ehrenmitglied ernannt. Weiter sind ihm in großer Zahl Medaillen und andere Auszeichnungen verliehen worden, zuletzt das Große Verdienstkreuz der Bundesrepublik Deutschland.

Ende 1946 trat Prandtl als Direktor des Kaiser-Wilhelm-Instituts für Strömungsforschung zurück, im Sommer 1947 wurde er an der Universität emeritiert. 1953 starb er im Alter von 78 Jahren. Ein arbeits- und ehrenreiches, erfülltes Leben lag hinter ihm.

Ernst-August Müller

Universitätsprofessor für Angewandte Mechanik und Strömungsphysik an der Universität Göttingen

Direktor am Max-Planck-Institut für Strömungsforschung 


\section{Inhaltsverzeichnis}

Seite

Vorwort

1. Einleitung 1

2. Die Kindheit 2

3. Studienzeit - MAN - Berufung 14

4. Verlobung und Heirat 43

5. 1911-1918 Beruflicher Alltag $\quad 61$

6. Häuslicher Alltag 75

7. Segelfliegerei 78

8. Der Ruf nach München 80

9. Institutsaufbau und neue Projekte $\quad 89$

10. Das neue Kaiser-Wilhelm-Institut 94

11. Reise nach London 98

12. Japanreise 105

13. Wieder häuslicher Alltag 116

14. Ferienreisen 119

15. Das Jahr $1933 \quad 123$

16. Ehrendoktor von Cambridge und Trondheim 132

17. Das Gebirgshaus 134

18. Eintreten für W. Heisenberg 139

19. Stimmen zur Situation jener Zeit 142

20. Kongreß in Amerika 144

21. Der Physikerstreit 149

22. Rumänienreise 152

23. Aus der Zeit der letzten Kriegsjahre 156

24. Kriegsende 165

25. Neuanfang an der Universität 174

26. Erste Nachkriegsjahre 183

27. Allerletzte Lebensjahre 200

28. Schlußbemerkung 209

$\begin{array}{ll}\text { Anhang } & 210\end{array}$

$\begin{array}{ll}\text { Literatur } & 215\end{array}$ 



\section{Vorwort}

Im Laufe der letzten Jahre wurde es mir ein immer dringenderes Anliegen, in einer biographischen Studie die Gestalt meines Vaters, Ludwig Prandtl, nachzuzeichnen. Konnte ich doch als Tochter aufgrund vieler persönlicher Erinnerungen ein Lebensbild entwerfen, das in besonderem Maße den verschiedenen Seiten seines Wesens gerecht werden würde. Nicht fehlen sollten nämlich auch Szenen, die sich im engeren Kreis der Familie abgespielt haben und die ich nun als Letzte der Seinen wenigstens für meine Kinder und für diejenigen, denen Prandtl persönlich oder dem Namen nach bekannt ist, zur Charakteristik seiner Person festhalten möchte.

Es sei auch bemerkt, daß mein Onkel, Professor Ludwig Föppl, wiederholt bei Unterhaltungen mit seinem Schwager darauf zu sprechen kam, wie wichtig es sei, wenn jener jetzt im Alter seine Lebenserinnerungen schriebe, so wie es einst sein Vater August Föppl getan habe. Prandtl wies dieses Ansinnen jedesmal lächelnd zurück: "Vielleicht später, noch habe ich zu viele andere Aufgaben vor mir." Ich kannte ihn aber gut genug, um nach dieser Art der Antwort zu wissen, daß er es offensichtlich nicht im Sinn hatte, über sein eigenes Leben zu reflektieren und darüber zu berichten, auch nicht zu späterer Zeit.

Als mein Vater 1953 starb, wandte sich mein Onkel Ludwig Föppl nunmehr an mich mit den Worten: "Jetzt solltest Du über ihn schreiben!"

Jedenfalls war dies für mich der erste Anstoß, mir Gedanken darüber zu machen, wie mir ein solches Unterfangen gelingen könnte. Ein Mangel mußte sich allerdings bemerkbar machen. Fachkundige Interpretationen seiner wissenschaftlichen Arbeiten konnte ich nicht geben und deshalb nur sehr allgemein über die Forschung meines Vaters sprechen. Seine wissenschaftlichen Leistungen sind aber in seinen Gesammelten Abhandlungen [50] ${ }^{1)}$ ausführlich dokumentiert und dem Leser leicht zugänglich. Außerdem wurden zahlreiche Schrifttumshinweise angegeben, um dem interessierten Leser das weitere Studium der Werke Ludwig Prandtls zu erleichtern.

1) Die Nummern in eckigen Klammern weisen auf das Literaturverzeichnis am Ende des Buches hin. 
Als ich dann anfing, die Papiere zu ordnen und seinen Lebenslauf aufzuzeichnen, ergab es sich, daß ich in diesen Dingen auch viele gedruckte Formulierungen übernehmen konnte, wie ich sie in Zeitschriften, Aufsätzen und Briefen fand, die hier zitatweise mitgeteilt werden. Es mag sein, daß Aerodynamiker und naturwissenschaftlich interessierte Leser die von mir angeführten Kommentare über spezielle Arbeiten Prandtls als recht ungenügend einschätzen. Jedenfalls aber sollte all jenes doch von mir wenigstens erwähnt werden, was für ihn selbst freilich den Schwerpunkt seines Lebens ausgemacht hat.

Mein Vorhaben war es indessen gewesen, über den "Menschen" Ludwig Prandtl Aussagen zu machen; und dabei habe ich es seinen eigenen Briefen und Aufsätzen und den Briefen seiner Schüler zu verdanken, daß mein Text zu einem erheblichen Teil gewissermaßen authentische Züge trägt.

Zum Schluß möchte ich meinem Mann danken für letzte Durchsicht und Korrektur des Textes.

Im besonderen Maße gilt mein Dank auch Herrn Dr. Julius Rotta, dessen engagierte Teilnahme an meiner Arbeit ihn bewog, noch Ergänzendes beizutragen. Er fügte wissenschaftliche Artikel hinzu und überprüfte viele Zitate auf ihre Authentizität hin. Als besondere Bereicherung für das Buch erstellte er eine umfassende Bibliographie der Schriften Ludwig Prandtls. Für sein Korrekturlesen möchte ich ihm ebenfalls meinen Dank ausssprechen.

Dankbar verpflichtet fühle ich mich auch Herrn Dr. Walter Tillmann, dem Verwalter des Archivs des MPI, für sein Entgegenkommen und seine Hilfsbereitschaft sowie für seine kompetente Mitarbeit bei der Drucklegung des Buches. 


\section{Einleitung}

Was sind es für Erinnerungen an meinen Vater, die mir vor allem im Gedächtnis geblieben sind? Sein gütiges Wesen, seine innere Harmonie sind mir gegenwärtig, ebenso wie seine ruhige, bedächtige Art, ganz unbeeinflußt von dem meist ungeduldigen Eifer seiner Umwelt. Und ich sehe ihn vor mir, wie er behutsam mit den Dingen umzugehen pflegte, die ihn umgaben. Wenn er etwa das heruntergelaufene Gewicht seiner stets genau regulierten Wanduhr sorgsam mit unterstützender Hand hochkurbelte, lauschte er noch einen Moment dem gleichmäBigen Pendelschlag, ehe er den Glaskasten sachte wieder schloß.

Sein Sinn für liebevolles Bewahren und Erhalten war sehr ausgeprägt. Der schlichte Lebensstil in unserem Haus blieb durch die Jahre unverändert. Es wurde mehr an die sachlich nützliche Verwendbarkeit der Gegenstände gedacht als an eine moderne Aufbesserung. Die Gewohnheit bestimmte den fast unwandelbaren Fortgang des Bestehenden. Daran, daß mein Vater jemals von irgendwelchen Wünschen materieller Art gesprochen hätte, erinnere ich mich tatsächlich nicht. Seine übergroße Bescheidenheit und Anspruchslosigkeit befähigte ihn sogar, in den knappen Nachkriegsjahren mit geringsten Gaben dankbar zufrieden zu sein.

Es würde ihn wunder nehmen, wenn er von meinem Bemühen erführe, Vergangenes zu fixieren, und er hätte wohl eingewendet, daß sein Leben, von dem ich nun schreiben will, doch gar nicht so wichtig gewesen sei. 


\section{Die Kindheit}

Wenn ich nun versuche, von der Kindheit meines Vaters zu erzählen, so kann dies leider nur bruchstückartig und lückenhaft geschehen, weil niemand vorhanden ist, der mir helfen könnte, den Schatz der Erinnerungen ganz zu heben. So begnüge ich mich mit der Wiedergabe von Einzelheiten, die ich teils aus den Gedenkblättern meines Großvaters entnehme, der getreulich, wenn auch nur skizzenhaft, die Entwicklung seines einzigen Sohnes festgehalten hat, und gebe weiterhin einige Geschichten wieder, die uns mein Vater aus der Erinnerung erzählt hat. Die Tatsachen über die Familiengeschichte entnehme ich aus den Unterlagen der Familienforschung, die von zwei Vettern meines Vaters, Professor Wilhelm Prandtl und Ministerialrat Carl Prandtl, gesammelt worden sind.

Ludwig, erstes Kind des Alexander Prandtl, Professor in Weihenstephan zu Freising, und seiner Ehefrau Magdalena, geb. Ostermann, wurde am 4. Februar 1875, Donnerstag um dreiviertel sieben Uhr am Abend, im dritten Stock des Hauses seiner Großmutter, der Kaufmannswitwe Maria Ostermann geboren.

Dieses Geburtshaus in Freising, auf der Hauptstraße 64 gelegen, war damals seit über hundert Jahren im Besitz der Familie Ostermann, deren Stammvater Ludwig Ostermann 1760 aus Österreich übergesiedelt war. Zusammen mit seinem Bruder Franz, der als Glasmaler arbeitete, hatte er seinen Heimatort Kranebitten bei Kiefersfelden verlassen, um sich in Freising eine neue Existenz aufzubauen. Der nun gegründete Kolonialwarenladen grenzte an ein Stadttor, das Veitstor, das aber gerade im Jahre 1875 wegen Baufälligkeit abgerissen wurde. Dabei mußten auch Änderungen an dem Kaufmannshaus vorgenommen werden. Im Westen des Hauses lagen Pferdeställe und niedrige Katen, die zu einer Gastwirtschaft gehörten. Die rückseitigen Fenster blickten auf mittelalterliche Giebel und kleine Hinterhäuser.

Dort in dem besagten Kaufmannshaus hatte Alexander Prandtl 1869 bei der Witwe Maria Ostermann ein Zimmer gemietet, als er mit 29 Jahren seine Tätigkeit als Hochschullehrer an der landwirtschaftlichen Zentralschule Weihenstephan in Freising begann. Er kam aus München, wo er seine Schul- und Studienjahre absolviert hatte. Nach dem Besuch der dortigen Politechnischen Schule wurde er mit der 
Abschlußprüfung Kulturingenieur und trat als solcher in den Staatsdienst Niederbayerns. Nach Freising war er nun als Professor für angewandte Mathematik und Meliorationskunde ${ }^{1)}$ berufen worden. In Weihenstephan gab es außerdem folgende Unterrichtsfächer: Landwirtschaftliche Chemie, Landwirtschaftliches Geräte- und Pflanzenzeichnen, Anatomie und Physiologie der Haustiere, Forstwirtschaft, Meteorologie und anderes; angeschlossen war ein Brauereibetrieb zu Studienzwecken. Alexander arbeitete dort wissenschaftlich im Laboratorium der Molkereiversuchsstation. In den Jahren 1870 bis 1875 beschäftigte er sich vorwiegend mit der Konstruktion einer kontinuierlich arbeitenden Milchzentrifuge. Die Idee, sich mit dem Problem der Milchentrahmung durch Zentrifugalkraft zu befassen, stammte von seinem Bruder Antonin, der elf Jahre zuvor eine Arbeit darüber im Politechnischen Journal veröffentlicht hatte. Dieser war zuerst mit chemischen Kenntnissen an die praktische Aufgabe herangetreten, eine Konzentration der Milch zu ermöglichen. Alexander gelang es, der Erfindung seines Bruders einige wesentliche Verbesserungen hinzuzufügen, und 1875 zeigte er auf der Weltausstellung in Frankfurt am Main seine neue Entrahmungsmaschine, die als erste kontinuierlich arbeitende Milchzentrifuge der Welt erhebliches Aufsehen erregte und den Anstoß zu weiterer Entwicklung gab. Dieses selbe Modell wurde später im Deutschen Museum in der Abteilung für Milchwirtschaft aufgestellt. In den nächsten Jahren entwickelte er einen neuen Apparat, einen Milchteiler, der es ermöglichte, die Milch in Teile zu vergeben, ohne daß dabei Aufrahmung auftrat. Weiterhin veröffentlichte Alexander in der Weihenstephaner Milchzeitung mehrere wissenschaftliche Arbeiten, deren Themen ich der Vollständigkeit halber nennen möchte. 1877 entstand die Arbeit "Über den theoretisch zu erwartenden Effekt der Aufrahmung durch Zentrifugalkraft" und 1879 "Über den Einfluß der durch Erwärmung oder Abkühlung der Milch verursachten S t r ö m u n g".

Die Familie Prandtl, oder früher auch Präntl, war seit dem Anfang des 18. Jahrhunderts durch mehrere Generationen in München ansässig, aber wenn man die Linie noch weiter zurückverfolgt, findet man die Vorväter in der Tegernseer Gegend. Dort lebte der Zimmermann Bartholomäus Präntl, dessen älteste Tochter Maria in einer Chronik in Egern erwähnt wird, denn sie wurde die Gründerin des Mariani-

1) Bodenverbesserungskunde. 
schen Bundes in ihrem Heimatort. Am 19. Januar 1770 starb sie nach einem gottseligen Lebenswandel, und folgende Worte sind im Totenbuch von Egern hinzugefügt worden:

"Huius nomen, benigne lector, non leviter praetereas, illius Mariae nomen est, quae plurimas, et verbo et exemplo, animas docuit imitari quoad possibilitatem nostram in castitate Virginem Beatissimam. Fundatrix enim seu auctrix pacti ut vocant Mariani in Egern, haec erat immo et benefactrix, quod suo labore sudore re sibi lucrata fuerat, Deo, pauperibus et Beatissimae Virgini consecraverat. Conclude bone lector, qua morte mortua fuerit, quae tam pie vixit. A Daemone quidem obsessa fuit, sed crede non ad suam, sed ad maiorem daemonis torturam, daemonis inquam utpote tot excellentes virtutum actus, quos illa quotidie exercuerat, aegre certe ferentis, quia videntis. 19. Jan. ab hoc inviso hospite et simul a carcere carnis liberata est cum Christo aeternum regnatura in coelis, quem unice amavit in terris et ante abitum ex hoc mundo saepius in Domino devotissime suscepit Altaris sacramento."

"Ihren Namen, freundlicher Leser, übergeh nicht leichthin, es ist der Name jener Maria, welche zahllose Seelen durch Wort und Beispiel lehrte, in der Tugend der Keuschheit der allerseligsten Jungfrau nachzueifern, soweit uns dies möglich ist. Sie war nämlich die Gründerin und Förderin des sogenannten Marianischen Bundes in Egern und wahrhaft eine Wohltäterin, die das, was sie sich im Schweiße ihres Angesichts erworben, Gott, den Armen und der allerseligsten Jungfrau weihte. Schließ daraus, lieber Leser, welchen Todes die gestorben, die ein so frommes Leben geführt. Sie war zwar von einem bösen Geiste besessen, aber glaub es, nicht zu ihrer, sondern zu des Dämons größerer Qual, des Dämons, sag ich, der sich gewißlich sehr ärgerte, wenn er die vielen hervorragenden Taten der Frömmigkeit sehen mußte, die sie täglich übte. Am 19. Januar wurde sie von diesem ungebetenen Gaste und zugleich von den Banden des Fleisches befreit, um in Ewigkeit im Himmel mit Christus zu weilen, den sie auf Erden einzig geliebt und den sie vor ihrem Scheiden aus dieser Welt öfters Gott tief ergeben im Altarssakrament empfangen."

Marias Bruder Wolfgang Präntl, ebenfalls Zimmermann wie sein Vater, war der erste, der nach München übersiedelte; er fand dort eine Anstellung im Angerkloster. Es würde zu weit führen, die sämtlichen Familienmitglieder aufzuzählen, die sich 
durch die Generationen aneinanderreihen, und so greife ich vor und komme zu dem Großvater von Ludwig Prandtl, Antonin Prandtl, geboren 1795. Dieser war als junger Mann Berufssoldat gewesen, ehe er die Laufbahn des Beamten erwählte, die ihn später zu dem Beruf eines Aktuars und Steuerliquidators führte. 40-jährig in guter Position, verheiratete er sich mit Anna Charlotte Hauttmann, Tochter eines kurfürstlichen Hofbildhauers. Sein Schwiegervater Michael Hauttmann, geb. 1772 zu Waldsassen, entstammte einer berühmten Künstlerfamilie, erwähnt in Franz Bienbacks "Geschichte des Cisterzienserstiftes Waldsassen", deren verschiedene Familienmitglieder bildschnitzerische Arbeiten in der Klosterkirche in Waldsassen geschaffen haben. Der Hofbildhauer Michael lieferte Arbeiten für die ausgebrannten Gemächer König Maximilians I. in der alten Residenz sowie die Verzierungen der Königsloge im Hoftheater. Er widmete sich später bildschnitzerischen Arbeiten in Elfenbein, Alabaster und Perlmutt. Im bayerischen Nationalmuseum befinden sich Stücke aus diesem Elfenbeinkabinett. Ein paar kleine Arbeiten aus seiner Schaffenszeit von Anfang des 19. Jahrhunderts sind noch in unsere Hände gekommen, sehr feine Holzschnitzereien, die ebenfalls Museumswert besitzen. 1868 ist er im 97. Lebensjahr in München gestorben.

Das Ehepaar Antonin Prandtl hatte sich in Untergiesing ein Gartengrundstück erworben und dort eine kleine Kaffeewirtschaft eingerichtet. Ihre Gäste waren nur junge Leute, vor allem Künstler, die in die "fremde" Vorstadt hinausstrebten. Dieses großzügige, freiheitliche Leben dort draußen mit den vielen Anregungen durch die Gäste hatten wohl Antonins heranwachsenden Kindern - es waren drei Jungen und ein Mädchen - viel Freude bereitet und wird zugleich ihre geistige Entwicklung sehr gefördert haben. Die Eltern ermöglichten ihnen den Besuch der höheren Schule und anschlieBend eine gute Berufsausbildung. Carl hörte die chemischen Vorlesungen von Justus Liebig, ging dann zur Gärungschemie über und widmete sich ausschließlich dem Brauereifach. Er wurde Assistent für Chemie und Technologie an der Landwirtschaftlichen Zentralschule in Weihenstephan. In seinem Fachgebiet lieferte er einige wissenschaftliche Arbeiten und Beiträge und erfand die Prandtl-Filterpresse und die Prandtl-Hefepresse und wurde Generalvertreter für diese Brauereimaschinen. Von den geistigen Leistungen Antonins des Jüngeren war bereits die Rede. Nachdem es ihm nicht vergönnt war, seine Ideen über Milchwirtschaft selbst in die Praxis umzusetzen, wandte er sich auch dem Braufach zu. Er war Braumeister in der Schweiz, lange 
Jahre in Hamburg und kehrte dann 1884 nach München zurück und erwarb dort mit seinem Bruder Carl zusammen das Giesinger Bräuhaus. Ein Jahrzehnt später, als der elektrische Strom seinen Einzug in die Brauereien hielt, konnten sie den kleinen Betrieb nicht mehr umstellen und gerieten in Konkurs. Als Sachverständige haben sie dank ihrer guten wissenschaftlichen Kenntnisse noch weiterhin wirken können. Die Jüngste der Geschwister, Anna, heiratete einen Amtsrichter. Von Alexander, dem Vater Ludwig Prandtls, war bereits die Rede.

Die Verhältnisse im Hause Ostermann in Freising, in dem er sich, wie gesagt, eingemietet hatte, waren wesentlich bescheidener und enger als die der Familie Prandtl in Untergiesing. Natürlich lebte man in einer Vorstadt von München, die sogar durch eine Pferdebahn mit der Residenzstadt verbunden war, angeregter und freier als in dem kleinen Städtchen am linken Ufer der Isar, dort wo die Mosach einmündet. Die Einwohnerschaft der Mosachstadt, wie sie auch mitunter genannt wird, zählte damals, als Alexander seine Zelte dort aufschlug, 7000 Seelen. Vier alte Kirchen ragten mit ihren Türmen zwischen den alten Häusern empor. Weithin sichtbar auf einem Hügel, dem sogenannten Domberg, lag eine Basilika mit anschließenden Klostergebäuden, in denen sich ein Priesterseminar befand. Die Witwe Maria Ostermann, geb. Döbl, war die Tochter eines Bäckermeisters in Freising. Der Handelsmann Ludwig Ostermann - als solcher bezeichnet steht er im Freisinger Kirchenregister - war 22 Jahre älter als seine Frau. Er starb, als die Kinder noch klein waren, und somit mußte Maria Ostermann allein die Lasten und die Verantwortung für die Heranwachsenden tragen. Die Erziehung ihrer vier Kinder, Magdalena, Ludwig, Leopold und Maria - sei es nun, weil man im Bannkreis dieses heiligen Zentrums lebte, oder sei es aus traditioneller Gebundenheit - wurde von Grund auf streng katholisch geleitet. Sie sorgte dafür, daß diese die Klosterschule besuchten und hielt sie zu regelmäßigem Kirchgang an, denn sie vertraute ganz der Autorität der Kirche, die ihr bei der schwierigen Aufgabe helfen sollte. Als Alexander seine spätere Frau kennenlernte, war sie der Schule noch nicht entwachsen, sie war gerade 14 Jahre alt. Doch schon in dieser ersten Zeit faßte er eine besondere Neigung zu dem kleinen, zarten Mädchen, das in rührender Gewissenhaftigkeit seine häuslichen und schulischen Pflichten auf sich nahm. Mehrere Schulhefte von Magdalena sind noch erhalten, mit vielen frommen Sprüchen und Lebensregeln angefüllt, in zart geschwungener, fehlerloser Handschrift niedergeschrieben. Ebenso bewahrte mein Vater, Ludwig Prandtl, einige Buchpreise 
auf, die eine Widmung enthalten, wie zum Beispiel folgende: "1. Preis aus dem allgemeinen Jahresfortgang für Magdalena Ostermann, Schülerin der höheren Töchterschule Freising". Alle diese Geschenkbände waren erste Preise. Alexander schloß das Bild des ernsthaften, sehr schüchternen Mädchens immer mehr in sein Herz. Am 18. September 1872 feierte er mit Leni das Fest der Verlobung. Mit der Achtzehnjährigen ging er am 19. März 1874 in der Freisinger Pfarrkirche den Ehebund ein. Beide waren katholisch, allerdings stand Alexander nicht sehr fest in den kirchlichen Bindungen. In einem Brief an seine künftige Frau schrieb Ludwig Prandtl 1909: "Bis vor nicht allzu langer Zeit war ich strenger Katholik - wohl ein Erbteil meiner frommen Mutter"; er fragte Gertrud Föppl nach ihrer religiösen Einstellung und fuhr dann fort: "Wenn man miteinander harmonieren soll, so bilden gerade die religiösen Anschauungen einen sehr wichtigen Punkt, ich habe das zu meinem Leide an meinen Eltern beobachten können, die, obwohl beide sehr gute Menschen, in vielen Punkten sehr schlecht miteinander harmonierten, sei es nun Religion oder Erziehungsfragen oder etwas anderes gewesen. Ich sehe in der Ehe meiner Eltern, abgesehen von ihrer späteren Trübung durch die traurigen Krankheiten, ein Musterbeispiel einer Ehe, die aus gegenseitiger Liebe geschlossen wird und durch mangelndes Verständnis der Ehegatten für einander hinterher nicht glücklich wird."

Als Ludwig Prandtl 1875 zur Welt kam, war seine Mutter erst 19 Jahre alt, der Vater 35. Einige Notizen aus dessen Tagebuch folgen hierzu: "Am 11. Februar fand die Taufe statt. Am 4. Mai machte man sich auf zur Schießstätte, um dort 12 Stück Nadelholz zu pflanzen, zum Gedächtnis der Geburt Ludwigs. Am 16. Dezember fiel Ludwig aus dem Wägerl, ohne einen namhaften äußerlich sichtbaren Schaden zu nehmen." Es wird an jedem Geburtstag Gewicht und Körperlänge genau gemessen. 4. Februar 1879: "Ludwig kann Gegenstände bis zu 10 aufzählen und vorgesungene Töne rein nachsingen."

Inzwischen war die junge Familie in eine eigene Wohnung gezogen, die sich ebenfalls auf der Hauptstraße befand und die Hausnummer 41 trug. 30 April 79: "Ludwig kann zu Botschaftsgängen zur Großmutter geschickt werden." Auf diesen Wegen machte er viele selbständige Beobachtungen. Voll Neugier schaute er in die von Straßenarbeitern geöffneten Kanallöcher und verspätete sich mit dem Heimkommen. Über eine ganz frühe Erinnerung erzählte er mir folgendes: Das einsame, verträumte Kind 
spielte wie so oft vor dem Haus auf der Straße, als eine dunkle Wolke plötzlich ihre Schleusen öffnete und es zu regnen begann. Statt gleich ins Haus zu laufen, blieb das Kind noch im Regen, denn es war ja so spannend zu beobachten, wie die Gosse sich mehr und mehr mit Wasser füllte und Blätter und Papierfetzen mit fortschwemmte. Indem eilte eine Frau an ihm vorüber, die ihr Gewand geschürzt hielt und das Ende ihres weiten Rockes wie eine Kapuze über den Kopf geschlagen hatte. Dabei machte der kleine Ludwig eine unerwartete Entdeckung: Unter den Röcken der Frauen verbargen sich Beine, die wie diejenigen der Männer beschaffen waren. Die Mode der fußlangen Röcke und die Prüderie der Zeit hatten ihm das verborgen gehalten. Ein anderes Histörchen, das sich später zugetragen hat, spielte sich am Bahnhof ab. Der Vater nimmt Ludwig dahin mit, um Verwandte am Zug abzuholen. Man trifft den erwarteten Besuch, eine herzliche Begrüßung findet statt, langsam sucht man im Menschenstrom die Sperre zu erreichen. Aber da bemerkt der Vater, daß Ludwig nicht mehr neben ihm steht, er ist überhaupt nicht zu sehen. Etwas aufgeregt läuft der Vater am Bahnsteig entlang. Da sieht er sein Söhnchen bäuchlings auf dem Randstein liegen, direkt vor der Lokomotive, die er aufmerksam von unten beguckt und beobachtet. Der Erzieher spart nicht mit strengen Worten, während er ihn fortholt. Beim Erzählen dieser Geschichte hat mein Vater mir versichert, daß er nicht recht schuldbewußt gewesen sei, begreiflicherweise habe er sich bei den Gesprächen gelangweilt und sei darum seinen eigenen Interessen nachgegangen.

Vom Osterfest taucht eine andere Erinnerung auf: Man hatte dem kleinen Ludwig die bunten Eier im Garten versteckt. Mit Gründlichkeit begann er danach zu suchen und lud seine Schätze in einem Körbchen ab, das die Mutter für ihn bereit hielt. Es dauerte ziemlich lange, bis alles eingebracht war. Aber welche Enttäuschung sah man jetzt auf seinem Gesicht, als er das Körbchen an sich nehmen durfte. Er hatte mit einem Blick übersehen, daß längst nicht alle Eier, die er zuvor aus den Verstecken herausgeholt hatte, hier im Körbchen lagen. Er begann nun gründlich zu prüfen und zu zählen, und zum Erstaunen seiner Eltern hatte er genau im Gedächtnis, wieviele Ostereier er von jeder Sorte aufgesammelt hatte, und diese Summe stimmte nicht entfernt mit der in seinem Körbchen überein. Der Vater hatte nämlich, um den Spaß etwas zu verlängern, immer wieder heimlich die gerade gefundenen Eier neu versteckt, in der Meinung, bei einem so kleinen Bürschlein könne er sich diesen Schwindel erlauben. Um nicht des Betruges und der Naschhaftigkeit bezichtigt zu 
werden, mußte er nun seinem Sohn die ganze Wahrheit seiner Handlungsweise offenbaren.

1880: "Ludwig fängt an, Gedrucktes zu lesen." 1881: "Ludwig ist zwar dünn, aber von gesundem Aussehen. Er will Turnlehrer werden." Im Herbst 1881 kommt er in die Schule. 1882: "Ludwig ist der erste unter 82 Schülern!" Er bleibt der Beste auch in den darauffolgenden Volksschulklassen. Im September 1885 wird er zur Lateinschule angemeldet, die auf dem Freisinger Domberg liegt. Am 4. April 1886 geht Ludwig zur ersten heiligen Kommunion, am 15. Mai wird die Firmung gefeiert.

Die häuslichen Verhältnisse waren in diesen Jahren durch häufiges Kranksein der Mutter recht schwierig geworden. Schwere Schicksalsschläge hatten ihre zarte Gesundheit angegriffen und sie körperlich und seelisch zerrüttet. Sie hatte im April 1877 einem zweiten Knaben das Leben geschenkt, der aber unerwartet nach einer Woche verstarb. Im Januar 1879 wurde das dritte Kind, ein kleines Mädchen, geboren, es brachte die Gelbsucht mit auf die Welt und starb nach zwei Wochen daran. Frau Magdalena Prandtl geht im Sommer allein nach Altötting, um dort im Gebet Trost zu finden. 1881 bringt sie ein Sechsmonatskind tot zur Welt, 1883 geschieht dasselbe Unglück noch einmmal. Sie erlebt noch zwei weitere Fehlgeburten, dann ist ihre ganze Kraft erschöpft. Es lag nach heutigen medizinischen Erkenntnissen offensichtlich bei der Mutter ein Fall von "Rhesus negativ" vor. Vorbeugende Maßnahmen konnten ja nicht ergriffen werden, da der Sachverhalt noch nicht bekannt war.

Magdalena Prandtl leidet des öfteren an Herzkrämpfen. 1888 ist die tiefe Gemütsverstimmung zu einem Nervenleiden geworden, und sie kann nicht länger zu Hause bleiben. Der Arzt rät dem Vater, sie in die Nervenheilanstalt nach München zu bringen. Als sie nach einem halben Jahr nach Hause kommt, ist sie immer wieder bettlägerig. Da sich ihr Zustand nicht bessert, wird sie nach einiger Zeit in das Pflegeheim Neufriedheim gebracht.

Von dem Leiden der Mutter fiel ein trauriger Schatten auf die Knabenjahre Ludwigs, obschon sein Vater sich um so mehr um ihn kümmerte. Die unverheiratete Schwester Magdalenas, Marie, führte ihrem Schwager in den schwierigen Zeiten den Haushalt 
und beschäftigte sich viel mit ihrem Neffen. Sie spielte mit Ludwig Klavier zu vier Händen und sang mit ihm Volkslieder und Kunstlieder. Jedoch Alexanders Persönlichkeit stand in seinen Kinderjahren durchaus im Mittelpunkt von Ludwigs Erleben, wogegen der Einfluß der Mutter durch ihre Krankheit immer mehr zurücktrat. Der Vater förderte das früh auftretende Interesse seines Sohnes an physikalischen Erkenntnissen, er gab ihm seine Bücher, erklärte ihm die Maschinen und Instrumente darin. Er regte ihn zu eigenen Naturbetrachtungen an, dies geschah besonders häufig auf gemeinsamen Wanderungen im heimatlichen Gebirgsland. Das große naturkundliche Sachwissen des Vaters befriedigte ganz den geistigen Anspruch des Knaben, der in seinen vielen Fragen zum Ausdruck kam. Zur Bereicherung seines Privatnaturkundeunterrichts brachte der Vater eines Tages als Anschauungsmaterial eine Kiste mit zwei weißen Mäusen ins Haus, die auf dem Balkon aufgestellt wurde. Nicht lange danach erschienen die ersten Mäusekinder im Nest, die der Aufmerksamkeit und Pflege bedurften. Dies wurde eine heitere Beschäftigung für den einsamen Knaben. Allerdings war die Mäusefamilie schon nach einigen Monaten so beängstigend zahlreich geworden, daß man sich entschließen mußte, die erfolgreiche Zucht wieder aufzugeben.

Auch Erziehungsfragen beschäftigten Alexander mitunter sehr. Es bereitete ihm viel Ärger, wenn Ludwig bei seinen Schularbeiten träumte und säumig war, wie es häufig vorkam. Das erregte dann seine Ungeduld aufs äußerste, so daß er manchmal strenge Maßnahmen ergriff, um ihm diese Schwächen auszutreiben. So formte und lenkte er den Knaben, dessen Gedeihen ihm so sehr am Herzen lag. Ludwigs Werdegang betreffend, notierte er in seinem Tagebuch besonders genaue Einzelheiten, als da sind Zeugnisse, Krankheitsfälle und Reisen. Die Geschwister Alexanders, Carl und Anna, kamen oft auf Besuch, natürlich auch Carls Kinder, die mit Ludwig eines Alters waren. Auch traf man sich häufig in München, der alten Heimatstadt. In besonders schöner Erinnerung blieben meinem Vater die Tage und Wochen, die er auf Besuch in Dingolfing bei seiner Tante Anna, der Schwester des Vaters, verbrachte. Diese war in ihrer Ehe kinderlos geblieben und lud sich in den Ferien mehrere ihrer Neffen und Nichten ins Haus, deren fröhliches Treiben in Garten und Haus ihr niemals zu viel wurde. Bei dieser Tante, der Frau Oberamtsrichter Kastner, fühlte sich Ludwig immer ganz besonders liebevoll aufgenommen, und im Kreise seiner Vettern und Kusinen vergaß er seine Kümmernisse über die eigenen traurigen Verhältnisse. Die 
gleichaltrigen Verwandten waren die besten Spielgefährten und konnten ihm ein wenig die fehlenden Geschwister ersetzen. Durch sein ganzes Leben hindurch hat er ihnen seine Anhänglichkeit bewiesen. Eine Kusine schrieb 1944 an ihren Vetter Ludwig: "Ich habe daran gedacht, wie Du schon als Schüler über Gleichgewicht und Statik nachdachtest. Erinnerst Du Dich an Deine Nachtisch-Experimente mit Flaschen, Tellern, Gabeln und Messern, die meist eine beängstigende Höhe erreichten?"

Damals lebte auch noch die Großmutter, Anna Charlotte Prandtl, bei ihrer Tochter in Dingolfing und freute sich, ihre heranwachsenden Enkel oft bei sich sehen zu können.

Auch die Ferienfahrten allein mit dem Vater waren Erlebnisse, deren er sich später gern erinnerte. Diese Vakanzreisen, so bezeichnet stehen sie in Alexanders Tagebuch, führten entweder in das Münchner Seengebiet oder über Innsbruck in die verschiedenen Gebirgstäler Österreichs, manchmal sogar bis nach Südtirol, bis Bozen und Meran. Wenn zwischendurch ein längerer Aufenthalt gemacht wurde, verbrachte Ludwig seine Zeit damit, die Landschaft in aller Genauigkeit abzuzeichnen. Auch seine Heimatstadt Freising wurde mehrfach zum Objekt seines zeichnerischen Eifers. Die liebevolle Art, mit der er dabei ins Detail ging, zeigte für das Alter eine gute Begabung und dabei die Handschrift eines geduldig Schaffenden.

Auf die Entwicklung der musikalischen Begabung seines Sohnes legte Alexander besonderen Wert. Mit neun Jahren erhielt Ludwig die ersten Klavierstunden bei einem Professor Durmayer. Der Vater spielte selbst sehr gern Klavier und pflegte musikalische Abendunterhaltungen mit einem Freisinger Lehrer zu veranstalten. Außerdem hatte er in der Kunst des Hornblasens einige Virtuosität erlangt, ebenso wie sein Bruder Carl. Alexander und Carl haben einmal zusammen ein öffentliches Konzert mit Hornduetten gegeben, dessen umfangreiches Programm nahezu zwei Stunden dauerte. Die musikalische Betätigung entsprach wohl einem inneren Bedürfnis Alexanders, der in seiner Religion keine Erquickung fand. Seine Haltung der Kirche gegenüber wurde immer ablehnender. Er konnte die Glaubensdogmen der katholischen Religion mit seinem naturwissenschaftlichen, kritischen Denken nicht vereinen. Besonders das Dogma von der Unfehlbarkeit des Papstes, das 1870 verkün- 
det worden war, schien ihm nachträglich unannehmbar. Vielleicht hat er auch unter dem Einfluß jener Gruppe von Münchener Professoren gestanden, die gemeinsam gegen das Dogma protestiert haben (Altkatholiken). Alexander trat ganz aus der Kirchengemeinschaft aus, etwa im Jahre 1886.

Der Einfluß des Vaters auch auf religiösem Gebiet ist aus Ludwigs Leben nicht hinwegzudenken. Die Aufgabe, die durch die Krankheit seiner Frau auf Alexander gefallen war, sich der Fürsorge und Pflege seines Kindes zu widmen, war ihm zeitlich doch nur schwer möglich gewesen, da er beruflich häufig unterwegs war. So entschloß er sich im Herbst 1888, Ludwig im königlichen Erziehungsinstitut, dem Ludwigsgymnasium in München, bei dem Direktor, Willy von Coulon, anzumelden. Er wurde in einem Heim, dem Hollandeum, untergebracht und fuhr nur in den Ferien nach Hause. Mein Vater sprach manchmal davon, daß diese Zeit für ihn recht schwierig gewesen sei. Er machte trübe Erfahrungen im Zusammenleben mit anderen Schülern, denn er wurde viel gehänselt und von gewandteren, stärkeren Kameraden unterdrückt. Innerlich war er gegen alle diese Rüpeleien wehrlos, er erlitt still, was ihm angetan wurde. Als das Schuljahr zu Ende war, holte ihn sein Vater wieder zurück nach Freising, denn inzwischen hatte sich der Krankheitszustand der Mutter wieder gebessert. Es war aber, wie schon gesagt, nur eine vorübergehende Besserung. Ihr Leiden verschlimmerte sich bald wieder. Zwei Jahre Freisinger Lateinschule folgten nun für Ludwig. Als dann aber die Mutter ganz aus dem Familienleben ausscheiden mußte, wurde der Knabe wieder auf das Münchener Gymnasium geschickt. Diesmal wußte er sich unter den Mitschülern etwas besser zu behaupten, und er fand auch Freunde. An diese gemeinsame Internats- und Schulzeit erinnerte sich Oskar Winsauer; er war 1940 Stadtpfarrer bei der Heilig-Kreuz-Kirche, München-Forstenried, geworden:

\section{"6. April 1941. Lieber Studienkollege!}

Und jetzt schreibe ich doch! Oft schon wollte ich mich hinsetzen, um meinem lieben Koäven und Mitzögling vom Hollandeum zu schreiben und zu gratulieren, besonders damals, als im 'Neuen Münchner Tageblatt' Dein Bild erschien samt der Mitteilung, daß Dir eine hohe staatliche Auszeichnung zuteil geworden ist ${ }^{1}$ ) - aber immer hielt

1) Gemeint ist vermutlich: Freistaat Bayern, Goldener Ehrenring mit dem Bayrischen Staatswappen. München, 7.5.1926. 
mich der Gedanke zurück, was wird sich der berühmte Wissenschaftler um einen einfachen Pfarrer scheren. Nun habe ich aber Klotz und Reiter getroffen, die mir mitteilten, daß Du ihnen freundlichst ein Lebenszeichen gegeben habest. So möchte ich Dir auch ein Lebenszeichen geben und Dir einliegend eine Urkunde aus dem vorigen Jahrhundert übermitteln. Armer Leidenskollege! Aber, was mußt Du auch Deine Karte beschmieren? Übrigens wird das kaum der einzige Pultarrest gewesen sein, den wir erhalten haben. Ich wenigstens brachte deren 60 pro Jahr zusammen - weil ich mir erlaubte 'mit Tinte ins Buch zu schreiben' oder 'wegen geräuschvollen Niesens' und dergleichen mehr - meist aber wegen Unaufmerksamkeit.

Solltest Du einmal wieder während Deiner Ferien nach München kommen, würde ich Dich herzlich bitten, mich anzurufen."

Ludwigs Leistungen in den naturwissenschaftlichen Fächern lagen in all den Jahren weit über dem Durchschnitt, und durch diese geistige Überlegenheit hat er sich mit der Zeit doch den Respekt seiner Klassenkameraden erwerben können.

1894 konnte er mit dem Studium beginnen, und zwar blieb er in München. Er war vier Jahre lang Hörer an der Technischen Hochschule.

Der Haushalt in Freising war unterdessen ganz aufgelöst worden. Alexander, der an Herzschwäche litt, trat mit 52 Jahren in den Ruhestand und zog zu seiner Schwester Anna nach Dingolfing. Die Bürde des Schicksals lastete auf ihm. Er starb dort am 17. März 1896. Im Jahre 1898 wurde seine Frau Magdalena nach vielem Leiden durch den Tod erlöst. Ludwig stand nun allein im Leben. Er vertiefte sich ganz in seine Wissenschaft, was ihn schon nach wenigen Jahren auf den Weg des Erfolges führte. Es bewegt mich zu sagen, daß es besonders traurig war, daß seine Eltern diese Freude nicht mehr erlebten. 


\section{Studienzeit - MAN - Berufung}

Ludwig Prandtls Interessen waren vor allem auf physikalische und technische Dinge gerichtet, so daß die Entscheidung für sein Studium nicht schwer fiel. Er wählte die Ausbildung zum Maschineningenieur. Den Ratschlägen seines fürsorglichen Vaters folgend, begann er gleich im August 94 - im Juli hatte er die Schule beendet - eine dreimonatige Werkstattpraxis. Diese Lehrpraxis, die er vor dem Studium abzuleisten hatte, führte ihn nach Nürnberg, wo er sich bei der Maschinenbaugesellschaft MAN beworben hatte. Er arbeitete in der Gießerei sowie in der Modellschreinerei. Anschließend im Herbst 94 begann für ihn das theoretische Studium an der Königlich Technischen Hochschule in München.

Seine wichtigsten Lehrer waren: Professor für Mechanik, August Föppl; Professor für Mathematik, S. Finsterwalder; Professor für Physik, L. Sohnke; Professor für theoretische Maschinenlehre, M. Schröter.

In den Ferien nutzte er die Zeit zu weiterer praktischer Tätigkeit, teilweise wieder in Nürnberg. 1898 schloß er seine Ausbildung an der TH mit der Prüfung zum Maschineningenieur ab.

$\mathrm{Da}$ diese Münchner Studienjahre seinen Gesichtskreis sehr erweiterten, ist gewiß. Er trat in eine studentische Verbindung ein, den Münchner Gesangsverein, der vor allem musikalische Studenten zusammenführte. Mein Vater hatte eine schöne Baßstimme, und er sang gern in einem mehrstimmigen Chor. Wie einst sein eigener Vater griff er nun auch zu einem Blasinstrument und lernte das Waldhorn blasen. Ein Bundesbruder, der sich nach 40 Jahren wieder meldete, nahm in seinem Brief vom 5.5.39 darauf Bezug. Hermann Peckert schrieb: "Ich nehme an, daß Du Dich noch an mich erinnerst. Wenn auch nicht so deutlich, wie ich den Trompetenprandtl mit seinem schwarzen Vollbart und seinem glücklichen Temperament, das stets von Erschütterungen frei war, im Gedächtnis behalten habe. Und so wird's auch wohl geblieben sein. Möglicherweise hast $\mathrm{Du}$ das Trompetenblasen aufgesteckt, nachdem $\mathrm{Du}$ die dadurch erzeugten Luftwirbel genügend studiert hattest". Sein eigentliches Instrument blieb jedoch das Klavier. Sechs Jahre Übungszeit hatten ihn weit gebracht. Er spielte die 
Sonaten von Beethoven, Haydn und Mozart. Er sang Schubertlieder und begleitete sich selbst dazu auf dem Pianoforte.

Die Studenten unternahmen auch Wanderungen in die nähere Umgebung. Und in manch kleinem Dorfkirchlein stieg er zur Orgel hinauf, prüfte den Blasebalg und präludierte dann eine Weile, alle Register im Wechsel einsetzend. Er liebte dieses vielseitige Musikinstrument ganz besonders.

Als später sein Göttinger Institut baulich erweitert wurde, hatte er sogar mit dem Gedanken gespielt, in einer der Hallen eine Orgel einbauen zu lassen.

Es bot sich auch manche Geselligkeit, die Freude bereitete. Mein Vater hat von einem Wäschefest erzählt, das zur Faschingszeit mit allerhand Phantasie ausgestaltet war. Die meisten Damen im Kostüm von Holländerinnen brachten Wäschekörbe mit. Überall im Saal waren Wäscheseile aufgezogen, und jeder konnte seine eigene Wäsche dort aufhängen. Die feine Sitte wurde natürlich gewahrt - keine "Unaussprechlichen"! Aber Handtücher, Servietten und Kissenbezüge hingen bald bunt durcheinander auf der Leine. Und in dieser Umgebung, die einem großen Trockenboden ähnelte, wurde fröhlich getanzt.

Im Hause seines Onkels Carl Prandtl, der damals in München lebte, war er häufiger zu Gast. Er traf Vorbereitungen mit seinem Vetter Carl zu gemeinsamen Bergwanderungen, oder er begleitete seine Cousine Clara auf Spazierwegen an der Isar entlang oder im Park von Nymphenburg.

Als Prandtl 1898 seine Schlußprüfung mit der Gesamtnote "sehr gut" bestand, wurde ihm von Professor Föppl eine Hilfsassistentenstelle angeboten, die er freudig annahm. Der Posten, der für einen angehenden Doktoranden gedacht war, wurde nur auf ein Jahr vergeben. Nun hätte Prandtl nach Abschluß seines Studiums seiner Militärpflicht genügen müssen. August Föppl hatte deshalb am 8.7.98 ein Gesuch an das Commando des königlichen Pionier Detachement gerichtet mit folgendem Inhalt:

"Mit Beginn des neuen Studienjahres im Herbst des Jahres sollen an dem von mir geleiteten mechanisch-technischen Laboratorium der Königlich Technischen Hoch- 
schule Übungen eingerichtet werden, wozu ein weiterer Assistent einzustellen ist. Besonders geeignet für diesen Posten, auf dessen Besetzung mit einem dazu gut vorbereiteten Ingenieur wegen der Neueinrichtung dieses Unterrichtszweiges viel ankommt, wäre Herr Ludwig Prandtl, der am Schlusse des Semesters die Hochschule verläßt und dann stellungspflichtig ist. Wenn es zulässig ist, den genannten Prandtl auf ein Jahr zurückzustellen, möchte ich mir erlauben, an das königliche Commando die ergebenste Bitte zu richten, die Zurückstellung gütigst aussprechen zu wollen. Dem Unterricht an der Königlich Technischen Hochschule würde hierdurch ein wichtiger Dienst erwiesen werden. In der Hoffnung auf Gewährung meiner Bitte Des königlichen Commandos mit größter Hochachtung ergebener Dr. A. Föppl, königlicher Professor."

Das Gesuch wurde bewilligt. Die Zeit, die Prandtl bei August Föppl in seinem mechanisch-technischen Laboratorium gearbeitet hat, läßt sich noch genau angeben: vom 1.10.1898 bis 30.11.1899. Er beschäftigte sich neben dem Assistieren beim Unterricht mit verschiedenen experimentellen und theoretischen Arbeiten über Festigkeit und Elastizität. Eine davon wurde dann zu seiner Doktorarbeit ausgebaut.

Es war damals üblich, daß ein Assistent von seinem Professor auch einmal nach Hause eingeladen wurde. Man versuchte, dem jungen Studenten auch eine Sicherheit im Menschlichen zu geben. Natürlich mußte vorausgehen, daß der betreffende junge Mann eines Sonntags in einer Droschke vorfuhr, seine Visitenkarte dem Hausmädchen überreichte und dann, die weißen Handschuhe abstreifend, von dem Professor und seiner Frau im Salon begrüßt wurde. Die Familie Föppl nahm die Etikette nicht zu genau, so konnte Prandtl sich bei ihnen wohlfühlen. Als er zum ersten Mal in die Familie eingeladen wurde, lernte er auch die Kinder kennen. Meine Mutter, die älteste Tochter im Haus, war damals 16 Jahre alt, eine schüchterne Blonde, dann kamen zwei Söhne, noch Gymnasialschüler, und eine kleine Schwester von sechs Jahren. Als meine Großmutter erfuhr, daß der neue Assistent seine beiden Eltern vor kurzem verloren hatte, lud sie ihn des öfteren zu mancher Mahlzeit im Familienkreis ein.

Einer der beiden Söhne, Professor Ludwig Föppl, später ein Schwager Prandtls, hat mir eine private kleine Schrift übersandt, die er "Erinnerungen an Ludwig Prandtl" 
betitelte. Seine Darstellung der Persönlichkeit und Wirksamkeit seines Schwagers wird meine Aufzeichnungen in vieler Hinsicht glücklich ergänzen. Sie beginnt bereits mit Erinnerungen aus dieser Zeit:

"Die erste Begegnung mit Ludwig Prandtl, an die sich der Verfasser dieser Zeilen noch erinnert, dürfte in das Jahr 1898 fallen, als der Dreiundzwanzigjährige Assistent meines Vaters, August Föppl, war und in dieser Zeit gelegentlich von meinen Eltern zum sonntäglichen Mittagessen eingeladen wurde. Er blieb auch nach dem Mittagessen gerne noch zum Kaffee bei uns, zumal er von Seiten meiner Mutter eine mütterliche Zuneigung empfand. Diese praktisch denkende Frau mit ihrem guten Herzen hatte das Gefühl, daß sie den jungen Mann, der so allein und ohne weibliche Hilfe dem Leben ausgesetzt war, gelegentlich unter ihre Fittiche nehmen müsse. Sie gab ihm manche praktischen Ratschläge, die ihm sicher als wertvolle Hinweise für die Bewältigung seines Alltags dienten. Als sie einmal sah, daß der Aufhänger seines Mantels abgerissen war, nähte sie ihn fest, und als Prandtl von uns wegging, war er nicht wenig erstaunt, daß inzwischen Heinzelmännchen seinen Mantel wieder in Ordnung gebracht hatten. Bei einem dieser Besuche Prandtls, in der Weihnachtszeit ich war damals elf Jahre alt - schlug mein Vater nach dem gemeinsamen Mittagessen vor, daß ich auf meiner Violine ein Weihnachtslied vorspielen solle. Ich ging nur zaghaft daran, und das Vorspiel gelang auch nur mäßig. Ich habe längst nicht das feine Gehör, das Prandtl besaß, und ich kann mir heute vorstellen, daß es für ihn kein Genuß war, mir zuhören zu müssen. Nachdem ich fertig war, meinte er, die Violine müsse wohl etwas verstimmt sein. Ich merkte aber, wie vorsichtig er Kritik übte, um mich nicht zu kränken.

Prandtl schrieb damals, als er bei meinem Vater Assistent war, eine Doktorarbeit. Das selbstgewählte Dissertationsthema behandelte Kipperscheinungen an belasteten Stäben.

Da diese seine erste Arbeit, die er auch ganz selbständig durchführte, schon die charakteristischen Merkmale echt Prandtlscher Prägung zeigte, soll hier auf das Problem und seine Behandlung durch Prandtl kurz eingegangen werden. Denkt man sich etwa eine Reißschiene, horizontal gestellt, an ihrem einen Ende, wo sich das Querstück der Schiene befindet, festgehalten und das andere Ende (bei Hochkantstellung der Reißschiene) durch anwachsendes Gewicht belastet, so bewirkt schon ein verhältnismäßig kleines Gewicht ein seitliches Ausweichen des belasteten Schienen- 
endes. Prandtl hat dafür die Bezeichnung 'auskippen' eingeführt, die seitdem für solche Vorgänge bei Trägern allgemein verwendet wird und eine große praktische Bedeutung für Baukonstruktionen hat.

Obwohl für die Kipperscheinung schon manchmal eine Erklärung gesucht worden ist, so sollte es erst dem jugendlichen Prandtl gelingen, die Erscheinung restlos zu erklären. Verfolgt man in der Dissertation seinen Gedankengang, der ihn zur Lösung des Problems geführt hat, so ist die enge Anlehnung des mathematischen Ansatzes an den beobachteten geometrischen Vorgang beim Auskippen des Trägers besonders charakteristisch. Das große Geschick Prandtls, die Beobachtung eines Vorganges in ihren wesentlichen Zügen, unter Beiseitelassen aller Nebenerscheinungen durch einen geeigneten mathematisch-physikalichen Ansatz wiederzugeben, tritt schon in dieser ersten wissenschaftlichen Arbeit klar zutage.

Da Prandtl mit seiner 1899 fertiggesteliten Dissertation an der Technischen Hochschule München nicht promovieren konnte - dieser Hochschule wurde erst im Jahr 1900 das Promotionsrecht verliehen -, reichte er die Arbeit an der Universität ein. Die philosophische Fakultät der Münchner Universität bestimmte den berühmten Mathematiker Ferdinand Lindemann zum Referenten. Der Prüfer im Hauptfach war Professor Leo Graetz. Die mündliche Prüfung fand am 29.1.1900 statt. Da in der Dissertation, die für das Auskippen maßgebende Differentialgleichung als Typ der Besselschen Differentialgleichung gefunden worden war und die zahlenmäßige Auswertung einer Besselschen Funktion bestimmter Ordnung zum ersten $\mathrm{Mal}$ in der Dissertation erfolgt ist, fand die Arbeit das Interesse des Mathematikers, und Prandtl bestand die Doktorprüfung mit einem guten Prädikat." (Soweit Ludwig Föppl.)

Der Titel der Doktorarbeit lautet: Kipperscheinungen, ein Fall von instabilem elastischem Gleichgewicht. Die Veröffentlichung zog sich noch etwas hin; 1901 ist die Dissertation in Nürnberg erschienen [28].

Natürlich wurde die gedruckte Arbeit sogleich an August Föppl geschickt. Er antwortete darauf am 21. Februar 1901:

"Lieber Herr Prandtl! Ich habe mich sehr gefreut über die schöne Arbeit, die Sie mir übersandt haben und die ich sofort von Anfang bis Ende durchgelesen habe. Namentlich war ich sehr überrascht durch die eingehende und umsichtige Diskussion aller der verschiedenen Fälle des Zusammenhangs mit den Kipperscheinungen. Ich wußte vor- 
her gar nicht, daß Ihre Arbeit einen so großen Kreis von Erscheinungen umspannen würde. Es ist zum ersten Mal, daß mir von einem meiner Schüler eine so tüchtig durchgeführte Arbeit vorgekommen ist, und meine Freude ist daher umso größer."

Nun war die Münchner Studienzeit ganz abgeschlossen, und die Berufslaufbahn begann. Er schrieb an den Baurat Anton Rieppel (bekannt als der Erbauer der Müngstener Brücke, der höchsten Eisenbahnbrücke in Deutschland) in Nürnberg (MAN) als Antwort auf dessen Brief: "Was nun Ihr wertes Anerbieten betrifft, so werde ich mit Vergnügen bereit sein, die Einrichtung des Laboratoriums zu übernehmen, und zwar bin ich vom 1. Januar an bereit, bei Ihnen einzutreten. Wenn dann im Laboratorium alles ins Geleise gebracht ist, wird es ja vielleicht möglich sein, daß ich in Ihr Gasmotoren- oder Dampfmaschinenbüro übertrete. Doch das sind zukünftige Dinge, die zu verhandeln hier nicht der Ort ist.

Ich habe mir erlaubt, eine Abschrift des Zeugnisses beizufügen, das mir Herr Professor Föppl bei meinem Abgang ausgestellt hat.

Ich sehe nun Ihrer geehrten Entscheidung entgegen und erkläre mich auch bereit, eventuell zu einer von Ihnen gewünschten Zeit in Nürnberg vorzusprechen."

Er trat dann also am 1.1.1900 als Ingenieur in das Werk der Maschinenbaugesellschaft in Nürnberg ein, die sich damals mit der Maschinenfabrik Augsburg zur MAN zusammenschloß. Hier in der bekannten Fabrik in Nürnberg bestand seine Tätigkeit zunächst in der eines Mitarbeiters in einem Konstruktionsbüro. Es war ein neues Werkgebäude geplant, und die maschinelle Einrichtung sollte in zeichnerischen Plänen vorliegen. Unter anderem wurde der junge Ingenieur beauftragt, eine mangelhafte Anlage zur pneumatischen Absaugung der Hobelspäne in der neuen Waggonabteilung zu verbessern. Die war dringend geboten, da die Arbeit in der Schreinerei durch die Mengen von sich anstauenden Hobelspänen behindert wurde. Es stellte sich nämlich auch heraus, daß die Arbeiter in der Schreinerei des Betriebes unter dem Staub und den feinen Holzspänen, die von Holzbearbeitungsmaschinen abfielen, sehr $\mathrm{zu}$ leiden hatten und daß manche von ihnen als Folge der verschmutzten Atemluft an der Lunge erkrankten. Die Absaugvorrichtung sollte sich über mehrere Baracken erstrecken. So wurde Prandtl zum ersten Mal auf Strömungsfragen aufmerksam. Bei der Durchsicht der ihm zugänglichen Literatur über dieses Problem konnte er nur feststellen, daß recht wenig gesicherte Erkenntnisse auf diesem Gebiet vorhanden 
waren. So machte er sich daran, durch eigene Messungen zunächst mit verhältnismäßig rohen Methoden sich selbst Klarheit über eine Reihe von bisher ungeklärten Dingen zu verschaffen. Gemäß den Ergebnissen dieser Studien wurde dann die Späneabsaugungsanlage gänzlich umgebaut. Mit Hilfe der Konstruktion einer mit einem Zyklon versehenen Abscheidevorrichtung gelang die Lösung des Problems, und bald erwies sich, daß es möglich geworden war, durch bessere Formgebung und richtige Abmessungen der Rohrleitungen mit etwa einem Drittel der bisherigen Betriebskraft auszukommen und dabei einen störungsfreien Arbeitsvorgang zu erhalten. Die Fabrik nahm von da an die Herstellung der Prandtlschen Späneabsauganlage in ihr Programm auf und hatte bald viele Aufträge.

In den Urlaubstagen fuhr er immer zu seinen Verwandten nach Dingolfing oder auch nach München und versäumte es nie, dort seinen verehrten Hochschullehrer August Föppl aufzusuchen, der interessiert seinen Werdegang verfolgte.

Im Jahr 1901 sollte in Hannover der Lehrstuhl für Mechanik, der frei geworden war, neu besetzt werden. August Föppl, der nach einem Nachfolger befragt wurde, schlug unter anderem als sehr empfehlenswert den jungen Ingenieur aus Nürnberg vor, dessen Doktorarbeit eine große Begabung gezeigt hatte. Prandtl wurde Anfang August durch einen Brief des Preußischen Kultusministeriums Berlin informiert, daß er zur Besetzung der Mechanikprofessur in Hannover neben anderen Herren auch in Vorschlag gebracht worden sei, und er möge sich deswegen in Berlin zu einer Besprechung einfinden, falls er diesen Lehrauftrag im Falle seiner Wahl anzunehmen gedenke. Wenige Wochen später wurde er davon in Kenntnis gesetzt, daß die Wahl auf ihn gefallen sei. Prof. Carl Runge, der seit 1886 einen Lehrstuhl für Mathematik an der Technischen Hochschule Hannover innehatte, muß daran entscheidend mitgewirkt haben, daß die vakante Stelle an den jungen Ingenieur vergeben wurde. Am 21. August wurde die Bestallungsurkunde unterzeichnet:

"Wir Wilhelm, von Gottes Gnaden, König von Preußen thun kund und fügen hiermit zu wissen, daß Wir Allergnädigst geruht haben, den bisherigen Ingenieur Dr. Ludwig Prandtl in Nürnberg zum etatsmäßigen Professor an der Technischen Hochschule in Hannover zu ernennen." 
Am 30. September hatte er seinen Ingenieursposten in Nürnberg aufgegeben und reiste nach Hannover als preußischer Beamter, als jüngster Professor in Preußen. Er war 26 Jahre alt. Er hielt Vorlesungen für Mechanik in der Abteilung für Maschineningenieurswesen sowie Übungen über graphische Statik. Die vielen Prüfungen, die im Laufe eines Semesters abgenommen werden mußten, waren eine zusätzliche Aufgabe. Daneben fand er doch noch genügend Zeit, seinen besonderen Forschungen über Strömungsvorgänge nachzugehen. Die in Nürnberg gemachten Erfahrungen über die Gesetze der Luftströmungen hatten verschiedene Einzelheiten unaufgeklärt gelassen. So zum Beispiel blieb die Frage offen, warum ein Luftstrom in einem kegelförmig erweiterten Rohr nicht den Rohrwänden folgt, sondern nahezu wie ein freier Strahl durch die Rohrmitte strömt.

Die Eindrücke seiner Umsiedlung teilte er den Verwandten in der bayrischen Heimat mit. Die häufigen Briefe, die als Rundbriefe konzipiert waren, gingen an die Geschwister seines Vaters, die nun beide in München lebten, und an die Familie Ostermann in Freising.

Brief vom 26.10.1901: "Meine Möbel habe ich einstweilen bei meinen Nürnberger Hausleuten gelassen. Und weil ich nun gerade bei Nürnberg bin, will ich auch erzählen, wie es mir bei meinem Auszug dort ergangen ist. Ich habe natürlich verschiedene Abschiede dort gefeiert, einmal im Nürnberger Philisterverband, wo mir Gelegenheit gegeben war, Freibier aufzulegen. Dann im Männergesangverein, Rede und Gegenrede. Abschiedslied mit Hornsolo (den Hornpart spielte er selbst) 'Behüt dich Gott'. Des anderen Tages um sieben Uhr früh dampfte ich in den Nebel hinein. An der Hochschule in Hannover sind so ziemlich alle Gaue Deutschlands vertreten, wir haben Bayern, Schwaben, Badenser, Kurhessen, Österreicher und natürlich ein ganzes Rudel von Preußen. (Meinen Diensteid habe ich noch nicht geschworen, also darf ich mich einstweilen noch als Nichtpreuße fühlen.)

Noch einiges von meiner Wohnungssuche. Auf meine Annonce habe ich 60 Angebote bekommen, die richtige war nicht darunter, sie wurde mir von einem Kollegen verschafft, ich bin recht zufrieden." (Er zog in die Nienburgerstraße 12.) "Die Lage ist ungefähr wie die Königinstraße in München, nur mit dem Unterschied, daß ich hier zur besseren Unterhaltung eine Elektrische vorbeirumpeln sehe, höre und fühle. Sonst aber ist die Lage sehr schön, gegenüber ist der Park, hinter demselben manchmal ein Sonnenuntergang, meist aber wegen Nebel nicht zu sehen." 
Brief von 3.1.1902: "Übrigens wollte ich Euch ja von dem Leben und Treiben in Hannover erzählen. Zunächst die Sprache; man sagt, in Hannover würde das reinste und beste Deutsch gesprochen, vom Volke nämlich. Nun hört! Meine erste Entdeckung war, daß ich den Hotelkellner nur schwer verstand, ebenso die Geschäftsleute. Aber bald machte ich die großartige Entdeckung, daß die hiesige Sprache aus dem Deutschen abgeleitet werden könne, wenn man nur eine Reihe Ausspracheregelungen berücksichtigt. (So einfach ist der altsprachliche Dialekt nicht zu fassen, nicht wahr?) Der spitze Stein ist hier sprichwörtlich, dabei wird aber das 'ei' gesprochen wie bei Euch das 'A' in Kas. Wenn man diese Ausspracheregeln einmal kann, dann findet man wohl, daß das Volk hier ziemlich gut Schriftdeutsch redet.

Auch sonst hat Hannover verschiedene Eigentümlichkeiten: eine Straßenbahn, die mit Akkumulatoren fährt (keine Oberleitung in der inneren Stadt). Das Straßenbahnnetz ist nach Berlin das größte in Deutschland. Die Bahn fährt auch auf jedes Nest in der Lüneburger Heide hinaus, gerade als ob die Münchner bis Freising, Dachau, Starnberg, Wolfratshausen, Sauerlach und Grafing ginge.

Daß Hannover auf sieben Hügeln liegen soll, wurde mir versichert. Ich habe sie aber noch nicht alle gefunden. Einen habe ich selbst ohne fremde Hilfe entdeckt. Es ist der Schneiderberg, über den ich jetzt täglich zur Hochschule gehe. Er ist so hoch, daß tatsächlich der größte Mann nicht hinüberschauen kann (so drückt man sich hier aus). Das Wetter ist hier abwechselnd neblig, naß oder windig, zur Abwechslung auch mal naß und neblig oder naß und windig. Mit diesem Klima mag es zusammenhängen, daß hier alle Fenster nach außen aufgehen, so daß dann keine Winterfenster davor Platz haben.

Etwas, was ich hier vermisse, ist unser gutes Hausbrot, wenig Salz und gar kein Gewürz. Hier wird ja Brot nur mit Butter gegessen (auch Bettler nehmen's nicht anders an)."

Brief vom 1. Juli 1902: "An einem der ersten Tage des Mai machte ich eine geologische Exkursion in den Harz mit, wo wir bei Regen Gebirgsschönheiten und Gesteinsformationen besahen, es war trotz des schlechten Wetters sehr schön; der Harz ist ein ganz tüchtiges Gebirge, der bayrische Wald kann sich nicht damit vergleichen, wenigstens wie ich ihn in Erinnerung habe. Die Parkanlagen von Herrenhausen sind jetzt sehr prächtig, überall blüht der Flieder, die Nachtigallen singen, die Frösche quaken. Auch an der Hochschule ist der Mai nicht spurlos vorübergegangen: 
Ein Kollege, bis dahin mein täglicher Tischgenosse, hat sich verlobt. Unter den jüngeren Dozenten bin ich jetzt, glaube ich, der einzige Unverlobte. Trotzdem haben einstweilen die Mädchen Hannovers noch keine Aussicht, mich einzufangen. Ich bilde mir immer noch ein, die Meine müßte mal Knödel und Nockerln kochen können und nicht etwa Gelüste haben, in den Spinat Rosinen zu tun."

Seine Verbundenheit mit der bayrischen Heimat erschwerte ihm in mancher Beziehung ein Vertrautwerden mit dem hannoverschen Lebensstil.

Es gab auch in bezug auf die Geselligkeit an der Hochschule andersartige Auffassungen. Man betonte die Förmlichkeit in jeder Beziehung. So wurde mein Vater einmal aufgefordert, bei einer kleinen Vorführung mitzuwirken. Es sollte nämlich eine bayrische Sängergruppe auftreten und die Herren dazu in Lederhosen erscheinen. Als sich dann die jungen Dozenten zur Probe in der gut bayrischen Tracht einfanden, wurden fleischfarbene Beintrikots an sie verteilt, die man unter der Lederhose tragen sollte, weil es doch unzumutbar sei, vor den Damen der Gesellschaft nackte männliche Knie vorzuzeigen.

Hingegen entwickelte sich eine menschlich herzliche Beziehung zwischen dem Professor Carl Runge, einem gebürtigen Bremer, und dem 19 Jahre jüngeren Ludwig Prandtl. Mein Vater verehrte den geistreichen, weltgewandten Kollegen, in dessen Haus in Kirchrode er glückliche Stunden erlebte. In den Betrachtungen über Carl Runges Leben schreibt seine Tochter Iris [44]: "Damals brachte Runge häufiger einen jungen Freund mit, Ludwig Prandtl, an dessen Berufung er selbst Anteil gehabt hatte und mit dem er sich gern wissenschaftlich unterhielt. Bald zeigte es sich, daß dieser neue Freund viel Musikverständnis hatte und eine schöne Baßstimme." (In der Familie Runge wurde der Versuch unternommen, die Matthäuspassion aufzuführen.) "Mit seiner klangvollen Stimme im Baß, Vater Runge im Tenor und den Töchtern Sopran und Alt konnte nun wirklich der volle Zusammenklang hervorgebracht werden, was freilich bei den ungeübten Stimmen erst nach vielen Versuchen einigermaßen gelang."

An die Verwandten Brief vom 30.1.1904:

"Den Weihnachtsabend verbrachte ich heuer bei meinem Kollegen und Konphilister 
Runge (4 Mädel und 2 Buben, daher ein sehr lebendiges Haus). Ich komme überhaupt jetzt oft dorthin, wir haben viele gemeinsame wissenschaftliche Interessen, auch wird fleißig musiziert (gemischtes Quartett)."

Es gab noch einige andere Kollegen, die bald seine Freunde wurden. Einer war der Privatdozent für Literatur, Dr. von Hanstein, in dessen Haus er oft eingeladen wurde. Es ergab sich auch, daß Prandtl $1903 \mathrm{ihm}$ schräg gegenüber eine Wohnung bezog und sie nun in engster Nachbarschaft lebten.

\subsubsection{3 - er war in die Militärstraße umgezogen:}

"Das letzte Vierteljahr brachte mir sehr viel Arbeit, so viel, daß ich mir's nicht wieder wünsche. Am meisten aber zwang mich zu arbeiten der Umstand, daß ich begonnen hatte, zu meinen sämtlichen Vorlesungen autografierte Blätter herauszugeben, in denen die wichtigsten Dinge zusammengestellt waren. Ich war gezwungen, meinen Stoff gleich mit der Sorgfalt zu bearbeiten, daß ich ihn mehrere Jahre hindurch brauchen kann. Mit meinen Forschungen bin ich ein gutes Stück weiter gekommen."

Er hatte sich nämlich eine kleine Versuchseinrichtung mit einem Wasserkanal gebaut. Das Wasser, das er mit einer schaufelradähnlichen Maschine bewegte, war zuvor mit glänzenden Blättchen (Eisenglimmer) untermengt, um die Strömungsbewegung sichtbar zu machen, die sich bei verschiedenen Versuchsanordnungen ergaben. Wie er durch Zufall an diesen Eisenglimmer gekommen war, hat er einmal seinem Schüler Dr. W. Tillmann erzählt: Als Prandtl bei der MAN in Nürnberg tätig war, kamen eines Tages Bauarbeiter zu ihm. Sie brachten aus einer Baugrube rötlich gefärbte Klumpen mit und meinten, sie wären auf kupferhaltigen Boden gestoßen. Beim Aufschlämmen des Materials in Wasser entdeckte er winzige schuppenförmige Teilchen, mit denen sich eine Strömung sichtbar machen ließ. Unter der Einwirkung einer Scherung nehmen nämlich diese suspendierten Teilchen eine bevorzugte Orientierung ein. Das von den Teilchen reflektierte Licht vermittelt dann ein Bild der Strömung. Chemisch handelte es sich bei den Teilchen um Eisenoxyd, das hier in Form von Eisenglimmer vorlag. Durch Aufschlämmen des gefundenen Materials in vielen selbst gefalteten Pappschälchen hat er damals eine große Menge des für Strömungssichtbarmachung geeigneten Eisenglimmers gewonnen. Ein ähnlich geeignetes Ausgangsmaterial ist nie wieder entdeckt worden. Der Vorrat an Eisenglimmer wanderte 
bei seinen Berufungen nach Hannover und Göttingen mit und reichte bei sparsamem Einsatz fünfzig Jahre lang, bis man ihn schließlich durch ein synthetisches Perlglanzpigment ersetzen konnte.

Auf der Suche nach Gesetzmäßigkeiten zeichnete und rechnete Prandtl bis in die späten Nachtstunden. Aus dieser Erfahrung, daß übermäßiger Arbeitseifer zu Überanstrengung führen kann, hat er bewußt für sein weiteres Leben die Lehre gezogen, sich trotz drängender Probleme darin zu mäßigen.

Brief vom 23. Januar 1903: "Ganz unversehens habe ich im Februar einmal zu viel bekommen von der Arbeit, und das hängt mir immer noch nach, d.h., ich werde vom Arbeiten schnell müde. Der Zerstreuung halber habe ich das Photographieren angefangen."

Seine tägliche Arbeitszeit lag aber auch künftig weit über dem Normalen, so daß man danach annehmen muß, daß er in jener Zeit ganze Nächte durchgearbeitet hat. Er lebte nun etwas zurückgezogen und machte Pfingsten eine längere Wanderung ins Wesergebirge, die ihm genügend Entspannung brachte. Seinen Reisebericht versah er mit kleinen Zeichnungen zur Veranschaulichung seiner Marschroute und seiner landschaftlichen Eindrücke.

Brief vom 23. Juni 1903: "Mit der Eisenbahn nach Coppenbrügge, Ithwanderung1), Gabelfrühstück in Lauenstein, dann weiter auf den Kamm, Rast auf dem Felsen Hammerslust, abends nach Eschershausen. Morgens über Homburg (alte verfallene Burg auf hohem Berge) nach Stadtoldendorf, von da auf den Ebersnacken und die Königszinnen. Bei Bodenwerder aufs Schiff und auf der Weser bis Hameln. Stadtbesichtigung, Bad in der Weser. Nächster Tag Ohrberg (schöner Park), Bad in der Weser, abends heim. Der höchste Berg, den ich sah, war 495 m hoch!"

Brief vom 30. Januar 1904:

"Ich beginne mit meinem Abschied vom schönen Bayernland im letzten September. Ich ging damals, wie Ihr wohl wißt, zu der Naturforscher- und Ärzteversammlung

1) Der Ith ist ein Höhenrücken entlang der Weser in der Nähe von Hameln. 
nach Kassel. Ich bereue es nicht, diese Versammlung mitgemacht zu haben. Ich habe dort eine Reihe wertvoller Bekanntschaften gemacht, hauptsächlich von Mathematikern und Physikern. Meine eigenen Vorträge hatten etwas darunter zu leiden, $\mathrm{daß}$ sie beide am Nachmittag des letzten Tages angesetzt wurden. Ich war selbst schon etwas abgespannt. Der eine wurde beifällig aufgenommen, bei dem anderen (Vektoren) gab es, wie zu erwarten, große Meinungsverschiedenheiten. Zum Abschluß der Tagung waren eine Menge Mathematiker und Physiker einer Einladung nach Göttingen gefolgt, wo es ungemein viele interessante Dinge und Persönlichkeiten gibt. Die Gastfreundschaft ist da ganz großartig. Ich übernachtete bei dem Astronomen Schwarzschild und aß zu Mittag bei Professor Nernst, Chemiker, zwei Plätze neben mir war Herr Ramsay gesessen, der englische Chemiker. Als ich nach Hannover kam, ging bald ein anderes Geschäft an: vormittags prüfen und nachmittags wieder prüfen, so an die 4 Wochen. Inzwischen haben die Vorträge begonnen, dann kamen nochmals Prüfungen neben den Vorträgen, und so ging die Zeit vorüber bis Weihnachten. Seit 5. Januar sind die Vorlesungen wieder im Gange. Auch sonst gab's viel Arbeit: Erweiterte Veröffentlichungen meiner Vorträge, einige andere Veröffentlichungen sind in Arbeit, und dann die Kommissionen, so daß ich also nie Mangel an Arbeit habe. Trotzdem habe ich mir neulich an Kaisers Geburtstag das Vergnügen geleistet, einen ganzen Tag nichts zu tun. Ich bin Schlittschuh gelaufen und spazierengegangen."

Dann ging er wieder an die vielseitige Arbeit.

Im Frühjahr kam von Geheimrat Felix Klein aus Göttingen die Anfrage, ob Prandtl das Institut für technische Physik übernehmen wolle, das vorher Profesor $\mathrm{H}$. Lorenz geleitet hatte. Dieses Institut, zu dem eine außerordentliche Professur gehörte, war auf die Initiative von Felix Klein, des schöpferischen Mathematikers und Organisators des mathematisch-physikalisch-technischen Unterrichtswesens, geschaffen worden, als von der "Göttinger Vereinigung zur Förderung der angewandten Physik und Mathematik" unter dem Vorsitz von Henry Th. Böttinger und F. Klein die Geldmittel dafür zur Verfügung gestellt worden waren. Prandtls früherer Chef bei der MAN, Baurat Rieppel, äußerte sich in einem Brief an Klein folgendermaßen zu dieser möglichen Berufung: "7. März: Ihren Gedanken, in erster Linie Herrn Dr. Prandtl in Betracht zu ziehen, halte ich für sehr glücklich. Herr Prandtl ist ein ungewöhnlich begabter und 
dabei äußerst fleißiger Mensch. Bei seinem verträglichen Charakter halte ich ein angenehmes Zusammenarbeiten für gewährleistet..."

Runge äußerte sich von Hannover aus wie folgt: "Ich habe eine sehr hohe Meinung von seiner Begabung und würde alles tun, was in meinen Kräften steht, ihn an unserer Hochschule zu halten..."

Karl Schwarzschild schrieb in derselben Angelegenheit am 22. April an Klein: "Von Runge erhielt ich einen Brief über Prandtl. Trübe Aussichten!"

Am 4. Mai schickte Prandtl an Klein eine vorläufige Erwiderung auf dieses Angebot.

"Brief vom 4. Mai, Hannover

An Prof. Felix Klein

Sehr geehrter Herr College!

Meinem Versprechen gemäß teile ich Ihnen im folgenden mit, was ich mir über die Göttinger Maschinenprofessur zurechtgelegt habe. Einerseits lockt mich das eigene Laboratorium und die größere freie Zeit, nicht zumindestens aber der schöne wissenschaftliche Göttinger Verkehr. Andererseits ist mir meine Tätigkeit in Hannover in den nicht ganz drei Jahren meines Hierseins sehr lieb geworden. Meinen großen Wirkungskreis hier würde ich mit einem wohl recht viel kleineren vertauschen. Weniger Wert würde ich darauf legen, daß ich in Göttingen als a.o. Professor keinen Sitz in der Fakultät hätte, während ich hier ordentliches Mitglied der Abteilung bin. Das schwerste Bedenken entsprang meinem Zugehörigkeitsgefühl zur Technik. Es war seit langem ein Lieblingsgedanke von mir, nach Kräften an der Hebung der Wissenschaftlichkeit im Unterricht an den technischen Hochschulen mitzuarbeiten. Unter diesem Gesichtspunkt scheint mir der Übertritt an die Universität nur dadurch zu rechtfertigen zu sein, daß ich in dieser Stelle, die, wie ich denke, nicht meine letzte sein wird, außerordentliche Gelegenheit haben würde, meinen eigenen wissenschaftlichen Wert zu heben und mich für künftige Aufgaben vorzubereiten, andererseits auch durch den Gedankenaustausch mit den Theoretikern noch manche der Praxis naheliegende Fragen lösen helfen könnte." 
Die Gehaltsforderung von 6500 Mark jährlich entsprach dem Einkommen an der Technischen Hochschule in Hannover.

Die Angelegenheit sollte im Ministerium von Berlin entschieden werden. Klein hatte die Vorschläge mit einem persönlichen Schreiben weitergereicht und bezüglich Prandtl folgende Angaben gemacht: "Die Arbeiten von Prandtl zeichnen sich dadurch aus, daß Prandtl mit Sachkenntnis und Beherrschung des Mathematischen Apparats eine starke Kraft der Intuition und eine große Originalität des Denkens verbindet. Andererseits ist Prandtl hervorragend pädagogisch interessiert."

Da das Ministerium der Gehaltsforderung nicht zustimmte, wollte Henry von Böttinger (Kaufmännischer Leiter der Farbenfabriken vorm. Fr. Bayer in Elberfeld) die an 6500 Mark fehlende Summe aus privaten Mitteln dazulegen. Insofern war der Ruf nach Göttingen zu erwägen. Prandtl fuhr zu Verhandlungen nach Berlin und bat sich eine Bedenkzeit aus.

In einem Brief vom 25. Juni an Professor Klein war alles noch in der Schwebe:

"Hannover, den 25. Juni 1904

Sehr geehrter Herr Geheimrat!

Die Entscheidung ist noch nicht da, ich habe auch den schriftlichen Ruf noch nicht. Die Verzögerung kommt daher, daß die hannoverschen Collegen im Ministerium Anstrengungen machten, mich hier zu halten. Ich will Ihnen bei dieser Gelegenheit auch mitteilen, daß ich dieser Tage schwer habe innerlich kämpfen müssen, als es galt, alle die Fäden, die mich hier halten, durchzuschneiden; man hat sich auch wirklich Mühe gegeben, mich hier zu halten. Einige Herren der Bauingenieursabteilung boten mir ihr der Vollendung entgegen gehendes schönes Festigkeitslaboratorium zur beliebigen Benutzung an u. s. w! Ich wog lange ab und neigte schließlich doch Göttingen zu."

Am 1. Juli fiel die Entscheidung für Göttingen.

Die Verhandlungen mit dem Ministerium waren allerdings noch nicht ganz abgeschlossen. Aber am 1. Juli 1904 war es so weit, und Prandtl konnte seine endgültige 
Zusage geben. Er schrieb auf einer Postkarte an Klein: "Sehr geehrter Herr Geheimrat! Nach einem eben erhaltenen Brief von Herrn (Ministerialrat) Naumann habe ich mich entschlossen, den Ruf nach Göttingen anzunehmen."

Obwohl er ungewöhnlicherweise einen Rückschritt in seiner akademischen Laufbahn machte, indem er eine ordentliche Professur aufgab und eine außerordentliche annahm, sah Prandtl vor sich die Möglichkeit, sich nun erst recht seinen wissenschaftlichen Forschungen widmen zu können. Sein Doktorvater, August Föppl, hatte ihm dringend abgeraten, auf ein solches Angebot einzugehen. Es sei ganz wider die Vernunft, sich beruflich verschlechtern zu wollen. Aber Prandtls schöpferischer Geist setzte die Akzente anders. Es lockte ihn die Aussicht, an diesem neuen Wirkungsplatz für seine Probleme und Ideen nun erheblich mehr freien Raum beanspruchen zu können. Und er war auch fest davon überzeugt, daß sich später eine Gelegenheit bieten würde, wieder zu einer ordentlichen Professur zu gelangen.

Prandtl hegte eine große Bewunderung für den Mathematiker Klein, von dem er sich auch persönlich angezogen fühlte und unter dessen Schirmherrschaft er sich ein gutes Arbeitsklima versprach.

Klein hatte besondere Ziele für den Lehrbetrieb des mathematisch-naturwissenschaftlichen Zweiges. Er wollte den Studierenden, die häufig einen praktischen Beruf anstrebten, z. B. in einer Fabrik zu arbeiten oder an Schulen zu unterrichten, eine zweckgebundenere Ausbildung ermöglichen. Die deutschen Universitäten hatten in der damaligen Zeit sehr wenig Verbindung mit dem Ingenieurswesen und der Industrie. Durch Felix Klein wurde die Verbindung zwischen den UniversitätsWissenschaften und der Technik wieder angeknüpft. Dabei haben ihm amerikanische Universitäten als Muster gedient. Er war ein großartiger Organisator, und seine Aktivität war in weiten Kreisen spürbar. Seiner Initiative ist es zu verdanken, daß in Göttingen eine Reihe von Lehrstühlen und Instituten eingerichtet wurde, die den praktischen Anwendungen der Wissenschaft dienen sollten. Mit Prandtl hatte er einen Lehrer gefunden, der als Ingenieur ganz von der praktischen Seite seinen Wissensstoff entwickeln konnte. Felix Klein wurde dann für ihn der große Freund, der an seinen Plänen teilnahm und ihn jederzeit durch Fachgespräche in seinem Wissenschaftsbereich förderte. 
Am 12. August 1904, noch vor seiner Übersiedlung nach Göttingen, reiste er zu einem Kongre $B$ nach Heidelberg. Dort fand der III. Internationale Mathematiker-Kongre $B$ statt. Hier hielt er einen Vortrag über seine neue wissenschaftliche Theorie, die Grenzschichttheorie genannt wurde [35]. Es war das Ergebnis seiner schon erwähnten experimentellen und theoretischen Arbeiten. Dieser Vortrag erregte erhebliches Aufsehen bei den dort anwesenden Mathematikern, die seinen neuen Ideen über Strömungsvorgänge mit größtem Interesse gefolgt waren. Es war ein grundlegender Schritt der Erkenntnis getan, der bald für die Entwicklung der Luftfahrt bedeutungsvoll wurde. Nun war er im Kreis der Naturwissenschaftler bekannt geworden.

In seinen Erinnerungen gibt Professor Ludwig Föppl kommentierende Anmerkungen zu Prandtls Grenzschichttheorie:

"Mit Rücksicht auf die Bedeutung dieser Arbeit sei kurz auf den wesentlichen Inhalt hingewiesen. Bis zu diesem Zeitpunkt war es nicht gelungen, den Widerstand eines Körpers in einer strömenden Flüssigkeit oder im Wind theoretisch zu erklären, ebensowenig wie den Auftrieb eines Flugzeugs. Die klassische Mechanik ging entweder von einer reibungsfreien Strömung aus, oder sie berücksichtigte die Reibung, wobei aber die mathematischen Schwierigkeiten so groß wurden, daß bis dahin keine praktische Iösung gelungen war. Der befreiende Gedanke Prandtls, der aus diesem Engpaß führte, war die Annahme einer reibungsfreien Strömung im ganzen Bereich mit Ausnahme der Strömung längs fester Grenzen. Prandtl zeigte, daß eine, wenn auch noch so kleine Reibung in einer dünnen Schicht längs fester Grenzen berücksichtigt werden muß. Man nennt seitdem diese Schicht die Prandtlsche Grenzschicht. Mit dieser vereinfachenden Annahme konnten die eben erwähnten mathematischen Schwierigkeiten, die die klassische Strömungsmechanik der reibenden Flüssigkeiten aufwiesen, in vielen praktischen Fällen überwunden werden. Prandtl konnte theoretisch und experimentell nachweisen, daß sich die Grenzschicht an geeigneten Stellen der Oberfläche der umströmten Körper ablösen kann, um sich aufzuwickeln und als Einzelwirbel den Körper zu verlassen.

Sommerfeld hörte damals auf dem Mathematiker-Kongreß in Heidelberg Felix Klein zu Prandtl sagen: 'Ihr Vortrag war der schönste des ganzen Kongresses.'

Es ist bezeichnend für die Fülle an genialen Gedanken, die damals Prandtl beschäftigten, daß er auf dem gleichen Mathematiker-Kongreß außer der erwähnten Grenz- 
schichttheorie auch noch eine Arbeit auf dem Gebiete der Elastizitätstheorie vorlegte. Es handelt sich um das seitdem unter der Bezeichnung Prandtlsches Seifenhautgleichnis jedem Elastizitätstheoretiker geläufige Gleichnis zwischen der Torsion eines prismatischen Stabes und dem Wölbungshügel einer Seifenhaut, die sich über dem Querschnitt des Stabes als Loch bei einseitigem Überdruck ausbildet. Das Gleichnis ist zur Lösung von Torsionsaufgaben auf versuchstechnischem Wege seitdem vielfach verwendet worden."

Über das letztere Problem sind zwei Artikel im Druck erschienen $[24,40]$.

Das Ernennungsschreiben für die Göttinger Professur war zur Zeit dieses Kongresses in Heidelberg bereits in Prandtls Händen. Der genaue Wortlaut ist bekannt:

"Der Minister der geistlichen Unterrichts- und Medizinal-Angelegenheiten, Berlin, 31. Juli.

Im Verfolg der in meinem Auftrag mit Ihnen geführten Verhandlungen ernenne ich Sie mit allerhöchster Ermächtigung Seiner Majestät des Kaisers und Königs vom 1. September dieses Jahres ab zum außerordentlichen Professor in der Philosophischen Fakultät der Universität zu Göttingen und verleihe Ihnen in derselben das durch den Weggang des Professors Lorenz erledigte Extraordinariat mit der Verpflichtung, die technische Physik und die landwirtschaftliche Maschinenkunde in Vorlesungen und Übungen zu vertreten. Gleichzeitig übertrage ich Ihnen die Leitung der zum physikalischen Institut gehörenden Abteilung für technische Physik. Ich ersuche Sie, Ihr neues Amt rechtzeitig vor Beginn des nächsten Semesters anzutreten und das Verzeichnis der von Ihnen für das letztere anzukündigenden Vorlesungen umgehend an den Dekan der Fakultät einzusenden.

An Stelle Ihres bisherigen Diensteinkommens bewillige ich Ihnen vom 1. September dieses Jahres ab eine Besoldung von jährlich

\section{$4000 \mathrm{M}$}

nebem dem tarifmäßigen Wohngeldzuschuß von jährlich 
Für den Monat September ließ sich Prandtl noch vertreten, nahm dann am 1. Oktober seine neue Arbeit an der Universität auf. Zum gleichen Herbstsemester 1904 hatte Felix Klein auch die Berufung Carl Runges nach Göttingen durchgesetzt, der diesem Wechsel ebenso wie Prandtl mit besonderer Freude entgegensah. Felix Klein hatte im Juni 1904 Carl Runge persönlich befragt, ob er nicht auch nach Göttingen kommen wolle. Als Runge in Berlin deswegen bei Ministerialdirektor Althoff vorsprach, wurden zu seiner Freude alle gestellten Forderungen bewilligt. Die neue Stelle wurde nämlich gleich in eine ordentliche Professur verwandelt, mit entsprechender Gehaltszulage. Runge hatte zwar noch andere Rufe, nach Marburg, Danzig, Aachen, erhalten, aber seine Gehaltsforderungen konnten von keiner dieser Universitäten erfüllt werden. Seine Professur, die als Lehrstuhl für angewandte Mathematik bezeichnet wurde, war das erste Ordinariat Deutschlands für dieses Fach. Prandtl war die Professur für angewandte Mechanik übertragen worden. Beide zogen in ein altes ehrwürdiges Institutsgebäude in der Prinzenstraße ein, in das sogenannte Michaelishaus, in dem einst Karl Friedrich Gauss und Wilhelm Eduard Weber ihre ersten Versuche mit dem elektromagnetischen Telegraphen unternommen hatten.

Iris Runge schreibt [44]: "Die ziemlich kleinen winkligen Räume, die ausgetretenen Dielen und Treppen erinnerten an das Alter des Gebäudes, das aus dem 18. Jahrhundert stammte. Doch war alles hell und neu, wenn auch sehr schlicht und sachlich hergerichtet.

Als Runge nach Göttingen kam, wurden er und Prandtl sogleich von Klein zu einem gemeinsamen Seminar über Fragen der Elektrotechnik aufgefordert.

Bei der Immatrikulation wurde den naturwissenschaftlichen Studenten ein Studienplan überreicht, den Klein zusammengestellt hatte, um die jungen Leute ohne Umwege an die wichtigen Aufgaben heranzuführen, dessen Titel lautete: 'Ratschläge und Erläuterungen für die Studierenden der Mathematik und Physik'. Jedenfalls ergab sich in diesen Jahren ein einzigartiges Zusammenwirken aller, die am großen Bau der Naturerkenntnis als Lehrende beteiligt waren. Von den Vertretern der praktischen Anwendung, zu denen Prandtl mit seinem Maschinenlaboratorium zählte sein Fach wurde von einigen Kollegen 'Fakultät Schmieröl' - bis zu den Hütern der reinen Höhen der mathematischen Theorie waren alle zur Mitarbeit vereint." 
Die größte Berühmtheit unter den Mathematikern war Professor David Hilbert. Klein hatte Erfolg gehabt mit seinen Bemühungen, ihn nach Göttingen zu bekommen, wo er bis zum Lebensende geblieben ist, und er schlug sogar 1902 einen Ruf nach Berlin aus. Die von Klein vorgeschlagene Erweiterung des Naturwissenschaftlichen Zweiges der Philosophischen Fakultät war ganz im Sinne Hilberts und brachte eine breite Basis für die Studenten aus aller Welt.

Besonders nahe Beziehungen hatten Runge und Prandtl, deren Freundschaft schon in der Hannoverschen Zeit begründet worden war. In Göttingen war man sich räumlich und fachlich noch näher gerückt, eine besonders glückliche Konstellation. Aber erst die freieren Arbeitsmöglichkeiten in Göttingen brachten Prandtls mathematischtechnische Originalität zur vollen Entfaltung. Die Vereinigung des Prandtlschen Instituts mit dem von Runge gab häufige Gelegenheit zu anregenden Diskussionen, die für die Entstehung und Entwicklung neuer Gedanken förderlich war.

Prandtl, der weiterhin in seiner speziellen Forschung über Strömung neue Erkenntnisse suchte, beschäftigte sich jetzt im wesentlichen mit der Bewegung von strömenden Gasen. Er bekam gute Arbeitsmöglichkeiten in seinem Institut. Klein hatte schon 1898 mit interessierten Industriellen und einigen Göttinger Professoren die Göttinger Vereinigung zur Förderung der angewandten Mathematik und Physik gegründet. Durch erhebliche Spenden der Industriellen konnten neue Institutsprojekte in Angriff genommen werden, z. B. 1905 das physikalische Institut in der Bunsenstraße. Dadurch war in der Prinzenstraße im alten physikalischen Institut mehr Platz für die neuen Dozenten geschaffen, und Prandtl konnte die vorhandenen Einrichtungen ergänzen durch einen Wasserumlaufkanal zur Anschauung der Strömungsvorgänge.

Ich möchte an dieser Stelle betonen, daß Prandtl, wie aus dem vorherigen hervorgeht, seine Strömungsforschung als rein wissenschaftliche Arbeit fortführte. Nachdem er die praktische Aufgabe für die MAN gelöst hatte, forschte er auf dem neuen Gebiet aus eigenem Interesse weiter um der Erkenntnis willen. Daß seine Wissenschaft so zukunftsvoll sein würde, ahnte er im Anfang nicht.

Wiederum unter Mitwirkung von Ministerialdirektor Althoff wurde 1906 eine neue Gesellschaft gegründet: die Motorluftschiff-Studiengesellschaft, deren wesentliches 
Ziel es sein sollte, die Entwicklung des Parsevalluftschiffes zu fördern. Prandtl wurde in den technischen Ausschuß gewählt. Um beste wissenschaftliche Arbeitsbedingungen für die Prüfung und Voruntersuchung zu schaffen, schlug Klein vor, ein Projekt für eine Modellversuchsanstalt ausarbeiten zu lassen. Er übergab diesen Auftrag an Prandtl. So wurde ihm gewissermaßen von außen her der Anstoß gegeben zu einer Entwicklung, die seinen Möglichkeiten und Wünschen besonders entsprach. Die Pläne lagen bald vor, und Anfang 1907 wurde mit den Vorarbeiten begonnen. Übrigens erhielt Prandtl 1907 einen Ruf an die TH Stuttgart. In einem Brief an Ministerialdirektor Althoff schilderte er seine Situtation im Lehramt und eröffnete ihm seine Stellungnahme zu der Frage des Rufes.

\section{"30. März 1907}

An seine Excellenz den Herrn Ministerialdirektor

$$
\text { Dr. Althoff, Berlin, Kultusministerium }
$$

Euer Excellenz beehre ich mich davon in Kenntnis zu setzen, daß mir gestern ein vom 26. März datiertes Schreiben des Württembergischen Kultusministeriums zugegangen ist, in dem mir die ordentliche Professur für technische Mechanik an der Technischen Hochschule Stuttgart angeboten wird.

Wenn dieses Angebot auch viel Verlockendes für mich hat, so veranlassen mich doch manche Gründe, ein Verbleiben in Göttingen stark in Erwägung zu ziehen. Freilich bin ich nicht gerade wunschlos. Mit meinem Institute bin ich durchaus zufrieden, ausgenommen den viel zu knappen Etat, dessen Erhöhung bisher nicht erreicht worden ist, doch bin ich deswegen, dank der Fürsorge der 'Göttinger Vereinigung', die das Institut bisher über Wasser gehalten hat, nicht in allzu großer Sorge.

Weniger zufrieden bin ich mit meiner bisherigen Lehrtätigkeit, indem es mir nicht möglich war, trotz meiner Bemühungen, einen weiteren Kreis von Studierenden für meine Bestrebungen zu interessieren. Es liegt zum Teil daran, daß man das Fach als unnötiges Nebenfach beiseite läßt, da es ja nur durch ein Extraordinariat vertreten wird und an den Prüfungen wenig oder gar nicht beteiligt ist.

Auf die Mittel zur Hebung des Ansehens des von mir vertretenen Fachs richten sich daher in der Hauptsache meine Wünsche.

Ein Wunsch, den ich speziell an Eure Excellenz richte, geht dahin, daß meine Lehr- 
stelle in ein Ordinariat umgewandelt werden möge oder, wenn das nicht möglich sein sollte, daß mir das persönliche Ordinariat verliehen werden möge. Meine persönliche Stellung zu der Frage ist noch dieselbe wie vor 3 Jahren, ich habe gern auf das Ordinariat in Hannover verzichtet und trage auch heute kein Verlangen nach Sitz und Stimme in der Fakultät. Dem Ansehen meiner Lehrstelle aber glaube ich es schuldig zu sein, diese Bitte hier auszusprechen.

Eine zweite Maßregel zu diesem Ziele meiner Aufnahme in die Prüfungskommission für angewandte Mathematik (Lehramtsprüfung) ist bereits in die Wege geleitet worden, eine dritte, die sich auf eine Änderung der Promotionsbestimmungen für das Fach Physik bezieht, denke ich der Fakultät in Göttingen vorzulegen.

Außer diesen Dingen liegt mir eine weitere Bitte auf dem Herzen: Ich bin in Göttingen genötigt, sehr heterogene Dinge zu treiben, unter diesen liegt meinen wissenschaftlichen Interessen die landwirtschaftliche Maschinenlehre sehr fern. Die Übertragung der landwirtschaftlichen Maschinenlehre an einen geeigneten Dozenten, über die ich dem Herrn Minister einmal berichtet habe, würde mir die gewünschte Entlastung der landwirtschaftlichen Abteilung, dagegen einen wissenschaftlichen Gewinn bedeuten.

Da das württembergische Ministerium die Angelegenheit für dringlich erklärt, darf ich wohl die ergebene Bitte um baldige Nachricht aussprechen.

Ergebenst L. Prandtl"

Er lehnte dann den Ruf nach Stuttgart ab, da seine Forderungen für Göttingen bewilligt wurden und seine Professur in ein persönliches Ordinariat umgewandelt wurde. Die geplante Versuchsanstalt hielt ihn fest. Es entstand nach Prandtls Angaben im Herbst 1907 östlich des Leinekanals an der Hildebrandstraße ein geschlossener Windkanal mit einem Querschnitt von zwei mal zwei Metern und einem starken Gebläse zur Winderzeugung, später als Göttinger Bauart im Ausland nachgebaut. Unabhängig davon hatte etwa zur gleichen Zeit der Ingenieur Alexandre Gustave Eiffel in Paris einen offenen Windkanal gebaut. Auch diese Konstruktion wurde weiterentwickelt. Seine Versuchseinrichtung sollte vor allem einer speziellen Aufgabe dienen, nämlich den Winddruck auf den von ihm erbauten Eiffelturm zu prüfen.

Professor Ludwig Föppl schreibt: "Ungefähr gleichzeitig mit dem Bau des deutschen Windkanals in Göttingen errichtete der Erbauer des Eiffelturms in Paris einen ähn- 
lichen Windkanal und ließ dort Widerstandsmessungen durchführen. Man hatte also die Möglichkeit, die Göttinger mit den Pariser Meßergebnissen zu vergleichen. Bei den meisten Modellkörpern fand gute Übereinstimmung statt. Dagegen unterschieden sich die Meßergebnisse bei einigen Körpern erheblich. Obwohl die Messungen sowohl in Göttingen wie in Paris mit aller Sorgfalt wiederholt wurden, blieben die Unterschiede in den Widerstandsbeiwerten bestehen."

Nachdem verschiedene Vermutungen über den physikalischen Grund für die Unstimmigkeit geäußert worden waren, gelang Prandtl die Erklärung in überraschend einfacher Weise mit Hilfe seiner Grenzschichttheorie. Die Ursache war, daß der Windstrom im Göttinger und im Pariser Windkanal verschieden war. Im Göttinger Windkanal stand nach Einbau einer Kontraktionsdüse eine turbulenzarme Windströmung für die Messungen zur Verfügung, hingegen war im Pariser Windkanal der Wind stärker turbulent. Durch gezielte Strömungsversuche mit Kugeln, wobei er in einem Fall mit einem Maschennetz künstlich Wirbel im Luftstrom erzeugte und in einem anderen Fall durch Auflöten eines Drahtringes auf die Oberfläche der Kugel die glatte Strömung störte, konnte er die Diskrepanzen beseitigen und damit die Richtigkeit seiner Überlegungen zweifelsfrei unter Beweis stellen [22].

"Für diese sehr eindrucksvolle Erklärung der strittigen Frage wurde Prandtl der Benett-Preis verliehen."

Die Vielseitigkeit der Aufgaben, die Prandtl sich stellte, erstaunte immer wieder. Er war damals mit dem Einverständnis der Motorluftschiff-Studiengesellschaft auch noch mit der Konstruktion eines Drachenfliegers beschäftigt. Seine Studien mit dem Windkanal brachten Erkenntnisse, die die Entwicklung der Flugobjekte förderten, indem man mit den Ergebnissen Angaben machen konnte, wie man die großen Energieverluste beim damaligen Fliegen weitgehend verringern könnte. Es wurden Flugzeugmodelle, Modelle von lenkbaren Luftschiffen sowie Tragflügelprofile in den Kanal gehängt und der Luftwiderstand bei verschieden eingeschalteten Windstärken gemessen. Aus der wissenschaftlichen Auswertung der genauen Messungen hat sich dann die Stromlinienform entwickelt. 
In der Nachbarschaft war das Anschalten des Gebläses gut zu hören; es war nicht zu verbergen, daß dort in der Hildebrandstraße Ungewöhnliches vor sich ging; aber das neue "Windheim" gehörte nun zu dem fortschrittlichen Göttingen. Wenn man bedenkt, daß Otto Lilienthal 1891 mit seinem selbst konstruierten vogelflugähnlichen Gleitflugapparat als erster fliegender Mensch gestartet ist und daß die amerikanischen Brüder Wright 1903 mit ihrem Doppeldecker, dessen Flugeigenschaften noch wenig erprobt waren, den ersten Motorflug gewagt haben, so kann man nur feststellen, daß diese Wissenschaft der Flugforschung, deren Ergebnisse uns heute selbstverständlich geworden sind, damals ganz neuartig und von großem öffentlichen Interesse begleitet war.

Auch das Fliegen mit Luftschiffen fand sehr viel Beachtung und Anerkennung, denn die Tatsache, daß ein Fahrzeug, leichter als Luft, sich beim Fliegen bewähren müßte, war offenbar.

Als am 2. Juli 1900 dem Grafen Zeppelin mit seinem lenkbaren Luftschiff seine Jungfernfahrt über den Bodensee gelang, schrieb ein Reporter, Eugen Wolf, in der Zeitschrift "Die Woche" daraufhin folgenden enthusiastischen Artikel: "Christoph Kolumbus kann, als der Ruf 'Land' an sein Ohr drang, von keinem beseligenderen, höheren Gefühl durchdrungen gewesen sein, als die Empfindungen waren, deren sich das Gemüt des schneidigen Reitergenerals Graf Zeppelin bemächtigte, als nun endlich das majestätische, schlanke, in allen seinen Teilen das Gefühl der Sicherheit verleihende Fahrzeug der Lüfte, einem leisen Hebeldruck seines Führers gehorchend, sich ruhig und geräuschlos von seinem Lagerplatz erhob und gleich einer überirdischen Erscheinung seinen Kurs durch die Lüfte nahm."

Hingegen glichen die allerersten Versuche der Brüder Wright, mit Motorkraft die Erdenschwere zu überwinden, weniger dem schwerelosen Flug eines Zugvogels, sondern eher dem Aufflattern eines Huhnes. Erstmalig glitt ein Motorflugzeug 12 Sekunden lang über die Erde hin, bis seine Kufen nach 50 Metern den Boden wieder berührten. Die Zuschauer, die sich zu dieser Vorführung einfanden, starrten nicht in die Luft, sondern sie legten sich flach auf den Boden, um auf diese Weise Zeuge eines ersten Motorfluges sein zu können. Nur so war nämlich zu beurteilen, ob sich das Flugzeug ganz von der Erde gelöst hatte. Nach ausdauernd wiederholten Versuchen 
gelangen den beiden Flugzeugtechnikern weitere und höhere Flüge. 1908 führten Orville und Wilbur Wright ihre inzwischen immer neu verbesserten Maschinen in Frankreich, Deutschland und England mit Erfolg vor. Der Luftraum war damit erobert worden. Für die fliegenden Objekte eine entsprechende Stabilität und Flugtüchtigkeit zu erreichen, war nun eine der Aufgaben für den Aerodynamiker. In der Versuchsanstalt fanden sich bald wissenschaftliche Mitarbeiter ein. Einige Namen sind mir bekannt: Zuerst möchte ich Th. von Kármán nennen. Sein Studienweg führte ihn schon 1906 nach Göttingen. 1907 wurde Dipl.-Ing. Georg Fuhrmann eingestellt, der dann beim Aufbau der Versuchsanstalt mitarbeitete. 1909 trat Dipl.-Ing. Otto Föppl ein. 1911 und 1912 wurden zwei weitere Hilfskräfte gewonnen: Dipl.-Ing. A. Betz und Dr.-Ing. C. Wieselsberger.

Der ungarische Maschineningenieur Theodore von Kármán hatte 1906 brieflich bei Prandtl angefragt, ob er bei ihm auf dem Gebiet der Mechanik als Doktorand arbeiten könne.

\section{"8.9. 1906, Budapest}

Sehr geehrter Herr Professor!

Gemäß dem Auftrage der hiesigen Technischen Hochschule beabsichtige ich, den nächsten Semester an der Göttinger Universität zu verbringen und während dieser Zeit mich zumeist mit Studien über technische Mechanik und Wärmelehre zu beschäftigen. Meine Aufgabe bezieht sich nämlich darauf, in jene Gebiete der angewandten mathematischen Lehren tiefere wissenschaftliche Einsicht $\mathrm{zu}$ gewinnen, welche im technischen Unterricht und speziell in der Ausbildung von Maschineningenieuren den rein technischen Disziplinen unmittelbar als Vorbereitung und Grundlage dienen. ...

Ich bin erst überzeugt, eine Aufgabe am besten erfüllen zu können, wenn ich mich Ihrer Führung vollkommen anvertraue ...

Ihr ergebener Theodor Kármán"

Kármán, ein sehr erfolgreicher Schüler Prandtls - er hat 1908 bei ihm promoviert -, wurde dann 1913 Professor an der Technischen Hochschule in Aachen. Unter seiner Leitung entstand dort schon Anfang des Jahres 1914 ein Windkanal nach dem bekannten Muster in Göttingen. 1929 nahm er das Angebot aus Amerika an, als 
Direktor in einem Forschungslabor für Luftfahrt in Pasadena zu arbeiten. Er war beunruhigt über die politische Entwicklung in Deutschland und meinte, schon voraussehen zu können, wohin die Ideen der Nationalsozialisten noch führen würden, die ihn als Juden besonders betreffen mußten. Dort in Amerika fand er beste Arbeitsbedingungen vor. Dank seines regen Erfindergeistes verhalf er der amerikanischen Luftfahrtforschung, für deren Förderung große finanzielle Mittel zur Verfügung standen, zu erheblichem Aufschwung.

Kármán ließ die Verbindung mit seinem einstigen Göttinger Lehrer nicht abreißen, solange er sich noch in Deutschland aufhielt. Beide Wissenschaftler forschten über turbulente Strömung und tauschten dann ihre Ergebnisse aus.

In seiner Biographie "Die Wirbelstraße" schreibt Kármán [15]: "Meines Erachtens enträtselte Prandtl einige Naturerscheinungen von grundsätzlicher Bedeutung und hätte den Nobelpreis verdient."

Prandtl hatte sich in Göttingen gut eingelebt. Mit einer heiteren Runde von jungen Dozenten, die ebenfalls noch Junggesellen waren, hatte er einen Mittagstisch. Dazu gehörten Karl Schwarzschild, Astronom, Professor Max Pohlenz, Altphilologe, sowie der Philologe Jakob Wackernagel. Der geistige Austausch war sehr vielseitig. Besondere Freundschaft verband ihn bald mit dem nur zwei Jahre älteren Karl Schwarzschild, einem sehr liebenswerten Menschen. Seine Sternwarte war oft der gesellige Treffpunkt für viele seiner Freunde, zu denen auch Carl Runge gehörte. Sein fast spielerischer Umgang mit der Mathematik inspirierte ihn, seine Gäste mit kurzweiligen Experimenten zu unterhalten.

Schwarzschild war in gleicher Weise wie Prandtl begeistert von den in Aussicht stehenden Ballonfahrten. Man hatte den niedersächsischen Verein für Luftfahrt gegründet, der es den Mitgliedern ermöglichte, in Göttingen einen Ballon aufsteigen zu lassen. Er war in einer Augsburger Ballonfabrik angefertigt worden, bestand aus doppeltem Perkalstoff und hatte einen Durchmessser von 14 Metern bei der Füllung. Man nannte ihn "Segler". 
Auf einer Wiese in der Nähe der Gasanstalt wurde er verankert und mit Gas gefüllt, bis er gut gerundet seine Reise in die Luft antreten konnte. Ich habe später selbst als Kind noch einmal einen solchen Ballonstart dort miterlebt. Es war mit viel Warten verbunden; aber die Spannung wuchs in dem Moment, als die Verankerung gelöst werden konnte, und der Ballon entschwebte, unseren Blicken noch lange sichtbar.

Der Vereinsvorstand hatte genaue Bestimmungen festgelegt für diejenigen, die die Berechtigung erwerben wollten, einen Ballon zu führen. Man hatte sich dem Deutschen Luftschifferverband angeschlossen und richtete sich nach den auf einem Merkblatt vereinbarten Bedingungen. Zum Beispiel: Nachweis über die Befähigung, Instrumente abzulesen und atmosphärische Verhältnisse (Wetterlage, Sonnenstrahlung und Wolkenbildung) zu beurteilen. Eine weitere Festsetzung: "Der Vereinsvorstand läßt durch einen besonderen Ausschuß den Aspiranten prüfen, ob er das Fertigmachen und Füllen des Ballons ohne Hilfe eines Sachverständigen zu leiten und die erforderlichen technischen Handgriffe persönlich zu machen versteht." Auch Zahlungsbedingungen für die Mitfahrer waren vereinbart worden.

Daß Prandtl als Mitfahrer an einer Ballonreise teilgenommen hat, erfährt man durch eine Notiz des Göttinger Tageblatts vom 10. Januar 1908:

\section{"Im Luftballon von Göttingen nach Berlin}

Wie wir mitteilten, sind neulich vier Dozenten der Göttinger Universität, nämlich die Herren Professor Prandtl sowie die Doktoren Linke, Pütter und Bestelmeyer, im Ballon nach Berlin geflogen. Um neun Uhr morgens waren sie mit dem Ballon 'Segler' aufgestiegen und landeten nach siebenstündiger glücklicher Fahrt um vier Uhr nachmittags an den Ufern des Müggelsees, unweit Rahnsdorf. Das Luftschiff hatte Dr. Linke geführt. Der Ballon 'Segler' ist ein Fahrzeug mit 1400 Kubikmetern Gasgehalt. Der Verein für Luftschiffahrt hielt an demselben Tage seine Hauptversammlung in Berlin ab. Als die Herren nun aufstiegen, ließ die Windrichtung wohl an die Möglichkeit glauben, daß ihr Ballon Berlin, und zwar noch rechtzeitig genug, erreichen würde, so daß sie an der Versammlung teilnehmen könnten. Aber da sie nicht über ein lenkbares Luftschiff, sondern nur über einen gewöhnlichen Freiballon verfügten, so stand diese Hoffnung doch auf recht schwankenden Füßen. Um so stolzer waren daher die vier Gelehrten, daß sie pünktlich die Versammlung erreichen konnten." 
Prandtl hat nach kleineren Probefahrten mit Unterweisung dann ein solches Patent zur selbständigen Führung eines Ballons erhalten. Er schrieb am 15.8.1909 an seine Braut Gertrud: "Du kannst hiermit einem neugebackenen Ballonfahrer gratulieren, gestern habe ich die Prüfung bestanden."

Er hat als Ballonführer mehrere Fahrten unternommen, die ihn außerordentlich beglückt haben. Die Möglichkeit, natürliche Windströmung zu beobachten und sie fliegend als Elementarkraft zu erleben, war eine einzigartige Erfahrung. Daß er auch die Wolkenbildung und die unter ihm ausgebreitete Landschaft mit großer Aufmerksamkeit betrachten konnte, bereitete ihm besonderes Vergnügen. Schwarzschild hat indessen bei seinen Flügen vom Ballon aus mit einem Vermessungssextanten astronomische Ortsbestimmungen durchgeführt. Die schöpferische Phantasie der Wissenschaftler wurde bei diesen Unternehmungen immer neu angeregt.

Schwarzschild bekam 1909 einen Ruf nach Potsdam und wurde dort Direktor des astrophysikalischen Observatoriums. Er verließ das vertraute Göttingen mit all seinen guten Freunden.

Prandtls stetiger Aufstieg war hingegen festgefügt in die Göttinger Verhältnisse.

Am 11. Januar 1909 erhielt er aus Berlin folgende ministerielle Anordnung: "Euer Hochwohlgeboren beauftrage ich, vom nächsten Semester ab in Ergänzung des Ihnen durch Erlaß erteilten Lehrauftrags auch das gesamte Gebiet der wissenschaftlichen Aeronautik in Vorlesungen und Übungen zu vertreten. ..."

Darauf meldete eine Zeitung: "Der Kultusminister hat Dr. Prandtl in Göttingen einen Lehrauftrag für Aerodynamik erteilt. Soweit wir unterrichtet sind, dürfte dies die erste Professur für Luftschiffahrt sein."

Sein Kolleg sollte in sechs Abschnitte zerfallen:

1. Aerostatik: über das Gleichgewicht des Luftmeeres und den Grundriß der dynamischen Meteorologie

2. Aerodynamik: allgemeine Strömungsgesetze

3. Gleichgewicht von Drachenfliegern und Gleitfliegern 
4. Propulsion von Luftschrauben

5. Stabilität von Ballonkörpern und Flugmaschinen

6. Über Navigation - terrestrische und astronomische Ortsbestimmung. Aktionsradius unter Einfluß des Windes

Die Berliner Illustrierte Zeitung vom 15.4.1909 wandte sich mit folgendem Anliegen an Prandtl:

"Sehr geehrter Herr Professor!

Wir lesen in den Zeitungen, daß Sie demnächst an der Universität in Göttingen das erste Kolleg über Luftschiffahrt lesen und ihre Vorführungen mit praktischen Vorführungen verbinden werden. Wir möchten sehr gern eine solche Vorlesung, in der Versuche mit Modellen angestellt werden, durch einen unserer Zeichner zeichnen lassen und hoffen, Sie sind damit einverstanden."

Auch die französische Presse berichtete über den neuen Lehrstuhl, und in der englischen Times vom 7. April 1909 veröffentlichte der Aerodynamiker F. W. Lanchester einen Artikel über Probleme der Luftschiffahrt, aus dem ich einen Absatz zitiere:

"In Germany a chair of aerodynamics has been founded at Göttingen, appropriately filled by a very able physicist, Professor Prandtl, whose work is well known and who continues to hold the chair of applied mechanics at the Göttingen University, in addition to his more recent appointment.

The aerodynamic laboratory at Göttingen had already been built and equipped by private enterprise before the new chair was founded, and it is probably the best thing of its kind in the world." 


\section{Verlobung und Heirat}

Die Verbindung zu dem Hause Föppl war all die Jahre lebendig geblieben. Man traf sich immer wieder zur Urlaubszeit, da Prandtl, wenn er in München weilte, nicht versäumte, bei seinem verehrten Lehrer einen Besuch zu machen. Dabei mochte auch ein geheimer Anziehungspunkt im Spiel gewesen sein, nämlich die Aussicht, die nun erwachsene Tochter Gertrud im Föpplhaus antreffen zu können, die sich freilich bescheiden zurückzog, sobald der Vater den Besucher in Beschlag nahm.

Der Gedanken- und Meinungsaustausch zwischen dem älteren und so viel jüngeren Kollegen war stets anregend. Man diskutierte miteinander über manche wissenschaftliche Themen, die immer wieder neu durchdacht werden konnten; und während sie dabei ihre geistige Welt einander näher brachten, wuchs das Vertrauen zueinander. Auch über Personalfragen, Neubesetzungen an Technischen Hochschulen betreffend, wünschten sie sich auszusprechen. Es finden sich in vielen Briefen August Föppls neben seinen familiären Mitteilungen Vorschläge zu Berufungen sowie wissenschaftliche Erörterungen, die hier in meinem Text allerdings nicht berücksichtigt werden können. Lediglich die kleinen Abschnitte privater Mitteilungen möchte ich wiedergeben.

Aus den Briefen von August Föppl:

19. November 1903:

"Bei uns geht es gut. Meine Tochter" (Gertrud) "war neulich einmal einige Wochen in Hannover zu Besuch und hat Sie aus der Ferne, von der Galerie aus, bei einem Commerse gesehen."

\section{Januar 1906:}

"Meine Frau und ich werden uns sehr freuen, wenn Sie am Donnerstag, d. 4 Januar, 12 Uhr 45 zum Mittagessen zu uns kommen wollten (ganz in der Familie, daher bitte im Reiseanzug kommen). Am 3. Januar fange ich wieder zu lesen an; daher würden Sie mich auch am 3., 4., 5. Januar nach der Vorlesung um 10 Uhr im Laboratorium antreffen." 
1908 wandte sich August Föppl an Prandtl mit einem persönlichen Anliegen:

\section{Juli 1908:}

"Mein jüngerer Sohn Ludwig hat jetzt zwei Jahre als Maschinen-Ingenieur studiert und steht gegenwärtig in der Vorprüfung. Er wird sie ohne Zweifel mit der ersten Note bestehen. Nun hat sich aber herausgestellt, daß mein Sohn zwar für die mathematischen Fächer gut begabt ist und daran viel Freude hat, vom Maschinenkonstruieren aber nicht viel wissen will. Ich habe die Absicht, ihn vorläufig einmal ein Jahr lang Mathematik studieren zu lassen, und zwar in Göttingen. Wenn das Jahr herum ist, mag er sich dann entscheiden, ob er seine technischen Studien fortsetzen oder ganz zur Mathematik übergehen will.

Meine Bitte geht nun dahin, daß Sie meinem Sohn einen Stundenplan zusammenstellen möchten. Sie wissen ja, welche Vorlesungen in Göttingen für einen jungen Mann, der fleißig und begabt ist, besonders empfehlenswert sind.

Im voraus für freundliche Auskunftserteilung (wenn sie nicht mündlich erfolgt, was mir noch viel lieber wäre) bestens dankend,

Ihr ganz ergebener August Föppl."

Man traf sich auch in diesem Sommer wieder in der Ferienzeit, die Prandtl immer in Süddeutschland verbrachte. Da die Familie Föppl seit 1894 ein Ferienhaus am Starnberger See besaß, konnten ihre Gäste dort auf dem Lande in der schönen Jahreszeit gut unterkommen. Prandtl, der im August von München aus, wie schon so oft, einen Abstecher an den Starnberger See machte, traf in Ammerland die Familie an und hatte dabei Gelegenheit, den Sohn Ludwig hinsichtlich des Studienwechsels ausführlich zu beraten.

Zum Herbstsemester 1908 begann der Münchner Student, die mathematischen Vorlesungen in Göttingen zu besuchen. Er hörte Kollegs bei David Hilbert und Felix Klein, deren Berühmtheit viele auswärtige Studenten anzog. Es war ein Vorteil, daß es ihm in Göttingen auch möglich war, an einem Seminar über Mechanik teilzunehmen, nämlich jenem, das wir schon erwähnten, das Klein, Prandtl und Runge gemeinsam veranstalteten. 
So wuchs eine neue engere Beziehung zwischen dem Hause Föppl und Ludwig Prandtl. Der Göttinger Professor kümmerte sich auch persönlich um den studierenden Sohn seines einstmaligen Lehrers.

Prandtl fragte ihn dann auch immer nach dem Befinden der übrigen Familienangehörigen in München. Als Ludwig Föppl ihm im Dezember 1908 die Mitteilung machte, seine Schwester Gertrud werde sich demnächst verloben, konnte der junge Gelehrte eine gewisse Erregung nicht unterdrücken. Wie mir mein Onkel Ludwig später erzählte, habe er auf diese Nachricht hin sehr traurig vor sich hin geschaut.

Am 31. Dezember 1908 sprach er dem Kollegen Föppl seine Glückwünsche zum Jahreswechsel aus und verband damit eine Gratulation zur Verlobung von Fräulein Gertrud.

\section{Januar 1909, Brief von August Föppl:}

"Vielen Dank für Ihren freundlichen Neujahrsbrief. Von den darin enthaltenen Glückwünschen hat allerdings der eine sein Ziel verfehlt. Die Verlobung meiner Tochter Gertrud wurde schon nach kurzem Bestand wieder aufgelöst."

(Es liegt nahe anzunehmen, daß Prandtl diese Nachricht über die Wendung der Dinge nicht gleichgültig aufnahm.)

August Föppl fuhr dann fort: "Vielmals danke ich Ihnen auch für die freundliche Aufnahme und Förderung, die Sie meinem Sohn Ludwig zuteil werden ließen. Meinen Sohn Otto bekommen Sie nun auch nach Göttingen! Mir hat es anfänglich nicht recht gefallen, daß er seine Stelle in Gotha so bald wieder aufgeben wollte. Ich lege viel Wert auf die Stetigkeit und Beharrlichkeit der Lebensführung. Hoffentlich vermag er die Erwartungen, die Sie in ihn setzen, zu erfüllen."

Ingenieur Otto Föppl, der ältere Sohn, kam also auch zu Prandtl nach Göttingen und war dann vom 1. Januar 1909 bis zum 1. Juni 1911 bei dem jungen Aerodynamiker Assistent in der Modellversuchsanstalt.

Auch für die Tochter Gertrud sollte bald die Stadt Göttingen eine besondere Bedeutung bekommen, aber in einem anderen, viel schicksalhafteren Sinne als für ihre Brüder. Und darüber, wie Gertruds Lebensweg von München in diese Stadt führte, soll nun berichtet werden. 
Ostern 1909 traf Prandtl seine Entscheidung. Er entschloß sich, Gertrud um ihre Hand zu bitten.

Was nun folgte, hat Ludwig Föppl in seinen Erinnerungen aufgezeichnet: "Für die Osterferien plante Prandtl eine Erholungsfahrt an den Gardasee und nach Bozen. Wie schon öfter bei solcher Gelegenheit machte er in München Station und besuchte uns und unterhielt sich dabei angeregt mit meiner älteren Schwester Gertrud. Bald darauf bekam sie von Prandtl einen Heiratsantrag in einem Brief aus Riva:

'Riva, 20. April 1909

Sehr verehrtes Fräulein! In der Einsamkeit der Berge ist mir der Entschluß gereift, eine Frage an Sie zu richten, die ich schon lange mit mir herumtrage...'

Diese Nachricht löste bei mir große Freude aus, denn ich wußte meine Schwester bei keinem anderen Mann in besseren Händen. Genauso dachten auch meine Eltern. Gertruds Entschluß stand bald fest, den Heiratsantrag anzunehmen. Sie gab Prandtl schriftlich ihr Ja-Wort. Da er nach Bozen weiterreisen wollte, hatte er sie gebeten, ihre Antwort dorthin postlagernd zu schicken. Er hatte auch mitgeteilt, wieviele Tage er noch in Riva zu bleiben beabsichtigte, jedoch aus irgendeiner Zerstreutheit nicht das Hotel angegeben, in dem er Quartier genommen hatte. Da Gertrud mit der Antwort nicht zögerte, schickte sie diese nun nach Riva postlagernd. Indessen war Prandtl der Meinung, ihr Brief müßte, falls die Rückantwort schon baldigst erfolgen sollte, ihn im Hotel erreichen. In Bozen angekommen, wartete er dann vergeblich auf den postlagernden Antwortbrief aus München.

Für Gertrud sollte nun eine bange Woche kommen, in der Prandtl nichts von sich hören ließ. Als ich Ende April wieder nach Göttingen fahren mußte, um zu Beginn des Sommersemesters dort zu sein, war noch keine Antwort auf Gertruds Brief eingegangen. Ich tröstete sie damit, daß ich mich gleich nach meiner Ankunft in Göttingen erkundigen werde, ob Prandtl schon von seiner Reise zurïck sei. Doch ich erfuhr, daß er noch nicht wieder zurückgekehrt sei, aber in Kürze erwartet werde. Ich teilte dies Gertrud sofort mit. Nachdem ich den Tag seiner Rückkehr in Erfahrung gebracht hatte, ging ich abends zu ihm in die Wohnung am Kirchweg 1a und brachte nach den ersten Begrüßungsworten zögernd die Frage heraus, ob er den Brief, den meine Schwester ihm postlagernd nach Riva geschickt habe, nicht erhalten habe. Voll 
Erstaunen kam es nun aus ihm heraus: 'Nach Riva? Ich habe täglich auf der Post in Bozen nach einem Brief von ihr gefragt, und schließlich mußte ich nach Göttingen zurückfahren.' Nachdem dieser Irrtum aufgeklärt war herrschte eitel Freude, und wir begrüßten uns als Schwäger. Noch in der gleichen Nacht schickte ich ein Telegramm an Gertrud, mit der Versicherung, daß alles in Ordnung sei, und am anderen Tag schilderte ich in einem Brief den Vorgang."

Die Eltern Föppl begrüßten die Verbindung mit großer Herzlichkeit. August Föppl am 10. Mai 1909:

\section{"Lieber Herr Kollege!}

Ich bin sehr erfreut darüber, daß Sie mit meiner Tochter einig geworden sind, die Ehe einzugehen. Meinen Segen gebe ich dazu von ganzem Herzen. Ich habe Sie nicht nur als Gelehrten, sondern auch als Menschen stets sehr hoch geschätzt, und ich wüßte niemanden, den ich lieber als Schwiegersohn willkommen heißen möchte, als Sie. Da wir nun noch in engere Beziehung kommen werden als bisher, fordert die Grammatik, daß wir uns in Zukunft mit "Du" anreden werden, und ich mache davon sofort Gebrauch. Gertrud ist mir stets eine gute und liebevolle Tochter gewesen. Ich werde sie hier sehr vermissen. Zu Pfingsten hoffen wir, Dich mit unseren anderen Söhnen bei uns zu sehen. Über alle Einzelheiten können wir uns dann ja noch verständigen.

Dein alter Lehrer und neuer Schwiegervater."

Frau Emilie Föppl schreibt:

"Auch ich will, wie mein Mann, gleich das vertraute Du einführen, indem ich Dich als lieben Sohn herzlich willkommen heiße. Ich freue mich sehr über diese Verbindung. Habe ich doch schon seit vielen Jahren eine besondere Vorliebe für Dich gehabt, und ich bin der festen Überzeugung, daß mein Kind an Deiner Seite ein Lebensglück findet. Da Gertrud dazu erzogen ist, das größte Glück in treuer Pflichterfüllung im eigenen Heim zu suchen, hoffe ich, daß sie Dir als Lebensgefährtin das sein wird, was Du wünschest.

Möge Euch Gottes Segen auf Eurem gemeinsamen Weg begleiten.

Herzlichste Grüße! Deine tr. Mutter E. Föppl."1)

1) In diesem Zusammenhang sei darauf hingewiesen, daß die Darstellung, die Professor Th. von Kármán in seinem Buch "Die Wirbelstraße" [15] beiläufig von Prandtls Heiratsgeschichte gibt, in keiner Weise den Tatsachen entspricht. 
Aus Prandtls Briefen in der Verlobungszeit:

5. Mai 1909:

"Meine Jugend war ja recht trübe gewesen durch das Unglück meiner Eltern. Aber mein gleichmütiges Temperament hat mir geholfen, auch die traurigsten Zeiten zu überstehen, ohne die Freude am Dasein gänzlich zu verlieren. Später habe ich ja ungewöhnlich viel Glück gehabt. Wenn mir das Schicksal nun auch das noch gönnt, daß wir beide uns finden zu glücklicher Übereinstimmung, zu dauerndem harmonischen Zusammenwirken, dann hat es mir wirklich weit mehr gegeben, als es mir je nehmen konnte."

\section{Mai 1909:}

"Wir Männer sind ja leider fast nie imstande, unseren Frauen im gleichen Maße wiederzugeben, was sie uns an aufopfernder Liebe zuwenden. Die Frau widmet sich ganz dem Hauswesen um ihres Mannes willen - ihn dagegen muß sie mit seinen Berufsinteressen teilen.

Bei mir ist die Sache eigentlich besonders schlimm: Du wirst es gleich mit zwei Rivalinnen aufzunehmen haben, einer würdigen Dame, die aber die ihr Ergebenen mit fast göttlicher Gewalt in ihrem Bann hält, und einer anderen, die noch knospenhaft jung zwar, doch schon verführerisch lockend ihre Netze auswirft nach allen, die für ihre Schönheit empfänglich sind. Soll ich sie noch nennen? Es sind die Wissenschaft und die Luftschiffahrt.

Daß ich gerade dieses Semester mehr als jemals um die Ohren habe! Da ist der Ausbau meiner Modellversuchsanstalt - von der jetzt bereits im englischen Parlament die Rede war - die Vorlesung über Luftschiffahrt, zu der ich natürlich einiges neu erarbeiten muß, verschiedene Vorträge, die ich übernommen habe (einen vor der Hauptversammlung des Vereins Deutscher Ingenieure, einen für die Frankfurter Ausstellung (ILA - Internationale Luftfahrtausstellung), wo ich einmal Aussteller und daneben Leiter von Preisbewerbern bin).

Wenn ich wüßte, wo ich Zeit dazu hernähme, möchte ich auch zu gerne noch an den Bau einer Flugmaschine gehen. Ich werd's aber doch wohl aus verschiedenen Gründen einstweilen bleiben lassen.

Du fragst, was ich am Sonntag in der Regel treibe: Briefe schreiben, Literatur nachlesen. Nach dem Mittagessen im 'Englischen Hof' im Kreise von verschiedenen 
jungen Dozenten wird meist ein gemeinsamer Spaziergang unternommen, je nach Lust und Wetter vom einfachen Kaffeebummel in ein Nachbardorf bis zum großen Ausflug irgendwohin ins Mittelgebirge. Heute zum Beispiel sind wir durch liebliche Täler mit blühenden Kirschbäumen nach der stolzen Burg Hanstein gewandert. Das wird Dir überhaupt an Göttingen sehr gefallen, daß man überall die Natur so nahe hat, daß man überhaupt wie auf dem Lande wohnen kann, weil die neueren Stadtteile als Gartenstadt angelegt sind."

2. Juli 1909 - Prandtl unterbreitet seiner Braut Wohnungsvorschläge: "1. Prinz- Albrechtstraße 20, erster Stock, bevorzugte, hübsche Lage. Grenzt hinten an das Sternwartengrundstück" (dort wirkte damals Freund Schwarzschild), "zwölf Minuten zum Institut, neun Minuten zum Markt."

Er erwähnt auch eine weiter abgelegene Wohnung und legt folgende Rechnung vor: "Bei zweimaligem Institutsweg täglich 40 Minuten mehr Laufzeit, bei 288 Arbeitstagen im Jahr würde das acht volle Tage und Nächte ausmachen. Wenn ich alles gegeneinander abwäge, komme ich zu keinem Schluß, weil die Vorteile und Nachteile sich ausgleichen. Hoffentlich geht's Dir besser als mir, hoffentlich neigst Du etwas Bestimmtem zu."

Gertrud hat offenbar von der Ferne aus ihre Wahl getroffen und sich für die Wohnung in der Prinz-Albrecht-Straße entschieden.

\section{Juli 1909:}

"Heute habe ich also die Möbelzeichnungen weggeschickt. Es hat mir keines der verschiedenen Buffets entsprochen, also habe ich mich wieder selber darangemacht, einen Entwurf zu liefern."

Die Zeichnung ist noch vorhanden, und ich habe genau das Buffet wiedererkannt, das in dem elterlichen Eßzimmer stand.

Wieviele Wege, Schreiberei und Gedanken er trotz seiner enormen Arbeitsbelastung an diese privaten Dinge wendete, die ihm ja auch wichtig waren, geht aus all den Briefen hervor. 
Den Einzug in die neue Wohnung schilderte Prandlt wie folgt: "Der Umzug verlief so: Aufstehen um 1/2 6 - von 6 bis 8 hatte ich eine Ballonfüllung (Freiballon) - um $9 \mathrm{Uhr}$ kam der Packer, ich trug ihm bis 11 Uhr zu. Von 11 bis 1 hatte ich Seminar zu halten Mittagessen - 2 bis $1 / 24$ Verladen der Möbel, $1 / 24$ bis 4 Transport, 4 bis 1/2 6 Einrichten in der neuen Wohnung. Nun kam eine Ruhepause. Um 9 Uhr zu guter Letzt noch eine Sitzung der Seminardirektion."

Die Heirat stand bevor. Man hatte sich in bezug auf die Religionsfrage dahingehend geeinigt, daß Prandtl zwar in der katholischen Kirche blieb, daß aber Gertruds protestantisches Herkommen für die Eheschließung bestimmend sein solle. Am 11. September 1909 wurden Ludwig Prandtl und Gertrud Föppl in München evangelisch getraut. Die Hochzeitsfeier fand in der Föpplschen Wohnung, Heßstraße 10, statt.

Meine Tante, die zehn Jahre jüngere Schwester, hat mir noch in ihrem Alter davon erzählt, daß sie trotz ihres Aufenthaltes in einem Schweizer Internat, wo sie Französisch lernte, an Gertruds Hochzeit teilnehmen konnte. Anders als für ihre erwachsenen Brüder gehörte für sie der neue Schwager ganz zur Generation ihres Vaters, da nämlich beide als Kollegen miteinander verkehrt hatten.

Das Verhältnis zwischen den beiden Wissenschaftlern änderte sich jedoch allmählich. Der Schwiegervater hielt sich von da an mehr an familiäre Gespräche - zu Fachgesprächen war er nur selten noch bereit.

In der Familie Föppl wurde drei Wochen darauf eine zweite Hochzeit gefeiert. Der ältere Sohn Otto heiratete eine Münchner Kollegentochter. Das junge Paar zog dann ebenfalls nach Göttingen. Otto Föppl, der in seiner Göttinger Zeit einen Teil seiner Arbeitsergebnisse über das Thema "Windkräfte an ebenen und gewölbten Platten" in seiner Dissertationsschrift [8] niedergelegt hatte, wurde später Professor für Festigkeitslehre in Braunschweig.

Als meine Mutter Ende September 1909 nach Göttingen kam, war sie entzückt von dem Leben in dieser kleinen Stadt, und es wurde ihr nicht schwer, sich bald heimisch zu fühlen. 
Sie kamen von ihrer Hochzeitsreise, die an den Gardasee geführt hatte, zurück. Am Göttinger Bahnhof stiegen sie in eine offene Kutsche ein, die sie in gemächlichem Schritt durch die Stadt fuhr und zur Prinz-Albrecht-Straße (heutige Keplerstraße) brachte. Unterwegs zeigte mein Vater seiner jungen Frau verschiedene wichtige Gebäude, etwa das physikalische Institut mit Leineblick, die Universitätsbibliothek. Dann war man schon an der Biegung zur Hauptstraße und fuhr Richtung Quentins Eck ein Stück auf der Weender Straße entlang. Daß diese kurze Strecke vom Auditorium bis zum Markt die Hauptverkehrsader von Göttingen darstellte, erheiterte die Münchnerin außerordentlich. Mein Vater gab ihr manche Hinweise auf die Möglichkeiten, hier oder dort einzukaufen. Rathaus und Gänselieselbrunnen wurden in Augenschein genommen. Das Rößlein lenkte nun am Markt das leichte Gefährt um die Ecke, man fuhr die Lange Geismar-, die Kurze Geismarstraße hinauf, durch das alte Geismartor hindurch, von dem die mächtigen Steinlöwen sphinxhaft herabschauten. Gleich darauf war die Fahrt beendet, das Haus Prinz-Albrecht-Straße Nr. 20 war ja das Ziel der langen Reise gewesen. Nun kam der Einzug in die Sechs-ZimmerWohnung, die mein Vater inzwischen gemietet hatte. Auf den Rat von Verwandten hatte er auch schon ein Hausmädchen engagiert, welches sie nun empfing und ihnen beim Auspacken behilflich war.

Am nächsten Morgen wollte sich meine Mutter ein wenig in der Stadt umsehen und einige Besorgungen machen. Als sie in ein Geschäft auf der Weender Straße eintrat, wurde sie besonders aufmerksam bedient. Und dann hörte sie die Verkäuferin sagen: "Ja bitte, Frau Professor, sollen wir Ihnen die Sachen in Ihre Wohnung schicken?" Sie konnte nur schnell entgegnen: "Aber wieso kennen Sie mich?" "Ja, wir haben Sie doch gestern nachmittag mit dem Herrn Professor in der Kutsche hier vorbeifahren sehen." Meine Mutter fühlte sich gewissermaßen verzaubert und zugleich amüsiert. In dieser Stadt, die sie soeben als Fremde durchwandert hatte, kannte man sie bereits. In München war sie halt unbeachtet durch die Straßen gegangen. Hier aber hatte man sie schon erwartet und erwies ihr nun die Aufmerksamkeiten, die man in dieser kleinen Universitätsstadt einer Frau Professor zukommen ließ. Das Paar in der Kutsche hatte wohl, ohne daß sie es geahnt hatte, manche Blicke auf sich gezogen.

Mein Vater, brünett mit schwarzem Vollbart, sah ernst und gereift aus. Neben ihm wirkte meine Mutter mit ihrem blonden hochgesteckten Haar sehr jung und zart. Sie war damals 27 Jahre alt. 
Bald gewöhnte sie sich an die neue Rolle, die ihr durch die Heirat so plötzlich zugeteilt worden war. Wenn sie morgens mit einem Klopfzeichen und den folgenden Worten geweckt wurde: "Frau Professor, das Wasser ist heiß", dann mußte sie allerdings erst nachdenken und stellte dann verwundert fest: "Das bin ja ich, diese Frau Professor!"

Sie sagte einmal zu mir: "Es ist sicher auch sehr schön, wenn man den ganzen Aufstieg seines Ehemannes miterlebt, ihm so manches mitgeholfen hat und sich von Stufe zu Stufe mit ihm über sein Weiterkommen freuen kann. Ich habe es gleich unverdient gut gehabt." Sie wurde dem hohen Ansehen ihres Mannes entsprechend eingestuft und stets als Respektsperson behandelt.

Obwohl sie schon seit einigen Monaten dieser neuen Welt entgegengelebt hatte, die sie aus Erzählungen ihrer Brüder und aus Berichten ihres Verlobten ein wenig zu kennen meinte, war doch alles überraschend anders. Sie war bald durch ihren neuen Lebenskreis ganz ausgefüllt. Da ihr Mann damals noch keine eigene Sekretärin hatte, ergab es sich, daß sie für ihn Schreibarbeiten übernahm. Beide hatten die gleiche Kurzschrift gelernt, die Gabelsberger. Das erleichterte die Zusammenarbeit. Bei dieser Gelegenheit konnte sie sich ein wenig Zugang zu seiner geistigen Welt und vor allem Einblick in seinen Menschenkreis verschaffen. Ihre klare, entschiedene Art war oft für meinen Vater eine beglückende Ergänzung zu seinem Wesen, denn für ihn ergaben sich oft auch in unwichtigen Einzelheiten Probleme durch allzu reifliches Nachdenken und Abwägen. Soweit es sich auf ganz Alltägliches bezog, so hatte seine Genauigkeit, mit der er uns immer geduldig seinen Standpunkt erklärte und die verschiedenen Möglichkeiten bedachte, geradezu etwas Rührendes. Meiner Mutter hingegen fiel es leicht, einen schnellen Entschluß zu fassen, und es war gut, wenn kleine Entscheidungen im Alltagsleben ohne Aufschub getroffen werden konnten. Eine Szene, die sich mir durch Wiederholung eingeprägt hat, mag dies veranschaulichen. Während des Frühstücks öffnete er seine neuangekommene Post und vertiefte sich in die Lektüre der Briefe. Dann stand er sehr plötzlich auf, nun schon in Eile. Trotzdem schaute er aber doch noch auf den verschiedenen Seiten unserer Wohnung zu den Fenstern hinaus, um den Himmel zu betrachten, las dann noch die Temperatur am Außenthermometer ab und erwog nun, welchen Mantel er überziehen sollte. Noch schwieriger war die Entscheidung, wenn verdächtige Wolken die Landschaft verschat- 
teten: Sollte er einen Schirm mitnehmen? Er bat meine Mutter um ihren Ratschlag. Sie zögerte nicht mit ihrer Antwort. Ohne einen Blick aus dem Fenster zu tun, sagte sie mit frohem Optimismus: "Du wirst keinen Schirm brauchen." "Gut", meinte er, "auf Deine Verantwortung", und ließ den langen schwarzen Gegenstand zu Hause hängen.

Große Freude fanden beide Ehegatten an weiten Spaziergängen. Sowohl am Samstagnachmittag als auch am Sonntag wanderten sie durch die nahen Wälder, manchmal bis über die nächsten Dörfer hinaus.

Eine erste Geselligkeit fand in der Prinz-Albrecht-Straße laut einer Notiz am 7.12.1910 statt. Die junge Ehefrau mußte sich nun als Gastgeberin bewähren, nachdem sie im ersten Ehejahr bei Kollegenfamilien reihum eingeladen worden waren. Mein Vater war sehr glücklich, nach so vielen Göttinger Junggesellenjahren seine verehrten Kollegen endlich im eigenen Heim empfangen zu können. Es kamen das Ehepaar Hilbert, Geheimrat Klein und Frau, Professor Runge, Professor Wiechert, Professor Simon und andere zu ihnen zum Abendessen. Aus befriedigten Äußerungen meines Vaters zu schließen, muß es ein gelungener Abend gewesen sein.

Aber meine Mutter verstand sehr gut, daß häufige Abendgesellschaften dem Gatten Stunden nehmen würden, die er sonst für sein nächtliches Arbeitspensum nutzte. So vermieden sie es, allzu große gesellschaftliche Verpflichtungen einzugehen. Hingegen kamen Gertruds Brüder oft ins Haus, zum gemütlichen Sonntagmittagessen.

Im übrigen genoß das Ehepaar aber auch seine schöne Häuslichkeit zu zweit. Einer der Räume war als Musiksalon eingerichtet, an der Fensterseite stand der Bechsteinflügel, den mein Vater zum Einzug erworben hatte. Es verging wohl kein Tag, ohne daß er zum Klingen gebracht wurde. Es blieb ihm bis ins Alter ein unentbehrliches Bedürfnis, sich täglich wenigstens einmal an sein Instrument zu setzen, um sich in die Welt der Töne zu vertiefen. Ohne irgendwelcher Noten zu bedürfen, spielte er dann, kraftvoll in die Tasten greifend, und schöpfte dabei ganz aus dem Reichtum seiner Phantasie. Dabei ließ er sich inspirieren von Ideen von Bach oder von Mozart, Beethoven und Brahms, die er in eigenen, orginellen Strukturen abwandelte und weiterführte. Seine Improvisationen ähnelten sich wohl ein wenig im Stil, aber seine musikalischen Einfälle waren so reich, daß es doch immer wieder neu und ursprüng- 
lich klang, niemals gab es eine Wiederholung. Als wir ihm einmal unsere Bewunderung ausdrückten, meinte er nur: "Ach, ich habe das Thema ja bei Haydn gestohlen, es ist nicht von mir." Aber er konnte freilich auch ein Thema selbst erfinden, das er in einer Fuge weiterentwickelte. Seine Möglichkeiten, sich musikalisch je nach seiner Stimmung auszudrücken, schienen unerschöpflich.

Für uns hat sein Spiel sehr viel bedeutet. Man fühlte, wie sehr seine Musik Ausdruck seiner ganzen Persönlichkeit war. Wenn er am späten Nachmittag aus seinem Institut nach Hause kam und sich gleich ans Klavier begab, suchte er Entspannung im Spiel. Und seine Phantasien verbreiteten eine Stimmung von Harmonie und durch Kunst gefilterter Lebensfreude.

Wir haben ihn später, als wir schon etwas von Musik verstanden, mitunter auch gebeten, eine dreistimmige Fuge zu probieren. Dann überlegte er eine kurze Weile und spielte alsbald die kleine Komposition zu unserem Erstaunen mit der üblichen Verflechtung der immer wiederkehrenden Themen. Es war eine wunderbare Überraschung zu erleben, wie sich sein Können, das wir auf die Probe gestellt hatten, so souverän bewährte. Wir durften nun das Thema auch einmal selbst erfinden. Das war für ihn gleich ein neues Spiel, und mit heiterem Sinn löste er die Aufgabe.

Ich möchte hier noch von einer Begebenheit berichten, die ich durch die Erzählung meiner Mutter gut im Gedächtnis behalten habe. Als meine Eltern einmal bei Kollegen zu Gast waren, die auch einen Flügel besaßen, teilte die Frau des Hauses ihnen voll Bedauerns mit, daß seit einiger Zeit eine Taste ohne Ton sei, sonst hätte sie so gern meinen Vater gebeten, darauf vorzuspielen. Er präludierte ein wenig und mußte feststellen: Trotz kräftigen Anschlags blieb die Taste stumm. Während man nun im anstoßenden Zimmer bei bester Unterhaltung zusammensaß, begab sich mein Vater unbemerkt hinüber in das Nebenzimmer, um den Flügel zu untersuchen. Er klappte ihn behutsam auf und fand bald die Ursache heraus, warum die eine Taste ohne Ton blieb: Ein Fingerhut war zwischen die Saiten gefallen und klemmte dort fest. Nachdem er ihn vorsichtig herausgeholt hatte, setzte er sich nun vor den Flügel und begann zu spielen, mächtig von den tiefen Bässen bis hinauf zum Diskant in reichen Harmonien. Man horchte. Als die Hausfrau die Zwischentür öffnete, sagte er, sie müsse sich wohl geirrt haben, es seien alle Töne in Ordnung, er habe es doch soeben probiert. 
Sie schaute ihn ungläubig an und wollte ihm den einen Ton zeigen - siehe, da klang er ganz richtig. Die Gastgeberin fing nun an zu beteuern, daß die Taste noch gestern ohne Ton gewesen sei. Da meinte mein Vater, er habe ihr etwas abzuliefern, was er gefunden habe, und überreichte ihr zur Erheiterung der übrigen Gäste den Fingerhut. Nun wurde er gebeten, noch einmal zu spielen. Die freudige Zustimmung der kleinen Gesellschaft war ihm Dank genug.

Meine Mutter war verschiedentlich auf Reisen, sie besuchte ihre Eltern und fuhr dann noch ins Gebirge zur Erholung. Wie sehr beide Ehegatten miteinander verbunden waren, zeigen die Briefe, in denen sie sich mitteilten.

Ludwig an Gertrud am 4. August 1912:

"Nun ist Semesterschluß. Ich habe ihn dadurch gefeiert, daß ich lang schlief. Die einzig positive Leistung ist dieser Brief an Dich. Und dabei warten mindestens ein Dutzend Briefe auf Erledigung! Montag 9 bis 11 Sommerfeld, 11-1 Uhr eine eingeschobene Doppelvorlesung, nachmittags Turnen, dann Abendessen mit Ludwig Föppl bei uns zu Hause. Kármán kam noch dazu, sie blieben bis 11 Uhr und arbeiteten an einem Artikel. Sonst hätte ich gestern noch geschrieben.

Gestern war hier ein großer Tag. Das Zeppelinschiff 'Hansa' hat über Göttingen eine Schleife gefahren (die Stadtverwaltung und der Verein für Luftfahrt haben die Schleife bezahlt). Ganz Göttingen war teils auf den Beinen, teils auf den Dächern. Wir waren auf dem Verandadach und haben ihn prächtig gesehen. Die Glocken läuteten, die Türme waren beflaggt, und es war großer Jubel. Schade, daß Du nicht da warst!"

Ein Brief Gertruds vom 15. August 1912 endet wie folgt:

"Lebe wohl, mein guter, guter Mann. Wenn ich allein durch den Wald wandere, dann unterhalte ich mich gewöhnlich mit Dir.

Tausend Grüße Deine Gertrud."

Ludwig Föppl berichtet aus dieser Zeit: "Nach dem Lehrexamen in München ging ich zum Wintersemester 1910 wieder nach Göttingen um zu promovieren. Die folgenden viereinhalb Jahre gaben mir oft Gelegenheit, mit dem jungerverheirateten Ehepaar Prandtl zusammenzukommen. Ein für alle mal war ich bei Prandtls zum sonntäg- 
lichen Mittagessen eingeladen. Gerne denke ich an diese Sonntage zurück, die immer sehr harmonisch verliefen. Prandtl war kein Kostverächter. Er widmete sich dem Sonntagsbraten mit sichtlichem Genuß und ließ auch beim Essen seiner lebhaften Phantasie bei der Geschmackskombination verschiedener Gerichte, die auf dem Tische standen, freien Lauf. Nach dem Mittagessen setzte er sich nach kurzer Pause ans Klavier, einen schönen Bechsteinflügel, und phantasierte. Ich hörte ihm, in einem Sessel versunken, immer gerne zu und bewunderte seine Gabe, ohne Noten seine augenblickliche Stimmung musikalisch umzusetzen. Natürlich mußte das Klavier gelegentlich auch Versuchszwecken dienen, indem er zum Beispiel Zeitungspapier auf oder unter die Saiten legte und die Wirkung auf den Klang untersuchte. Da er das absolute Gehör besaß, konnte er sein Klavier auch selbst stimmen. Prandtl konnte sich in sein Klavierspiel so vertiefen, daß er alles andere darüber vergaß. Es bildete für ihn eine Quelle geistiger Erholung.

$\mathrm{Zu}$ meinen sonntäglichen Besuchen bei Prandtls gehörte ein gemeinsamer Nachmittagsspaziergang. Gewöhnlich führte uns unser Weg den Hainberg hinauf zum KaiserWilhelm-Park oder zum Kehr, wo wir Kaffee tranken. Der wache Geist Prandtls beobachtete alle einzelnen Besonderheiten ringsum auf unserem Weg. Er konnte sich im Frühjahr über die ersten Blumen wie ein Kind freuen und lauschte gespannt auf den Gesang der Vögel. Wind und Wetter verfolgte er mit Aufmerksamkeit. Immer wußte er zu seinen Beobachtungen interessante Ergänzungen zu geben, so daß diese Spaziergänge stets angeregt verliefen. Auch von dem Spieltrieb in ihm bekam ich manche Probe. So erinnere ich mich, daß er beim Kaffeetrinken im Gasthaus gerne mit dem Kaffeegeschirr, nachdem der Kaffee getrunken war, zu bauen begann, indem er Tassen und Teller übereinander türmte und die Stabilität dieses Aufbaus prüfte. Es kam aber auch vor, daß dabei eine Tasse in Scherben ging, die er dann bei der Kellnerin mit vielen Entschuldigungen bezahlte. Diese Sonntagsspaziergänge taten uns allen wohl. Prandtl hatte das Bedürfnis, wenigstens einmal in der Woche einen tüchtigen Marsch zu machen. Es bedeutete ein Gegengewicht zu seiner sonstigen Lebensweise. Hierzu diente auch das Professorenturnen, an dem er am Spätnachmittag jedes Samstages teilnahm.

So vergingen köstliche Jahre, in denen Prandtls Ansehen dank seines Fleißes und seiner guten Einfälle ständig wuchs.

$\mathrm{Da}$ in diesen Jahren meine Neigung zur Mechanik klar zu Tage getreten war, so daß ich sowohl in meiner Doktorarbeit als auch in meiner Habilitationsschrift mecha- 
nische Probleme behandelt habe, so war für mich das häufige Zusammensein mit Prandtl außerordentlich anregend und befruchtend für mein wissenschaftliches Fortkommen. Wenn ich irgendwelche Schwierigkeiten hatte, so genügte oft ein Gespräch mit Prandtl, um mir über den toten Punkt hinweg zu helfen. Diese Hilfestellung gewährte er nicht nur mir als seinem Schwager, sondern allen jungen Leuten, die mit ähnlichen Anliegen zu ihm kamen. Seine Güte und Menschenfreundlichkeit kannten keine Grenzen. Deshalb erfreute er sich sowohl bei seinen Schülern und Assistenten wie auch bei seinen Kollegen größter Beliebtheit. Freilich kam es dabei auch vor, daß seine Güte ungebührlich ausgenutzt wurde.

Auch in den Sommerferien traf ich oft mit Ludwig Prandtl zusammen, da wir manche Wochen gemeinsam am Starnberger See im Landhaus meiner Eltern verbrachten. Er nahm dann immer eine Mappe mit unerledigten Arbeiten und unbeantworteten Briefen mit, die ihn vor allem bei schlechtem Wetter an den Schreibtisch fesselten. Bei schönem Wetter genoß er mit uns den Garten und die reizvolle Landschaft sowie das Baden im See. An einem schönen Aussichtspunkt im Garten, der einen Blick auf den See und auf die ganze Kette der bayrischen Berge gestattete, standen wir oft zusammen, und Prandtl schaute in die Runde, und indem er alle Einzelheiten aufmerksam betrachtete, sprach er sich gerne darüber aus. Namentlich die Abendstimmungen, die von hier aus besonders eindrucksvoll wirkten, konnten Prandtl hell begeistern. Oft, wenn er eine besonders schöne Färbung am Himmel sah, rief er uns alle herbei und machte uns auf die verschiedenen Farbtönungen aufmerksam. Ein besonderes Anliegen war für ihn immer, sich mit Wetterbeobachtungen zu beschäftigen. Es ließ sich von unserem Aussichtspunkt aus eine Entwicklung der Wetterlage ganz gut voraussehen. Herannahende Gewitter hat hier Prandtl immer wieder beobachtet und dabei die eigenartigen Wolkengebilde in ihrem Entstehen und Wachstum verfolgt. Oft blieb er noch, bis die ersten Tropfen fielen, dort. Als eines Sommers eine neugepflanzte Fichtenhecke unmittelbar vor unserem Aussichtspunkt so hoch gewachsen war, daß sie dadurch den früheren Weitblick versperrte, entschlossen wir uns, einen kleinen Hügel aus Kies anzulegen, um uns einen erhöhten Standpunkt zu verschaffen. Viele Schubkarren voll schafften wir von einer Kiesgrube dorthin. Bei diesen körperlichen Arbeiten half Prandtl kameradschaftlich mit, wennn es ihm auch schwerer fiel als uns Jüngeren. Überhaupt war er bei allen unseren Unternehmungen gerne dabei und freute sich über jeden Spaß und wußte hierbei oft neue Gesichtspunkte beizutragen. Er paßte sich bereitwillig jeder Situation an und war niemals 
Spielverderber, auch wenn wir uns gelegentlich über seine körperliche Ungeschicklichkeit lustig machten. Dabei merkte man nichts von dem gelehrten und berühmten Professor. Er blieb immer gleich freundlich und bescheiden, wie ja überhaupt die Bescheidenheit ein Merkmal hoher Bildung ist. Er spielte auch mit uns Tennis auf unserem Tennisplatz, obwohl er keinerlei Übung darin hatte und das schnelle Reagieren seiner bedächtigen Art nicht entsprach. Aber trotzdem freuten wir uns immer, wenn er mit uns spielte. Da gab es oft viel zu lachen, wenn er zum Beipsiel bei einem fehlerhaften Schlag eine eingehende Analyse des Schlages geben wollte und wir ihn auf den Unterschied zwischen Theorie und Praxis aufmerksam machten.

Mit besonders erfreulichen Erinnerungen verbinde ich die gemeinsamen Spaziergänge mit Prandtl in Ammerland und Umgebung. Er war immer ein liebenswürdiger und interessanter Weggenosse. Jede Pfütze, an der wir vorbeikamen, regte ihn zu Experimenten an, und er mußte mindestens einen Stein hineinwerfen, um die Ausbreitung der Wellen zu studieren. Einmal ging ich mit ihm bei einem starken Westwind am See entlang, und wir beobachteten dabei die Gruppengeschwindigkeit von Wellen verschiedener Höhe. Nachdem er mich auf dieses Phänomen, das mir bis dahin noch unbekannt war, aufmerksam gemacht hatte, setzten wir uns auf eine Bank, und er begann mit Hilfe einiger Formeln, die er auf einen Zettel schrieb, seine Unterrichtung. Er leitete die Interferenz zweier Wellen von nahezu gleicher Frequenz ab, woraus die Gruppengeschwindigkeit gleich der Hälfte der Fortschreitungsgeschwindigkeit der Einzelwellen erfolgt. So verband er in seinem Geist mit seinen Beobachtungen stets das der Erscheinung zugrunde liegende physikalische Gesetz.

Gerade das war seine erstaunliche Begabung: die geistige Verarbeitung von Beobachtungen mit Hilfe der Grundgesetze der Physik. Da ihm diese Denkweise von Jugend an gegeben war und er sie unwillkürlich auf Schritt und Tritt anwandte, so bedeutete sie für ihn keine besondere geistige Anstrengung, so daß man selbst bei seiner Arbeit den Eindruck der spielerischen Leichtigkeit empfand. Es schien mir oft so, als ob er über einen unermeßlichen Born an physikalischen Kenntnissen verfüge, aus dem er jederzeit mühelos schöpfen konnte, um eine gerade zur Diskussion stehende Frage zu befruchten. Damit erklärt sich sowohl das Riesenwerk seiner wissenschaftlichen Leistungen als auch der weite Bogen seines wissenschaftlichen Interesses auf dem gesamten Gebiet der Naturwissenschaften. $\mathrm{Ob}$ es sich um rein physikalische oder rein technische Probleme oder um Astronomie, Geologie oder Mechanik handelte, stets überraschte er durch tiefreichende, oft sehr spezielle Kenntnisse und originelle Folge- 
rungen. Es ergab sich immer wieder, daß er sich mit den verschiedensten Kollegen seiner Fakultät über deren Spezialgebiete unterhielt, ohne besonderer Erklärungen zu bedürfen.

Ich hatte das Glück, in dem Fachgebiet der Mechanik den beiden bedeutendsten Vertretern auf diesem Gebiet in Deutschland, nämlich meinem Vater August Föppl und meinem Schwager Ludwig Prandtl, durch Verwandtschaft nahe verbunden zu sein. Von beiden habe ich sehr viel gelernt, sowohl auf dem Gebiet der Wissenschaft wie auch rein menschlich. Wenn ich auch nur im Schatten dieser beiden Großen stand, so glaube ich doch, ihrer beider Lebenswerke und Lebensarten wie kaum ein zweiter beurteilen zu können. Was mir dabei im Laufe der Jahre zur großen Überraschung wurde, war die Erkenntnis von der Großzügigkeit, mit der Mutter Natur ihre Gaben verteilt; denn obwohl beide Männer auf dem gleichen Gebiete der Wissenschaft tätig waren, so war doch keinerlei Übereinstimmung in ihrer Wesensart zu finden. Selbstverständlich glichen sich die Charaktere der beiden Männer, was Gediegenheit und Zuverlässigkeit betrifft. Auch braucht kaum der Fleiß der beiden, der wie ein stetiger Strom ihren Lebensweg begleitete, hervorgehoben $\mathrm{zu}$ werden; denn er ist für den Erfolg, auch in der Wissenschaft, unerläßlich. Jedoch waren sie, sowohl was Veranlagung wie Arbeitsweise anbetrifft, voneinander grundverschieden. Auch in ihrem Lebensstil waren sie aus zweierlei Holz geschnitzt. Zwei Typen von Wissenschaftlern lassen sich unterscheiden: der Klassiker und der Romantiker, wie es Wilhelm Ostwald in seinem Buch 'Große Männer der Wissenschaft' darstellt. Letzterer ist als genial begabter Mensch charakterisiert, der mühelos in erstem Ansturm in jungen Jahren Großes vollbringt, während der Klassiker sich langsam und stetig weiter entwickelt und erst nach langen, mühevollen Jahren zum großen Erfolg gelangt. Wendet man diese Klassifikation auf August Föppl und Ludwig Prandtl an, so ist der erstere als 'Klassiker' und letzterer als 'Romantiker' zu bezeichnen. August Föppl verdankt seine Erfolge disziplinierter, zäher Arbeit. Im Gegensatz dazu fallen Prandtl die Erfolge anscheinend mühelos in den Schoß. Mit seiner Doktorarbeit erschließt er mit 23 Jahren der Elastizitätstheorie ein neues Gebiet, und mit 29 leitet er durch seine Arbeit über die Grenzschichten ein neues Zeitalter der Hydrodynamik ein. Fürwahr, ein romantischer Aufstieg! Aber August Föppl ist der überlegene Lehrer, dessen Vorlesungen und wissenschaftliche Arbeiten sich durch kristallklare Darstellung auszeichnen. Prandtl konnte als Lehrer nicht solche Erfolge aufweisen. Während er für Fortgeschrittene und Doktoranden besonders anregenden Unterricht erteilte, tat er 
sich gegenüber Anfängern mitunter in den Vorlesungen recht schwer. Es dürfte damit zusammenhängen, daß ihm die Grundlagen der Mechanik selbst in seinen Studienjahren nicht die geringsten Schwierigkeiten bereitet haben. Sie waren ihm mehr oder weniger selbstverständlich. Daher konnte er die Schwierigkeiten, die seine Studenten dabei zu überwinden hatten, nicht nachvollziehen.

Bei aller gegenseitigen Hochachtung zwischen den bedeutenden Männern bestanden doch so starke Gegensätze, daß sie gelegentlich im wochenlangen Zusammensein in Ammerland zu einer kleinen Trübung des Verhältnisses zwischen Schwiegervater und Schwiegersohn führten, obwohl es niemals zu einer ernsten Verstimmung gekommen ist. Der Altersunterschied zwischen ihnen betrug nur 21 Jahre, aber diese fielen in die Zeit eines tiefgehenden Umbruchs, der zwei Epochen voneinander trennt. Mein Vater wurzelte noch in den autoritären und starren Anschauungen der zweiten Hälfte des 19. Jahrhunderts, während Prandtl mehr durch die sozialen Ideen und Fortschrittsgedanken unseres Jahrhunderts geprägt war. Es fiel ihm darum schwer, sich in allem unserem Vater unterzuordnen, wie wir Kinder dies von Jugend an als selbstverständlich ansahen. August Föppls starke Persönlichkeit übte auch großen moralischen Einfluß auf die Menschen seiner Umgebung aus, so daß Kollegen ihn als das 'Gewissen der Fakultät' bezeichnet haben. August Föppl hat sich über die großen wissenschaftlichen Erfolge seines Schwiegersohnes von ganzem Herzen gefreut. Er hat wohl auch als erster die geniale Begabung Prandtls erkannt.

Ich habe aufgrund meiner Lebenserfahrungen letztlich den Eindruck gewonnen, daß ein hochbegabter Mensch unwillkürlich unter einem gewissen Zwang steht, das Leben gemäß seinem Talent einzurichten. Er kann sich nur glücklich fühlen, wenn ihm Gelegenheit geboten wird, seine Begabung zu nutzen. Solange ihm diese Möglichkeit versagt blieb, wird er zwangsläufig nach solcher Beschäftigung streben, in der er seine Begabung entfalten kann. Hat er glücklich den Wirkungskreis hierfür gefunden, fühlt er seine Bestimmung, nun sein Talent zu entfalten; und er wird weitere Förderung suchen, um das Höchstmögliche damit zu erreichen.

Prandtl packte nur Probleme an, die im Bereich seiner ausgesprochenen Begabung lagen. So vielseitig auch seine Interessen für Naturerscheinungen angesprochen wurden, so beschränkte er sich auf spezielle Forschungsaufgaben und ging so mit seinem geistigen Potential haushälterisch um. Es gelang ihm auf diese Weise ein imponierender Vorstoß in ein Neuland der Forschung, wodurch er seinem Namen für alle Zeiten ein Denkmal gesetzt hat." 


\section{1911-1918 Beruflicher Alltag}

In jenen ersten Ehejahren, die sich so harmonisch gestalteten, sah sich Prandtl einer Fülle von neuen Aufgaben gegenüber. Die Modellversuchsanstalt, die von vornherein nur als Provisorium gedacht war, reichte nun nicht mehr aus für die flugtechnische Forschung, die sich ständig weiter entwickelte. Im Jahr 1911 ging Prandtl daran, wiederum auf Anregung von Felix Klein, einen Plan zu erstellen für ein neues umfangreiches Forschungsinstitut. Die Geheimräte F. Klein und von Böttinger traten dafür ein, daß das geplante Institut als Kaiser-Wilhelm-Institut ausgeführt werden sollte. Die Kaiser-Wilhelm-Gesellschaft war jedoch der Meinung, daß der preußische Staat an den Unterhalts- und Aufbaukosten stark beteiligt werden müßte. Die Verwirklichung der Institutspläne hat sich dadurch allerdings bis 1925 hingezogen. Immerhin konnte 1918 schon ein erster Bauabschnitt fertiggestellt werden. Als 1914 der erste Weltkrieg ausbrach, wurde das Projekt erst einmal fallengelassen. Sehr beschleunigt wurde hingegen die Planung einer Reichsversuchsanstalt für Luftschiffahrt, woran Prandtl zusammen mit H. Hergesell durch Erstellung von Gutachten beteiligt war [13]. Die Versuchsanstalt wurde 1912 unter dem Namen "Deutsche Versuchsanstalt für Luftfahrt e. V." (DVL) in Adlershof errichtet.

Ein ganz neuer Betrieb wurde 1912 außerhalb Göttingens in Arenshausen eingerichtet, als Prüfstelle für Luftschrauben. Die Meßwerte wurden an die Flugzeugfabriken weitergegeben. Eine zusätzliche Arbeitsbelastung entstand für ihn durch die vielen erbetenen Auskünfte zu technischen Problemen und die dadurch ständig zu erstellenden Gutachten. Die Möglichkeit, durch Meßanlagen Winddruck zu prüfen, war so neu und überzeugend, daß nun über die vielseitige Anwendung dieser Methode allgemein nachgedacht wurde. Brückenbauer zum Beispiel waren an einer Überprüfung des Winddrucks auf Brückenpfeiler interessiert, was mittels der Messungen zu einem befriedigenden Resultat führte. Immer wieder meldeten sich aber auch Erfinder bei Prandtl, die um eine Begutachtung ihrer Projekte nachsuchten. Ich erinnere mich, daß einer sogar glaubte, das perpetuum mobile erfunden zu haben. Prandtl wurde zum Beispiel von einem unbekannten Erfinder gebeten, ein Urteil über dessen Arbeit abzugeben, die Beschreibung einer vorgestellten Meßanlage zu überprüfen. 
Prandtls Antwort 1909: "Auf Ihre Anfrage erlaube ich mir zu antworten, daß meiner Meinung nach mit der in der Anlage zu Ihrem Briefe vorgeschlagenen Vorrichtung Winddrücke überhaupt nicht gemessen werden können..." Prandtl schlug eine Verbesserung vor und stützte diesen Vorschlag durch eine wissenschaftliche Erklärung, die er mit genauen Zeichnungen versah. Am Ende des Briefwechsels war wohl eine Lösung in Sicht. Obwohl er aber nicht glücklich war, wenn solche Erfinder sich an ihn wandten, wurde jedoch jede Anfrage gewissenhaft beantwortet. Ich möchte hier noch einige Beispiele dieser Korrespondenz mit Erfindern hinzufügen.

\section{Dezember 1912: "Sehr geehrter Herr K.}

Ich habe mir nun Ihr Projekt sorgfältig durchüberlegt und glaube, daß es ausgeführt zu werden verdient. Nur verhehle ich mir nicht, daß ganz außerordentliche Schwierigkeiten noch zu überwinden sein werden."

22. März 1912: "Sehr geehrter Herr M.

Auf Ihre geehrte Anfrage muß ich leider erwidern, daß wir uns auf eine allgemeine Begutachtung von flugtechnischen Erfindungen hier nicht einlassen können. Die Modellversuchsanstalt unternimmt jedoch auf Antrag die experimentelle Bestimmung der Luftkräfte an Modellen. Die Kosten werden dabei dem Antragssteller berechnet, und zwar etwa 60 Mark pro Versuchstag."

\section{Juni 1912: "Sehr geehrter Herr A.}

Ihr an Geheimrat Böttinger gerichtetes Gesuch wurde von diesem an mich weitergeleitet. Nach Kenntnisnahme Ihrer Darlegungen kann ich Ihnen nur raten, die Idee Ihres Gebläsefliegers nicht weiter zu verfolgen, da ein Mißerfolg ganz sicher sein würde."

In dem folgenden Brief aus dem Jahre 1911 geht es um Prandtls Anliegen, dem Luftpionier August Euler zur Durchführung einer Flugveranstaltung im Göttinger Raum zu verhelfen. Euler hatte als erster Deutscher eine Flugprüfung gemacht und damit das Flugzeugführerzeugnis Nr. 1 erhalten. Er organisierte den ersten Luftpoststreckendienst. Später schuf er die Grundlagen für ein deutsches Luftverkehrsgesetz. Prandtls Schreiben an Senator Friedrich Jenner sollte dazu dienen, die Veranstaltung vorzubereiten. 
"... Euler wünscht, auf dem kleinen Hagen zu fliegen. Er hält die Absperrung durch Mannschaften und Schutzleute für durchaus ausreichend, selbst wenn nur eine verhältnismäßig kleine Anzahl verwendet wird. Er meint, gefährlich wäre nur Publikum, das Eintritt bezahlt hätte, wenn es sich aber nur geduldet fühlt, sei es viel friedsamer. Kurze Erörterungen in den Zeitungen über die unbedingte Notwendigkeit, den Flugplatz frei zu halten, würden seiner Erfahrung nach auch sehr wirksam sein. ('Solange der Platz nicht frei ist, wird nicht geflogen.') Euler will gerne alle Göttinger von seinen Flügen etwas sehen lassen. Nur den Zutritt zu den Flugmaschinen und zum Startplatz will er für Bevorzugte reserviert sehen. Die Kosten für die Veranstaltung, bestehend aus Transport und Reisespesen, Materialverbrauch u.s.w., trägt Euler, von Göttingen sind lediglich zu tragen die Kosten für Absperrung und für Fliegerzelte, auch für Betreuungsmannschaften (ein paar Mann). Wegen der Aufbringung der Kosten besteht, da ja der ganzen Bevölkerung etwas geboten werden soll, wohl die Möglichkeit, daß die Stadt etwas dazu gibt. Der Luftschifferverein wird auch sein Teil dazu beischießen und für diese Leistung das Recht erwerben, daß die Mitgliedskarte zum Zutritt zum Startplatz berechtigt. Alles in allem dürfte die Veranstaltung, wenn auch das Wetter gut ist, für Göttingen höchst erfreulich werden.

Mit besten Grüßen Ihr ergebener L. Prandtl."

$\mathrm{Zu}$ August Euler hatte Prandtl nach vorherigem Briefwechsel bereits 1909 auf der Ersten Internationalen Luftschiffahrtsausstellung (ILA) in Frankfurt a. M. Beziehungen angeknüpft. Diese hatten dazu geführt, daß Euler im Frühjahr 1911 anbot, in Göttingen Flugvorführungen zur Förderung des wissenschaftlichen Interesses an der Fliegerei zu veranstalten. Prandtl nahm dieses Anerbieten zum Anlaß, die damaligen Vertreter der Flugwissenschaften zu einer Versammlung nach Göttingen einzuladen. So war im November 1911 ein flugtechnischer Kongreß zustande gekommen, auf dem eine Anzahl interessanter Fachvorträge gehalten wurde [37]. Prandtl erinnerte sich elf Jahre später [41]: "Der Kongreß verlief nicht zum mindesten durch den sehr gelungenen geselligen Teil in einer Hochstimmung, wie ich sie bei keinem anderen bisher erlebt habe, wozu nicht wenig beitrug, daß alle Versammelten sich in dem Ziel, dem sie zustrebten, völlig einig waren, ... Es ist daher nicht verwunderlich, daß die allgemeine Stimmung, die auch in der Aussprache zum unmittelbaren Ausdruck kam, dahin ging, es müßte bald wieder eine solche Versammlung stattfinden. Uns von der Göttinger Vereinigung wurde das Mandat angetragen, dafür zu sorgen, daß diese 
Versammlung zustande kam. ..." Von Böttinger, Klein und Prandtl hatten dieses Mandat gerne auf sich genommen und Vorbereitungen getroffen, daß 1912 in Berlin unter dem Ehrenvorsitz des Prinzen Heinrich von Preußen die Wissenschaftliche Gesellschaft für Luftfahrt gegründet werden konnte, die noch heute unter dem Namen "Deutsche Gesellschaft für Luft- und Raumfahrt e. V." fortbesteht.

Es gab auch Briefe privaten Inhalts, in denen Ratschläge sowie materielle Hilfe erbeten wurden, die ich heranziehen möchte, um den tiefverwurzelten Grundzug einer echten Menschlichkeit zu charakterisieren.

Aus einem längeren Briefwechsel mit einem früheren Göttinger, der offensichtlich nachbarlich gewohnt hatte, geht dessen verfahrene Lebenssituation hervor. Er wendet sich an Prandtl mit der Bitte, ihm ein größeres Darlehen zu gewähren, da er durch Spekulationen in Not geraten sei. Prandtl ist bereit, ihm zu helfen, und vermittelt auch noch zwischen den zerstrittenen Familienmitgliedern.

Prandtl 1. September 1910: "Aus Ihrem Briefe habe ich mit größtem Bedauern von Ihrem Unglück vernommen. Sie sollen sich in Ihrem alten Zimmernachbarn nicht getäuscht haben, ich werde Ihnen das gewünschte Darlehen geben."

Z. antwortete: "Lieber Herr Professor Prandtl!

Seien Sie herzlich bedankt für Ihr überaus freundliches Entgegenkommen, mit dem Sie mir geholfen haben und wodurch Sie mich aus großer Not herausgeeist haben. Ihre Bereitwilligkeit ist mir ein schöner Beweis Ihrer Freundschaft und hat mir doppelt gut getan, da meine persönlichen Freunde, oder besser sogenannten Freunde, mich alle im Stich gelassen haben.

Ihr ergebener Z."

Der Familienkonflikt konnte später auch beigelegt werden.

Das war Prandtls Art: Um Rat und Unterstützung befragt, war er immer spontan bereit zu helfen. Ich kenne aus späterer Zeit noch mehrere Fälle, wo Bittsteller an ihn herantraten, die dann ein Darlehen von ihm erhielten. 
Ein Schreiben aus einem anderen Bereich scheint mir ebenfalls von Interesse. In einem Brief von 1913 gibt Prandtl seine Zusage zur Mitgliedschaft im Keplerbund. Der Keplerbund zur Förderung der Naturerkenntnis stellte folgende wissenschaftliche Forderungen und naturwissenschaftliche Grundsätze auf:

1. Freiheit der Wissenschaft,

2. Objektivität der Forschung,

3. Unterstützung der Naturwissenschaft und Naturphilosophie,

4. Anerkennung der Unzulänglichkeit der Naturwissenschaft, für sich allein eine Weltanschauung zu bilden,

5. Anerkennung der Neutralität der Naturwissenschaft in Fragen der Weltanschauung und Religion,

6. Vertretung des Rechtes des Gottesglaubens, d. h. seiner Vereinbarkeit mit naturwissenschaftlichem Denken, als logische Folgerung aus Punkt 5.

Prandtl hat sich in seiner Beitrittserklärung folgendermaßen geäußert:

25. März 1913: "Auf Ihr vor längerer Zeit versandtes Rundschreiben komme ich erst jetzt, nach Semesterschluß, zurück. Ich habe das Rundschreiben mit aufrichtiger Sympathie durchdacht und finde, daß ich mich zu den sämtlichen sechs Punkten, die Sie aufführen, bekennen kann und mit den Absichten des Bundes vollständig übereinstimme, wenn die praktische Betätigung des Bundes tatsächlich in der durch die "Richtlinien" gekennzeichneten Art erfolgen soll. Nach den früheren, offenbar von gegnerischer Seite kommenden Äußerungen, hatte ich die Vorstellung gewonnen, daß das Ziel des Keplerbundes die Hinführung der naturwissenschaftlich Interessierten zu den alten positiven Religionen sei.

Nach den in Ihrem Rundschreiben genannten Leitsätzen dagegen darf ich wohl annehmen, daß der Keplerbund ebenso, wie er einer Beugung der religiösen Anschauung unter die Naturerkenntnis entgegenarbeitet, er auch Eingriffen von aus der Religion stammenden Vorstellungen in den voraussetzungslosen Betrieb der Naturwissenschaften (Wunderglauben etc.) entgegentritt. Wenn diese Auffassung von Ihren Zielen richtig ist, so bin ich gern bereit, dem Bund als Mitglied beizutreten.

Eine Unrichtigkeit, die mir in Ihrem Rundschreiben aufgefallen ist, möchte ich noch kurz erwähnen; es ist da von einer "künstlichen Feindschaft" zwischen Naturwissenschaft und Religion die Rede, an der die monistisch-materialistischen Kreise schuld 
sein sollen. Meiner Ansicht nach sind an dieser Feindschaft die positiven Religionen viel mehr schuld, die sich der Naturforschung, insbesondere der Entwicklungslehre, entgegengestemmt haben, und der Monismus ist lediglich eine - allerdings über das Ziel hinausschießende - Reaktion gegen diese Rückschrittsbestrebungen."

Die Arbeitsbelastung wuchs, wie schon gesagt, in diesen Jahren besonders an. Prandtl sah die Notwendigkeit, für seinen Betrieb einen Assistenten zu suchen. Auf die Anzeige einer offenen Assistentenstelle in der Modellversuchsanstalt meldete sich ein einziger junger Wissenschaftler, der auf dem Gebiet der Hydrodynamik gearbeitet hatte. Während Prandtl ihn durch die Räume der Anstalt führte und seine Einrichtungen zeigte, unterhielten sie sich angeregt. Offenbar war dieser Ingenieur hochbegabt und für den Posten bestens geeignet. Es war der Diplomingenieur Albert Betz, der spätere Direktor der AVA, der am 1. September 1911 als Hilfsassistent bei Prandtl eingestellt wurde. Nur noch wenige Jahre der gemeinsamen Forschung blieben bis zum Beginn des Krieges. Dann meldete sich Albert Betz als Freiwilliger zum Heeresdienst. Es erwies sich aber innerhalb des nächsten Jahres, daß man ihn im Institut nicht entbehren konnte. Deshalb schrieb Prandtl am 25. Juni 1915 an den Kurator: "Euer Hochwohlgeboren bitte ich ergebenst veranlassen zu wollen, daß der frühere Hilfsassistent Dipl.-Ing. Albert Betz, der bisher als Kriegsfreiwilliger im Heeresdienst stand, jetzt aber zu meiner Verfügung aus dem Heeresdienst entlassen worden ist, um bei dem Neubau der Modellversuchsanstalt mitzuwirken, wieder in seine alte Stellung eingesetzt wird."

So geschah es dann auch. Seine endgültige Entlassung aus dem Kriegsdienst brachte ihn wieder an seinen alten Arbeitsplatz zurück.

Die Assistenten und Mechaniker des Instituts waren größtenteils seit August 1914 zum Heeresdienst einberufen, so daß Prandtl in dieser ersten Zeit ohne die eingearbeiteten Hilfskräfte seinen Betrieb weiterführen mußte.

1912 war die Motorluftschiff-Studiengesellschaft aufgelöst worden, die Modellversuchsanstalt wurde danach von der Universität übernommen und dem Institut für angewandte Mechanik angegliedert. Die Betriebskosten übernahm das Kultusministerium. Der Erfolg dieser Anstalt war evident, und die Einrichtungen, die hier erstmalig 
entwickelt worden waren, dienten bald auch als Vorbild für andere Forschungszentren dieser Wissenschaft. Der erste Weltkrieg allerdings brachte, wie schon erwähnt, eine Stockung der Planung für eine vergrößerte Anstalt. Jedoch 1915 erklärte die Heeresleitung ihr Interesse an der Weiterentwicklung der Modellversuchsanstalt. Man hatte fortlaufend für Heer und Marine die Versuchseinrichtungen in Anspruch genommen, die aber kaum noch ausreichten. So verfaßte Prandtl im April 1915 eine neue Denkschrift, um die Notwendigkeit eines Neubaus darzutun. Ich zitiere daraus:

"Die Entwicklungsrichtung, die die Arbeiten der Modellversuchsanstalt genommen haben, ließ nun den Gedanken entstehen, daß es im eigensten Interesse der Heeresund Marineverwaltung liegt, durch Gewährung der erforderlichen einmaligen und laufenden Mittel zur Schaffung eines großen aerodynamischen Laboratoriums zu verhelfen, das allen z. Z. übersehbaren Aufgaben für die Weiterentwicklung des militärischen und des Marine-Flugwesens gewachsen ist."

Die Denkschrift konnte in Kiel persönlich Prinz Heinrich von Preußen überreicht werden, und er gab alsbald die Prandtlsche Planung mit persönlicher Befürwortung an das Kriegsministerium und das Reichsmarineamt weiter:

"Kiel den 30ten April 1915

Mein sehr verehrter Herr Professor Prandtl,

Gelegentlich eines Besuches am 27ten d. Mts. auf der Bauwerft von Max Oertz, Hamburg, welcher zu meiner Information diente, um den Fortgang des gerade in jetziger Zeit so überaus wichtigen Baues der Wasser- und Landflugzeuge zu studieren, überreichte mir Herr Oertz Ihre am gleichen Tage eingegangene Denkschrift sowie den Sonderabdruck aus der Zeitschrift des Vereines deutscher Ingenieure, (Fachgebiet Luftschiffahrt) in drei Exemplaren mit dem Bemerken, dass es von Wichtigkeit sei, diese Schriften an die geeigneten zuständigen Stellen gelangen zu lassen, und der Bitte, ob ich die Vermittlung hierzu übernehmen wollte.-

Von der Bedeutung des Inhaltes der Schriften sowie von der Notwendigkeit der Vergrösserung und Unterstützung der Göttinger Anstalt überzeugt, habe ich 
mich sofort bereit erklärt, das Weitere, soweit es in meinen Kräften steht, zu veranlassen, und habe ich dementsprechend umgehend je zwei Exemplare an den Kriegsminister sowie an Admiral Dick vom RMA mit einem kurzen Geleitschreiben übersandt, in welchem ich versucht habe, in Kürze darzulegen, welche Wechselwirkung zwischen dem Göttinger Institut und den Erbauern von Flugzeugen bestünde, unter dem besonderen Hinweis darauf, dass wir aus dem Studium der Empirik nunmehr tatsächlich herausgetreten seien und dass die Wissenschaft den Bau von Flugfahrzeugen in erster Linie unterstütze und durch wissenschaftliche Untersuchungen sowie Feststellung von Tatsachen wesentlich fördere.-

Wenngleich ich nicht in der Lage bin, die weiteren finanziellen Überlegungen der genannten Behörden zu beurteilen oder zu beeinflussen, so bin ich doch froh, dass ich wenigstens die Aufmerksamkeit auf eine Materie richten durfte, die mir einmal sehr am Herzen liegt und die ferner durch den Vortrag des Herrn Oertz, an der Hand seiner Konstruktionszeichnungen, den engen Zusammenhang zwischen Wissenschaft und Bauausführung mir schlagend bewies; hiermit ist ein Ziel erreicht, welches ich mir stets erträumt habe und welches weiter zu verfolgen sein dürfte, welches ferner in erster Reihe Ihren Bemühungen zu verdanken ist.-

Die Ereignisse der Jahre 1914/15 haben, besonders in den verflossenen 9 Monaten, es naturgemäß mit sich gebracht, dass ich mich um diese Details bisher nicht bekümmern konnte, nun aber bin ich glücklich, dass mir wiederum hierzu Gelegenheit ward.-

Ihnen dieses mitzuteilen ist der alleinige Zweck dieser Zeilen.

Indem ich Ihnen einen sehr herzlichen Gruss sende und hoffe, dass es gelingen wird, Ihre Bestrebungen, die dem Reiche zu Gute kommen, in gebührender Weise zu unterstützen,

verbleibe ich, mein sehr verehrter Herr Professor

Ihr

sehr aufrichtig und dankbar ergebener

Heinrich Prinz von Preußen"

Es fand kurz darauf eine Sitzung in Berlin statt, von der Prandtl in Kürze an Felix Klein eine Mitteilung machte. Seine Betroffenheit über die Verluste und die Härte in der Kriegführung ist deutlich. 
Berlin, 11. Mai 1915: "Sehr geehrter Herr Geheimrat!

Das Resultat der heutigen Konferenz im Kriegsministerium ist geradezu überwältigend, um nicht zu sagen niederschmetternd (besonders von meinem persönlichen Daseinsstandpunkt aus).

Die neue Modellversuchsanstalt soll aus Kriegsmitteln sofort mit der größtmöglichen Schnelligkeit auf der Böttinger Wiese gebaut werden, um noch dem Kriege durch Meßresultate zugute zu kommen." (Geheimrat Böttinger, Kaufmännischer Leiter der Bayerschen Farbenfabriken in Elberfeld, hatte für den geplanten Erweiterungsbau ein eigenes Grundstück, das er 1907 erworben hatte, zur Verfügung gestellt.) "Ich habe die ersten Resultate in einem halben Jahr versprochen, was als annehmbar erklärt wurde. Demnach rechnen die Herren noch mit einem sehr langen Krieg. Ich habe bereits meine Assistenten reklamiert, werde jedenfalls meine Lehrtätigkeit einschränken, vielleicht das Dekanat abgeben müssen. Alles Nähere mündlich. Prandtl."

So wie Albert Betz konnte auch der andere junge Mitarbeiter, Dr.-Ing. C. Wieselsberger aus dem Heeresdienst zurückgeholt werden. G. Fuhrmann war schon im September 1914 in Belgien gefallen. Betz wurde zum 15. Mai und Wieselsberger zum 1. Juni 1915 als Hilfsassistent eingestellt. Der Dipl.-Ing. Max Munk hatte bereits im April einen Posten als Hilfsassistent erhalten. So war ein Fortschreiten der geplanten Arbeiten zur Erweiterung der Anstalt gewährleistet. Im Juli 1915 wurde der Schwager, Dr. Hans Thoma, als Bauleiter des neuen Projekts nach Göttingen gewonnen. Inzwischen hatte nämlich auch Else Föppl, Gertruds Schwester, geheiratet, ebenfalls einen begabten Ingenieur. Die Zusammenarbeit mit Thoma, der von der Kaiserlichen Werft in Wilhelmshaven bis 1. März 1916 freigestellt wurde, brachte die Neubauarbeiten in erfreulicher Weise voran.

Am 29. Mai schreibt Ludwig Föppl in einem Feldpostbrief "Funkerkommando 6:

Von Gertrud erfuhr ich, daß Du jetzt Dein neues Institut erhältst, wozu ich Dir gratulieren möchte. Wie werden Dich alle Deine Kollegen beneiden, daß Du die Möglichkeit hast, dem Vaterland auf diese Weise Dienste zu leisten. Daß Du eine so tüchtige Kraft wie Hans Thoma als Assistenten bekommst, dazu gratuliere ich Dir auch." 
23. Juni 1915: "Du schaffst jetzt auch stark im Dienst des Vaterlandes, indem Du den Neubau der Modellversuchsanstalt beschleunigst. Daß die Feinde uns in der Fliegerei überlegen sind, können wir Funker einwandfrei feststellen."

Im Verlauf von arbeitsreichen Monaten wurde ein neuer leistungsstarker Windkanal mit einer Beruhigungskammer von nun mehr $4 \times 4$ Metern und einem Luftstrahldurchmesser von 2,25 m gebaut. Der Forschung standen neue Möglichkeiten offen.

Professor Betz schreibt [3]: "Obwohl während des Krieges natürlich militärische Interessen im Vordergrund standen, so ist doch bemerkenswert, daß der Versuchsanstalt von den maßgebenden Dienststellen weitgehende Freiheiten in der Wahl ihrer Aufgaben gelassen wurde. Man war damals von der Wichtigkeit einer großzügigen Grundlagenforschung überzeugt und versprach sich auch am meisten Erfolg, wenn man dem Forscher half, seine Ideen zu verwirklichen, ohne ihn in seiner Arbeit einzuengen."

Aufgrund dieser Auffassung von der Freiheit der Forschung ist eine Anfrage eines Biologen über Meßbarkeit des Tierflugs zu verstehen. Hier Prandtls Antwort:

20. August 1915: "Sehr geehrter Herr Doktor!

Leider liegen die Verhältnisse nicht so, daß ich Ihnen viel Günstiges sagen könnte. Die Modellversuchsanstalt für Luftfahrt, um deren Bau es sich jetzt handelt, wird aus Kriegsmitteln erbaut und dient allein der Flugtechnik. Sie wird einen großen starken Luftstrom erhalten, in dem Modelle von Flugzeugen, Einzelteile von solchen usw. auf ihren Luftwiderstand geprüft werden. Andere Einrichtungen sind bisher nicht vorgesehen und würden auch nur dann hinzukommen, wenn sich ein militärisches Interesse dafür zeigte. Nun ist es allerdings geplant, dieses Institut im Frieden weiter auszubauen. Die Frage, ob später einmal auch der biologischen Aerodynamik spezielle Studien zu widmen sein würden, ist noch im weiten Felde. Sie wissen, daß ich solchen Fragen sympathisch gegenüberstehe, obwohl ich je länger desto mehr davon überzeugt bin, daß die Flugtechnik von dem Studium des Tierflugs sehr wenig Gewinn ziehen wird. Meiner Meinung nach wird man aus dem Flug der großen Vögel (Storch, Kondor, große Seevögel) noch am ehesten für die Flugtechnik nützliche Schlüsse ziehen können; schon der Flug der kleineren Vögel, noch vielmehr der Insekten ist nach 
den Vorbedingungen so stark von dem Menschenflug verschieden, daß das Studium dieser Dinge für die Flugtechnik kaum förderlich sein kann. Daß die Untersuchung dieser Dinge vom wissenschaftlichen Standpunkt aus reizvoll und lehrreich ist, will ich dabei natürlich keineswegs bestreiten. Nach dem Gesagten werden Sie es wohl verstehen, wenn ich Ihnen einstweilen keine Zusicherung geben kann, daß der Biologie des Fluges an dem Institut ein größerer Raum zugewiesen werden würde. Jedoch glaube ich sagen zu können, daß, wenn das Institut erst in eine ruhige Entwicklung gekommen ist, es sich wohl wird ermöglichen lassen, solche Apparate und Einrichtungen anzuschaffen, wie sie für Ihre Versuche nötig sind."

Im Neubau der Modellversuchsanstalt ging es jetzt darum, die versprochenen Meßresultate an die Heeresleitung weitergeben zu können. Dringend wurde für diese Arbeiten ein fähiger Mechaniker benötigt.

Prandtl schrieb am 8.12.1915 an das Reichsmarineamt:

"Durch die Aufträge, welche die Kaiserlichen Werften der Göttinger Versuchsanstalt erteilt haben, ist eine so große Häufung der Arbeiten entstanden, daß diese bei dem jetzigen Personalstand nur mit sehr großer Verzögerung würden erledigt werden können. Ich erlaube mir, deshalb ergebenst anzufragen, ob das Reichsmarineamt etwa in der Lage ist, mir für diese Arbeiten eine Hilfskraft zu stellen. Als solche käme am zweckmäßigsten ein Techniker in Frage, der im Stande ist, nach einer ihm gegebenen Anleitung die Meßgeräte abzulesen, die Meßresultate auszurechnen und die zugehörigen zeichnerischen Ermittlungen und Kurvenblätter herzustellen."

Da sein Vorschlag eine Ablehnung erfuhr, wandte sich Prandtl darauf an das stellvertretende Generalkommando in Magdeburg, um die Freistellung seines früheren Mechanikers Julius Lotze zu erwirken.

Am 15.2.1916 schrieb er: "In Göttingen wird gegenwärtig aus den Mitteln, welche die Kriegsverwaltungen bereitgestellt haben, unter meiner Leitung eine Modell-Versuchsanstalt für die Luftfahrt erbaut.

Da es nicht möglich war, aus heeresdienstfreiem Personal eine genügende Anzahl von Feinmechanikern für den Bau der Meßeinrichtungen für diese Arbeit zu erhalten, habe ich mich vor einiger Zeit an die Grusonwerke in Magdeburg-Buckau gewandt, 
um den früheren Mechaniker Julius Lotze wieder zurückzuerhalten. Dieser ist vor etwa einem Jahr durch kriegsministerielle Verfügung den Grusonwerken als Schlosser für ihre Kanonenwerkstatt zur Verfügung gestellt worden. Da Lotze nicht nur ein sehr geschickter Mechaniker ist, sondern auch durch seine frühere Tätigkeit die speziellen Bedürfnisse der in Betracht kommenden Versuchsarbeiten genau kennt, ist mir seine Hilfe bei den genannten Arbeiten besonders wertvoll."

Es gelang Prandtl, Julius Lotze aus den Grusonwerken wieder nach Göttingen zu holen, wo er nun beim Aufbau der neuen Anstalt eine große Hilfe war.

Es war inzwischen auch notwendig geworden, nun auch eine neue Schreibkraft einzustellen. Dies brachte Prandtl auf den Gedanken, sich bei seinen Kollegen nach einer geeigneten Sekretärin zu erkundigen. Durch menschliche Beziehungen konnten Probleme, auch die einer Anstellung, am zuverlässigsten gelöst werden. Herr Professor Wiechert, Leiter des seismographischen Instituts, hatte eine vorzügliche Schreibhilfe, Fräulein Frieda Kreibohm, die auch als technische Rechnerin arbeitete. Man fragte nach, ob diese Dame vielleicht noch eine Schwester habe, die man einstellen könne. Die Schwester war aber erst 16 Jahre alt und hatte die Schule noch nicht beendet. Als man ihr anbot, sie könne sofort eingestellt werden, zog sie es doch vor, ihr letztes Schuljahr nicht abzubrechen. Bis zu diesem Zeitpunkt konnte Professor Wiechert seine Schreibkraft für den halben Tag an Prandtl abgeben. Es mußten die Messungen, die bei den Versuchen gemacht wurden, rechnerisch ausgewertet werden. An demselben Tag, an dem die jüngere Schwester, Hilde Kreibohm, ihre Schulzeit mit der üblichen Prüfung abgeschlossen hatte, ging sie schon am Nachmittag in die Versuchsanstalt. Sie ist dort über 50 Jahre, ein ganzes Arbeitsleben, geblieben; aus der kleinen Schreibhilfe wurde bald eine Chefsekretärin. Als ich sie aufsuchte, fragte ich nur noch: "Konnten Sie denn Schreibmaschine schreiben?" "Nein," sagte sie, "Kurse gab es ja damals noch nicht. Ich bekam durch Professor Betz eine alte Maschine zu uns ins Haus gebracht zum Probieren, und da habe ich stundenlang für mich geübt."

Der personelle Betrieb im Büro und in der Werkstatt wurde ständig erweitert, indessen die Institutsbauten mehr und mehr der Fertigung entgegengingen. 1918 erlangte die Belegschaft ihre Höchstzahl von 50 Personen. Dr. Wieselsberger und Dr. Betz führten eine eigene Abteilung für Neukonstruktionen und theoretische Arbeiten. 
Unter den Hilfskräften waren auch eine Reihe von Studenten im freiwilligen Kriegseinsatz, so daß die Aufgaben der Berechnungen wunschgemäß durchgeführt werden konnten. Am 7. März 1917 konnte in dem neuen Kanal zum ersten Mal "Wind gemacht" werden. Dieses Datum hat Prandtl selbst notiert.

Da die Wege zwischen der alten und der neuen Anstalt einen ziemlichen Zeitverlust bedeuteten und die kleine Backsteinbaracke in mancher Weise mangelhaft geworden war, wurde sie 1918 auf das neue Böttinger-Grundstück verlegt. Damit war ein gewisser Abschluß des großen Bauvorhabens erreicht.

Als der Neubau fertiggestellt war und die Militärverwaltungen ab 1917 der Anstalt reichlicher Personal zur Verfügung stellten, konnten neben der Versuchstätigkeit auch wieder theoretische Forschungsarbeiten durchgeführt werden. Prandtl fand jetzt die Möglichkeit, die 1910 von ihm begonnene Tragflügeltheorie wieder aufzugreifen und sie zu einem gewissen Abschluß zu bringen. Ziel dieser schwierigen Theorie war aufzuklären, wie die Zusammenhänge zwischen Auftrieb und Widerstand durch die Gestaltung des Flügels beeinflußt werden. In der Sitzung der Gesellschaft der Wissenschaften zu Göttingen am 26. Juli 1918 legte er die erste Mitteilung über die Tragflügeltheorie vor [33].

Über die Bedeutung der Tragflügeltheorie schrieb Th. v. Kármán in seinem Artikel zum 50. Geburtstag Prandtls [16]: "Prandtls Hauptleistung für die Flugtechnik ist indessen zweifellos die Tragflügeltheorie, namentlich die Auffindung und Ermittelung des sog. 'induzierten Widerstandes', wodurch der Weg für eine rationelle Entwurfsberechnung der Flugzeuge, besonders für die Ermittelung des Einflusses der Spannweite, für den Vergleich zwischen Eindecker und Mehrdecker, für den Einfluß von Schränkung und Staffelung auf einen Schlag erschlossen wurde. Die Analogie zwischen Tragflügel und Wirbelfaden war wohl bekannt; auch die Tatsache, daß bei endlicher Spannweite der Tragflügel die Zirkulation am Flügelende nicht einfach aufhören kann, sondern sog. 'Wirbelzöpfe' sich ablösen müssen, ist von Lanchester festgestellt worden; Prandtl erkannte jedoch mit genialem Blick, daß die konsequente Durchführung der Helmholtzschen Wirbeltheorie unter der Annahme schwach belasteter Tragflächen zu einer vollständigen Theorie der idealen Tragflügel führen muß, welche alle Aufschlüsse über Auftriebsverteilung, Leistungsbedarf usw. liefert, 
die vom Profilwiderstand unabhängig sind. Der Entdeckung des Minimalwiderstandes des Idealflügels, des sog. 'induzierten Widerstandes', kommt für den Flugzeugbau ungefähr dieselbe Bedeutung zu wie der Entdeckung des Carnotschen Prozesses für den Bau kalorischer Maschinen: beide liefern einen Maßstab, an welchem die Güte der Konstruktion gemessen wird, ein Ordnungsprinzip, durch welches ein sonst unübersichtliches Erfahrungsmaterial auf einen Schlag klar und verständlich wurde. ..." 


\section{Häuslicher Alltag}

Im Frühjahr 1914 waren meine Eltern umgezogen in eine sonnigere, modernere Wohnung mit Bad und Zentralheizung in der Bergstraße (jetzt Calsowstraße). Der Hauptgrund dafür war, daß sich Nachwuchs angemeldet hatte. Im November 1914 konnten die glücklichen Eltern die Geburt ihrer ersten Tochter Hildegard anzeigen. Eine zweite Tochter, Johanna, wurde zweieinhalb Jahre später geboren. Nun war die große Wohnung von Leben erfüllt. Das Haus lag damals ganz am Rande der Stadt; angrenzend begann eine Pflaumenallee und verschiedene Feldwege, die zu Wiesenstücken und Schrebergärten hinführten. Einen eigenen Garten hatte man nicht, aber die Nähe von Wiesen und Wald war dereinst für uns Kinder ein herrliches Spielgelände. Dort wuchsen meine Schwester und ich in großer Freiheit auf. Meine Mutter, die einen sehr strengen Vater gehabt hatte, wollte ihre Kinder nicht mit Härte erziehen. Sie verstand es, uns mit liebender Hand und klugem Verständnis zu lenken, dabei ließ sie mit entschiedener Konsequenz keine unserer Unarten durchgehen. Sie hatte verständlicherweise die erzieherische Leitung übernommen, da unser Vater, dessen Gedanken voll und ganz mit seinen Plänen ausgefüllt waren, diese Aufgabe gern seiner Ehefrau überließ. Wenn wir Kinder ihn manchmal ungestüm zum Mitspielen herausforderten, gerade wenn er müde nach Hause kam, konnte er sich des Ansturms kaum erwehren. Doch da mischte sich rechtzeitig meine Mutter ein: "Laßt doch euren Vater in Ruhe! Er möchte sich jetzt ein wenig ausruhen!" Ich erinnere mich übrigens genau daran, daß sie gelegentlich sagte: "Ihr wißt ja gar nicht, was Ihr für einen guten Vater habt."

In den Nachkriegsjahren herrschte überall Knappheit. Auch die Kohlenzuteilung reichte nur noch für das Heizen eines einzigen Ofens. Wenn der Vater zu Hause war, was ja nur selten vorkam, etwa am Sonntag, wurden wir ermahnt, leise zu sein, um ihn möglichst wenig zu stören. Ich erinnere mich an eine kleine Szene, die sich in dem Familienwohnzimmer abspielte. Meine Mutter versorgte gerade den Ofen, sie kniete auf der Erde und stocherte in der Glut. Währenddessen waren meine Schwester und ich auf irgendeinen dummen Einfall gekommen, der sie erzürnte. Der Vater saß an dem großen Tisch über seine Arbeit gebeugt. Die mahnenden, tadelnden Worte der Mutter wurden überhört, der Unfug war in bestem Gange. Da wandte sie sich, um Unterstützung bittend, an ihren Mann, da sie selbst durch die kohlebeschmutzen 
Hände an der so notwendigen Erziehungsmaßnahme gehindert war: "Ludwig, gib' doch den Kindern einen Klaps." Der Vater schob seine Papiere ein wenig beiseite und erhob sich und ging auf unsere Spielecke zu. Wir waren sehr gespannt auf die ungewohnte Bestrafung, die uns durch unseren Vater zuteil werden sollte. Schlimm konnte es eigentlich nicht werden. Er zögerte, als er bei uns stand, wandte sich dann zur Mutter und fragte sie zur "Klärung" seines Auftrages: "Ja, aber wohin denn?" Wir beiden Schwestern brachen in ein befreites Lachen aus, selbst unsere Mutter konnte sich des Lachens nicht erwehren. Ich kann mich noch genau erinnern, wie der Vater uns nun zu erklären versuchte, daß seine Frage durchaus berechtigt gewesen sei, da das $\mathrm{MaB}$ der Strafe doch noch genauer hätte festgelegt werden sollen, je nach Art des Vergehens, das er ja nicht selbst beobachtet hatte. Von sich aus wäre es ihm nicht in den Sinn gekommen, uns handgreiflich zu bestrafen, - nein, diese Vorstellung wäre absurd. So sind wir wohl in seiner Gegenwart oft davon gekommen, obwohl wir ihn mitunter störten. Später hat er auf unsere Erziehung besonderen Einfluß genommen durch seine stets ruhigen und liebevollen Worte, mit denen er uns zur Einsicht brachte und zu richtigem Verhalten bewegte.

Die friedliche Stimmung seines Wesen war spürbar, wenn er am Tisch saß und arbeitete, vollkommen absorbiert von seiner Umgebung, während er schrieb und rechnete. Seine sorgende Frau hat uns meist fernzuhalten gewußt. Sie ermunterte uns, doch lieber draußen herumzuspringen; und, wie gesagt, meistens war ja der Vater im Institut, und wir durften unsere Freunde zum Spielen mit ins Haus bringen.

Durch die Knappheit jener Nachkriegsjahre, insbesondere was die Lebensmittel anbetraf, war eine allgemeine Notlage entstanden. Davon berichtete Prandtl einem schwedischen Kollegen, dem Professor Oseen in Upsala, mit dem er über Jahre hinweg einen Briefwechsel führte: "Im armen deutschen Vaterland sieht es ja sehr böse aus und wird auch noch schlimmer werden. Es gehörten eben eigentlich die Hälfte aller Deutschen in ein Sanatorium, um die Unterernährung zu beseitigen. Die Ernährung hier bei uns ist zwar knapp, aber doch wegen der Nähe des Landes wesentlich besser als in den Großstädten. Man kann eben nötigenfalls zu Fuß auf die Dörfer gehen, wo es immer noch etwas gibt." 
Meine Mutter ging meist wöchentlich zweimal durch den Wald nach Herberhausen zu der Familie Christmann, die sie gut kannte, und bekam dort Milch für ihre Kinder, ja oft auch ein Stück Butter und einige frische Eier. Am Wochenende hatte unser Vater auch Zeit, sie dorthin zu begleiten. Wir saßen dann alle in der überheizten guten Stube, und die Erwachsenen unterhielten sich, während wir Kinder gern einmal dort auf dem Hof und in dem Stall herumschauten. Die Eltern kannten jeden Weg im Hainberg, und manchmal kam man auch erst im Dunkeln nach Hause. So waren die Wochenendausflüge für uns erlebnisreiche Unternehmungen. Im Zufußlaufen mußte die Bevölkerung in den kleineren Städten, die noch keine öffentlichen Verkehrsmittel hatten, viel mehr als heute leisten können.

Auch während der Woche blieben für Prandtl die regelmäßigen kleinen Fußmärsche zum Arbeitsplatz eine selbstverständliche Gewohnheit. Auf diesen täglichen Wegen ins Institut sah man Prandtl, in Gedanken verloren, den Blick wie nach innen gerichtet; vorübergehende Passanten nahm er kaum wahr. Aber viele kleine Dinge auf seinem Wege beachtete er aufmerksam. Im Frühling sah er nach den ersten Blumen, die hinter Gartenzäunen in den kleinen Vorgärten standen, und freute sich an den Schneeglöckchen, später an Veilchen und Rosen. Er kannte die Bepflanzung dieser Gärten ganz genau und verfolgte Jahr für Jahr ihre Blütezeit. Er versäumte nicht, bei der gemeinsamen Mahlzeit seine Beobachtungen zu erwähnen. Auf dem Heimweg war er sehr häufig in Begleitung seiner jüngeren Mitarbeiter, die diese Gelegenheit schätzten, mit Prandtl ihre wissenschaftlichen Probleme durchsprechen zu können. Die Diskussion wurde meist vor unserem Haus noch eine Weile fortgesetzt, obwohl die Zeit für das Mittagessen schon weit überschritten war. Ein junger Physiker soll einmal folgenden Auspruch getan haben: "Wenn man zu faul ist, über ein auftretendes Problem nachzudenken, so braucht man es nur Prandtl zu erzählen. Entweder kann er sofort die Sache klarstellen, weil er längst schon über das gleiche Problem nachgedacht hat, oder die Anregung wird ihm keine Ruhe lassen, und er wird uns die Lösung in einigen Tagen sagen." 1 )

1) Entnommen aus dem Vortrag von A. Betz "Das Lebenswerk von L. Prandtl" [4]. 


\section{Segelfliegerei}

Die Nachkriegsjahre haben der speziellen Forschung keinen Stillstand gebracht, obwohl für Deutschland durch den Versailler Vertrag das Motorfliegen ganz eingeschränkt werden mußte. Auch die Demontage in manchen Fabriken traf die Luftfahrt hart. In Augsburg wurde anläßlich einer Tagung der Wissenschaftlichen Gesellschaft für Luftfahrt die Ballonfabrik Riedinger besichtigt, die zuvor schon einmal erwähnt wurde. Ein Zeitungsschreiber berichtete: "Beim Betreten der großen Halle wird der Vaterlandsfreund zunächst trüb gestimmt, denn sie birgt die Reste der Fluggeräte, die auch hier der Zerstörungswut der Entente zum Opfer gefallen sind. Sie ging soweit, daß selbst die Körbe der Fesselballons zerschnitten werden mußten."

Was das Fliegen anbetrifft, so gab es nun neue Impulse, von flugbegeisterten Studenten ausgehend, die sich der Segelfliegerei widmeten. Dies verstieß nicht gegen den Versailler Vertrag. Es bildeten sich an den verschiedenen Universitäten Fliegergruppen, die selbst ihre Segelflugzeuge in Gemeinschaftsarbeit bauten. Dieser Flugsport diente ja nicht militärischen Zielen und konnte sich, unbehelligt von der Überwachung der Siegermächte, frei entfalten. Der Redakteur der damaligen Luftfahrtzeitschrift "Flugsport", Oskar Ursinus, hatte die Idee, zu einem Segelflugwettbewerb aufzurufen. $\mathrm{Zu}$ diesem Vorhaben sollten sich die jungen Konstrukteure mit ihren Gleitapparaten auf den Höhen der Rhön einfinden. Es waren die verschiedensten Flugzeugtypen, die dorthin verfrachtet wurden und deren Piloten sich messen wollten. Man hatte das Gelände der Rhön gewählt, weil dort von den baumlosen Kuppen ein ständiger Wind wehte, der sowohl als Aufwind wie auch als Fahrtwind genutzt werden konnte. Die Teilnehmer des ersten Wettbewerbs 1920 konnten sich nur etwa zwei Minuten in der Luft halten. Die einzelnen Flüge wurden zeitlich genau abgestoppt. 1921, beim zweiten Rhönwettbewerb, gelang es dann dem Sieger, W. Klemperer, seinen Flug auf 13 Minuten auszudehnen, und damit gewann er zugleich den Weltrekord. Um diese Leistung zu steigern, war man bemüht, noch vieles an den Flugapparaten zu verbessern, und man war auch bereit, noch manches über die Theorie des Fliegens zu lernen. So wurden dort auf der Wasserkuppe von da an Seminare eingerichtet, um die jungen Segelflugbauer im Wissensgebiet der Aerodynamik zu unterweisen. Prandtl und von Kármán, Runge und Madelung lehrten dort, daß es auf die richtige, funktionsgemäße Bauweise ankam, und erklärten, wie man die Luftströ- 
mung bei günstigen Wetterlagen nützen könne [21, 29]. 1922 wurde der Rekordflug bereits mit drei Stunden verzeichnet, wie ein Berliner Zeitungsartikel mitteilt. Die Teilnehmerschaft des Rhönwettbewerbs wuchs, und ebenso breitete sich Begeisterung für diesen neuen Sport aus. Mit der individuellen Bauweise handgefertigter Modelle war auch persönlicher Einsatz der Betreffenden verbunden. Es herrschte in der Gruppe ein hervorragender Kameradschaftsgeist. Dort oben auf der Wasserkuppe hatte man bescheidene Baracken errichtet, wo die sportlichen Flieger teilweise auch über den Winter blieben, jeden günstigen Übungstag wahrnehmend. Der RhönSegelflugwettbewerb hatte durch viele Jahre Bestand [48]. Am 25. Juli 1926 erhielt Prandtl von den Veranstaltern des Wettbewerbs folgenden Brief:

\section{"Sehr geehrter Herr Professor!}

Wir erlauben uns, Ihnen anbei eine Liste der zum Wettbewerb gemeldeten Flugzeuge sowie eine Dauerausweiskarte und eine Rosette als Mitglied des Ehrenausschusses zu übersenden, und hoffen, Sie auf der Wasserkuppe begrüßen zu dürfen."

Während dieser Zeit machte unsere Familie einen Pfingstausflug in die Rhön. Mit der Kleinbahn gelangten wir von Fulda nach Gersfeld. Dort begann unser Wanderweg hinauf auf die Höhe der Kuppe. Unten war es warm und sonnig gewesen, aber oben war man sehr dem Wind ausgesetzt, der Himmel bewölkte sich. Als wir oben auf der Kuppe anlangten, machte sich gerade ein Flieger zum Start bereit. Das Segelflugzeug mußte auf kurzer Bahn von Kameraden an einem Gummiseil gezogen werden, um dann im freien Flug Höhe zu gewinnen. Unser Vater schaute ihm gebannt und zugleich tiefbefriedigt $z u$, bis es sich unserem Gesichtskreis entzogen hatte. Nach dem Mittagessen, das wir im Haupthaus einnahmen, wurde unser Vater geholt, denn inzwischen war der Flieger auf der kahlen Höhe wieder gelandet und wollte gern noch mit dem Strömungsprofessor über seinen Flug sprechen und des Professors Rat zur Klärung mancher aufgetretener Fragen einholen. Gegen Nachmittag begann es leise zu regnen, die Kuppe war bald in eine Nebelwolke gehüllt, der Flugbetrieb wurde daraufhin ganz eingestellt. 


\section{Der Ruf nach München}

Im Sommer 1920 erging an Prandtl ein Ruf an die technische Hochschule München, wo der Schwiegervater, August Föppl, mit 66 Jahren sein Rücktrittsgesuch eingereicht hatte. August Föppl behielt sich noch kleinere Aufgaben in seinem Laboratorium vor, aber von den Vorlesungen über Mechanik mit über 400 Hörern wollte er sich zurückziehen. Bei der Neubesetzung war geplant, den überlasteten Lehrstuhl zu teilen, so $\mathrm{da} ß$ die Arbeitsbedingungen recht günstig erschienen. Daß die Aussicht, wieder in die süddeutsche Heimat zurückkehren zu können, für meine Eltern eine große Verlokkung war, läßt sich denken. Doch andererseits schob Prandtl die endgültige Entscheidung, die ihm schwer fiel, noch bewußt einige Zeit hinaus.

Aus dieser Periode möchte ich aus einem Brief an Herrn Geheimrat Dr. Duisberg, Generaldirektor der Farbenwerke Bayer, einige Absätze zitieren. Es war nämlich für Prandtl die Hoffnung aufgetaucht, daß man ihm über die neugegründete HelmholtzGesellschaft Geldbeträge zukommen lassen wollte zur Weiterentwicklung seiner ständig drängenden Forscherpläne. Das hätte ihn in Göttingen gehalten.

\section{November 1920:}

"Da Sie bei unserer Nauheimer Begegnung die Freundlichkeit hatten, mir bezüglich meines Rufes mit Andeutungen über finanzielle Beihilfe für mein Forschungsinstitut zum Bleiben in Göttingen zuzureden, nehme ich mir jetzt die Freiheit, in dieser immer noch schwebenden Angelegenheit, das Folgende zu schreiben:

Das, was mir die Göttinger Stelle wertvoll macht, ist die Forschertätigkeit. Die Lehrtätigkeit ist daneben, wegen des kleinen Interessenkreises, den meine Gebiete auf der Universität finden, von keiner großen Bedeutung. Den Plan von Forschungsarbeiten, wie er mir vor dem Krieg bereits für das damals angestrebte KWI für Aerodynamik vorschwebte, werde ich wohl auf immer begraben müssen. Ich werde nur daran denken können, die Untersuchungen in wesentlich kleinerem Maßstab ausführen zu können. Aber auch hierfür würden größere laufende Mittel nötig sein."

Wie nun die Angelegenheit in bezug auf finanzielle Unterstützung geregelt werden sollte, ist mir nicht bekannt. Inzwischen erreichte Prandtl aber von München die Nachricht, daß der Lehrstuhl aus Sparmaßnahmen nicht geteilt werden könne. Eine solche Überlastung mit einer zahlreichen Studentenschaft wollte Prandtl nicht hin- 
nehmen: Er hätte dann kaum Zeit für seine Forschungen erübrigen können. Im August 1921 sagte er darum in München ab. Er machte dann der Kommission Vorschläge für einen anderen geeigneten Kandidaten.

Genau ein Jahr später wurde der Münchner Ruf erneuert, denn inzwischen hatten geschickte Verhandlungen es doch zuwege gebracht, daß der Mechanik-Lehrstuhl in zwei Aufgabenbereiche mit zwei Ordinariaten geteilt wurde. Den einen Lehrstuhl hatte bereits Ludwig Föppl erhalten. Diesmal entschied sich Prandtl für München. Am 30. Dezember 1922 gab er seine Zusage. Die Übersiedlung verzögerte sich noch, weil die Wohnungssuche in München erfolglos geblieben war. Man war mitten in der Inflation, die Preise für eine Mietwohnung waren, wie alle "Waren" damals, in einer permanenten Steigerung begriffen. In dieser Phase der angespannten Planung - es sollten noch verschiedene Bedingungen ausgehandelt werden: ein eigener Assistent sollte beantragt werden und ein Extra-Etat für ein Laboratorium - wurde Prandtl ein unerwartetes Angebot von der KWG unterbreitet. Man versprach, ihm für den Fall seines Bleibens in Göttingen ein neues Institut für Hydrodynamik neben den schon vorhandenen Institutsgebäuden der AVA zu errichten. Wieder wendete sich das Blatt, und Prandtl entschied sich fürs Bleiben. Allein, es gab nochmals einen Rückschlag, indem die von der KWG bewilligten Gelder wegen des Sturzes des Finanzministers nicht ausgezahlt werden konnten. Meine Eltern befaßten sich aufs neue mit Umzugsplänen. Ich erinnere mich noch ein wenig an dies Hin und Her. Bei einer kleinen Begebenheit ist mir die Bedeutsamkeit unserer persönlichen Schicksalsgebundenheit aufgegangen. Als wir einmal mit unserer Mutter auf den nahen Wiesen Margeriten gepflückt hatten, setzten wir uns auf eine Bank am Waldrand, und sie nahm eine Blume aus dem Strauß und zupfte einzeln die weißen Blütenblätter ab, um spielerisch das Schicksal zu befragen: München - Göttingen, München - Göttingen usw. Ich kann allerdings nicht mehr sagen, für welchen Ort sich das Margeritenorakel damals entschied. Nur war mir bewußt geworden, wie sehr die ungelöste Frage auf den Gemütern beider Eltern lastete.

Aus dieser letzten Phase der Entwicklung sind Briefe an Ludwig Föppl vorhanden, den Prandtl über den jeweiligen Stand der Angelegenheit auf dem laufenden halten wollte. Sie zeigen, wie sehr er um eine allen Beteiligten gerecht werdende Entscheidung gerungen hat. 
Prandtl an seinen Schwager, Ludwig Föppl:

13. Juli 1922: "Dieser Tage hat Schröter bei mir angefragt, ob ich bereit wäre, den Ruf nach München anzunehmen. Ich habe ihm erklärt, daß ich stark daran dächte, anzunehmen, daß ich mich aber nicht absolut binden könnte, bevor ich mit dem Ministerium verhandelt habe.

$\mathrm{Zu}$ einer Sache möchte ich noch Deine Stellungnahme kennenlernen. Ich bin in letzter Zeit durch das Dekanat sehr wenig zur Ausarbeitung meiner wissenschaftlichen Ideen gekommen; an diesen selbst habe ich jedoch keinen Mangel, da meine zur Zeit recht zahlreichen Doktoranden (nahezu ein Dutzend) mich fortwährend zwingen, neue Dinge für sie durchzudenken. Ich habe deshalb den lebhaften Wunsch, nun nicht plötzlich all das abschneiden zu müssen, und möchte auch die Doktoranden nicht so ohne weiteres ihrem Schickal überlassen. Es wäre mir deshalb sehr wichtig, noch bis nächste Ostern hierbleiben zu können."

\section{Januar 1923 an den Schwager:}

"Wie Du aus Familienbriefen wissen wirst, habe ich in München jetzt angenommen, mir allerdings den Zeitpunkt meines Eintritts noch vorbehalten, bis ich eine Wohnung habe."

\section{April 1923 an den Schwager:}

"Nachdem, was man mir hier in Aussicht zu stellen gedenkt, möchte ich natürlich, wenn ich nach München gehe, auch die Gewißheit haben, daß dort gute Möglichkeiten für hydrodynamische Forschungen offenbleiben."

\section{Juni 1923 an den Schwager:}

"Heute muß ich Dir leider mitteilen, daß die Angelegenheit des 'neuen Göttinger Rufes' in ein akutes Stadium getreten ist. Man glaubt, in kürzester Zeit in der Lage zu sein, mir für die wissenschaftliche Abteilung des Forschungsinstitutes, die neu hinzukommen soll, auf der Basis vom April des Jahres, 40 Millionen jährlich und für den Bau der hydrodynamischen Abteilung einmalig 500 Millionen auf Aprilbasis wertbeständig anzubieten. Auf das Schreiben der Kaiser-Wilhelm-Gesellschaft, in dem mich der Geschäftsführer bittet, umgehend zu antworten, ob ich bei Perfektwerden der angekündigten Bewilligungen hier bleiben würde, habe ich mit beiliegendem Durchschlag geantwortet: 
'2. Juni 1923 an den Direktor Dr. Glum:

Es ist mir heute noch nicht möglich, Ihnen, wie Sie wünschen, sofort meine endgültige Stellungnahme für den Fall der definitiven Genehmigung der angebotenen Summen durch die Ministerien mitzuteilen, denn es wäre nicht das Richtige, die Entscheidung in einer Angelegenheit, die auch meine persönliche Zukunft so stark betrifft, ohne eine Bedenkzeit von wenigstens einigen Tagen zu treffen.

Wie ich gestern dem Herrn Universitätskurator, der mich kommen ließ, auch schon zum Ausdruck brachte, erkenne ich es als eine erstaunliche Leistung an, daß es möglich war, in diesen Zeiten so große Beträge von Reich und Preußen zu erreichen. Die Hingabe an diese Aufgabe seitens der Kaiser-Wilhelm-Gesellschaft und seitens des preußischen Kultusministeriums, die sich durch die Erreichung dieses Zieles in so kurzer Zeit kundgibt, verpflichtet natürlich auch mich, die Angelegenheit in ernstester Weise zu prüfen."

\section{Juni 1923 an den Schwager:}

"Wie Du aus beiliegenden Abschriften meiner gleichzeitigen Briefe an Ministerium und Rektorat ersehen magst, habe ich jetzt in der Angelegenheit meines Münchner Rufes nach langem Besinnen mich entschieden, und zwar für Göttingen. Ich komme aber dabei über die Empfindung nicht hinweg, daß es sehr schade ist, daß nun aus unserer Zusammenarbeit nichts werden soll. Ihr werdet nun von neuem an die Berufungsfrage herantreten müssen, und ich möchte Euch sehr wünschen, daß Ihr einen geeigneten Mann findet. Wenn Ihr einen guten Lehrer gewinnt, der sich des Unterrichts sehr energisch annimmt, dann seid Ihr vielleicht letzten Endes besser daran, als es mit mir gewesen wäre, wenn ich mir etwa, entgegen den guten Vorsätzen, die ich gehabt habe, das Forschen nicht hätte genügend abgewöhnen können."

\section{Juni 1923 an das Bayrische Kultusministerium:}

"Dem Ministerium für Kultus und Unterricht beehre ich mich hierdurch zu berichten, daß in der Frage meiner Berufung an die Technische Hochschule München eine neue Lage dadurch eingetreten ist, daß mir das Preußische Unterrichts-Ministerium und die Kaiser-Wilhelm-Gesellschaft zur Förderung der Wissenschaften eine für heutige Zeit sehr hohe Summe in Aussicht stellen, um meine früheren Pläne für ein hydrodynamisches Forschungsinstitut zu verwirklichen. Die beabsichtigte Bewilligung soll nach den Mitteilungen aus Berlin auf 500 Millionen, bezogen auf die Aprilpreise, lauten." 
Dem Schwager wurden am 27. Juni Kandidaten zur Besetzung der vakanten Münchner Professur von Prandtl vorgeschlagen. Von einem Vorschlag sei hier die Rede:

"Ich kenne nur einen Kandidaten, der alle vorgenannten Bedingungen erfüllt, nämlich von Kármán in Aachen. Er hat auf allen Gebieten glänzende, zum Teil bahnbrechende Arbeiten geliefert. Dabei ist er, wie Dir bekannt ist und wie ich auch später immer wieder hörte, ein glänzender Lehrer. Ich bin mir natürlich vollständig darüber im klaren, daß seine Berufung der Abstammung wegen Schwierigkeiten machen wird, aber derartige Grundsätze dürfen nach meiner Ansicht nicht so weit gehen, daß eine Hochschule ihr wissenschaftliches Leben bewußt schädigt."

Schon damals hat Prandtl also, im Gegensatz zu seinen Münchner Kollegen, vorurteilslos für die Wahl eines hochgeschätzten jüdischen Wissenschaftlers plädiert.

\section{Juli an den Schwager Ludwig Föppl:}

"Mein großer Bericht mit Bauplänen und Kostenüberschlag für das hydrodynamische Institut ist am letzten Donnerstag nach Berlin abgegangen. Da die beteiligten Berliner Instanzen selbst ein großes Interesse daran haben, daß die Sache bald vorwärts kommt, wird, wie ich glaube, die Entscheidung nicht lang auf sich warten lassen."

\section{Juli an den Schwager:}

"Im Reichsministerium scheint Geneigtheit zu bestehen, die Angelegenheit in zustimmendem Sinne beschleunigt zu erledigen. Im preußischen Finanzministerium wird jedoch vor einem endgültigen Bescheid des Reichsfinanzministeriums eine entscheidende Erklärung nicht abgegeben werden können."

\section{Juli an den Schwager:}

"Ich würde mich dazu entschließen können, den Berlinern jetzt ein achttägiges Ultimatum zu stellen, mit der Maßgabe, daß ich nach Ablauf dieses Ultimatums mich für München entscheiden würde. Natürlich ist dabei eine für uns diskutable Wohnung eine notwendige Voraussetzung."

29. Juli, Brief Gertruds an den Bruder:

"Ich habe so oft das Gefühl, daß die jetzige Zeit, die so unerquicklich wie nur möglich 
ist, nicht gerade sehr günstig für den Institutsneubau sein wird. Ich habe mir sehr viel Mühe gegeben, meinen Mann zum gänzlichen Aufgeben dieses Planes zu bewegen, habe aber eingesehen, daß er sehr daran hängt."

\section{August an den Schwager:}

"Die Berliner reagieren auf meinen Drohbrief sauer und sagen, es würde ohnehin schon alles möglichst beschleunigt. Die Sache läge aber wegen der vielen beteiligten Stellen sehr verwickelt."

\section{September an den Schwager:}

"Ich habe auf der Wasserkuppe mit dem in Luftfahrtdingen maßgebenden Herrn aus dem Reichsfinanzministerium gesprochen, der mir bestätigte, daß dort die Absicht bestehe, den Ergänzungsbau des Instituts unter allen Umständen zu fördern, vor allem wegen der Stärkung der deutschen Luftfahrtinteressen, die man sich davon verspricht. Bei dieser Sachlage scheint es mir, als ob ich kein Recht hätte, Eure Geduld in München noch weiter in Anspruch zu nehmen."

\section{Oktober an den Schwager:}

"In den letzten Tagen war ich in Berlin zur Tagung der Wissenschaftlichen Gesellschaft für Luftfahrt und habe dabei auch in der Kaiser-Wilhelm-Gesellschaft vorgesprochen. Dort war man sehr unglücklich über die letzte Regierungskrise, denn es war gerade geglückt, den Finanzminister, Dr. Hilferding, für die Einsetzung meines Instituts in den Etat zu gewinnen, als dieser abtreten mußte. Andernfalls wäre in kürzester Zeit die Entscheidung für mich, allerdings in dem für Euch ungünstigen Sinne, zu erreichen gewesen. Jetzt weiß man natürlich wieder nicht, wie die Sache laufen wird."

\section{Oktober 1923 an den Schwager:}

"Wenn Du mich fragst, ob ich noch immer an die Verwirklichung meines Instituts glaube, so muß ich natürlich antworten, daß es im Augenblick, wo es in Sachsen losgeht und Bayern aufsässig ist, recht schlecht damit aussieht. Aber es handelt sich schließlich nicht um meine Privatmeinung, sondern um die in dieser Sache Maßgebenden, denen gegenüber ich mich gebunden habe. Ich will aber doch morgen noch einmal auf eine Entscheidung in Berlin drängen. Ich will lieber die Ablehnung in Berlin abwarten, als selbst die Sache hinzuwerfen, da ich doch mit der Kaiser-Wilhelm- 
Gesellschaft, mit der ich doch noch weiter zu tun haben werde, im Guten auseinanderkommen will."

28. November an den Schwager:

"Nach der erneuten Kabinettskrise habe ich mit etwas wehmütigen Gedanken meinen Abschied von Göttingen als sicher angesehen und mit Gertrud viel darüber gesprochen, wie wir es uns in München einrichten würden.

Da kam von der KWG die Nachricht, daß sich durch einen industriellen Spender eine neue Möglichkeit für das Göttinger Institut aufzutun schien. Die Wirkung war bei Gertrud und mir die gleiche, wir waren traurig, München nun wieder aufgeben zu sollen. In der Tat hängen wir beide stark an Göttingen und an München, und doch kann nur eines von beiden Wirklichkeit werden.

Da ich die Entwicklung nicht genügend übersehe, ist es schließlich die Sache der Münchner, zu bestimmen, wie lange sie die Entscheidung noch hinausschieben können."

28. November 1923 an den Rektor der Technischen Hochschule München:

"Hochverehrte Magnifizenz

Es ist mir außerordentlich peinlich, heute statt einer endgültigen Antwort noch einmal um einen kurzen Aufschub bitten zu müssen. Ich tue es auf dringende Bitten sowohl der KWG als auch der hiesigen Fakultät. Durch die Kabinettskrise in Berlin ist wieder eine Möglichkeit für die Genehmigung des geplanten Instituts, zu der bereits gute Ansätze vorhanden waren, gescheitert.

Der Geschäftsführer der KWG jedoch, der sich in dieser Angelegenheit äußerst rührig und tatkräftig gezeigt hat, hat aber die Flinte nicht ins Korn geworfen, sondern überraschte mich mit der Aussicht auf eine Möglichkeit, bei der die Mitwirkung eines sehr vermögenden Industriellen die wesentliche Rolle spielt, und er beschwor mich, ihm wenigstens einige Tage noch Zeit zu lassen. Ich bin mir vollständig bewußt, überhaupt kein Recht zu haben, von der Münchner Hochschule einen Aufschub zu verlangen. Immerhin erschien mir die Bitte der KWG begründet genug, um sie an die Münchner Hochschule weiterzuleiten. Wenn eine Möglichkeit dafür besteht, daß in Göttingen der zweite Teil des Forschungsinstituts geschaffen wird, und wenn diese Möglichkeit nur durch mein Hierbleiben erreicht werden kann, so fühle ich es als Pflicht, mich dieser Aufgabe zu widmen und so das begonnene Lebenswerk, die 
Erforschung der Gesetze der Luft- und Wasserströmungen, fortzusetzen. Fällt diese Möglichkeit aber fort, so würde meine Kraft zum guten Teil brachliegen, und ich bin überzeugt, daß ich in diesem Fall sie in München besser anwenden könnte."

\section{Dezember 1923 an den Rektor der TH München:}

"Euer Magnifizenz beehre ich mich zu berichten, daß laut einer soeben erhaltenen Nachricht der Institutsbau hier als gesichert gelten muß. Ich bin der getroffenen Abrede gemäß daher genötigt, endgültig auf die Münchner Professur für technische Mechanik zu verzichten. Ich habe selbst vor wenigen Tagen noch den entgegengesetzten Ausgang erwartet und empfinde es schmerzlich, daß aus so manchen Plänen, die ich mir für die Münchner Tätigkeit bereits zurechtgelegt hatte, nun nichts werden soll. Die Aufgabe, die mir hier zunächst gestellt sein wird, wird in Anbetracht der Zeitverhältnisse wohl große Schwierigkeiten mit sich bringen, jedoch wird sie, wenn ihre Durchführung auch nur in der Hauptsache gelingt, mir wohl reiche Gelegenheit zur Betätigung auf den mir besonders am Herzen liegenden Gebieten geben.

Ich bitte Eure Magnifizenz, die Münchner Kollegen wissen zu lassen, daß ich auch jetzt, wo aus meiner Übersiedlung nichts geworden ist, weiterhin eine starke Zugehörigkeit zu München empfinde und in jeder Weise bereit sein werde, falls sie meiner bedürfen."

\section{Dezember an den Schwager:}

"Von Eurem Rektor wirst Du erfahren haben, daß ich nun doch das Institut zugesichert bekam und daher in Göttingen bleiben werde. Eigentlich müßte ich mich über die künftigen Forschungsmöglichkeiten freuen, bis jetzt ist es aber nicht so weit, die Trauer über all das, was ich mir für München ausgemalt hatte und was nun eben nichts werden soll, überwiegt vorläufig durchaus. Dazu auch die Sorge, ob nicht doch mit dem Institutsbau noch etwas dazwischen kommt. Ich sage mir aber immer wieder, wenn andere mir die Möglichkeit zu umfangreichen Forschungen bieten, so darf ich, wo ich doch schon einmal als erster Fachmann des Gebietes in Deutschland gelte, nicht selbst die Sache zu Fall bringen. Ich hoffe auch bestimmt, daß ich noch viel Befriedigung aus dieser Tätigkeit werde schöpfen können, wenn das Gröbste erst geschafft ist.

Den Kindern, die sehr viel im Freien sind, geht es gut. Die Bergstraße hier erlaubt ja das reinste Landleben. Sie waren deshalb sehr glücklich, als es hieß, wir bleiben hier. 
Sie haben auch so nette Freundinnen. Uns Großen wäre es hauptsächlich um den Hainberg leid gewesen, den wir nicht hätten mitnehmen können!"

Am 3. Dezember 1923 sagte Prandtl in München endgültig ab. Die Herren von der KWG hatten also Ausschau gehalten nach einem privaten Spender, um den Plan eines neuen Instituts nicht fallenlassen zu müssen. Der Generaldirektor der W. Hoene-Aktiengesellschaft war in der Lage, Mittel zur Verfügung zu stellen, die den geplanten Neubau ermöglichen halfen. Die Hälfte der notwendigen Summe war von dem neuen Finanzminister Luther bewilligt worden. 


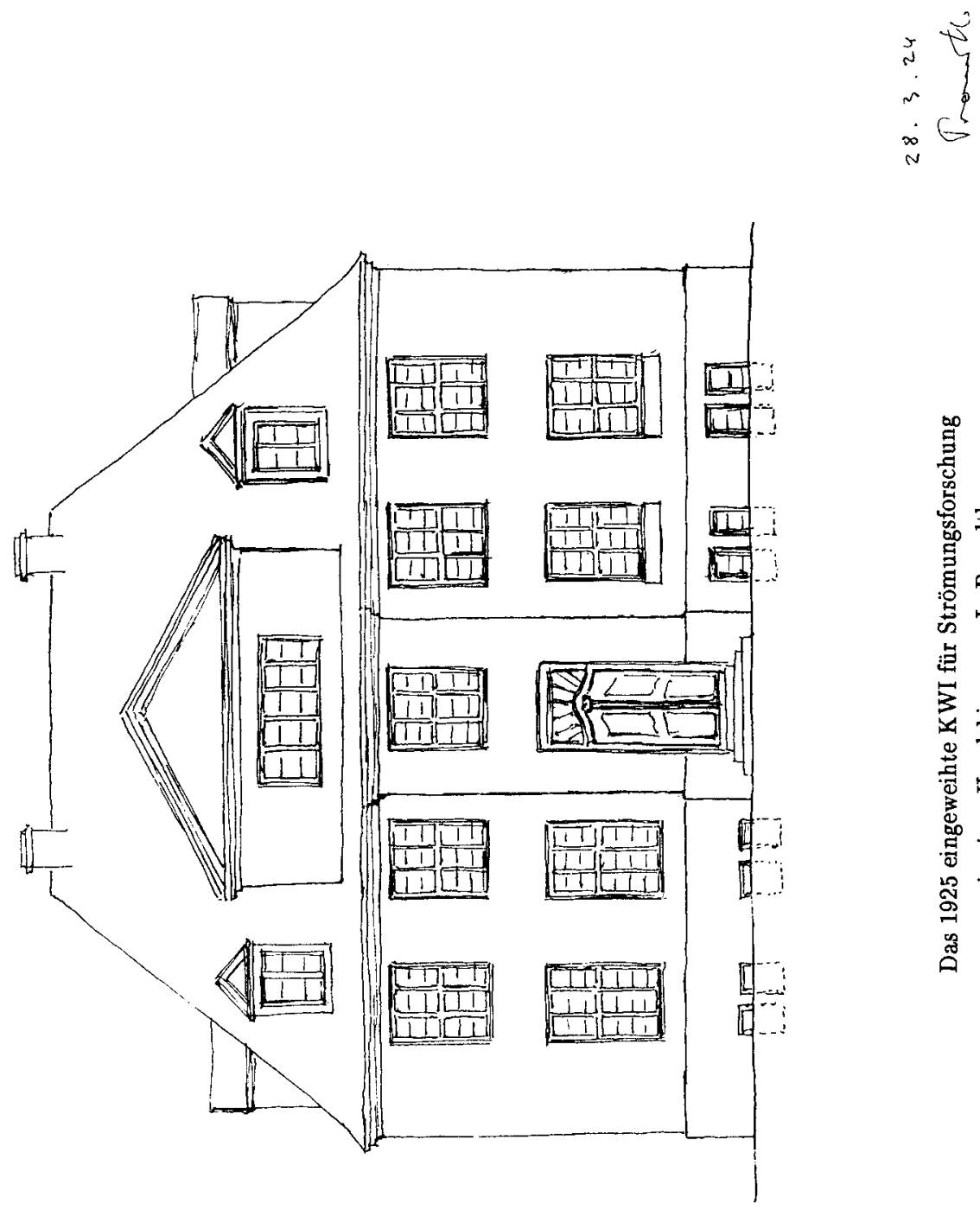

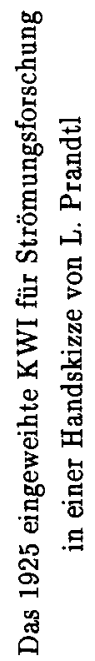




\section{Institutsaufbau und neue Projekte}

Alles, was Prandtl von Anbeginn an Aufbauarbeit geleistet hatte, brauchte nun nicht aufgegeben zu werden. Zusammen mit gut eingearbeiteten Assistenten und verläßlichen Mechanikern wurde der Göttinger Forschungsbetrieb weitergeführt, auch in der Phase der beginnenden Bautätigkeit. Der Neubau sollte die Möglichkeiten zur freien, weniger zweckgebundenen Forschung bieten, unabhängig von der mehr an der Praxis orientierten Versuchsanstalt, deren Aufgabe es war, Eigenschaften von Flugzeugen, Turbinen und anderen Modellen strömungstechnisch zu untersuchen. In diesen anderthalb Jahren, die nun folgten, in denen das neue Kaiser-Wilhelm-Institut entstand, wurde von den Betriebsangehörigen besonderer Einsatz gefordert. Aber das Planen und Vorankommen weckte in allen den Schwung, sich mit Freude und Eifer der Arbeit zu widmen.

Ing. Walter Müller berichtete mir: "Eine feste Arbeitszeit hat es damals für mich wie auch für andere nicht gegeben," es sei selbstverständlich für ihn gewesen, auch ganze Abende im Institut zu bleiben, wenn die Meßergebnisse noch zu berechnen waren oder für den kommenden Tag Versuchseinrichtungen aufgebaut werden mußten. "Auch eine Spezialisierung gab es ja noch nicht. Jeder konnte alles."

Die Forschung stand unterdessen nicht still. Bei der Grenzschichttheorie waren im Zusammenhang mit Turbulenzphänomenen wichtige Nebenprobleme aufgetaucht. Einige Aufsätze Prandtls über das neue Gebiet der Turbulenz erschienen dann in den verschiedenen wissenschaftlichen Zeitschriften. So gab es gleichzeitig mit dem Aufbau des Instituts eine ständige Fortentwicklung der theoretischen Erkenntnisse und sogar ganz neue Projekte.

Eines dieser neuen Projekte war das Flettner-Rotorschiff. Eine besonders interessante Arbeit, wissenschaftlich betreut von dem Assistenten, Dipl.-Ing. Jakob Ackeret (Schweiz), führte 1924 durch dessen Untersuchungen zu einem technisch gelungenen Ergebnis. Es handelt sich um das sogenannte "Rotorschiff". Die genauen Ermittlungen über die Energieleistung rotierender Zylinder, die als Drehtürme auf einem Schiff dem Wind ausgesetzt werden sollten, ergaben, daß sie eine größere Antriebskraft entfalten konnten als das übliche aufgespannte Segeltuch. Ingenieur Flettner, 
der Erfinder des Rotorschiffs, hat daraufhin sein Projekt mit Hilfe der Strömungswissenschaftler zum Erfolg gebracht. Auf der Kieler Werft "Germania" wurde das Versuchsschiff gebaut. Dorthin ist Prandlt mehrfach gebeten worden, um die Funktionstüchtigkeit des Schiffes zu begutachten. Und nachdem es sich auf mehreren Probefahrten bewährt hatte, konnte die "Buckau" im Küstengebiet verwandt werden. Notiz von Prandtl am 12. November 1924: "Fahrt mit der Buckau, mit Prinz Heinrich, Busley und vielen anderen nach Eckernförde ( 6,2 Seemeilen bei $6 \mathrm{~m}$ Wind)."

Mein Mann erinnert sich, daß er dieses originelle Schiff, das alle bestaunten, in der Außenelbe gesehen hat und daß das singende, monotone Geräusch weit über den Fluß hallte.

Dezember 1924, Prandtl verfaßte einen Rundbrief:

"In der Angelegenheit der Flettnerschen Segelschiffserfindung sind uns so zahlreiche Zuschriften verschiedener Art zugegangen, daß eine schnelle Beantwortung unmöglich war. Eine Reihe von typischen Fragen sind unten beantwortet. Wir bitten Sie, damit vorliebzunehmen.

1) Veröffentlichungen unsererseits über den genannten Gegenstand sind bis jetzt noch nicht vorhanden, jedoch wird Anfang nächsten Jahres ein Bericht von Dipl.-Ing. Ackeret in der Zeitschrift für Flugtechnik und Motor-Luftschiffahrt, einer von Dr. Betz in der Zeitschrift des Vereins Deutscher Ingenieure und einer von Professor Prandtl in den 'Naturwissenschaften' erscheinen, außerdem wird der Verlag Vandenhoek und Ruprecht in Göttingen eine Broschüre aus der Feder von Herrn Ackeret, betitelt 'Das Rotorschiff', herausbringen.

2) Bezüglich der Anwendung des rotierenden Zylinders auf andere Fälle sei bemerkt, daß solche nur dort Zweck haben, wo, wie beim Segelschiff, ein Interesse vorliegt, mit kleineren Flächentiefen auszukommen als bisher. In allen übrigen Fällen, wie bei Flugzeugen, Windmühlen usw, sind die bisher üblichen flügelartigen Bauformen ihres geringen Luftwiderstandes wegen vorzuziehen."

Kurz vorher, am 17. November 1924, hatte Prandtl vor der Göttinger Physikalischen Gesellschaft über das Rotorschiff vorgetragen [30]. 
Im Vorwort zu der Broschüre von Jakob Ackeret, "Das Rotorschiff und seine physikalischen Grundlagen" [1], schreibt Prandtl: "Der sensationelle Erfolg des eigenartigen Flettnerschen Windkraftschiffs hat plötzlich das große Publikum auf Dinge aufmerksam werden lassen, die bis dahin nur im engsten Kreise der Fachleute verhandelt $\mathrm{zu}$ werden pflegten. Man wünschte eine Erklärung dafür, wie es möglich ist, daß ein verhältnismäßig schlanker, schnell rotierender zylindrischer Turm eine zehnmal so große Segelfläche ersetzen kann."

Diese für Laien abgefaßte kleine Schrift, die jedoch einiges Verständnis für physikalische Zusammenhänge voraussetzt, erklärt das Phänomen einleuchtend.

Der interessierten Öffentlichkeit in Göttingen wurde die Erfindung in einem Vortrag erläutert. Ankündigung: Stadtpark, Freitag, den 20. Februar 1925, 8 Uhr. Lichtbildervortrag von Professor Prandtl über das Flettnersche Rotorschiff.

Aus den Ortsnachrichten, Göttingen, 22. Februar 1925:

"Über das Flettnersche Rotorschiff sprach gestern Professor Prandtl vor gut besetztem Hause. Wie es in der Natur der Sache lag, war der Vortrag zum guten Teil akademischer Art, aber doch so gehalten, daß auch der Laie den Vorgängen zu folgen vermochte. Es war in hohem Maße interessant, aus dem Munde des Mannes, der an der Verwirklichung der Flettnerschen Erfindung so hervorragenden Anteil gehabt hat, zu hören, wie sich auf wissenschaftlicher Grundlage und durch emsiges Studium über das Wesen der Luftströmungen schließlich das Ergebnis erzielen ließ, das in der ganzen Welt großes und berechtigtes Aufsehen erregt hat. Der Vortragende erläuterte seine teilweise von Beifall unterbrochenen Ausführungen durch Lichtbilder. Zum Schluß warf Professor Prandtl die Frage auf, ob wohl das Rotorschiff in der Schiffahrt eine Bedeutung erlangen werde. Er beantwortete die Frage dahin, daß die Verwendung des Rotorschiffes von wirtschaftlichen Erwägungen abhängig sei."

Die Hoffnungen, die sich an die Verbreitung dieses Schiffstyps knüpften - man erwartete Verbilligung der Frachtschiffahrt -, haben sich jedoch nicht erfülit.

$\mathrm{Daß}$ sich diese Erfindung in der Praxis dann doch nicht durchsetzte, hatte in der Tat wirtschaftliche Gründe. Die Kosten, die für die Wartung der "Technik" an Bord erfor- 
derlich waren, hätten die Fischer zum Beispiel für ihre Boote nicht aufbringen mögen. Denn ohne die ständige Betreuung durch einen Mechaniker, der für das einwandfreie Funktionieren der sich sehr schnell drehenden Rotoren sorgte, waren längere Fahrten des Schiffes nicht gesichert.

Heute ist man von neuem auf das energiesparende Prinzip der rotierenden Drehtürme zurückgekommen, die jetzt Turbosegel genannt werden. Mit einem solchen Windschiff war der Meeresforscher Jacques Cousteau neuerdings auf einer zweieinhalbjährigen Forschungsreise unterwegs. Er befand sich im Juni 1985 im Hafen von New York.

Ein anderes im Bereich der Anstalt liegendes Forschungsgebiet war damals das des Luftwiderstandes von Fahrzeugen zu Lande. Den Anfang machte eine Versuchsreihe, die sich um die Verringerung des Luftwiderstandes von Lokomotiven bemühte, um Energie einzusparen. Man erprobte den Winddruck an einem Modell, im Maßstabe 1:25, dessen Front und Seiten verkleidet waren. Die Berechnungen ergaben, daß in diesem Falle bei einem mit 90 Kilometer Geschwindigkeit fahrenden Zug 80 bis 100 Kilogramm Kohle stündlich eingespart werden konnten [23]. Diese Versuche wurden später mit einem hier in Göttingen stehenden Triebwagen, der nach den geprüften Modellen konstruiert war, mit Erfolg fortgesetzt. Wir wurden als Kinder manchmal auf der Probestrecke nach Northeim mitgenommen.

Inzwischen war nun die Erweiterung der Anstalt zum Abschluß gekommen. Ingenieur W. Müller erinnert sich noch an eine kleine Panne aus jener Zeit kurz vor der Einweihung. Das Direktorzimmer war mit Gummifliesen der Firma W. Hoene ausgelegt worden: schwarzweiß wie ein Schachbrett. Prandtl mißfiel dieser Bodenbelag gänzlich, als er ihn zu Gesicht bekam. Er meinte: "Vielleicht wäre dieses Muster in einem Schlachterladen passend gewesen." Er blieb in der Tür stehen und sagte: "Da gehe ich nicht hinein!" Es konnte aber noch geändert werden. Gewählt wurden beige-marmorierte Fliesen, die man dann noch rechtzeitig vor dem Festakt verlegte.

Am 16.Juli 1925 wurde dann die Einweihung festlich gefeiert, bei der auch der damalige Präsident der KWG, Adolf von Harnack, zugegen war. Bei dieser Veranstaltung wurde, wie vorgesehen, W. Hoene der Dr. h.c. verliehen. 
Hier möchte ich darauf hinweisen, daß die Verleihung eines solchen Ehrengrades an einen Industriellen durchaus eine Tradition hatte. So war Klein grundsätzlich der Auffassung gewesen, wenn er einen reichen Industriellen dafür gewonnen hatte, der Universität zum Bau eines neuen Institutes Geld zu spenden, ihm dann für seine Verdienste um die Wissenschaft einen Ehrengrad zu verleihen. Obwohl man in der Zwischenzeit in einer Fakultätssitzung gegen diese Regelung abgestimmt hatte, wurde von den Mitgliedern der gleichen Fakultät die Annahme dieser von Hoene gestellten Forderung durch Mehrheit beschlossen.

Präsident von Harnack übergab Professor Prandtl das neue Kaiser-Wilhelm-Institut mit folgenden Worten:

"Wir suchen mit großer Sorgfalt einen guten Forscher. Wenn wir ihn gefunden haben, lenken wir Ströme des Wohlwollens auf ihn hin, beschaffen ihm möglichst reichliche Geld- und Forschungsmittel und überlassen es dann ihm, damit zu machen, was er für richtig hält." 


\section{Das neue Kaiser-Wilhelm-Institut}

Der Aufgabenkreis der Anstalt war, wie schon erwähnt, außerordentlich erweitert worden. Hatte sie in den Kriegsjahren vor allem für Untersuchungen an Flugzeugen gedient, so untersuchte man jetzt wiederum auch den Winddruck auf eiserne Brücken, elektrische Leitungen und Hochbauten, um daraus zu lernen, wie man diese Bauten durch größere Stabilität vor Sturmschäden bewahren könne. "Die bisherigen baupolizeilichen Vorschriften sind veraltet und bedürfen dringend einer Erneuerung", schrieb ein einsichtsvoller Journalist.

Der neue Kanal von vier Metern Durchmesser ermöglichte es, daß nun auch größere Teile im Luftstrom exprobt werden konnten. Zum Beispiel konnte man Windmühlenflügel in ihrer natürlichen Größe hineinhängen. Man stellte sich die Frage, wie diese in ihrer Form verbessert werden könnten, um die Energie des Windes voll zu nutzen. Bei dieser Vielzahl von Forschungsthemen, die in den verschiedenen Institutsgebäuden bearbeitet wurden, war es notwendig geworden, daß sich nunmehr zwei Direktoren die Leitung teilten, Ludwig Prandtl und Albert Betz. Letzterer wurde stellvertretender Direktor des Instituts und übernahm die selbständige Leitung der Aerodynamischen Versuchsanstalt, Prandtl hingegen hatte die Gesamtleitung und widmete sich hauptsächlich dem neuen Institut für Strömungsforschung. Das Personal bestand im November 1926 aus 55 Mitarbeitern.

Auswärtige Kollegen wurden durch die neuen Versuchs- und Arbeitsräume geführt und trugen sich dann im Direktorzimmer in das neue Fremdenbuch ein. Auch meine Mutter und wir Kinder durften uns einmal dort umschauen und die hübschen Modelle im Windkanal bewundern. Eine neue Versuchsanlage wurde uns gezeigt, die uns besonders gefiel: das rotierende Laboratorium. Es war für Modellversuche gedacht, die im Kleinen die großräumigen Strömungsvorgänge auf der Erde nachbilden sollten. Während der Drehbewegungen wurde das Verhalten von Flüssigkeiten untersucht [25]. Für uns Kinder war es eine besondere Attraktion, dort einzusteigen und wie in einem Karussell einige Runden herumgedreht zu werden. Dr. Busemann, der dort seine wissenschaftlichen Spezialarbeiten ausführte, war so freundlich, uns viele Male mitfahren zu lassen. Von der Außenwelt war man durch die Wände abgeschlossen. Man hatte sich nämlich klargemacht, daß das Schwindelgefühl ja hauptsächlich 
durch das Vorübergleiten der feststehenden nahen Gegenstände erzeugt wird. Doch auch in dem geschlossenen Laboratorium waren wir bei höherer Drehzahl nicht gänzlich schwindelfrei, wie es Dr. Busemann selbst war, der sich durch ständiges Training daran gewöhnt hatte. Unser Vater, der auch mit eingestiegen war, belehrte uns, wie die Körperbewegungen durch Zentrifugalkraft nach der einen Seite gehemmt und in der anderen Richtung beschleunigt würden. Wir versuchten, unseren Arm mit aller Kraft gegen die Fahrtrichtung zu drehen, es war unmöglich, und zwar solange, bis die Geschwindigkeit wieder heruntergeschaltet wurde. Glücklich und bereichert durch diese besondere Erfahrung stiegen wir endlich aus. Jetzt gingen wir in das Gebäude, in dem sich die Windkanäle befanden. Unter Vaters Führung fühlten wir uns in den großen Räumen gleich sehr zu Hause. Der Größe nach wurden alle Kanäle durchprobiert. Vaters Anliegen, uns Kinder recht gut zu amüsieren, war wirklich rührend. Ein anderer hilfsbereiter Assistent begleitete uns und stellte je nach Wunsch an den Schalttafeln das Gebläse ein. Es war köstlich, bei kräftigem Wind in der Öffnung des Rohres zu stehen, die Haare wehten und die Röcke flatterten. Man konnte sich vorstellen, auf einem Schiff zu stehen, und das erfrischende bewegte Element schlug einem entgegen, es berauschte uns. Dann war plötzlich die Windstärke so sehr angewachsen, daß man nur mit Not zwischen den Rohren hindurchgehen konnte. Man fühlte genau, noch etwas mehr Winddruck und es würden unsere Füße nicht mehr am Boden haften, man wäre an die Wand gepustet worden. Zum Schluß gingen wir noch zu dem damals größten Windkanal, in dem verschiedene Modelle an Fäden befestigt herabhingen. Sie wurden für einen Augenblick herausgenommen, und dann wurden alle Schalthebel gedrückt. Diesmal begnügten wir uns mit dem grandiosen Lärm, den das Gebläse bei voller Kraft verursachen konnte. Die entfesselten Kräfte wurden sehr schnell wieder beruhigt und besiegt. Wie sehr hatte uns schlieBlich auch diese imponierende Lärmanlage gefallen!

Ich berichtete am nächsten Tag ausführlich meiner Freundin, Lilli Misch, von dem ungewöhnlichen Vergnügen; und da unsere Volksschule auf der Bürgerstraße nicht allzu weit erntfernt von der Böttingerstraße lag, beschlossen wir beiden kleinen Mädchen, direkt nach Schulschluß noch ein bißchen Karussell zu fahren. Aber das Unternehmen glückte nicht. Dort angekommen, erklärte ich an der Pforte, meinen Vater sehen zu wollen. Er war nicht in seinem Direktorzimmer, nicht in seinem Institut, sondern in einem anderern Gebäude. Man suchte ihn, und es dauerte eine ganze Weile 
bis er kam. Er lächelte verlegen, als er uns sah, aber mit großer Entschiedenheit schickte er uns dann nach Hause. Er hatte keinen Ärger gezeigt darüber, daß wir ihn von seiner Arbeit weggeholt hatten, aber ich hatte erlebt, daß er für mich auf einmal unerreichbar geworden war, und dies war schwer zu begreifen. Auch meine Freundin, die jetzt in Amerika lebt, erinnert sich noch genau an unser Vorhaben und die alles beendende Szene. Hätte meine Mutter von unserem Plan gewußt, hätte sie uns selbstverständlich zurückgehalten. Nie hat sie ihren Mann von zu Hause aus im Institut angerufen, so sehr respektierte sie seine Arbeitswelt dort. Sie wußte, daß erimmer übermäßig beschäftigt war und für das Gedeihen der Anstalt mit ihren verschiedenen Forschungsaufgaben ständig seine ganze Arbeitskraft einsetzte.

Jahr für Jahr gab es von nun an auch ein Betriebsfest für die Institutsbelegschaft, das man in einem ländlichen Gasthaus feierte. Die jungen Leute schätzten die Gelegenheit des abendlichen Tanzvergnügens. Zuvor sorgten Teilnehmer mit allerhand witzigen Einfällen für anregende Unterhaltung. So hatte man einmal das Programm für den geordneten Ablauf der Darbietungen auf den einzelnen Tischen ausgelegt - allerdings war auf Prandtls Liste absichtlich eine Nummer ausgelassen worden. Bei den anderen stand nämlich bei Punkt 3: "Prandtl spielt!". Geschickt mußte nun jemand, während Prandtl selbst eine kleine Rede hielt, eine Art technisches Spielzeug unbemerkt auf den Tisch bringen. Man war natürlich gespannt. Und der Spaß gelang. Prandtl, angezogen durch die unbekannten Gegenstände, griff unwillkürlich dananch und fing an, spielend damit zu experimentieren. Inzwischen waren alle von den anderen Tischen herangekommen, um aus nächster Nähe zuzusehen. Nun aber merkte Prandtl, daß er mit seiner Vorliebe für spielerische Betätigung "überführt" worden war und er beendete darauf lachend die unbeabsichtigte Vorführung.

Es waren trotz des immer vollbesetzten Arbeitsprogramms besonders glückliche Jahre für den Chef der neuen Forschungsanstalt. Aus dieser Zeit ist noch eine Erinnerung festgehalten von Frau Margarethe Winter, geb. Weppner, zu lesen in den Göttinger Monatsblättern:

"Ich kann noch von einer netten Unterhaltung berichten, die ich einmal mit dem berühmten Professor Prandtl hatte. Zufällig verließen wir zusammen die ehemalige AVA an einem schönen Frühlingstag. Professor Prandtl verspürte Lust, noch einen 
kleinen Spaziergang zu machen, und meinte, ob ich ihn noch etwas begleiten wollte. So wanderten wir zusammen, und dabei bemerkte er, daß ich etwas gehbehindert war, ich hatte gerade eine Venenentzündung hinter mir. Da sagte er spontan, das sei ja eigentlich auch eine "Strömungsangelegenheit" in den Blutbahnen, über die er einmal nachdenken wolle, da müßte er sich vielleicht mal mit einem Arzt zusammensetzen. Leider sind wir später nicht mehr auf dieses Thema zurückgekommen." 


\section{Reise nach London}

Das besondere Ereignis im Jahr 1927 war eine Reise nach London, wo Prandtl die Wilbur Wright Memorial Lecture vor der Royal Aeronautical Society halten sollte. Ungefähr anderthalb Jahre zuvor hatte er begonnen, im Privatunterricht Englisch zu lernen, unterstützt von seiner Frau Gertrud, die gut Englisch sprach. Es war ihm lange schon ein Hindernis gewesen, daß er sich die Veröffentlichungen aus England und Amerika übersetzen lassen mußte, obwohl ihm natürlich die Fachausdrücke darin verständlich waren. Seine sehr fähige Lehrerin, Beatrice Dammers (Mutter war Engländerin), förderte ihn nach besten Kräften. Es ist erstaunlich, wie er bei seinem sonstigen Arbeitspensum die Sprache, die er auf der Schule nicht gelernt hatte, nun in so kurzer Zeit so weit beherrschte, daß er seine gut vorbereitete "Lecture" dann in London auf Englisch vortragen konnte.

Die Zeitungen sowohl in England wie in Deutschland verfolgten seine Reise: 9.5.1927 Daily Chronicle:

"England to honour German Professor. A quiet retiring German, who cares nothing for ceremony or fame, but who is acclaimed the greatest living authority upon aerodynamics, is coming to London this week to receive from England an air honour, which in all the history of flying has only be given to six men. This famous scientist is Professor L. Prandtl of Göttingen University and the coveted distinction to be conferred upon him is the Gold Medal of the Royal Society.

Previous recipients have been:

1909 The Wright Brothers

1910 Professor Chanute

1915 E. T. Busk and Professor G. Bryan

1926 Professor Lanchester."

Diese Ankündigung machte publik, daß Prandtl die außergewöhnlich hochgeschätzte Medaille persönlich in Empfang nehmen würde.

$\mathrm{Zu}$ dem Flug Hannover-London mit einer Deutschen Lufthansa-Maschine muß noch berichtet werden, daß dies Prandtls erste Flugreise war; für ihn ein ganz besonderes Erlebnis. Er hielt seine Beobachtungen in kleinen Stichworten fest, mit genauer Zeitangabe: 
"Donnerstag, 12. Mai 1927:

4.58 Rotterdam, die Rheinmündung, Sonne

(Es ist nachmittags, man würde heute 16.58 Uhr angeben)

5.14 über See, Ebbe

5.25 Große Hafenstadt

5.56 Seekanal mit Stadt

6.06 Großer Seehafen (Dünkirchen)

6.20 über See, sehr diesig

6.27 letztes Land quer ab, Flugzeug liegt völlig ruhig in der Luft

6.35 Land in Sicht, Hafen, Steilküste."

Göttinger Zeitung, 14. Mai 1927:

"Professor Prandtl in London"

Wie aus I.ondon gemeldet wird, traf dort vorgestern abend im Flugzeug aus Deutschland Professor Prandtl von der Göttinger Universität ein. Professor Prandtl wird die höchste Auszeichnung, die die britische Luftfahrt bieten kann, nämlich die goldene Medaille der Kgl. Aeronautischen Gesellschaft verliehen werden."

Daily Telegraph 14. Mai 1927.:

"Professor Prandtl arrived in London by air on Thursday night. In conversation with the press representative yesterday he said: 'It is a great honour the Royal Aeronautical Society are about to bestow on me and nobody realizes it more than myself. If I have been able to throw new light on the science of aeronautics, that in itself is sufficient reward for me. The Gold Medal of the Royal Aeronautical Society is more than I ever dreamed I should receive, even in my most ambitious moments".

Am Montag, den 16. Mai hielt Prandtl in London die gewichtige "Lecture" [32].

Am 17. Mai schreibt ihm der Colonel Forbes-Sempill (Flieger und Flugsachverständiger), Chairmann of the Royal Aeronautical Society:

\section{"Dear Professor Prandtl!}

First of all, I want to take the opportunity of thanking you in the most sincere manner possible for your wonderful Lecture, illustrated by the most remarkable series of 
slides and cinematograph films, that have ever been the good fortune of the Society to see. Your Lecture has aroused the greatest possible interest und we are already receiving demands for the Society's Journal in which it will be reproduced."

Aus der "Morning Post":

"Colonel Master of Sempill, Chairman of the Royal Aeronautical Society, said yesterday, 'but we have chosen a German this time because Professor Prandtl is, in our opinion, and in the opinion of all people who are competent to judge, the greatest authority on the scientific side of aeronautical science. He has particularly distinguished himself by propounding what is commonly known as the Prandtl boundary layer. By his years of experimenting he has given us an insight, denied to the greatest men of science in the past, of what happens to the air surrounding an aeroplane in flight."

Darauf folgte in der Göttinger Zeitung ein Artikel am 18. Mai:

"Wie Wolffs Telegraphenbüro berichtet, hielt Professor Prandtl von der Göttinger Universität am Montag in London vor der königlichen aeronautischen Gesellschaft einen Vortrag, der besonders deshalb große Beachtung findet, weil der deutsche Gelehrte, nach einstimmiger Ansicht aller britischen Wissenschaftler eine führende Autorität auf dem Gebiete der Wissenschaft, als erster Nicht-Engländer oder NichtAmerikaner eingeladen wurde, einen Vortrag, der der Form nach ein Wilbur-WrightGedächtnisvortrag ist, zu halten. Die königlich aeronautische Gesellschaft betont in ihrer Einladung zu diesem Vortrag, daß ebenso, wie die Gebrüder Wright zum ersten Male ein praktisches Fliegen möglich machten, Professor Prandtl es ermöglicht hat zu verstehen, wie und warum die Luft die im Flug befindlichen Flugzeuge hält. Wie bereits gemeldet, wird Professor Prandtl heute die Goldene Medaille der aeronautischen Gesellschaft überreicht, die bisher erst sechs Männern vor ihm verliehen ist."

$\mathrm{Da} ß$ ich hier so viele Bestätigungen der besonderen Ehrung angeführt habe, sollte auch aus der Situation jener Nachkriegszeit verstanden werden. Die meisten Engländer betrachteten die unliebsamen Deutschen weiterhin mehr als kritisch. Daß der Air-Vizemarschall, Sir Sefton Brancker, bei der Gedächtnisvorlesung in seinen Begrüßungsworten Prandtl als "den bedeutenden Angehörigen einer großen Nation" bezeichnete, machte ihm ohnehin bewußt, daß er nun nicht nur vor dem Forum der 
Wissenschaftler stand, sondern auch als Deutscher sein durch die Siegermächte gedemütigtes Vaterland zu vertreten hatte. In der Heimat registrierte man diese Anerkennung mit Genugtuung.

Es muß hier noch erwähnt werden, daß der englische Professor Lanchester, einer der früheren Preisträger, sich mit den gleichen Problemen wie Prandtl befaßt hatte. Um keinen Zweifel aufkommen zu lassen, daß Prandtl seine Theorie, die Tragflügeltheorie, in eigener Arbeit und Intuition geschaffen hatte, äußerte sich letzterer auf der Tagung in London wie folgt:

"In England bezeichnet man die Tragflügeltheorie als Lanchester-Prandtl-Theorie, und das ist recht so, denn Lanchester erzielte unabhängig von mir einen wichtigen Teil der Ergebnisse. Er fing früher an, über diesen Gegenstand zu arbeiten, als ich. Diese Tatsache ließ die Meinung aufkommen, Lanchesters Untersuchungen, wie er sie 1907 in seinem Buche "Aerodynamics" veröffentlichte, hätten mir die Gedanken eingegeben, auf welchen die Tragflügeltheorie aufbaut. Das ist aber nicht der Fall. Die grundlegenden Ideen der Tragflügeltheorie, soweit diese Ideen in Lanchesters Buch behandelt sind, hatte ich schon erfaßt, bevor ich sein Buch zu sehen bekam. Zur Bekräftigung dieser Ansicht darf ich darauf hinweisen, daß Lanchester und seine Bedeutung in Deutschland eher verstanden wurde als in England. In Wahrheit liegt die Sache aber so, daß Lanchesters Abhandlung sehr schwierig zu verstehen ist, weil sie hohe Anforderungen an des Lesers intuitive Vorstellungsgabe stellt. Nur weil wir schon in ähnlicher Richtung gearbeitet hatten, waren wir in der Lage, sofort zu erfassen, was Lanchester meinte. Wie dem auch sei, deutlich möchte ich aussprechen, daß Lanchester in vielen speziellen Fragen andere Wege ging als wir, Wege, die für uns neu waren und uns viele wertvolle Fingerzeige gaben."

"Prandtl brachte die angedeuteten Ideen in ein geordnetes System und vereinfachte das Bild der Wirbelanordnung."1)

1947 hat sich Prandtl noch einmal zu diesem Problem geäußert [31]: "Vielleicht ist die Bemerkung nicht ohne Interesse, daß auch hier mich ein Widerspruch zu der ersten Beschäftigung mit der Theorie des Tragflügels angeregt hat. Es handelt sich um eine

1) Theodore von Kármán, Aerodynamik [14]. 
irrige Vorstellung von dem Wirbelsystem des Tragflügels in dem sonst verdienstvollen Buch von F. W. Lanchester (Übersetzung von C. und A. Runge, 1909)."

Prandtl blieb noch eine Woche in England und leistete den verschiedensten Einladungen Folge. Er besuchte auch noch seinen englischen Kollegen, Professor G. I. Taylor, in Cambridge, mit dem ihn dann jahrelang eine herzliche Freundschaft verband.

Zurückgekehrt, erwarteten ihn viele Glückwünsche. Zum Semesterende ehrten ihn die Studenten mit einem Fackelzug.

Göttinger Zeitung, 14. Juli 1927 "Fackelzug der Studentenschaft, Ehrung für den Aerodynamiker Professor Prandtl, dem kürzlich in London die höchste Auszeichnung für die Verdienste um die Luftfahrt verliehen wurde. Der Zug bewegte sich zur Calsowstraße 15. Es wurde eine feierliche Ovation dargebracht. Ein Vertreter der Studentenschaft hob in einer Ansprache die Verdienste Professor Prandtls um die Luftfahrt und damit um die Kultur der Menschheit hervor: 'Seinen Forschungen verdanken wir die Kenntnis des Fluges. Die Welt schaut auf Deutschland, auf unser kleines Göttingen, auf den verdienstvollen Gelehrten. Die Göttinger Studentenschaft ehrt den Lehrer durch ein donnerndes Hoch!' Es erklingt: 'Vivant professores!'

Mit der Bescheidenheit des echten Gelehrten versuchte nunmehr Professor Prandtl, als er der Studentenschaft dankte, seine Verdienste so darzustellen, als hätten sie eigentlich nicht viel zu bedeuten. Das Hauptverdienst hätte der verstorbene Professor Felix Klein, dem wir unser Aerodynamisches Institut verdanken. Außerdem sei der Anteil seiner Mitarbeiter sehr groß. So sehr wir aber die Bescheidenheit Professor Prandtls zu ehren wissen, wir halten doch daran fest, daß der Hauptteil ihm zufällt. Wie zu der guten Geige der Künstler so gehört eben zum Aerodynamischen Institut Professor Prandtl, um das zu leisten, was tatsächlich geleistet worden ist. Professor Prandtl schloß seine Ansprache mit einem Hoch auf das Deutsche Vaterland. Es wurde das Nationallied angestimmt. Dann marschierte der Zug zum Theaterplatz, wo die Fackeln zusammengeworfen wurden."

Ich erinnere mich noch gut an diesen Abend. Wahrscheinlich hatte ich schon ein Weilchen geschlafen, als ich ins Wohnzimmer geholt wurde. Es war wundervoll, oben 
von den geöffneten Fenstern auf die große Gruppe der Fackelträger, die sich vor dem Haus postiert hatte, herabzuschauen. Mein Vater stand dort am Mittelfenster, den Oberkörper ein wenig vorgebeugt, und hielt sich mit den seitlich ausgestreckten Armen am Fensterholz.

Der Student, der damals die Ansprache hielt, war Gustav Messmer. Er machte später seinen Doktor bei Prandtl. 1939 bekam er einen Ruf an die Technische Hochschule in Darmstadt als Professor für angewandte Mathematik, wo er bis 1949 blieb. 1947 bis 1949 wurde er zum Rektor der Technischen Hochschule Darmstadt ernannt. 1952 folgte er einem Ruf an die Washington University in Amerika, wo er 1981 verstarb.

Im Institut gab es einen Personalwechsel, von dem ich berichten möchte: An der Schreibmaschine, in einem Raum neben dem Direktorzimmer, saß eine neue Sekretärin, die am 19. Mai, direkt nach der Rückkehr ihres neuen Chefs aus London, ihren Dienst angetreten hatte. Es war Fräulein Eleonore von Seebach. Durch Bekannte war sie auf die frei werdende Sekretärinnen-Stelle aufmerksam gemacht worden - so wie es damals üblich war. Fräulein von Seebach erzählte mir, daß Prandtl gleich bei der Vorstellung ein Diktat verlangt hatte, um sich zu überzeugen, ob die Fähigkeiten der jungen Dame seinen Ansprüchen genügen würden. Dann bekam sie die Aufforderung, die Stelle zu dem besagten Zeitpunkt anzutreten, mit dem Vorbehalt einer Probezeit. Sie ist dann 43 Jahre als Privatsekretärin in dem Institut für Strömungsforschung geblieben, über Prandtls Tod hinaus. Auch Prandtls Nachfolgern stand sie als erfahrene Sekretärin zur Verfügung.

Sie erzählte mir, an die Anfangszeit erinnere sie sich noch lebhaft. Prandtl diktierte ins Stenogramm und unterlie $B$ es nicht, an dem fertigen Brief dann noch stilistisch herumzufeilen, ehe er getippt werden durfte. Die Korrespondenz blieb niemals liegen, er erledigte die Antworten schnell und sachlich. Wenn man einmal nicht gleich verstand, was er gemeint hatte, äußerte er sich ziemlich mißvergnügt. Begriffsstutzigkeit konnte er nicht gut vertragen. Ansonsten hatte er sehr viel Geduld und Ruhe beim Diktieren. Fräulein von Seebach paßte sich seinem Stil in hervorragender Weise an, so daß damit für ihren Chef eine vorzügliche Zusammenarbeit gewährleistet war. Darüber hinaus hielt sie sich bereit, für die Assistenten wissenschaftliche Arbeiten zu schreiben. Auch das von Prandtl verfaßte Buch "Führer durch die Strömungslehre" 
[27] hat sie im Diktat geschrieben. Sie erinnert sich auch noch an die selbstherrlichen Briefe von Erfindern, auf die Prandtl geduldig und in aller Klarheit antwortete, die aber, enttäuscht darüber, nicht anerkannt zu werden, hartnäckig ihre Dinge von neuem vorstellten, weil sie dem Gedankengang des Professors, der ihnen den Fehler in ihrem Denkgebäude nachwies, oft gar nicht verstanden hatten. Dann mußte der Beweis irgendeines Trugschlusses noch detaillierter erbracht werden. 


\section{Japanreise}

Als mein Vater die Vorbereitungen für die nächste große Reise traf, nahmen wir Töchter, nun 12 und 14 Jahre alt, lebhaft daran teil. Es war eine Weltreise, die über ein halbes Jahr ausgedehnt werden sollte. Hauptanlaß war eine Einladung aus Japan. In Tokio soltte ein Kongreß stattfinden. Daran anschließend ließ sich eine Reise durch Amerika planen, wo Prandtl verschiedene Universitäten besuchen wollte.

Große Überseekoffer kamen ins Haus, und meine Mutter sorgte für die Neuanschaffung von Kleidung. Sie hätte ihren Mann auf dieser interessanten Reise begleiten sollen, aber der Gedanke, uns beiden Töchter so lange allein zu lassen ohne ihre mütterliche Fürsorge, schien ihr unausdenkbar.

Eine Japanreise war im Jahre 1929 ein viel sensationelleres Unternehmen, als es das gegenwärtig ist. Heute ist eine Flugreise dorthin nichts Ungewöhnliches mehr. Damals mußte man auf dem Landweg über Rußland dorthin gelangen, Flugverbindungen über so weite Entfernungen gab es noch nicht.

Zu seinem Reisegepäck gehörte auch eine Leica, damals das beste Fotogerät. Er stellte sich vor, daß er dann später anhand der Bilder seine Erinnerungen würde auffrischen können. Am 13. September verließ er Göttingen und fuhr nun immer nach Osten. Meine Mutter erhielt zahlreiche Briefe, die er während seines langen Fernbleibens an sie absandte. Er hat diese Sendungen von Anfang an numeriert und ist bis über 70 gekommen.

Bevor ich aus diesen Briefen besondere Erlebnisse mitteile, möchte ich einen Zeitungsartikel auszugsweise wiedergeben, in dem mein Vater, gerade heimgekehrt, den Journalisten eine Zusammenfassung seiner Reiseeindrücke vermittelt hat.

März 1930 - Interview mit Professor Prandtl:

"Eindrücke und Erlebnisse auf seiner Fahrt nach Japan und Amerika: Wie wir schon kurz gemeldet haben, ist der bekannte Göttinger Aerodynamiker Professor Dr. Prandtl am 5. März nach Göttingen zurückgekehrt, nachdem er nahezu ein halbes Jahr auf Reisen war und dabei den Erdball umfahren hat. In einem unserem Vertre- 
ter liebenswürdigerweise gewährten Interview gab Professor Prandtl einen Überblick über seine Reiseeindrücke, der im folgenden zusammengefaßt wurde:

'Das eigentliche Ziel meiner Reise, die mich durch Rußland, Japan und Amerika führte, war Tokio. Hier tagte Ende Oktober, Anfang November vorigen Jahres der Welt-Ingenieur-Kongreß, an dem teilzunehmen ich dringend eingeladen war. Es lag natürlich nahe, dabei die Gelegenheit nicht ungenützt verstreichen zu lassen, andere Länder kennenzulernen und hier, wo immer es möglich war, allgemeine und fachwissenschaftliche Studien zu treiben. Dadurch wurde die Reisezeit entsprechend länger. Sie begann am 13. September und führte mich mit der Bahn zunächst nach Moskau. Hier wurden verschiedene Institute besichtigt. Die gute Einrichtung dieser Anstalten war erstaunlich. Zur Zeit sind neue große Versuchseinrichtungen im Bau. Trotz der schwierigen Lage tut die Sowjetregierung sehr viel für alles, was dem Fortschritt der Technik dient.

Von Moskau ging es zehn Tage lang mit der sibirischen Bahn dem fernen Osten entgegen. Auch diese Bahn machte einen sehr soliden Eindruck. Die Strecke, die Wagen und die Maschinen waren in tadelloser Verfassung, und wir kamen mit einer Verspätung von nur drei Stunden in Wladiwostok an. Ursprünglich ging mein Plan dahin, durch China zu fahren, aber durch das russisch-chinesische Zerwürfnis ist diese Reiseroute gesperrt.

Nun also Japan: Das ist nun ein Land, dessen rascher Aufschwung einem auf Schritt und Tritt klar wird. Eine kolossale industrielle Entwicklung macht sich im ganzen Lande bemerkbar. In keinem Land ist soviel elektrifiziert worden wie hier. Jedes Dorf in Japan hat elektrischen Anschluß. Diese Entwicklung ist umso erstaunlicher, als vor sechs Jahren das große Erdbeben dem Lande einen Riesenschaden zufügte. Große Städte sind völlig neu aufgebaut worden oder werden es zur Zeit noch. Japan ist ein Land mit einer ganz hohen Blüte der einheimischen Kunst. Herrliche Sachen stehen überall zum Verkauf, und man hat seine helle Freude daran.

Der Kongreß selbst, der ja das eigentliche Ziel meiner Reise war, war von den Japanern gut organisiert worden. Die Teilnehmerzahl war groß; aus Deutschland waren allein 30 Vertreter nach Tokio gefahren, dazu kamen etwa noch 30 Ingenieure, die in Japan arbeiten. Amerika war mit 200 Teilnehmern vertreten. Von der Gastfreundschaft der Japaner läßt sich nur Rühmenswertes berichten. Die Kongreßmitglieder wurden sehr verwöhnt, man wurde dauernd eingeladen, und Feste wurden veranstaltet." 
Damals gab es ja noch das alte Nippon. Die Wende kam erst Anfang der dreißiger Jahre, als die modernen Anschauungen des europäischen Westens anfingen, das ganze Leben des fernöstlichen Inselreiches zu beeinflussen.

"Die wissenschaftlichen Institute machten einen guten Eindruck. Auch die Aerodynamik wird sehr gepflegt, Windkanäle sind in größerer Anzahl als bei uns vorhanden.

Nach einem Aufenthalt von vier Wochen, der neben den speziellen wissenschaftlichen Studien dem Kennenlernen dieses interessanten Landes gewidmet war, ging es nun über den großen Ozean nach Amerika, wo ich zweieinhalb Monate blieb.

Besonders interesssierten mich natürlich die Institute der Luftfahrt.

Im allgemeinen fand ich auf den Hochschulen nicht sehr viel mehr Einrichtungen, als wir sie in Göttingen auch besitzen, nur daß sie in einer größeren Zahl von Universitäten vorhanden sind. Es gibt nämlich an vielen Universitäten Speziallaboratorien für Flugtechnik. Sie haben Windkanäle meist bis zur Größe des Göttingers und kleinere. Ganz hervorragend ist das Staatslaboratorium in Langley Field bei Washington. Hier wird vorzüglich gearbeitet, und wir finden zum Teil auch Einrichtungen vor, die weit über das hinausgehen, was wir in Europa haben. Da ist zum Beispiel ein Windkanal, der einen Durchmesser von sechs Metern hat. Ganze Flugzeuge kann man hineinstellen und so bessere Studien an Propellern und Motoren machen.

Die landschaftlichen Bilder? Sie waren natürlich sehr verschieden. In der sibirischen Steppe: nichts wie Gras und dann wieder niedrige Birkenwälder, in der amerikanischen Steppe ungefähr das gleiche, nur andere Baumarten. Es gibt Strecken, wo viele Morgen Weideland nötig sind, um eine einzige Kuh zu ernähren. So spärlich wächst dort das Gras. Ganz anders war es natürlich in Japan mit seinen Reisfeldern und bunten Tempeln.

Liebende Hände hatten die Tür seines Arbeitszimmers im Aerodynamischen Institut umkränzt, als er zurückkehrte, und das Zimmer, in dem er mich empfing, war voller bunter Blumen. Und das hat dem so Geehrten sicher die gleiche Freude, wenn nicht eine größere, bereitet als die Blumengeschenke, die ihm auf seiner Reise verehrt worden waren." (Ende des Berichts vom Interview)

Das Erlebnis der Weltreise erscheint mir so wesentlich im Leben Prandtls gewesen zu sein - eine Zeit voll der ungewöhnlichsten Eindrücke, zudem ausreichend Muße zu 
vielerlei Betrachtungen - daB ich den Verlauf dieser Reise anhand seiner Briefe noch einmal aufnehmen möchte.

Die erste Station war Berlin, wo er mit Professor Nägel aus Dresden, ebenfalls ein Kongreßteilnehmer, zusammentraf und in dessen Begleitung nun weiterreiste.

15. September 1929: "Nach 40stündiger Eisenbahnfahrt kamen wir beide heute um 11 1/2 Uhr in Moskau an. Beim Aussteigen schon wurden wir geknipst und gefilmt. Dann ging's mit Auto zu einer kleinen Rundfahrt mit prachtvollen Straßenbildern: einem Propagandazug von Schulkindern mit Aufschriften auf roten Schildern; dann zur Erlöserkirche, wo gerade eine feierliche Messe mit Priester und Chorgesang war, dann weiter um den Kreml mit seinen vielen Türmen zum Hotel, wo ich nun ein prachtvolles Zimmmer mit Bad bewohne. Der heutige Empfang und der erste Eindruck von der Stadt mit den kaleidoskopartig wechselnden Bildern wird mir wohl immer in Erinnerung bleiben."

Er hielt drei Vortäge in Moskau, wurde eingeladen vom deutschen Botschafter, wohnte einer Vorstellung des Bolschoi-Balletts bei, besichtigte die Bildergalerie Tretjakoff und das Revolutionsmuseum.

Am 29. September begann die lange Fahrt durch Sibirien im plombierten Eisenbahnzug.

29. September:

"Heute früh ging es über den Ural, ganz flacher Höhenrücken, ca. $400 \mathrm{~m}$, überwiegend mit Birkenwäldern bestanden."

2. Oktober: "Nun sind wir 4 mal 24 Stunden auf der Bahn und haben bald die Hälfte der Bahnfahrt hinter uns. Die Uhren zeigen hier bereits 5 Stunden früher als in Deutschland an. Gestern abend gegen $10 \mathrm{Uhr}$ fuhren wir über den Ob bei der Stadt Nowosibirsk. Es ist ein ganz gewaltiger Strom, wie es in Deutschland keinen gibt. Tausend Lichter der größten Stadt Sibiriens und zwei hellerleuchtete Dampfschiffe spiegelten sich in ihm." 
2. Oktober: "Heute morgen sahen wir in der Ferne Berge, ähnlich dem Schwarzwald. Die Wälder mit dem Goldgelb der Lärchen und dem Grün der Kiefern, dem Graugelb des verwelkten Grases sind besonders im Frührot der aufgehenden Sonne sehr schön."

3. Oktober: "Das Erlebnis dieses Tages war der Baikalsee. Die Bahn fährt etwa sechs Stunden an ihm entlang. Aber leider war es nachts ein Uhr, als wir an ihn kamen. So haben wir nur von 5 1/4-3/4 7 Uhr im Morgengrauen und bei aufgehender Sonne die Landschaft genießen können. Der See zeigte Brandung mit großen Schaumkämmen. Das Wasser dunkelgraugrün, der Himmel mit dunkelgrauen Wolken, die Berge am Ufer vom Morgenrot beschienen. Von 7 bis 9 Uhr haben wir noch einmal geschlafen."

6. Oktober: "Dies ist die letze Karte aus der sibirischen Bahn. Heute um 2 Uhr mittags fuhren wir auf einer Brücke, die mehr als $1 \mathrm{~km}$ lang ist, über den Amurstrom. Von $1 / 23$ bis 3 Uhr waren wir in Chabarowsk, einer bedeutenden Handelsstadt. Die Gegend ist dort recht reizvoll, die blauen Berge gegenüber gehören bereits zu China. Man sieht auf den Bahnhöfen viele chinesische Gesichter, meist Arbeiter, zum Teil europäisch gekleidet, zum Teil in phantastischen Lumpen. Die ganze Reise von Moskau an ist übrigens $9330 \mathrm{~km}$."

7. Oktober, Wladiwostock: "Die Hotels sind überfüllt, da man auf den großen Verkehr, der jetzt durch Sperrung der chinesischen Bahn hierher geht, nicht eingerichtet ist. Wir hatten unglaubliches Glück; Nägel entdeckte das Auto des deutschen Konsulats. Nach einigem Warten erschien der Konsulatssekretär, an den wir aus der russischen Botschaft in Moskau Grüße zu bestellen hatten, und ließ unser Gepäck zunächst ins Konsulat schaffen. Als wir da nun saßen, kam überraschend die Einladung der Frau Konsul, bei ihnen zu wohnen."

Von Wladiwostock erreichten sie dann Japan in einer mehrtägigen Schiffsreise. Am 11. Okober wurden sie in Kobe gastlich empfangen. Herr Professor Wieselsberger, der frühere Assistent aus Göttingen, und Herr Takao, Direktor einer Flugzeugfabrik, waren gleich an Bord gekommen, um die beiden Herren zu begrüßen. 
12. Oktober: "Heute nun etwas ganz Besonderes: Herr Takao hat uns zu einem Ausflug mit japanischen Damen zum Pilzsuchen und -essen eingeladen. Dazu mietet man sich in den nahen Bergen einen Platz, auf dem viele Pilze wachsen und der abgesperrt ist, damit nicht andere die Pilze wegnehmen. In vier Autos zog man dorthin. Zunächst am Treffpunkt der Autos an einem Flußufer, umständliche Begrüßung der Herrschaften untereinander, mit je drei ganz tiefen Verbeugungen. Dann ging's noch einmal mit dem Auto weiter, dann eine Viertelstunde zu Fuß auf einen kleinen Berg, wo nun die Pilze waren (andere als bei uns). Jeder bekam einen Korb, und nun wurde gesammelt. Inzwischen wurden kleine Kochherde aus Töpferton mit Holzkohle geheizt. Dann wurde auf diesen Herden, die auf dem Tischtuch stehen, gekocht (Hühnerfleisch, verschiedene Gemüse, quarkähnlicher Bohnenbrei, Eier) und gleich gegessen, wieder aufgelegt und gebraten. Gegessen wurde natürlich mit Stäbchen, was gut geht. Dann wurde Sake getrunken und viel photographiert. Alles in allem ein ganz reizendes Erlebnis. Nachmittags Besichtigung einer Flugzeugfabrik."

16. Oktober: "Besuch der Parkvilla des Fabrikbesitzers außerhalb der Stadt Kobe. Man fuhr in Autos dorthin. Das Haus stand in einem schönen Garten mit See und Brücken und einem kleinen Berg und mehreren kleinen Häuschen zum Teetrinken. Das Haupthaus hielten wir auch zunächst für einen großen Teesalon, es wurde uns aber versichert, daß die Familie wirklich darin wohnt. Das gänzliche Fehlen von Möbeln ist sehr eigenartig. Es werden nur Kissen und Armlehnen hingestelit, man sitzt auf dem Boden. Die Schuhe werden vor dem Haus ausgezogen. Im Garten gab's zunächst einen Tee aus Seetang; dann Händewaschen in feierlicher Weise, dann Warten in einem anderen Pavillon, bis ein Gong ertönte, dann vom Hausherrn in das Haupthaus geführt, auf den Kissen niedergelassen (in Hufeisenform). Die Damen stellten vor jeden ein Tischchen mit Speisen. Die Damen bedienten uns, aßen aber nicht mit.

Den nächsten Tag Besuch von Osaka (45 km von Kobe), hochinteressante Stadt mit Burg und Tempeln. Abends beim Generalkonsul eingeladen. Heute Ruhepause, die auch nötig ist."

20. Oktober: "Nun sind wir also in Tokio. Die letzten zwei Nächte haben wir in Kyoto, in dem berühmten Mijako-Hotel gewohnt, ein richtiges Kurhotel, am Berg hinauf gebaut. Ausblick erinnert an Baden-Baden, doch sind die Berge noch schöner. In 
Kyoto sind ganz wundervolle Tempel, von denen wir drei besichtigt haben (eigentlich hätte man mindestens zehn zu besuchen). Gegen Abend Wanderung durch die unglaublich bunten Einkaufsstraßen. Gestern waren wir in der Tempelstadt Nara, einem Wallfahrtsort mit schintoistischen und buddhistischen Tempeln, alles in einem wundervollen Park, wo ganze Rudel von zahmen Hirschen sich herumtrieben. Hier ist eine riesengroße Buddhastatue aus Bronze, wirkt sehr mächtig in der düsteren, hohen Tempelhalle.

Morgen, übermorgen und den nächsten Tag je von 2-4 Uhr meine Vorträge [38]; am Donnerstag bei Baron Schiba, der Direktor des Aerodynamischen Instituts ist."

3. November: "Die Einladungen gehen immer so weiter. Ich zähle gar nicht mehr alles auf, sondern berichte nur, daß wir zum Tee in herrlichen Gärten, zu Theateraufführungen, Lunches und Dinners, Bällen usw. eingeladen sind und sich alles in Liebenswürdigkeit überbietet. Die Vorträge treten ganz in den Hintergrund."

9. November: "Jetzt ist der Kongreß zu Ende, und wir sind heute morgen in die Tempelstadt Nikko gefahren. Ein unvorstellbarer Reichtum von Formen und Farben. Die großen Bauwerke sind über und über mit Figurenschmuck besät und durchsetzt, Figürchen bis zu Handgröße und diese wieder reizend bis ins einzelste ausgeführt. Alles in rot, grün, blau, schwarz. Das Tempelgebälk rot lackiert und geschliffen. Morgen geht's mit Autos $600 \mathrm{~m}$ hoch herauf zu einem Wasserfall und See."

11. November: "Gestern haben wir Herrn Nägel zur Bahn gebracht. Von jetzt an muß ich die Sache also alleine schaffen. Er war mir mit seiner Gewandtheit und seinen großen Sprachkenntnissen eine ganz wesentliche Stütze."

Prandtl hingegen reiste am folgenden Tag in östlicher Richtung weiter, nachdem ihm noch zum Abschied Geschenke überreicht worden waren (Anstecknadel mit Perlen und Landschaften auf Seide gemalt).

18. November an Bord des Schiffes "President Pierce": "Gestern hatten wir Montag, den 18.11, und heute noch einmal! Gestern hatten wir ihn zusammen mit den Japanern, während Ihr geschlafen habt, und heute haben wir ihn zusammen mit den Amerikanern. 
Heute hatten wir zum ersten Mal Sonnenschein, auch einen wunderschönen Sonnenuntergang. Denke Dir einen grünen Abendhimmel, ganz unten olivfarben, nach oben zu stahlgrau und darüber violett, und in den grünen Streifen zinnoberrote Wölkchen. Links ab von dieser Partie war der Himmel dunkelblau und unten weißlich und ganz am Horizont bräunlich. Später ging das Grüne in Gelb und noch später in Rot über, und nun waren die Farben ähnlich wie bei uns. Der Sternhimmel sieht hier ein gutes Stück anders aus, denk Dir den Nordhimmel ohne den großen Bären."

21. November: "Das Schiff legte für zwei Tage in Honolulu an. Wir wurden mit hawaiischer Musik empfangen. Ich ging über den Landungssteg hinaus in die große Zollhalle und wurde zu meiner großen Überraschung von einem Herrn in Empfang genommen, der fragte, ob ich Professor Prandtl sei, und der mir dann einen duftenden Kranz von Blüten um den Hals hängte. Es gibt hier eben zu allen Jahreszeiten blühende Bäume und Sträucher, und was für schöne (leuchtend gelbe, hellrote, dunkelrote, blaßlila, leuchtend rotviolett), alles Blumen, die man bei uns nicht kennt, und Früchte der verschiedensten Art. Hauptprodukte sind Ananas und Zuckerrohr. Honolulu liegt am Abhang eines riesigen Vulkans. Die Berge (Kraterrand) haben sehr interessante Formen. Ich erfuhr von meinem Begleiter, daß ich den nächsten Mittag zu einem Lunch eingeladen sei und daß ich dabei einen kleinen Vortrag halten sollte. Meine gewöhnlichen Themata waren alle ungeeignet, und so kamen wir überein, daß ich über den Segelflug sprechen sollte. Er setzte sich in sein Auto, und es ging dann hoch hinauf und durch einen $\mathrm{Pa}$ auf die andere Seite der Bergkette (in das Kraterinnere von ehemals). Die Wände fallen hier ganz stark ab, die Landschaft ist sehr romantisch, im Hintergrund das blaue Meer. Im Abendschein dann durch andere Straßen zurück.

Zum Lunch etwa 20 Herren, ein sehr schönes Clubhaus, eine Ansprache des präsidierenden Herrn, in der er mich begrüßte. Dann kam mein Speech, das erste Mal englisch frei gesprochen."

Als das Schiff nach zwölf Tagen mit der Landung in San Francisco amerikanischen Boden erreichte, begann für Prandtl die amerikanische Vortragsreise, die ihn durch viele bekannte Universitätsstädte führte. Nach einem Aufenthalt in Pasadena folgten einige Tage in Urbana, dann machte er Station in Chicago, Detroit, Wrightfield, Washington, Ann Arbor, New York, Boston, um überall Vorträge zu halten. Er ließ es 
sich aber auch nicht entgehen, auf der langen Fahrt durch den anderen Kontinent Orte aufzusuchen, deren Sehenswürdigkeiten gerühmt wurden.

So besuchte er die Insel Catalina und fuhr dort mit einem Boot, das einen durchsichtigen, gläsernen Boden hatte. "Man sieht die unterirdischen Gärten, Seegewächse und viele Fische. Auf der Insel gibt es im Gegensatz zu dem Festland von Kalifornien, wo es nur Autostraßen gibt und ein Fußgänger in den Außenbezirken als 'verdächtige Erscheinung' von den Hunden angebellt wird, auch schöne Fußwege (genauer Reitwege). Ich machte heute solch einen Weg hoch hinauf, der dann am Kamm des Berges plötzlich den Blick auf den Ozean öffnete. In der Ferne sieht man die kalifornischen Berge. Die Sonne war dem Untergang nahe, und das Meer, das glatte, immer friedliche des Stillen Ozeans glänzte im Abendgold, darüber der blaue Himmel, mit leichten Federwolken bedeckt. Links und rechts vom $\mathrm{Paß}$ je ein kleiner Gipfel, die ich beide erstieg."

Über den Aufenthalt am Grand Canyon berichtete er in einem Brief an seine kleine Tochter:

27. Dezember 1929: "Nun wird es hohe Zeit, daß ich Dir zu Deinem Geburtstag schreibe. Als kleines Geschenk schicke ich Dir ein Heft mit Aussichten der wunderbaren Gegend, in der ich seit heute bin. Denke Dir eine weite Hochebene, mit Kiefernwald darauf, $2100 \mathrm{~m}$ über dem Meere, also etwa die Höhe der Karwendelspitze. Nach Süden sieht man über dem Wald blaue Berge. Aber nun auf der anderen Seite! Da hat ein großer Fluß sich ein Tal mit 1000 Seitentälern ausgefressen, und man sieht überall den nackten Felsen. Oben etwas Muschelkalk, tiefer kommt roter Sandstein, wie er bei Reinhausen und Bremke herauskommt. Und dann noch 3-4 andere Gesteinsarten, alles waagerecht liegend. Das Flußtal liegt tiefer als Mittenwald, von der Karwendelspitze aus gesehen. Die Luft ist sehr klar, und man sieht sehr weit, und die Schatten sind dann beinahe himmelblau. Dazu der weiße und der rote und der graue und der violetttbraune Stein. Eine wundervolle Farbensymphonie, mit der Tageszeit wechselnd, von harten Farben im prallen Sonnenschein bis zu zarten weichen Tönen im Abenddämmerschein. So viel über den Grand Canyon. Ich denke, die Mutti gibt Dir noch ein Geschenk von mir aus der japanischen Kiste." 
In Detroit sollte nur eine Ford-Fabrik besichtigt werden.

Detroit: 16. Januar 1930. Prandtl, der diesmal nur ein Handköfferchen bei sich hatte, wurde von einem Bekannten am Bahnhof abgeholt, der ihn mit dem Wagen zum Hotel bringen wollte. Vorher aber hielt man vor einem Restaurant, um gemeinsam ein Abendessen einzunehmen. Als die Herren zum Auto zurückkamen, gab es eine traurige Überraschung, denn der Wagen war aufgebrochen worden und die Ledertasche verschwunden. Das betrübte den Weltreisenden zutiefst. Die Tasche enthielt nämlich außer seinem Nachtzeug die japanische Ehrennadel und die 13 unentwickelten Filme, die er mit sich geführt hatte als sein kostbarstes Reisegut. Seine persönlichen Erlebnisse hatten dort ihren Niederschlag gefunden. Mit dem Blick eines geübten Landschaftszeichners war er lohnenden Motiven nachgegangen, in stiller genießerischer Freude, auf dieser langen Reise einmal genügend Zeit zur Betrachtung von Sehenswürdigkeiten aller Art zu haben. Er setzte am nächsten Tag eine Annonce in die Zeitung, in der der Dieb aufgefordert wurde, gegen Belohnung wenigstens die Filme zurückzubringen. Leider vergebens. Der Verlust hat ihn noch sehr lange geschmerzt.

9. Februar 1930, New York: "Am ersten Tag war ich vormittags in "Down Town", dem Hauptgeschäftsviertel. Ich sah mir die Wolkenkratzer und die großen Brücken über den East River an und ging zum Bureau des Norddeutschen Lloyd. Dort wurde ich als prominenter Reisender dem Direktor vorgestellt, der sich angelegentlich über die Verhältnisse in Rußland und Sibirien erkundigte. Abends ging ich in eines der 100 Theater am Broadway, in einen Sprechfilm: Disraeli! Die Personen ganz vorzüglich dargestellt und mit einer vollendeten Wiedergabe der Stimmen und der sonstigen Laute (Gehen, Tellerklappern, feine Musik, alles ganz glänzend). [Anmerkung: Der Tonfilm war in Deutschland damals noch nicht verwirklicht.]

Am Samstagvormittag war ich im Naturgeschichtlichen Museum, das eine Sehenswürdigkeit ersten Ranges ist; am Nachmittag dann noch in dem Kunstmuseum (Gemäldegalerie mit vielen Rembrandts, Frans Hals, v. Dyck usw., ägyptische, griechische, römische Altertümer, Mittelalter und Neuzeit, China, Japan, Indien, Persien, eine erdrückende Fülle von schönen Sachen)."

19. Februar: "Dies ist mein letzter Brief von diesem Land. Die Vortäge in Boston sind gut vonstatten gegangen. Am Samstag war ich in der Harvard Universität, wo ich 
einige Laboratorien besuchte. In der Filmabteilung sah ich Embryogewebe vom Huhn wachsen, Zellen sich teilen usw. Wunderbar sind die Glasblumen im Botanischen Institut, in natürlichen Formen und Farben aus Glas modelliert, gemacht von einem Mann in Dresden und allein zu sehen in Harvard."

Meine Mutter fuhr am 1. März mit freudigem Herzen nach Bremerhaven, um ihren heimkehrenden Ehegatten direkt am Schiff abzuholen. Es gab dann damals daheim bei uns so viel zu erzählen, daß wir Tage brauchten, um alles Erlebte auszutauschen. Die Berichte und Vergleiche und Anspielungen, die von dem Besuch in Japan in die Unterhaltung einflossen, blieben noch lange Zeit nach der Heimkehr des Hausherrn das Hauptthema der Tischgespräche. Und sie waren ein deutliches Zeichen, wie stark die Eindrücke noch nachwirkten, die unser Vater in diesem fernöstlichen Land mit einer völlig anderen, feinen Kultur empfangen hatte.

Kinder bewahren ein ungetrübtes Andenken an die häufig wiederkehrenden Themen und Gegenstände der Unterhaltung ihrer Eltern. Und so möchte ich aus der Erinnerung einige Eindrücke aus Vaters Japanerlebnis zusammenfassend wiedergeben.

Die Verhaltensweise der japanischen Menschen untereinander hat meinen Vater, glaube ich, am meisten beeindruckt. Er erzählte, es habe nirgends Kinder gegeben, die in Gegenwart ihrer Eltern lärmten oder weinten. Die Japaner seien im alltäglichen Zusammensein überaus freundlich zueinander. Ihre anerzogene Bescheidenheit und Selbstbeherrschtheit sei zu einer Lebensform geworden, die uns als besondere Höflichkeit auffalle. Die unzähligen Gelegenheiten, die ein Japaner ergreife, Geschenke zu machen, immer geschmackvolle Dinge, mit ergebener Geste überbracht, lasse ihre liebenswürdige Haltung im mitmenschlichen Zusammenleben erkennen. Und er rühmte besonders ihre noble Gastfreundschaft. Ihr ausgeprägter Sinn für Reinlichkeit trage auch dazu bei, daß Fremde sich besonders wohlfühlen könnten. Dazu bemerke man überall den ungewöhnlichen Fleiß der Japaner.

Für uns bildeten die mitgebrachten japanischen Gebrauchsgegenstände - 2 Kimonos, die man mit dem Obi auf der Taille zusammenband, Holzschuhe, Strümpfe aus abgefüttertem Leinen, kleine Haarpfeile und natürlich mehrere Paare von Eßstäbchen eine eigene liebe Beziehung zu dem fernen Japan. 


\section{Wieder häuslicher Alltag}

Unser Zuhause hatte nun wieder einen Mittelpunkt, und wir spürten jetzt mehr als früher, wie viel von dem Wesen unseres Vaters ausging. Die alte Gewohnheit, am Samstagnachmittag mit meiner Mutter in den Hainberg zu gehen, setzte er ganz selbstverständlich fort. Nach dem Kaffeehaltepunkt hatte mein Vater oft noch Lust, den Wanderweg allein fortzusetzen. Auf unbekannten kleinen Pfaden, und deren gibt es viele in den hiesigen Wäldern, verfolgte er irgendein besonderes Ziel, sei es, einen schönen Aussichtspunkt zu erreichen oder eine von den Göttingern unentdeckte Stelle mit seltenen Blumen aufzusuchen. Manchmal begleitete ich ihn auf diesen "Pirschgängen", und er war dabei unermüdlich, mir vieles über Pflanzen, Bodenbeschaffenheit und Landschaft zu erzählen. Er konnte sich bei seinem reichen Wissen allerdings nicht in die Begriffsstutzigkeit seiner 13-jährigen Tochter hineinversetzen, die nicht immer imstande war, seinen Erklärungen aufmerksam zu folgen. Hingegen interessierte mich durchaus sein Vorhaben, versteckte Waldwege durch Ausschneiden der sperrigen Zweige passierbar zu machen. Bei einem solchen Streifzug durch den Wald schaute er immer nach Blumen aus und brachte seiner Frau einen hübschen Strauß mit. Er hatte ein wunderbar nahes Verhältnis zu den Dingen, die ihn in der Natur umgaben. Unermüdlich stellte er sich Fragen zu den Phänomenen der Pflanzen, der Gesteine, der Wolken. Einfach spazierenzulaufen ohne zu beobachten, das konnte er nicht. Jeder, der in seiner Begleitung mitspazierte, wurde durch seine Mitteilsamkeit bereichert. Besonders interessierte ihn natürlich jedesmal die Wolkenbildung, die Strömung in den verschiedenen Höhenschichten. Er äußerte dabei auch seine Freude über die Schönheit mancher Cumuluswolken, geradezu Begeisterung für wechselnde Stimmungen, wenn durch dahinziehende Wolkenfetzen die Landschaft in mannigfaltiger Weise beleuchtet wurde.

Abends, wenn wir Kinder endlich im Bett waren, las meine Mutter meinem Vater eine gute Stunde vor, ganz regelmäßig. Mein Vater, der selbst keine Zeit hätte aufbringen können, Bücher der modernen Literatur zu lesen, hörte dann gern und aufmerksam zu. Und für ihn bedeutete diese abendliche Vorlesestunde eine Entspannung und ein Abschalten seiner gewohnten Gedankengänge. Die Bücher, die meine Mutter auswählte, waren meistens Biographien oder neuerschienene Romane, wie z. B. Thomas Mann: "Der Zauberberg". Einmal lasen sie von Erich Edwin 
Dwinger "Die Armee hinter Stacheldraht". Mein Vater ließ sich von den Schilderungen so stark beeindrucken und litt so sehr beim gedanklichen Nacherleben einer realistisch grausamen Kriegsszene, daß meine Mutter das Buch mittendrin beiseite legen mußte. Auch Oswald Spenglers "Untergang des Abendlandes" hat mit zu ihrer Lektüre gehört und zu manchen Diskussionen Anlaß gegeben.

Als meine Mutter 1940 starb, entbehrte mein Vater nicht zuletzt diese liebe Gewohnheit des Vorlesens ganz wesentlich, so daß ich, um ihn zu erfreuen, beschloß, das Lesen für eine Weile fortzusetzen. Später hat er sich damit begnügt, zu dieser Abendstunde Sendungen im Radio einzuschalten.

Nach Beendigung dieser Lesestunde setzte er sich, nun von niemandem mehr beansprucht, an den großen Tisch in der Mitte des Zimmers und breitete seine Arbeitspapiere aus, und während er sich mit seinen wissenschaftlichen Problemen befaßte, vergingen die Stunden, und vor halb zwei Uhr wurde niemals das Licht im vorderen Zimmer gelöscht. Die Nachbarn kannten diese erleuchteten Fenster, und man sagte mir, daß man spät nachts auf der spärlich beleuchteten Straße dennoch mit einer Art beruhigender Sicherheit heimwärts ginge, weil ja der Herr Professor noch wach sei und Licht habe.

In seinem Arbeitszimmer stand noch ein zweiter Tisch an der Wand, der zur Ablage für unerledigte Post sowie für wissenschaftliche Zeitschriften diente. Mitunter wuchsen die einzelnen Stapel so stark an, daß man befürchten mußte, es könne demnächst einer einstürzen. Meine Mutter drängte dann, endlich ans Aufräumen zu denken, wobei sie ihm beim Aussortieren mithalf. Obwohl mein Vater den Leitsatz zur Maxime erkoren hatte: "Keine Postsendung kann so eilig sein, als daß sie durch Liegenbleiben nicht noch eiliger wird oder sich inzwischen von selbst erledigt", ging er doch bereitwillig am Sonntagmorgen auf den Vorschlag seiner ordnungsliebenden Frau ein. Hinterher setzte er sich dann gern an den Flügel und präludierte auf besonders fröhliche Weise. Immer wieder aber kam es vor, daß er irgendeine Schrift, die dort abgelegt war, noch vor seinem Aufbruch morgens ins Institut dringend brauchte und sich ans Durchsuchen seiner Stapel machte, aber, wie es oft geschah, ohne Ergebnis. Es reute ihn die verlorene Zeit, und das Erfolglose seiner Tätigkeit deprimierte ihn ungewöhnlich. Dann schaltete sich meine Mutter ein, sie suchte eilig mit - und, obwohl mein 
Vater von einem blauen Heft gesprochen hatte, fand sie gleich darauf ein gelbes mit der gewünschten Aufschrift und fragte heiter: "Ist es vielleicht dieses?" Ihre Gabe, aus der Fülle der Zeitschriften immer die richtige herauszufischen, erschien mir recht wunderbar. Sie hat ihrem Ludwig damit oft einen unschätzbaren Dienst erwiesen und war ihm geradezu unentbehrlich in solchen Situationen. 


\section{Ferienreisen}

In all den Jahren haben wir fast in allen Ferien Reisen unternommen. Das Ziel der Osterreise war meistens ein Kurort im Harz, wo wir uns mit der Familie von Professor Otto Föppl aus Braunschweig trafen. Mein Vater langte dort meistens ein paar Tage später bei uns an, da er noch vielerlei zu erledigen hatte; aber er nutzte seine Urlaubswoche, die er sich gönnte, zu langen Wanderungen durch die duftenden Tannenwälder und genoß das fröhliche Zusammensein der Doppelfamilie. Für Pfingsten hatten wir ein gutes Quartier in Sooden-Allendorf ausgemacht, und auch hier trafen wir mit der Braunschweiger Familie zusammen. Für meinen Vater ergaben sich auf den Spaziergängen mit seinem Schwager auch immer interessante Gespräche. Mein Vater war ein anspruchsloser Feriengast: Er war stets darauf bedacht, keinen anderen zu stören und sich für alle Aufmerksamkeiten durch freundliche Worte erkenntlich zu zeigen. Er machte nirgends Gebrauch von einem Vorrang, den er bei seiner Bedeutung wohl hätte zur Geltung bringen können. Im Gegenteil: Er schätzte, wie mir schien, andere Gäste oft höher ein als sich selbst; und er schien eine allgemeine Haltung gegenseitiger Rücksicht und Achtung als selbstverständlich vorauszusetzen.

Die meisten Sommerferien verbrachten wir in dem alten Föppl-Haus am Starnberger See. Der Name Ammerland hatte für uns alle einen besonderen Klang, der die Freuden eines unbeschwerten Landlebens in sich schloB, aber auch gleichzeitig die warmen Gefühle aufklingen ließ, die durch die Zusammengehörigkeit mit der in München lebenden Verwandtschaft unser Herz bewegten.

Die Zugfahrt nach München dauerte damals noch fast zehn Stunden, aber in Erwartung, unser Traumziel zu erreichen, verging die Reise doch ziemlich rasch. Die Erinnerung an ein Reiseerlebnis möchte ich hier aufzeichnen: Wir reisten mit der Mutter voraus, da Vaters Semesterferien immer erst 14 Tage später als unsere Schulferien begannen. In unser Abteil war in Würzburg ein Herr zugestiegen, der sich bald mit meiner Mutter angeregt unterhielt. Als er erfuhr, daß wir aus Göttingen kamen, stellte er unvermittelt die Frage: "Kennen Sie dort vielleicht einen Professor Prandtl?" Das spontane, heitere Lachen meiner Mutter daraufhin habe ich nicht vergessen. Wir Kinder lachten mehr verwundert mit, denn wir wußten einfach zu wenig über die Berühmtheit unseres Vaters. 
An dem ungezwungenen Lebensstil im Föppl-Haus fand auch mein Vater großen Gefallen. So war es für ihn das vollkommenste Urlaubsziel, das er sich denken konnte: Das Schwimmen im klaren Seewasser, die Ausflüge ins nahe Gebirge und zwischendurch anregende Fachgespräche mit dem Schwager und Kollegen, Hans Thoma. Bei einem Ausflug, wir hatten den Heimgarten erstiegen, erinnere ich mich an eine seltene Naturerscheinung, die meinen Vater völlig faszinierte und auch begeisterte. Man schaute von der sonnigen Höhe in eine Nebelschicht hinab und entdeckte seinen eigenen langen Schatten. Das Eigenartige war, daß wir bei jeder Schattenfigur um den Kopf einen sanften Strahlenkranz in Regenbogenfarben erblickten. Natürlich kannte er die physikalische Erklärung dieses Phänomens, daß nämlich durch kleinste Nebeltropfen das Licht gebrochen wurde. Aber dennoch konnte er sich so ganz ursprünglich an der wunderbaren Erscheinung erfreuen.

Im Sommer 1929 sollte meinem Vater eine neue Ehrung zuteil werden. In der Hauptversammlung des Vereins Deutscher Ingenieure, die am 22. Juni in Königsberg stattgefunden hatte, war bei einer Festlichkeit in Anwesenheit der 800 Ingenieure die Verleihung der Grashof-Gedenkmünze an Prandtl verkündet worden. Es ist die höchste Auszeichnung, die der Verein zu vergeben hat.

Am 3. August 1929 erhielt Prandtl folgenden Brief:

"Im Einvernehmen mit dem Vorstand des Vereins Deutscher Ingenieure gestatte ich mir, Sie und Ihre verehrte Gemahlin gelegentlich der Überreichung der GrashofMedaille auf meine Villa am Starnberger See für Samstag, den 10. August, freundlichst einzuladen.

Mit vorzüglicher Hochachtung

Ihr Oskar von Miller."

Und pünktlich am 10. August fuhren an einem schönen Sommermorgen mehrere Herren aus München von Starnberg mit einem privaten Motorboot nach Ammerland herüber, wo wir sie am Dampfersteg abholten und sie durch die Wiesenwege zu unserem Haus geleiteten. Herr Oskar von Miller, der Begründer des Deutschen Museums, war in ihrer Mitte. Seine Anwesenheit nahm die Familie mit großem Respekt auf. Alle Herren waren anschließend, wie angekündigt, in sein schönes Landhaus in Niederpöcking eingeladen. Gemeinsam bestiegen sie gegen Mittag das Motorboot, 
um bequem über den See ans andere Ufer zu gelangen, wo die feierliche Verleihung stattfinden sollte. Gegen Abend des 10. Augusts brachte man selbstverständlich den geehrten Gast wieder zurück nach Ammerland.

Für meinen Vater gab es noch ein besonderes Reiseziel in Oberbayern, das er meistens erst im September aufsuchte, wenn wir Schulkinder mit unserer Mutter schon wieder nach Göttingen zurückgekehrt waren. Der Ort hieß Schleching, bei Marquartstein gelegen. Dort hatten seine beiden Cousinen, Klara Prandtl und ihre Schwester Anna, ein einfaches Gästehaus. Mit diesen beiden Verwandten verband ihn die Erinnerung an gemeinsame Kinder- und Jugenderlebnisse, und er wurde dort immer besonders gastfreundlich aufgenommen.

Im Sommer 1930 fuhren wir einmal an die Ostsee nach Dahme. Im August war in Stockholm der Internationale Mechanikerkongreß, zu dem natürlich auch die Ehefrauen mit eingeladen waren. Meine Eltern wollten sich die lange Reise dorthin kürzen, indem sie dann gleich von Dahme aus weiter nach Schwedens Hauptstadt reisten. Als bemerkenswert ist vielleicht zu berichten, daß sich bei diesem Kongreß dort die Föpplgeschwister trafen: Eingeladen waren Professor Otto Föppl, Professor Ludwig Föppl, Professor Hans Thoma und Professor Prandtl, die Gatten der beiden Schwestern, da alle diese Mitglieder der Familie Lehrstühle der Mechanik innehatten. Bei dem großen Festessen war dann allerdings an der langen Tafel nur für einen der Professoren Föppl gedeckt worden, weil die umsichtigen schwedischen Helferinnen an einen verzeihlichen Irrtum geglaubt hatten, als der originelle Name zweimal auftauchte. So wurde Ludwig Föppl, der bei der Tischordnung keinen Platz bekommen hatte, an den Tisch der Festordnerinnen gebeten. Das Schicksal wollte es, $\mathrm{da} ß$ er dadurch seiner späteren Frau Christina begegnete. Übrigens muß es innerhalb des gesellschaftlichen Rahmens ein wunderschönes Familientreffen gewesen sein, in der bezaubernden nördlichen Stadt.

1931 ging meine Mutter aus gesundheitlichen Gründen zur Kur nach Bad Kissingen. Mit wieviel Aufmerksamkeit sich unterdessen unser Vater um die kleinen häuslichen Angelegenheiten gekümmert hat, geht aus seinen gewissenhaften Berichten an seine Frau hervor: "Marie versorgt uns recht ordentlich. Zum Zeichen meiner Zufriedenheit schicke ich sie morgen abend ins Theater: 'Land des Lächelns'. - Die Kinder 
haben heute Zeugnisse bekommen. Ich habe ihnen für die Noten 1, 2, 3, 4 im Hauptfach 40, 20, 0, -20 Pfennige angerechnet."

Auf die Bitte seiner Tochter nahm er sich in jenen Wochen auch einmal die Zeit, mit dem Rad ein Stündchen umherzugondeln. Als wir mit unseren beiden Rädern schön nebeneinander auf einer der Göttinger Straßen entlangfuhren, kam weit hinten auf der Gegenbahn ein Auto in gemächlichem Tempo heran. Autofahrer tauchten in den äußeren Stadtbezirken damals nur sehr vereinzelt auf, so daß die Radfahrer und Fußgänger sich wenig in ihrer Freiheit beeinträchtigt fühlten. Ich behauptete also: "Wir können ruhig zu zweit nebeneinander bleiben, da wir nicht mehr Platz beanspruchen als ein entgegenkommendes Auto." Darauf entgegnete mein Vater mit bedeutendem Nachdruck: "Nein, wir fahren jetzt hintereinander; man muß es den anderen Menschen immer so leicht und angenehm wie möglich machen!" Das war eine seiner Lebensregeln, die sein Denken und Handeln im Umgang mit anderen Menschen bestimmte.

1932 bei meiner Konfirmation ging er selbstverständlich mit uns in die evangelische Kirche. Er schrieb mir ein paar Zeilen in mein kleines Neues Testament, die mich sehr beglückten.

"Bleib treu Deiner Art! Pflichterfüllung im Großen wie im Kleinen ist die beste Grundlage für heiteren Seelenfrieden." 



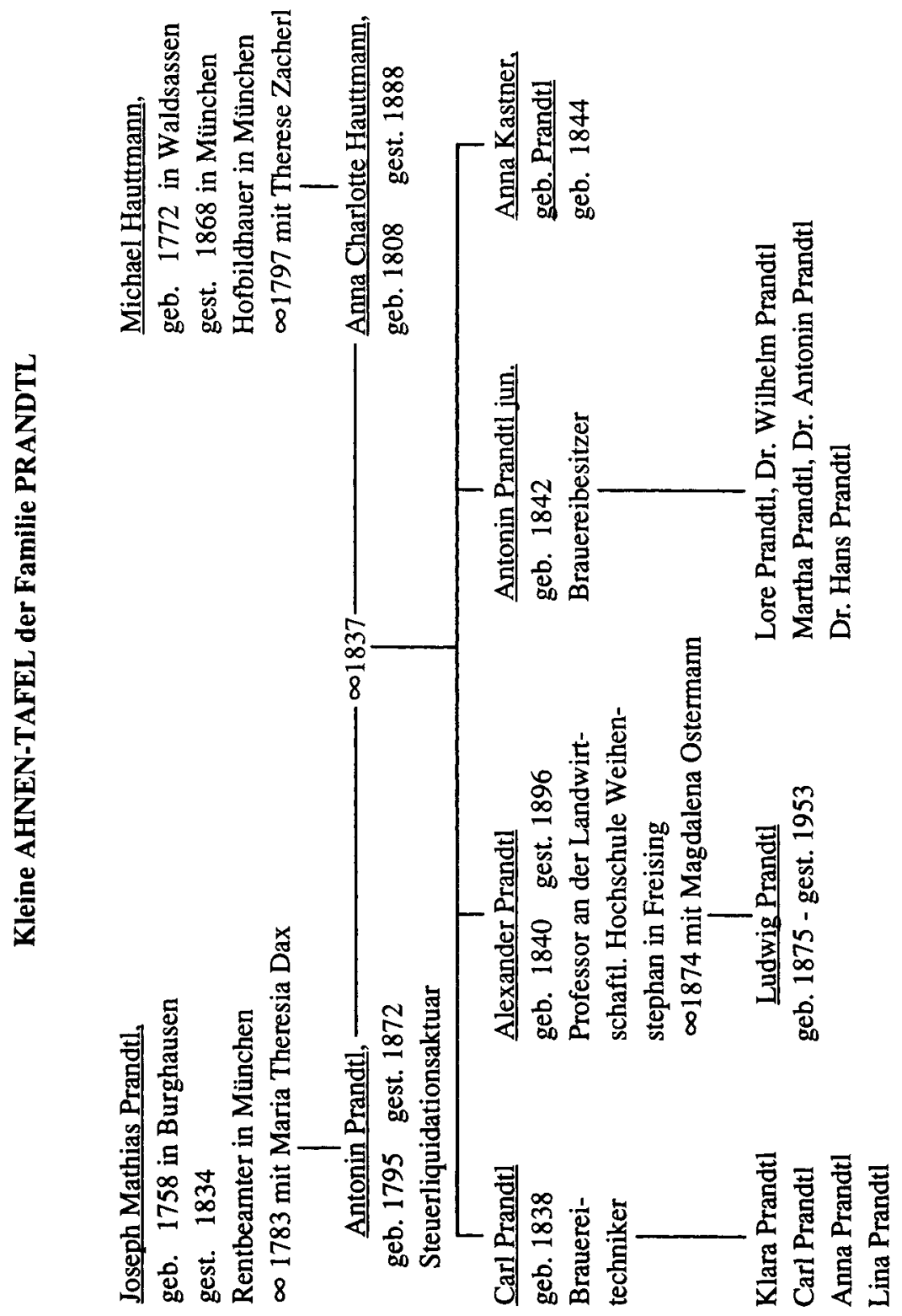




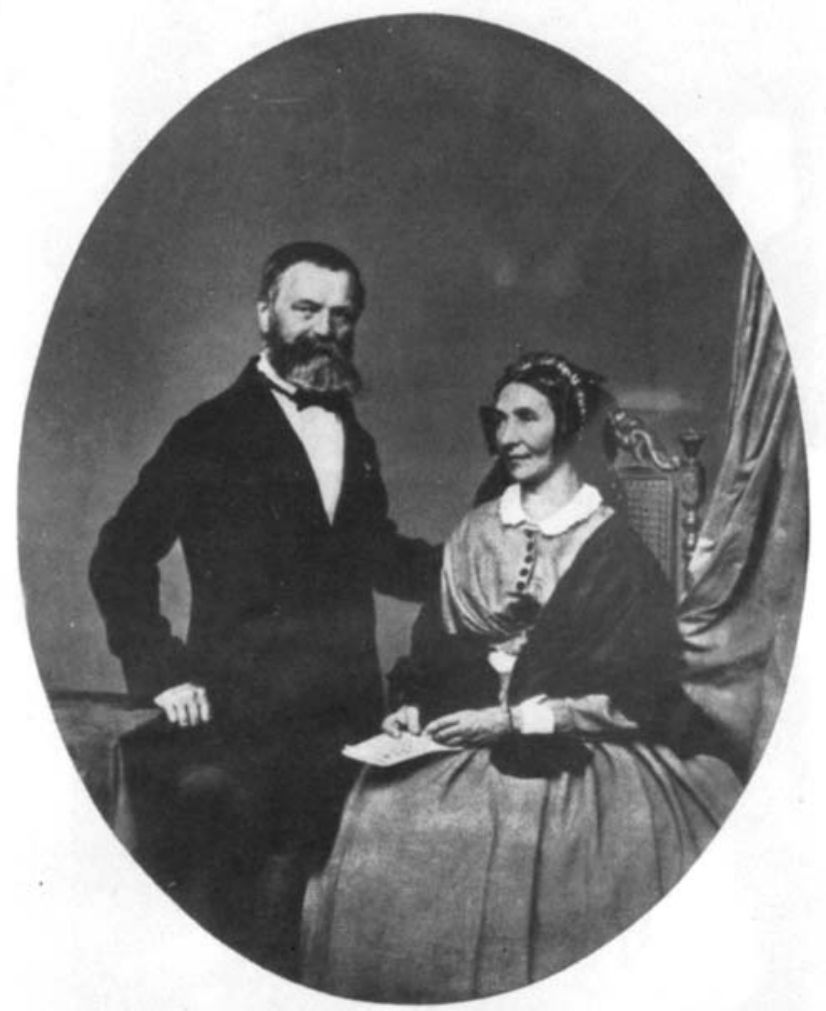

2utonin Franotl ô. Init feiner Frau 2Ina Ebarlote, geb. Sauttuan 

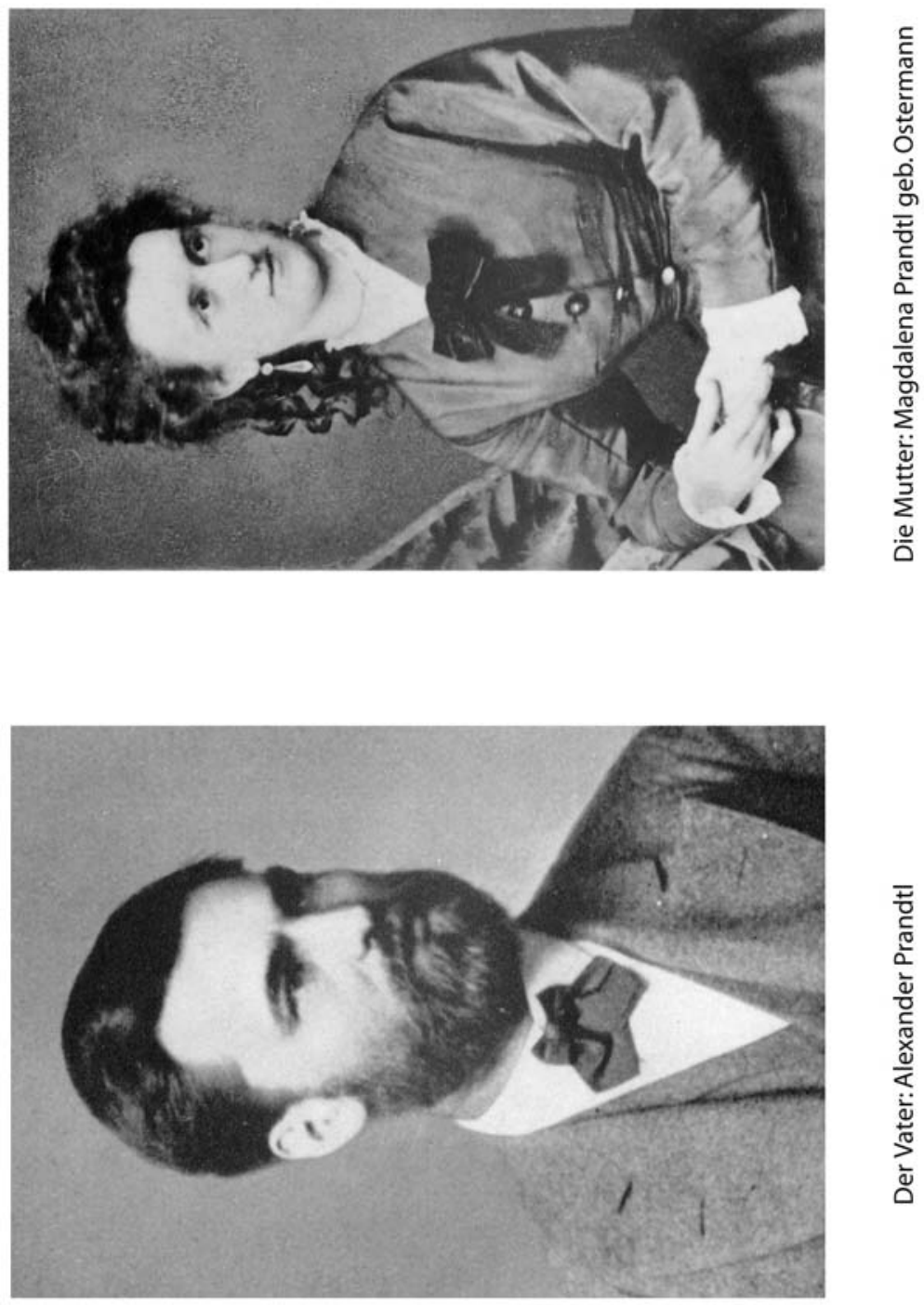

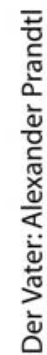



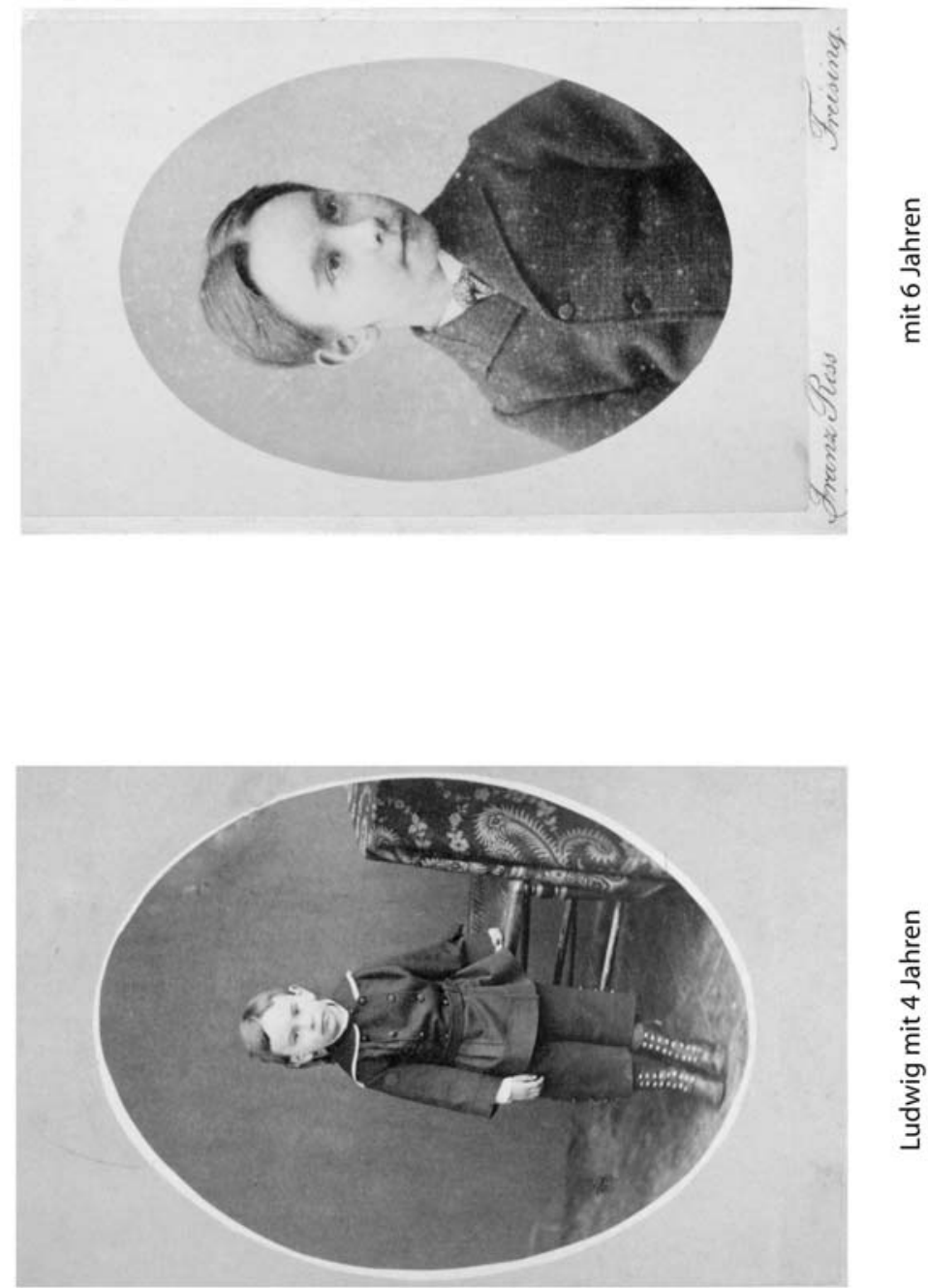

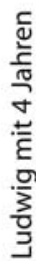




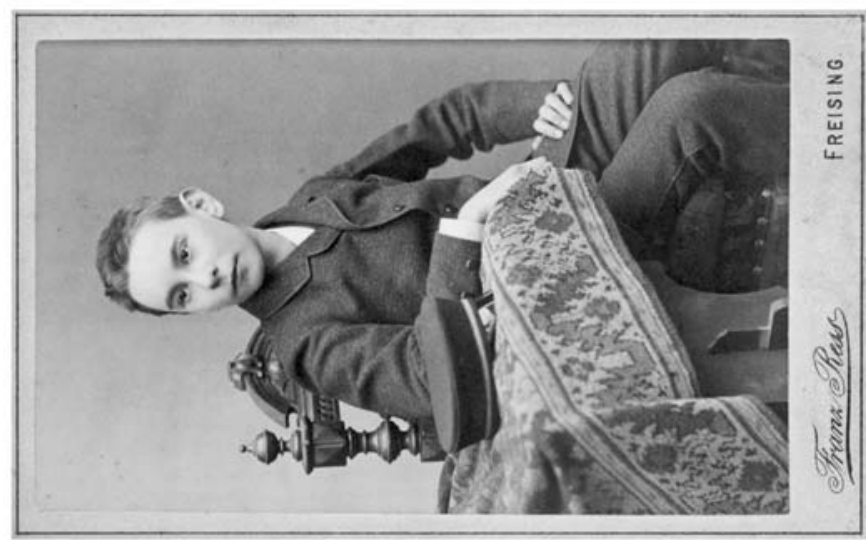

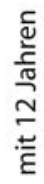

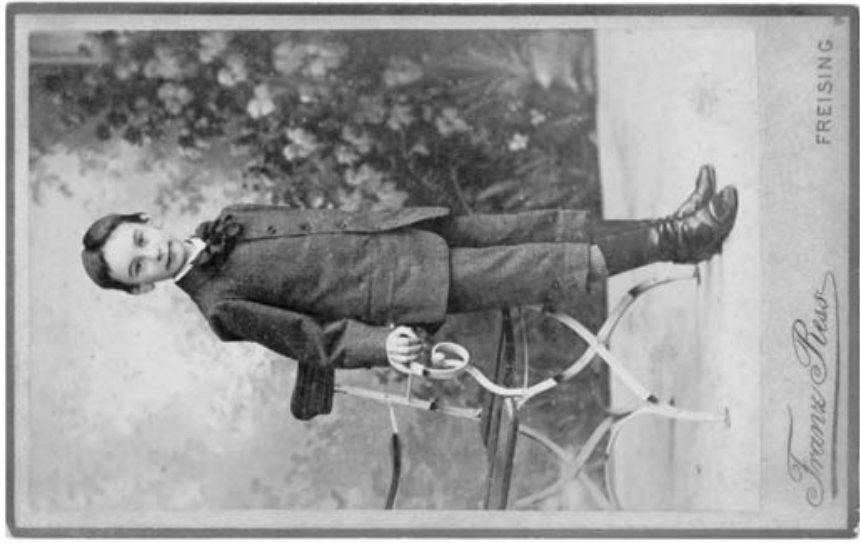

$\frac{}{\frac{0}{2}}$ 


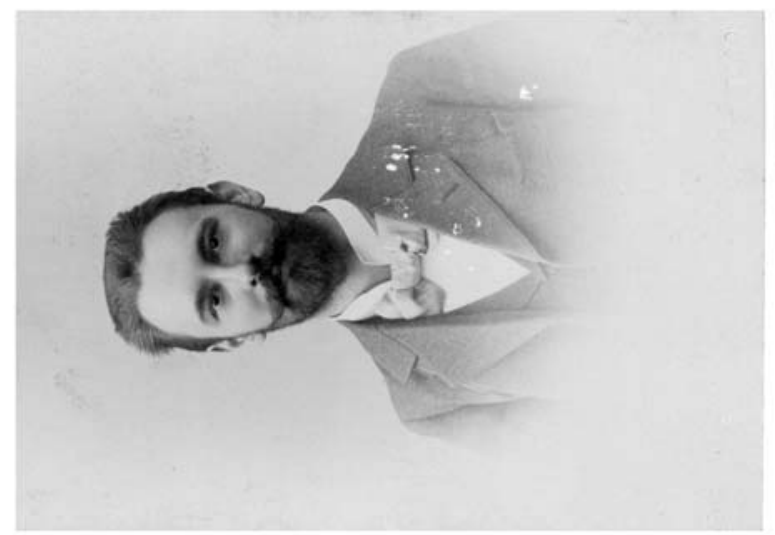

?
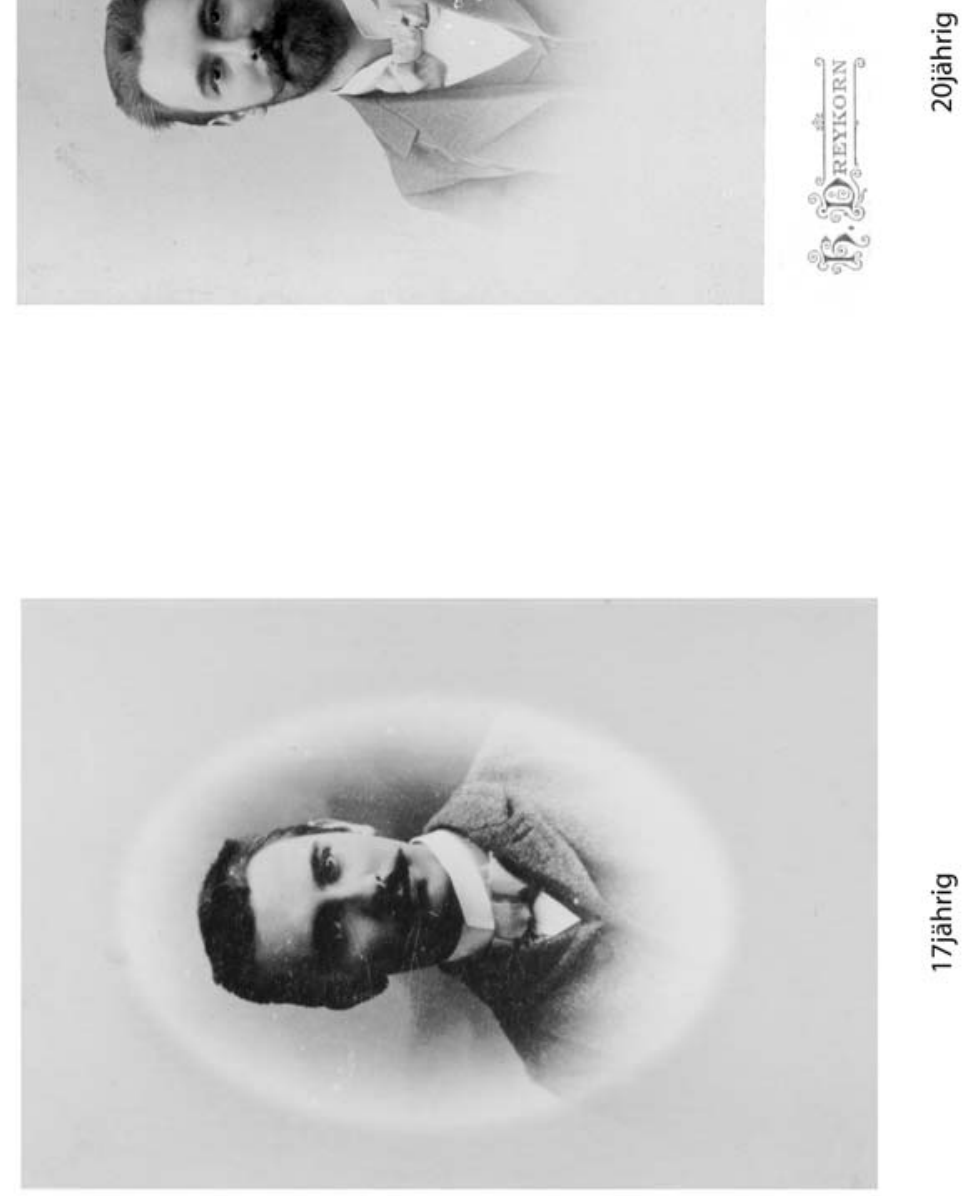


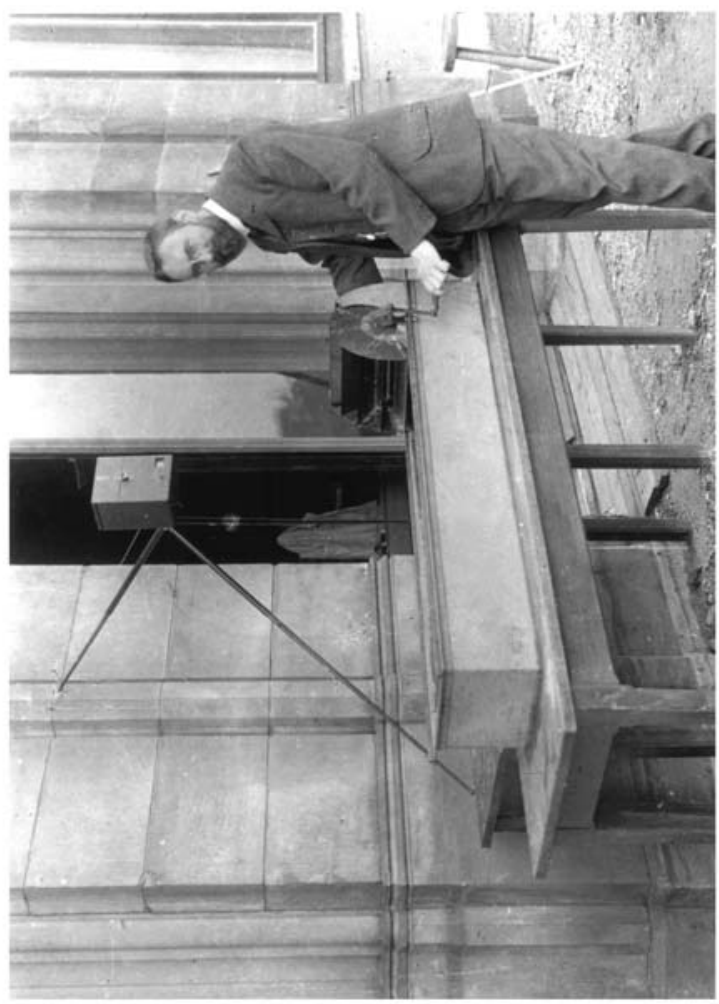

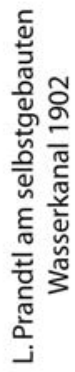

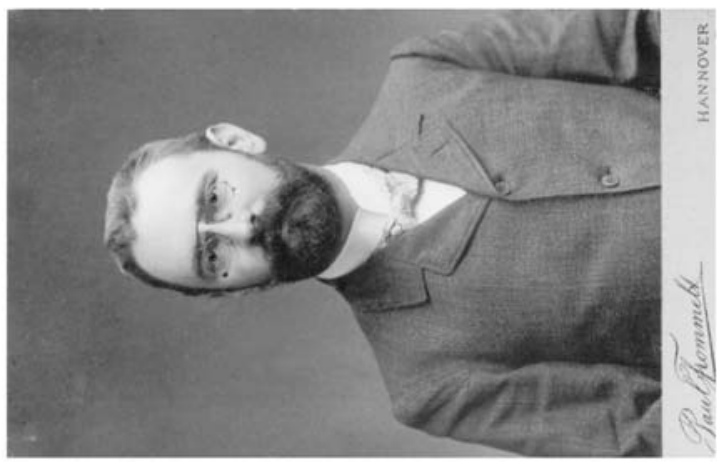

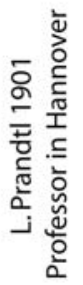



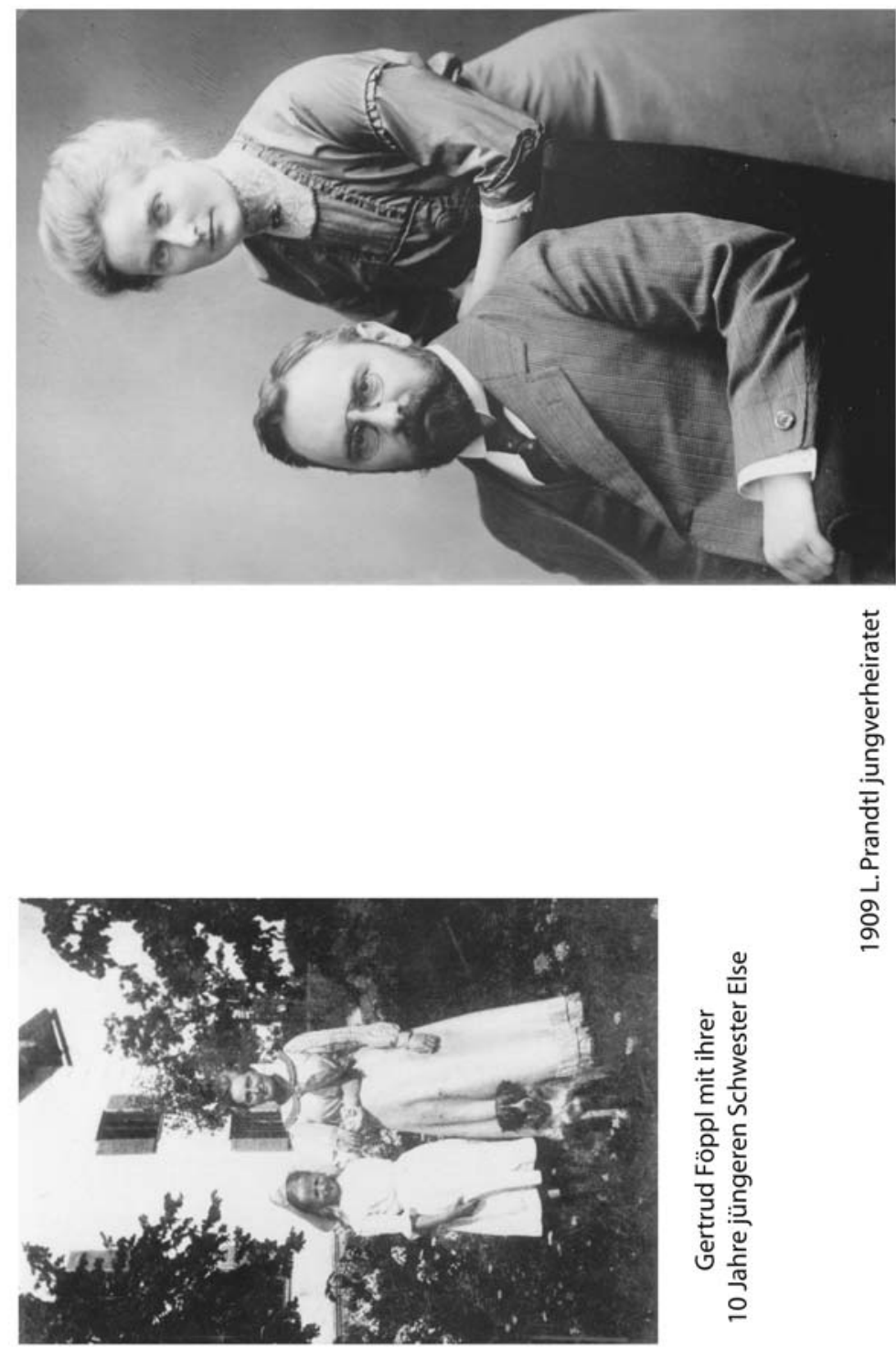

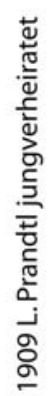

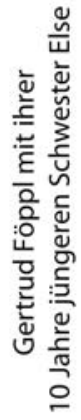



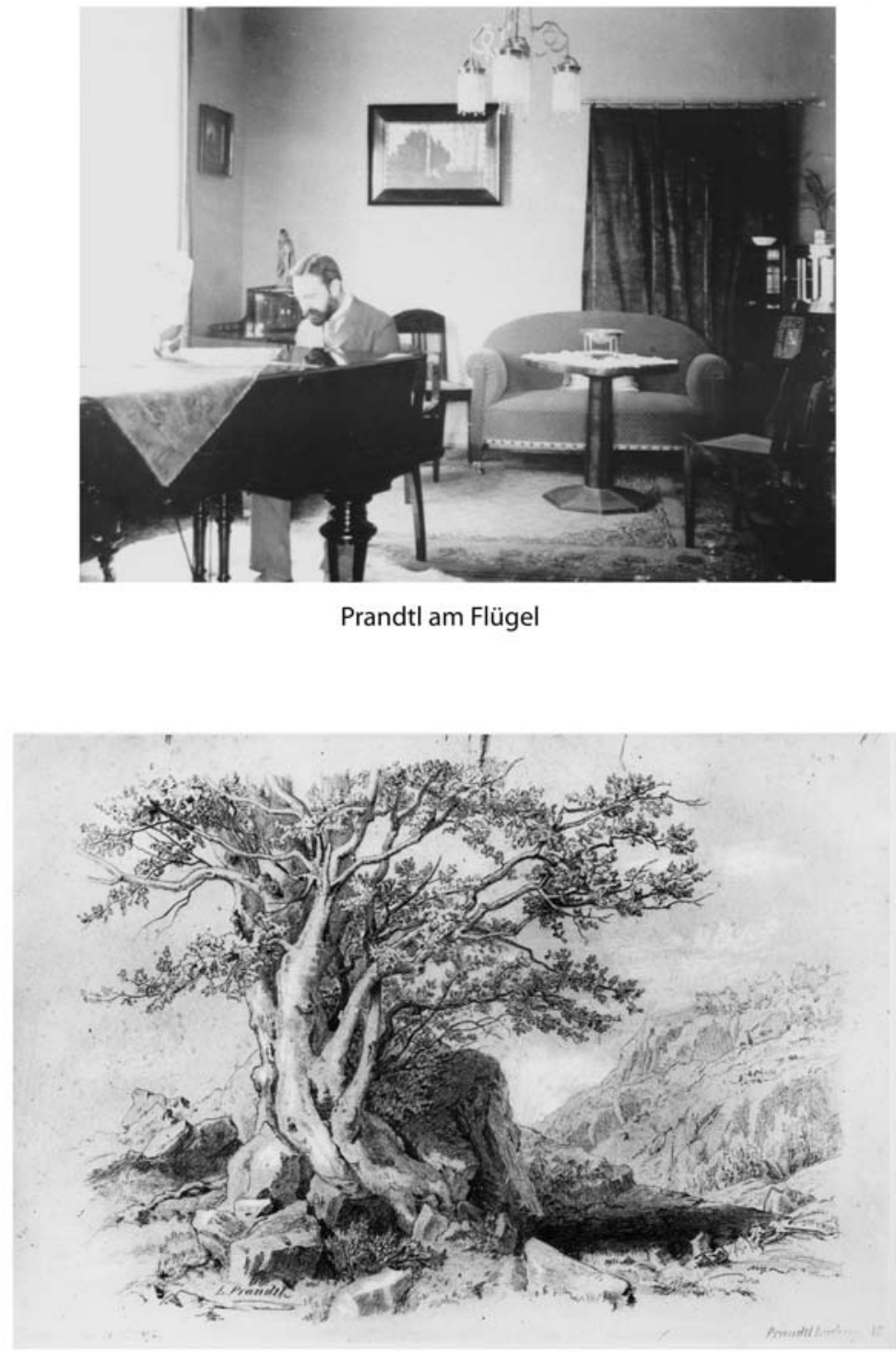

Signierte Zeichnung aus seinen Jugendjahren (nach der Natur) 


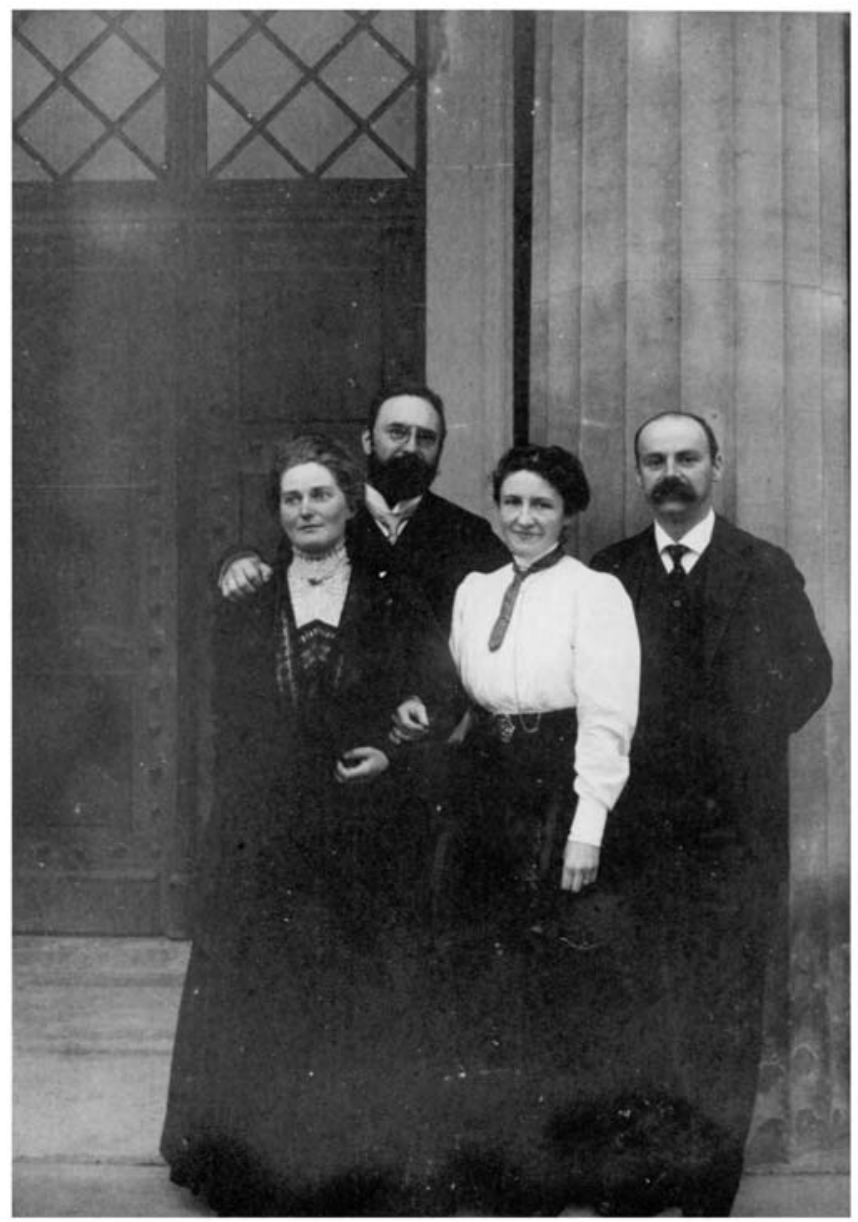

Die Freunde, L. Prandtl und K. Schwarzschild mit ihren Frauen; beide Paare jungvermählt 

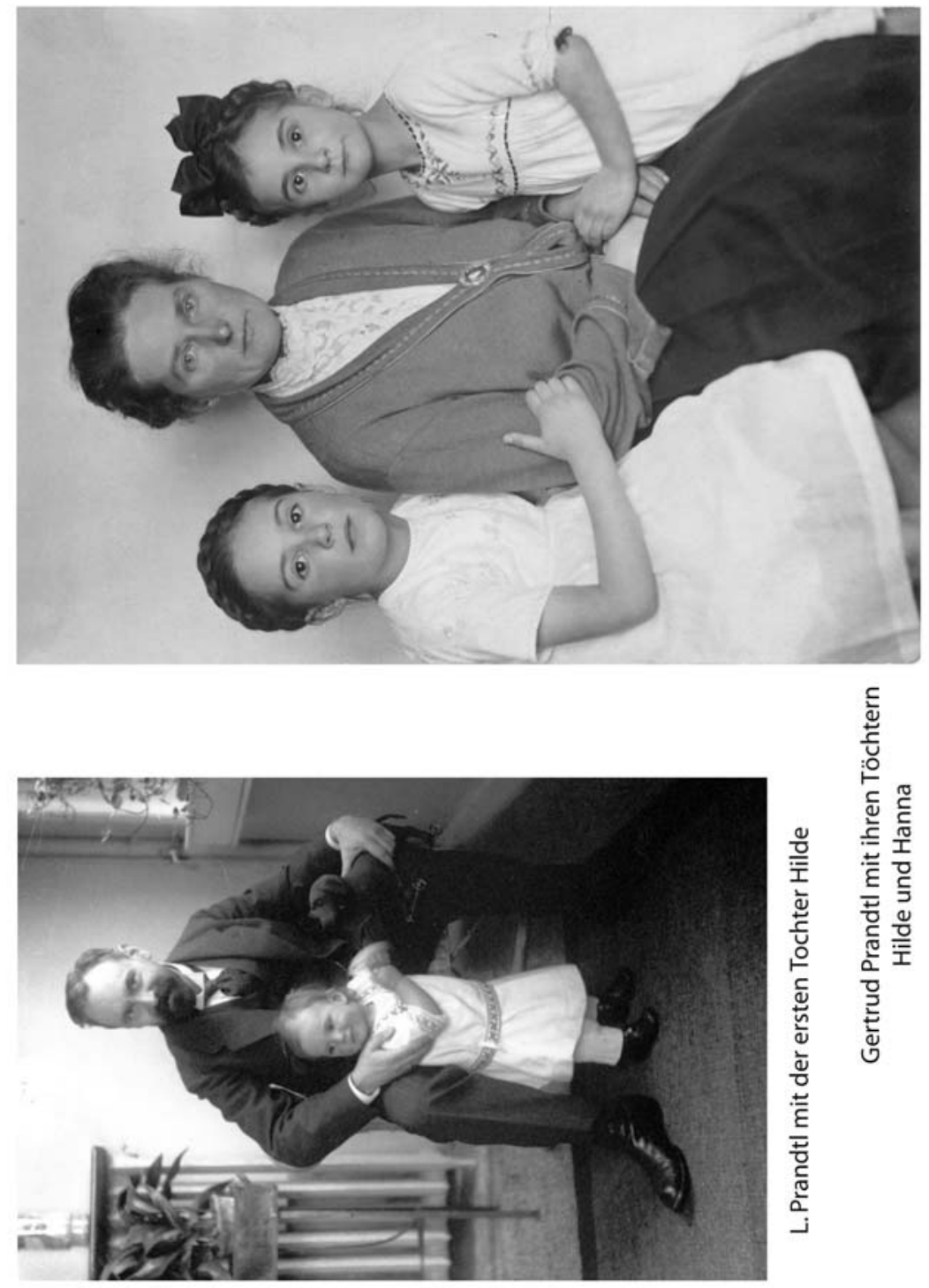


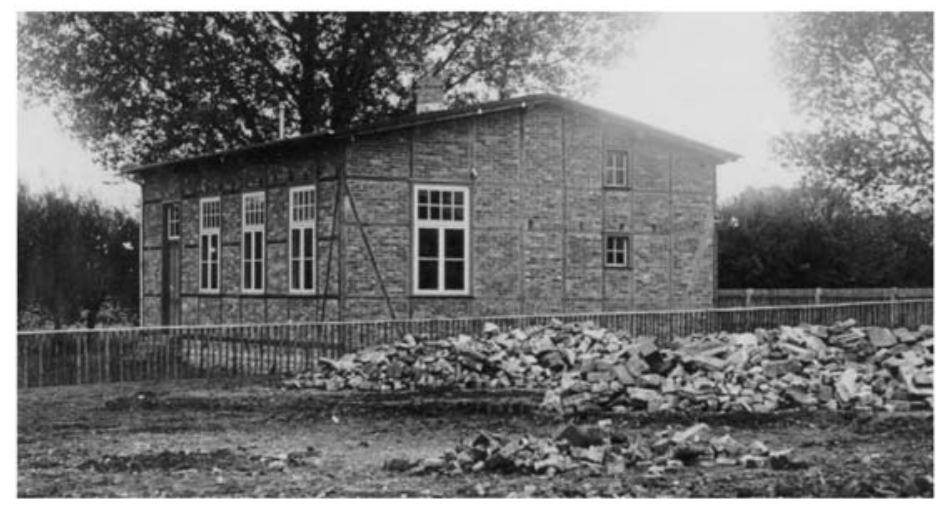

Die Modellversuchsanstalt in Göttingen 1908

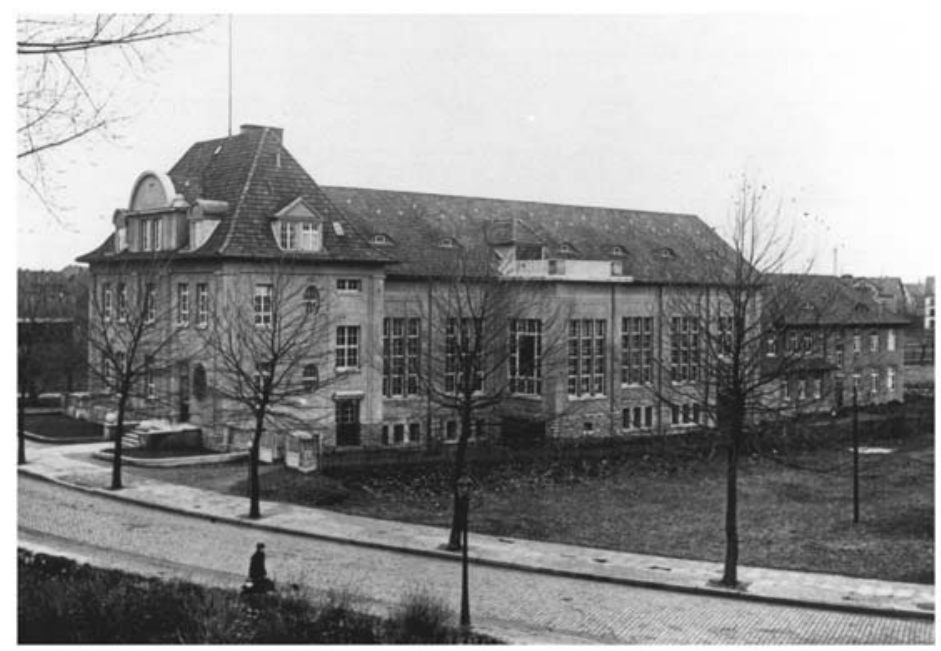

Die Aerodynamische Versuchsanstalt 1918 


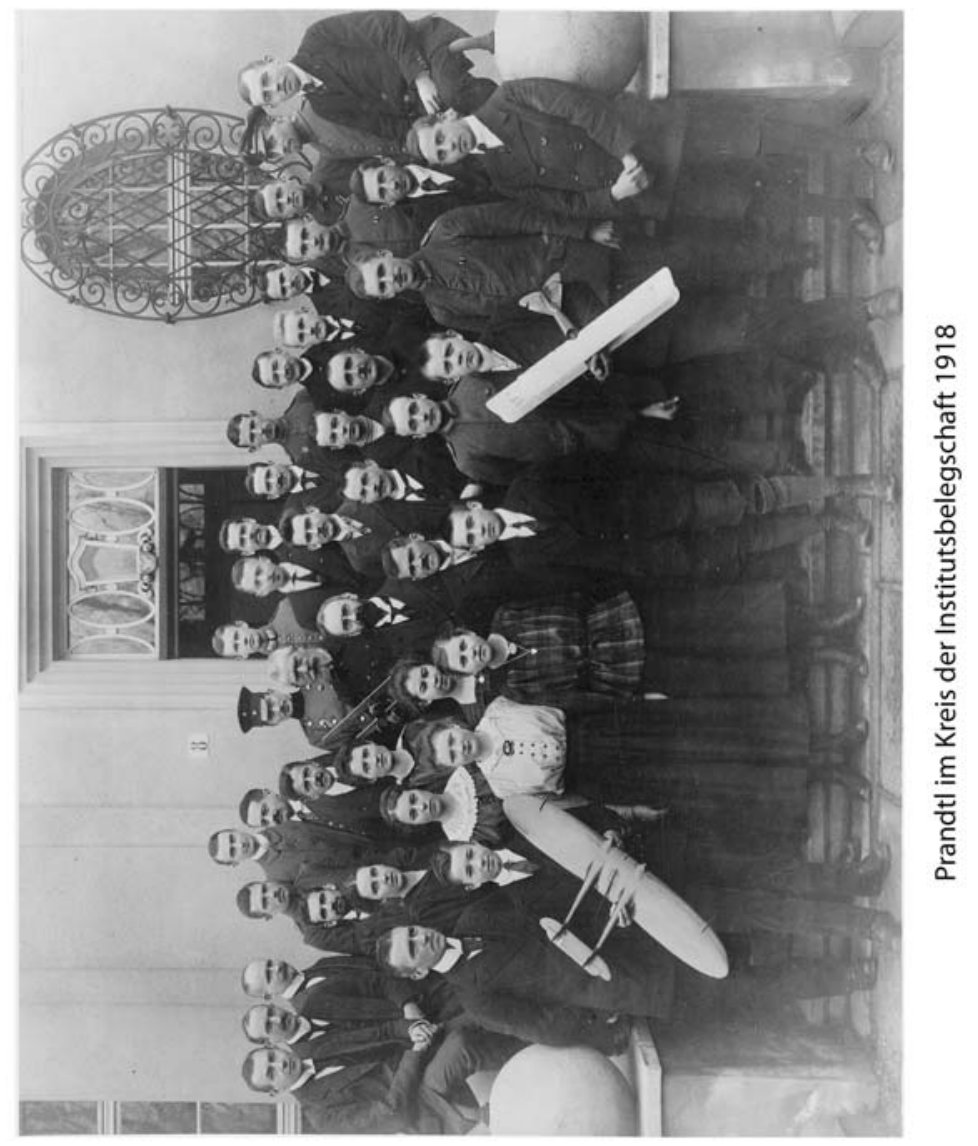



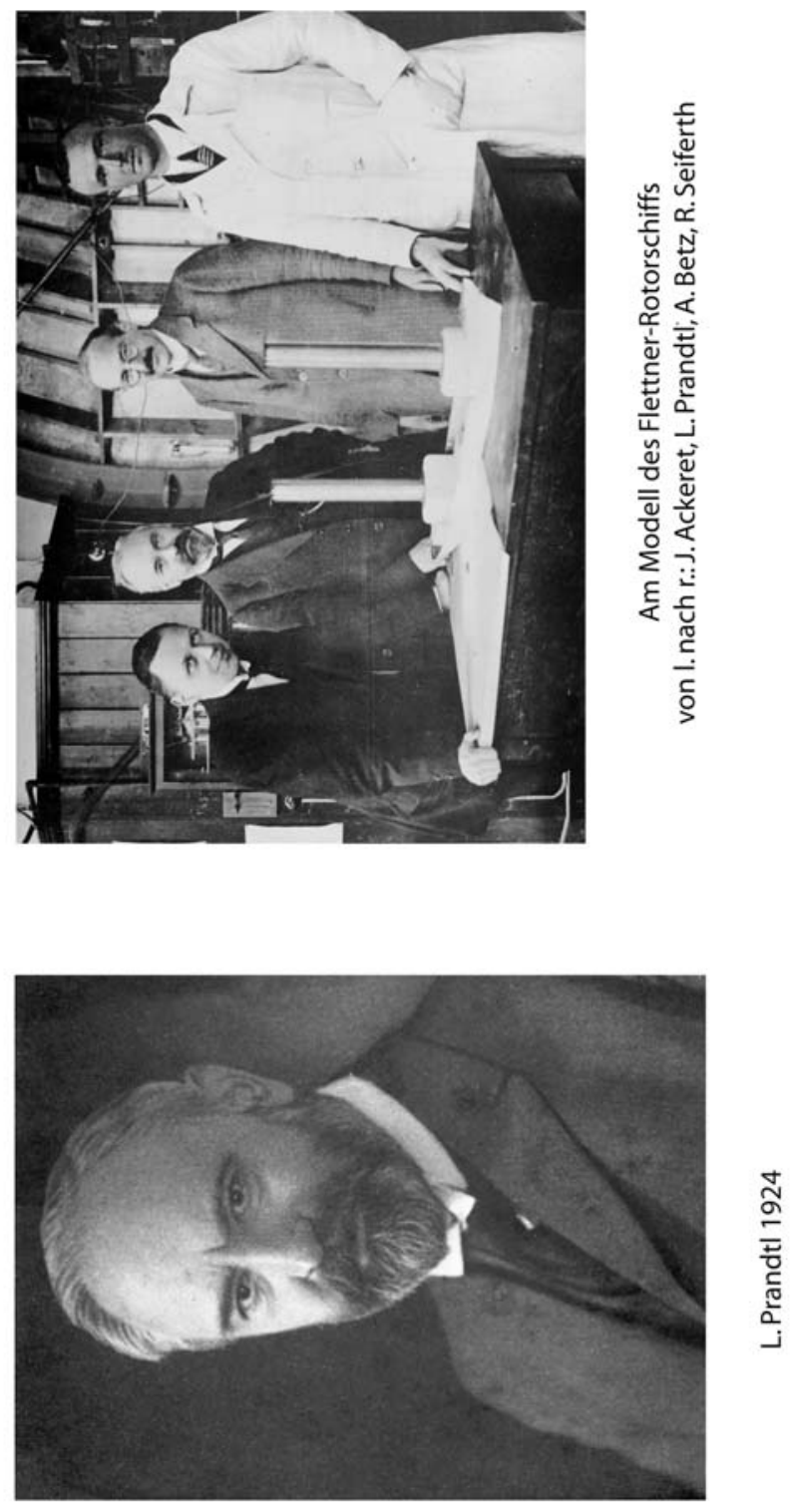

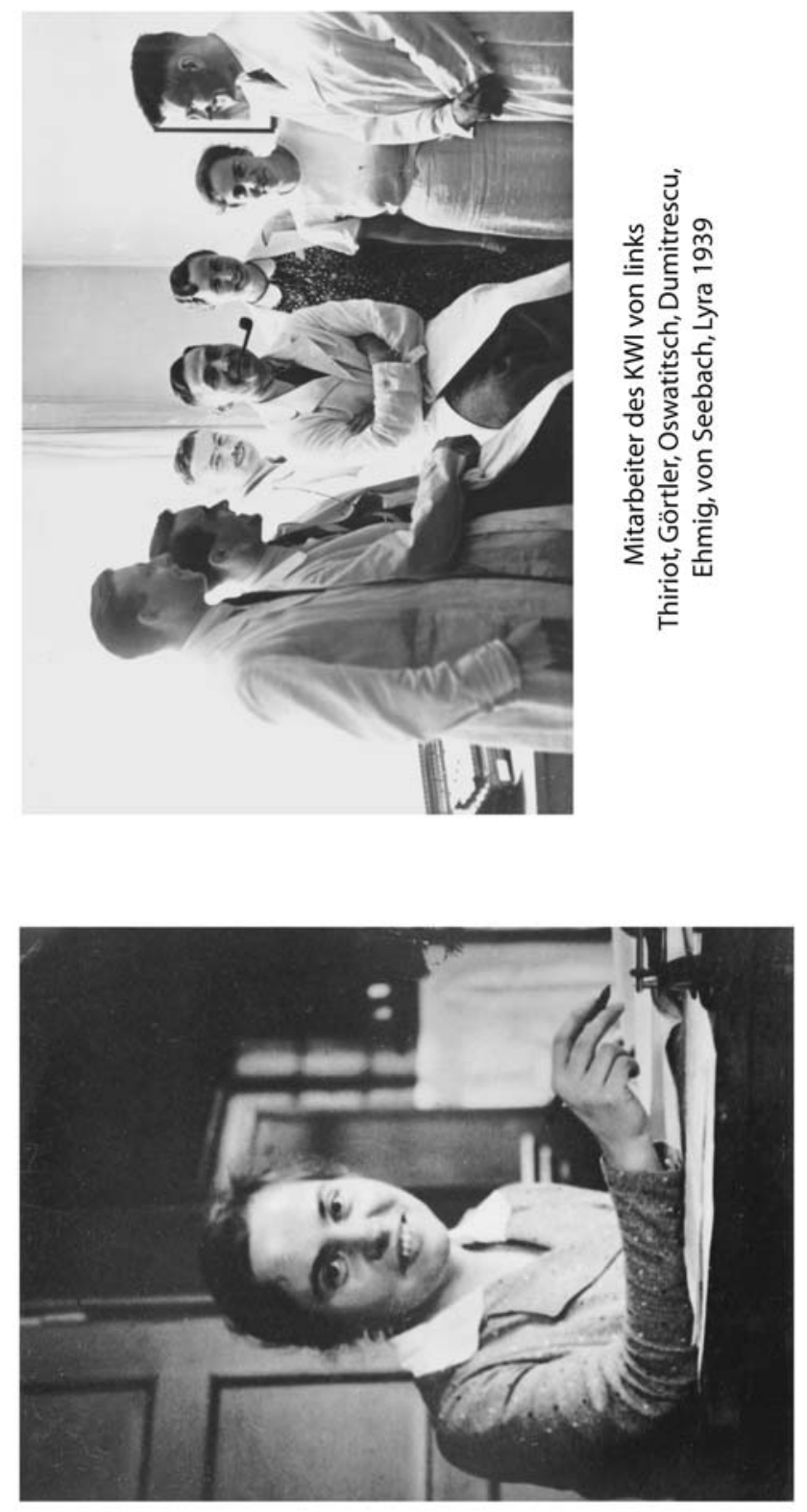

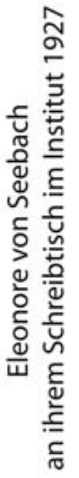




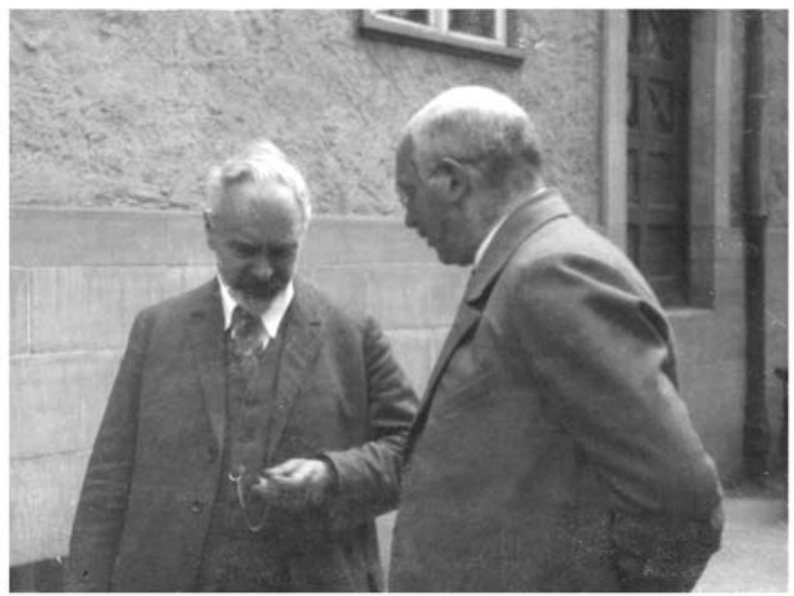

L. Prandtl und A. Betz auf dem Weg zur Vorlesung

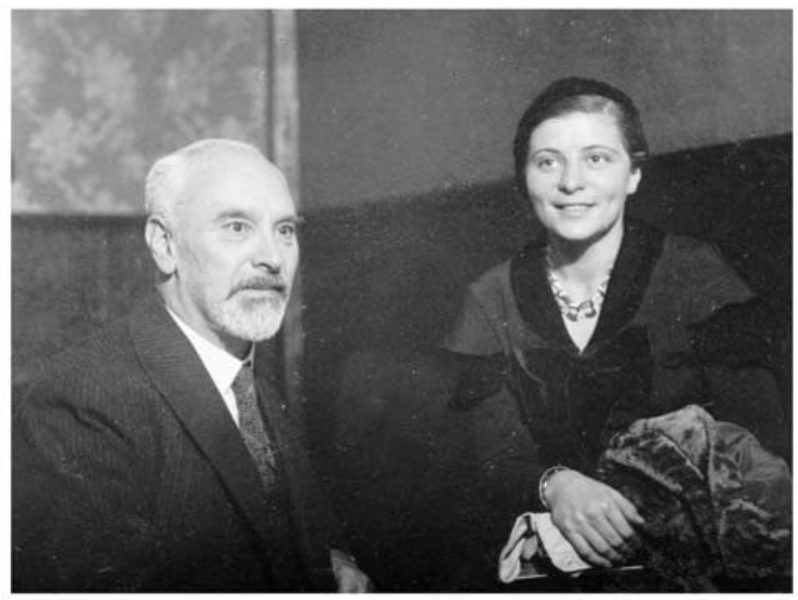

Die Fliegerin Elly Beinhorn zu Besuch bei Prandtl 1931 


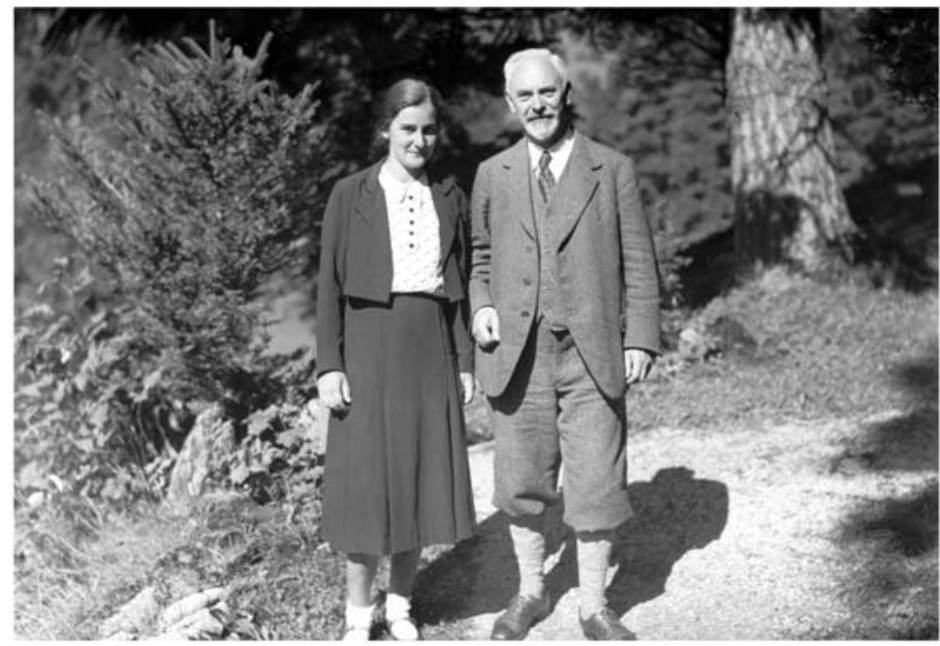

L. Prandtl mit Tochter Hanna

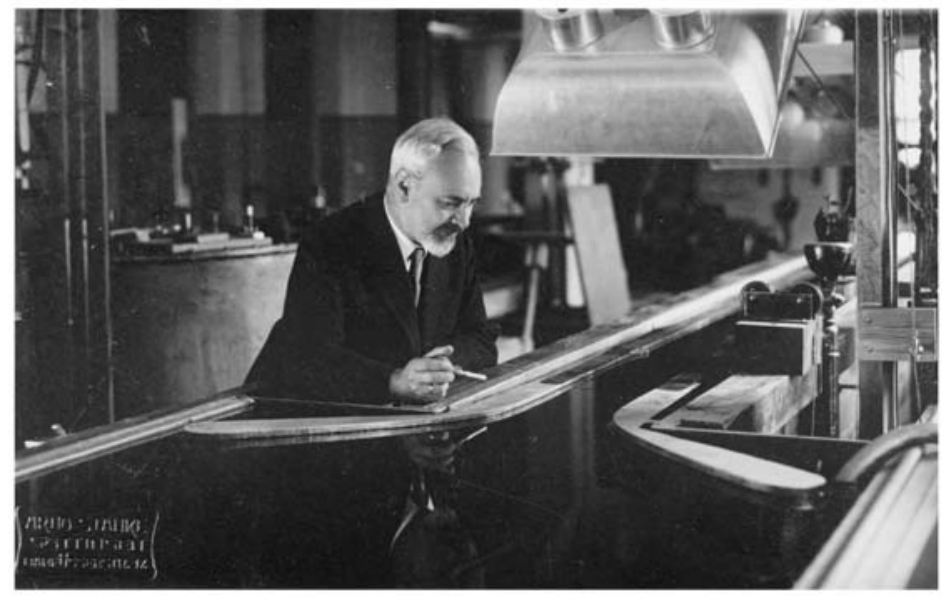

Im Strömungsforschungsinstitut 


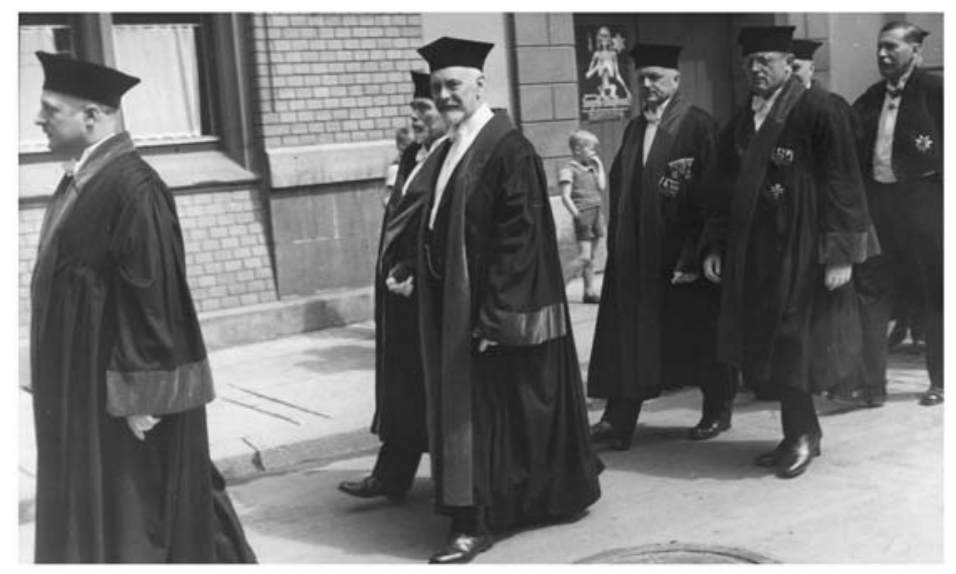

Auf dem Weg zur Universitätsfeier

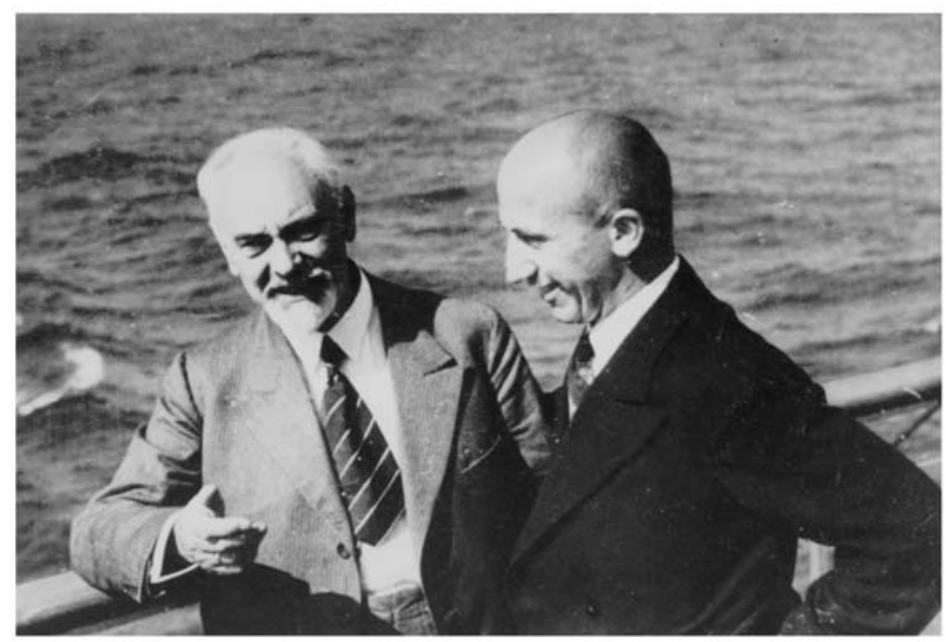

L. Prandtl und Prof. H. Blenk 1938 in Amerika 


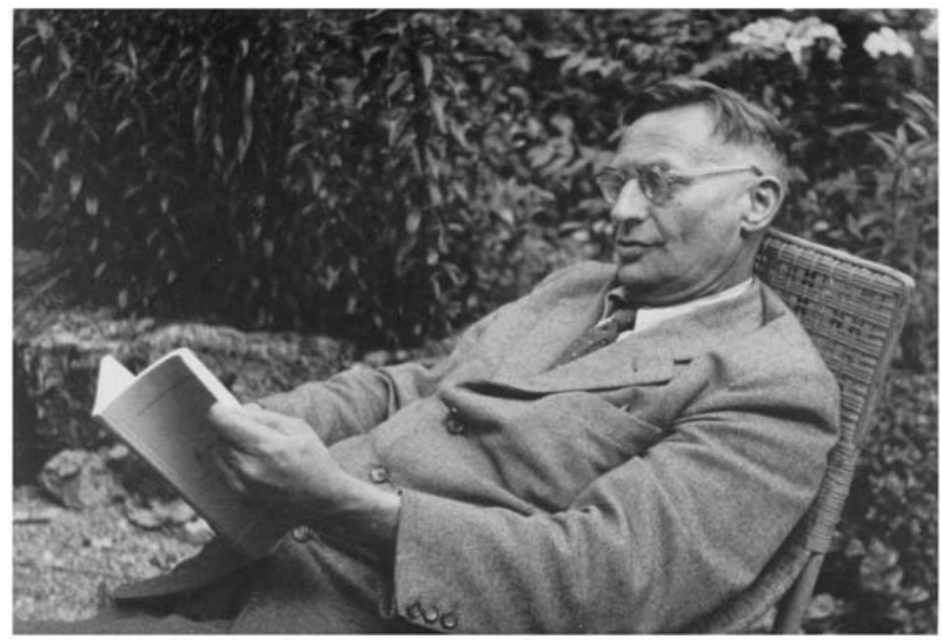

Prof. Ludwig Föppl, der Schwager, Sommer 1940 in Mittelberg

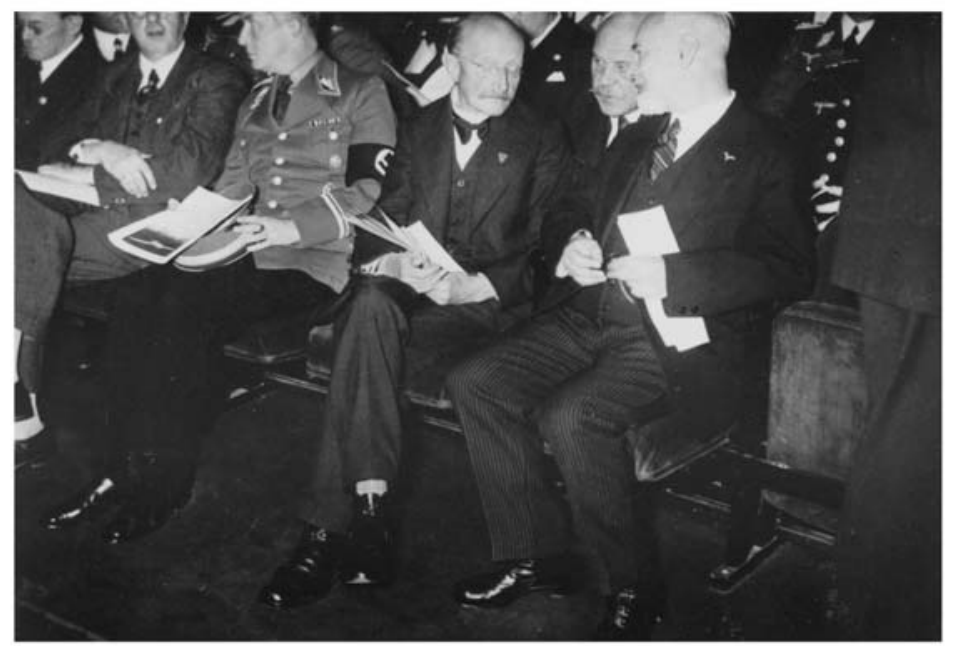

Geheimrat Max Planck, Prof. A. Sommerfeld und L. Prandtl in Berlin 

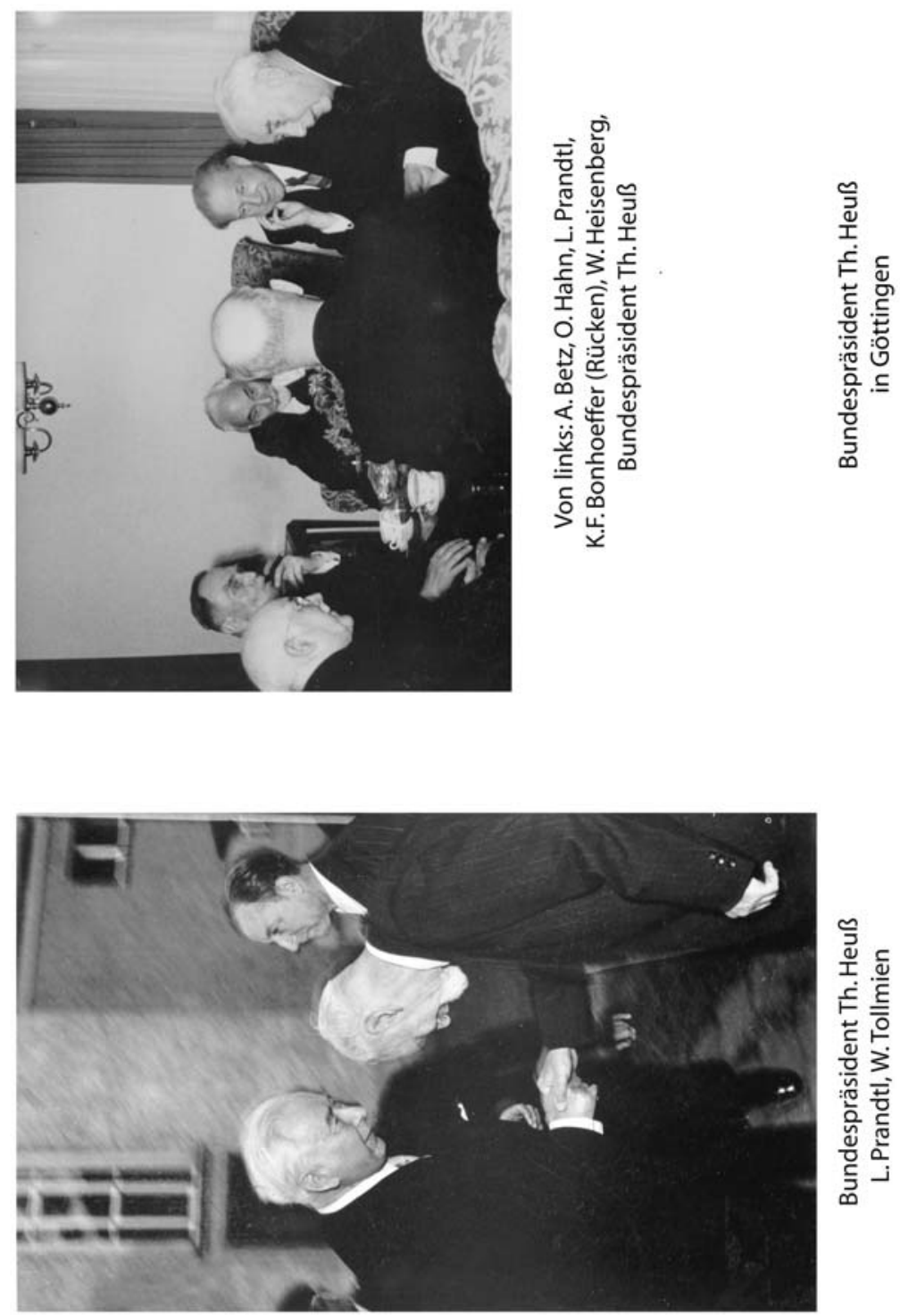

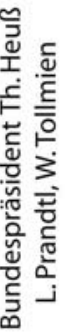




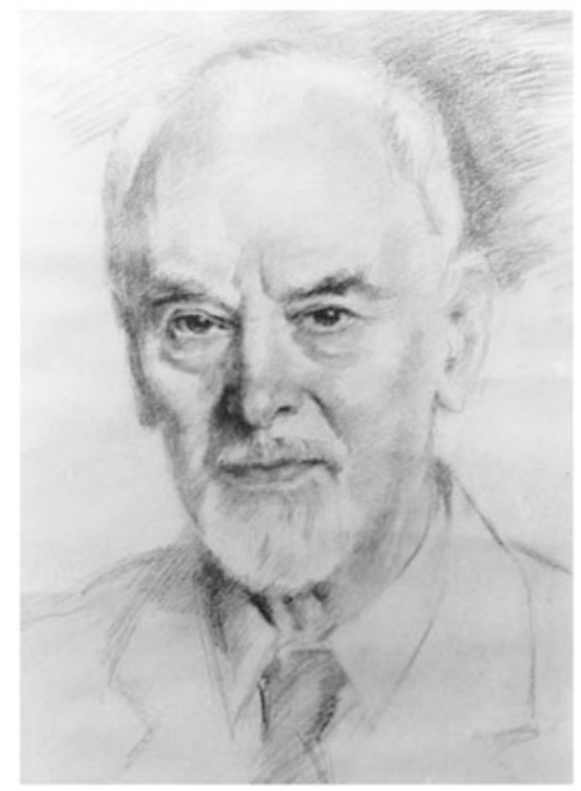

Zeichnung von Gottfried Stein 1950

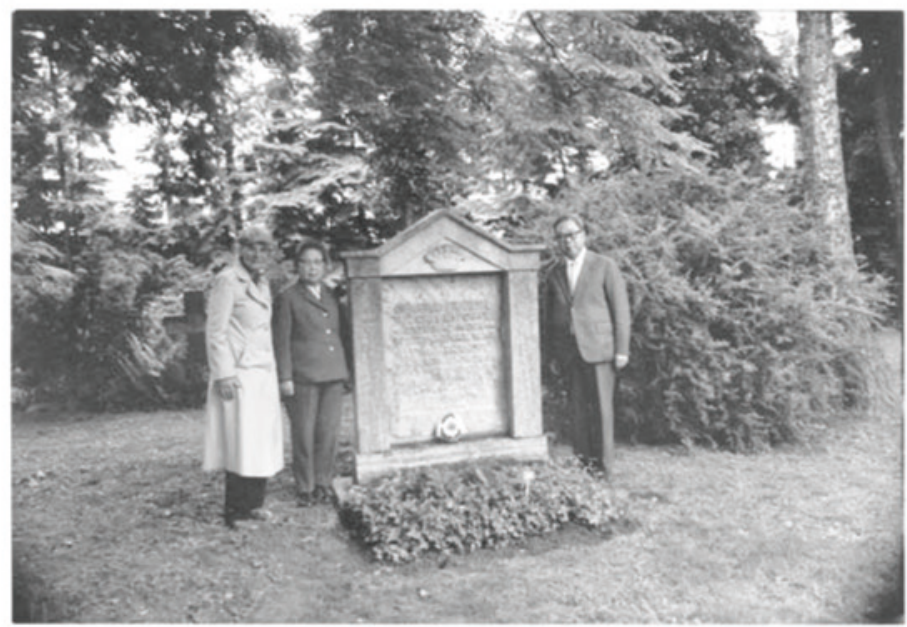

Lu Schang, geb. Hsin Cheng, mit ihrem Ehegatten und Johanna Vogel-Prandtl am Grab Ludwig Prandtls 


\section{Das Jahr 1933}

Ich komme nunmehr zum Jahr 1933 und der Zeit, die wir unter den Nationalsozialisten erlebten. Solange die Weimarer Republik noch bestand, wählten meine Eltern die Demokratische Partei, die 1930 in der Staatspartei aufging. Sie beschäftigten sich jedoch sehr wenig mit politischen Fragen und vertrauten der derzeitigen demokratischen Regierung. Diese Republik schien sich zu bewähren, so daß man trotz der Wirtschaftskrise, trotz des ständigen Parteienstreits an ihrem stetigen Weiterbestand nicht eigentlich zu zweifeln brauchte.

Im Haus Calsowstraße 15, und zwar in der Etage über uns, ertönte bei geöffnetem Fenster des öfteren die heisere Stimme eines neuen Wahlredners aus einem Radioapparat. Wir erfuhren, daß er Hitler heiße und begeisterte Anhänger habe. Meine Eltern nahmen wenig Notiz davon. Auch der Gedanke, sich selbst ein Radio anzuschaffen, lag ihnen damals fern. Als der Umsturz kam, war es für sie unerwartet. Man konnte es kaum fassen, wie es Hitler gelungen war, die Macht zu übernehmen. Und so begann die Herrschaft seiner zwölf Jahre währenden Diktatur.

"Die politische Verführbarkeit des bürgerlichen Geistes" (H. Plessner) war auch in Göttingen sehr bald spürbar. In besonderem Maße ging eine politisch radikale Initiative von Studenten aus, die sich bei steigender Mitgliederzahl schon vor dem 30. Januar 1933 zu den nationalsozialistischen Ideen bekannt hatten. Prandtl betrachtete die politische Lage wie bisher gelassen, war sie doch auch ohne unser Zutun über uns gekommen.

Jedoch war er bewegt und empört über Verordnungen, die seine Kollegen betrafen.

Dr. Marianne Wiener-Bernstein erinnert sich in einem Artikel des Göttinger Tageblattes vom 7.8.1987 an einige Aussagen von Kollegen ihres Vaters, Professor Felix Bernstein, der 1933 emigrieren mußte, nachdem man ihn aus seinem Institut für Statistik herausgedrängt hatte. Ich zitiere aus besagtem Artikel:

"Ferner weiß ich, daß Professor Ludwig Prandtl in seinen Seminaren laut auf die Nazis geschimpft hat." 
In der nun folgenden Zeit wurde gerade der Luftfahrtforschung seitens der neuen Regierung besonderes Interesse entgegengebracht, was sich dahingehend auswirkte, daß auf dem Institutsgelände große Bauvorhaben verwirklicht wurden. Dem beträchtlich vergrößerten Komplex stand Prandtl als erster Direktor vor. Einem in der Forschung stehenden Wissenschaftler kann eine solche Entwicklung im allgemeinen nur große Genugtuung bereiten. Man hätte also vermuten können, daß Prandtl öffentlich ein dem Erwarten entsprechendes Verhalten an den Tag legen würde, nämlich den politischen Wünschen der Befürworter der neuen Projekte entgegenzukommen, d. h. sich anzupassen. Indessen tat er nichts dergleichen. Er hat sich all die Jahre hindurch aufrecht geweigert, in die Partei einzutreten oder etwa in seinem Direktorzimmer ein Bild Hitlers aufhängen zu lassen. Man hat ihn jedoch niemals, wie so viele andere, vor die Alternative gestellt, sich entweder der Partei zugehörig zu bekennen oder andernfalls sein Amt niederzulegen. Aber ich bin sicher, in diesem Falle hätte er seinen Direktorposten aufgegeben, ehe er seine Überzeugung einem solchen Kompromiß geopfert hätte. Auch die jungen Leute in seinem Institut waren in der Mehrzahl seiner Anschauung.

Doch erinnere ich mich an ein Vorkommnis aus diesen dreißiger Jahren, als er einmal sehr bekümmert mittags zu Tisch kam und dann meiner Mutter folgendes berichtete: Er war in Begleitung eines Assistenten nach Hause gegangen, und dieser hatte ihm unterwegs mitgeteilt, daß er opportunerweise nun doch in die Partei eintreten wolle. Prandtl fand diese Haltung geradezu empörend, doch beherrschte er sich und riet ihm, mehr in väterlichem Ton, davon Abstand zu nehmen, man dürfe sich nicht zu den Ideen der Nationalsozialisten bekennen, er möge sich besinnen. Die Antwort des Assistenten, die nun an unserem Mittagstisch wiederholt wurde, prägte sich mir wortwörtlich ein: "Herr Professor, wir wollen auch mal etwas werden, Sie sind schon was!"

Wie sehr Prandtl 1933 durch die Hetze auf seine jüdischen Kollegen getroffen war, ist mir noch heute aus vielen erregten Gesprächen dieser Zeit bewußt. Über die Entwicklung, die dann mit den Reichsgesetzen begann und den deutschen Professoren jüdischer Abstammung eine Zwangsbeurlaubung verordnete, die später unwiderruflich in Entlassung umgewandelt werden sollte, ist schon sehr viel veröffentlicht worden, z. B. in den Büchern von Alan D. Beyerchen [7], Wissenschaftler unter 
Hitler, Constanze Reid [42], eine Biographie über Richard Courant, Max Born/James Frank: Luxus des Gewissens (Begleitband zur Ausstellung der Staatsbibliothek Berlin, mit Textbeiträgen von F. Hund, H. Maier-Leibnitz und V. F. Weißkopf [47]). Ich werde mich hier nur darauf beziehen, soweit darin von Prandtl die Rede ist.

Aus der Schrift "Luxus des Gewissens":

"James Franck, der im ersten Weltkrieg zur kämpfenden Truppe gehört hatte, wurde seines Lehramts nicht enthoben. Aber sein Stolz und seine Verbundenheit mit seinen jüdischen Kollegen ließen ihn einen eigenen Weg gehen. Am 17. April 1933 erklärte er seinen Rücktritt."

Prandtl war tief betroffen und traurig. Noch am 10.2.33 hatte er zusammen mit anderen Kollegen einen Brief an Franck unterzeichnet, um ihn, der nach Berlin berufen worden war, in Göttingen zu halten.

"Die Bedeutung und Leistungsfähigkeit unserer Fakultät beruht auf der Arbeitsgemeinschaft von Persönlichkeiten. Die Gemeinschaft hat in den letzten Jahren schon sehr schwere und folgenreiche Verluste erlitten. Durch Ihren Weggang würde das Werk, das hier unter Ihrer so wesentlichen Mitwirkung aufgebaut worden ist, in einer besonders schweren und gefährlichen Zeit vom Verfall bedroht sein."

Unterzeichner: Hilbert, Born, Windaus, Prandtl, Reich, Pohl, Neugebauer, Courant, Schermer, Eucken, Kienle, Angenheister und einige andere. ${ }^{1)}$

In der Biographie des jüdischen Kollegen Courant ist ausführlich und genauestens über den Ablauf der Geschehnisse an der Universität, soweit sie Courant selbst betrafen, berichtet worden. Wie sehr Prandtl sich eingesetzt hat, um dem bedrängten Kollegen zu helfen, über den Gerüchte verbreitet worden waren, er sei ein kommunistischer Agitator, geht aus der Darstellung im Kapitel "Frühling 1933" hervor. Ich möchte hieraus einige Stellen aus der deutschen Übersetzung zitieren: "Courant beschloß, sich selbst an die Behörden zu wenden. Dazu brauchte er einen Kollegen, der, von den 'Reichsgesetzen' nicht betroffen, Courants Version der Ereignisse vor der Universitätsverwaltung vertreten konnte. Seine Wahl fiel auf Prandtl.

1) Im Jahr 1953, dem Jahr der 1000-Jahrfeier der Stadt Göttingen, wurden Franck, Born und Courant zu Ehrenbürgern der Stadt Göttingen ernannt. 
Der Mechanik-Professor hatte allgemein als etwas naiv gegolten, aber während der hektischen Woche, die auf die Zeitungsnotiz über die Beurlaubungen gefolgt war, hatte er mutig und entschlossen gehandelt und einen seiner Assistenten, der sich als Spion der nationalsozialistischen Kräfte an der Universität entpuppt hatte, kurzerhand entlassen." Jener soll versucht haben, sich gegen ein Hinauswerfen zu wehren, und jemand erinnert sich, daß bei seiner Verabschiedung die Worte gefallen sind: "Herr Professor, Sie werden es bereuen, Sie werden noch an mich denken!" Hier möchte ich einfügen, daß es heutzutage wohl schwer zu begreifen ist, was es damals bedeutete, einen Parteigänger der Herrschenden, der Spitzeldienste für seine Vorgesetzten leisten sollte, von seinem Arbeitsplatz unerbittlich zu verweisen. Man muß obendrein bedenken, daß Prandtl seiner ganzen Natur nach nicht radikalen Lösungen zugeneigt war.

Nun zurück zu unserem Text über Courant, wo es weiter heißt: "Die beiden (Prandtl und Courant) kamen überein, daß Courant einen Brief an Prandtl schreiben sollte, in welchem er die Fakten über seine politische Betätigung nach dem Krieg (1. Weltkrieg) darlegen sollte. Dieses Schreiben wollte Prandtl dann an den Kurator weiterleiten."

Ich möchte noch eine Passage aus der Courant-Biographie zitieren. Sie handelt von der Abfassung einer Petition, die Courants Kollegen, Friedrichs und Neugebauer, zu seiner Unterstützung konzipiert hatten und die an 65 Kollegen versandt werden sollte. Es war eine Erklärung darüber, welche Bedeutung Courant erlangt hatte, der als Nachfolger Kleins das mathematische Institut übernommen hatte. Die Autorin schreibt: "16 antworteten überhaupt nicht, 21 verweigerten ihre Unterschrift zu geben, indem sie in einem Begleitschreiben ihre Gründe darlegten, wie z. B., man fürchte die Konsequenzen; man möchte auf keinen Fall die Aufmerksamkeit der Regierung erregen etc." Professor Kneser, ein früherer Assistent Courants, hielt es daraufhin für wirksamer, daß ein Brief verfaßt würde, der direkt an den Minister gelange.

"Dieser Brief, von Friedrichs, Kneser und Prandtl unterschrieben, beginnt wie folgt: 'Von uns Unterzeichneten kennt jeder Professor Courant aus mehrjähriger enger Zusammenarbeit. Nach dieser unserer Kenntnis hat sich Prof. Courant in seinem gesamten Wirken als deutscher Staatsbürger und Vertreter der deutschen Wissenschaft 
gefühlt und bewußt als solcher gehandelt. - Die seit 1921 wesentlich von ihm geschaffenen heutigen mathematischen Unterrichtseinrichtungen in Göttingen stellen ein Werk dar, das für die Wissenschaftspflege in Deutschland und für Deutschlands wissenschaftliche Weltgeltung von hoher Bedeutung und von seiner Person nicht ohne wesentliche Schädigung zu trennen ist.' Das Schreiben schloß mit der Bitte, daß man die drei Unterzeichneten persönlich anhören möge."

Unter die von Friedrichs und Neugebauer verfaßte Petition hatten nach dem Ablauf von zwei Wochen 28 Kollegen ihre Unterschrift gesetzt, einige seien hier genannt: Heisenberg, Hilbert, von Laue, Planck, Prandtl.

Diese Textstellen, die ich aus Courants Biographie anführte, erschienen mir wichtig, um zu belegen, wie sehr auch Prandtl sich wiederum exponiert hat, ohne vor den Folgen zurückzuschrecken, die seine Einmischung für ihn selbst hätte haben können.

Aus dem Text des Beamtengesetzes lautet nämlich ein Absatz des § 4: "Beamte, die nach ihrer politischen Betätigung nicht die Gewähr dafür bieten, daß sie jederzeit rückhaltlos für den nationalen Staat eintreten, können aus dem Dienst entlassen werden. Bei Beurteilung von Beamten in leitender Stellung wird ein strengerer Maßstab anzulegen sein."

Interessant ist noch, daß diese Bemühungen um Courants Rehabilitation letztlich tatsächlich von Erfolg waren. Die Beurlaubung wurde aufgehoben. Courant ließ sich später emeritieren und wanderte schließlich schweren Herzens, aber unter finanziell etwas günstigeren Bedingungen nach Amerika aus.

Der Zugriff der Machthaber verschonte jedoch keinen der jüdischen Dozenten an der Universität. Doch tat Prandtl sein möglichstes, der Rechtswidrigkeit entgegenzuwirken. Es gab weitere Beurlaubungen. Prandtl schrieb am 16. September 1933 aus Würzburg an seine Frau: "Der Kurator schreibt mir, daß Hohenemser vom Minister die Venia legendi entzogen worden ist. Es ist also so weit!" Auch für ihn hatte er sich eingesetzt und versucht, seine Entlassung zu verhindern. 
In der Folge von Intrigen eines anderen Unruhestifters im Institut waren auch einige Arbeitskollegen belastet worden, weil sie sich durch ihre Aussagen in die Affäre eingemischt hatten. Über die mißlichen Differenzen und Beschuldigungen wurde der KWG-Verwaltung zur Stellungnahme ordnungsgemäß Bericht erstattet. Ein Umlaufschreiben des Präsidenten der KWG folgte darauf: Zur Wiederherstellung des Arbeitsfriedens sollten nunmehr sieben Mitarbeiter, die als Zeugen ausgesagt hatten, entlassen werden. Das war nicht im Sinne Prandtls.

Die Verwicklungen des Falles, bei dem der Name des Georgiers Dr. Nikuradse immer wieder auftaucht, sind wohl niemals restlos aufgeklärt worden. Personen verschiedenen Ranges bemühten sich um gerichtliche Verfolgung der Sache. Ich zitiere aus der Akte des Rechtsanwalts, um die nun entstandene Situation verständlich zu machen: "Nachdem sich Herr Professor Prandtl zunächst geweigert hatte, der Aufforderung zur Kündigung nachzukommen, fand am 29. September 1933 mit den Herren Geheimrat Valentiner, Geheimrat Wolff und dem plötzlich dazutretenden SS-Hauptmann D. J. Weniger eine Unterredung statt, in der Weniger dem Professor Prandtl darlegte, es sei jetzt unwesentlich, ob ein Fehlurteil vorliege oder nicht, die Entlassung der sieben Herren sei eine beschlossene Sache und müsse unbedingt durchgeführt werden. Herr Professor Prandtl sei nur ausführendes Organ. Weigere er sich, so mache er sich zum Haupt einer Revolte gegen den nationalen Staat und müsse mit dem Konzentrationslager rechnen."

Trotz dieser schwerwiegenden Drohung hat Prandtl es dennoch nicht aufgegeben, sich für seine Mitarbeiter einzusetzen und die wahren Vorgänge beim preußischen Kultusministerium bekannt zu machen - er hatte am 4. Oktober dort in Berlin um eine persönliche Unterredung gebeten -, um die erneute Einstellung der Unschuldigen durch Revision zu erkämpfen.

Der Meinungskonflikt schwelte weiter.

\subsubsection{3, Prandtl an Planck:}

"Ich darf auch nicht verschweigen, daß ich mich durch die Behandlung in dem neuen Schreiben, wo meine Anträge ohne Angabe von Gründen abgelehnt werden, in meiner Ehre als Direktor eines Kaiser-Wilhelm-Institutes verletzt fühlen würde. Denn ich habe von meinen Pflichten gegen mein Institut eine zu hohe Auffassung, als daß ich 
ohne weiteres einem Dienstbefehl der vorgesetzten Stelle, den ich für schädlich für das Institut ansehe, einfach strammstehend nachkomme, ohne die letzte Möglichkeit einer Verständigung erschöpft zu haben."

\subsubsection{3, Planck an Prandtl:}

"Wollen Sie die Sache nicht doch endlich ruhen lassen? Die drei Herren (vier waren inzwischen freiwillig ausgeschieden) werden ja im Grunde genommen mit dem Schrecken davonkommen und im übrigen ihrer wissenschaftlichen Arbeit erhalten bleiben, wo sie die beste Gelegenheit haben, die erlittene Scharte auszuwetzen. Was mich bei dem allen am tiefsten schmerzt, ist der Gedanke, daß Sie selber nun fortwährend Ihre kostbare Zeit und Kraft auf diese widrige Angelegenheit verwenden zu müssen glauben, in die Sie durch die Schuld anderer hineingezogen worden sind.

Möge das neue Jahr Ihnen und Ihrem Institut Besseres bescheren.

Mit herzlichen Grüßen von Haus zu Haus

Ihr stets ergebener Planck."

\subsubsection{4, Prandtl an Planck:}

"Der Grund dafür, daß ich die Sache nicht ruhen lasse, wie Sie es mir nahelegten, ist einfach der: Ich wünsche meinen Leuten, die die Verfechtung ihrer Angelegenheiten vertrauensvoll in meine Hände gelegt haben, die Treue zu halten. Und ich habe selbst das lebhafteste Interesse daran, daß das Bild, das die Verhandlungen von den Zuständen in unserem Institut gegeben haben, richtiggestellt wird."

Mag der Leser für sich aus diesen Briefzitaten erkennen, wie Prandtl aufrichtig, mit unbestechlicher Festigkeit, nach seiner eigenen Überzeugung gehandelt hat. Letztlich konnten die drei Mitarbeiter aufgrund von Prandtls beharrlichem Eintreten ihre rechtmäßigen Arbeitsplätze behalten.

Im Laufe der unerfreulichen Verhandlungen hatte man überrascht zur Kenntnis nehmen müssen, daß Nikuradse seit mehreren Jahren als nationalsozialistischer Aktivist vertraulichen Kontakt zu seiner Parteidienststelle unterhielt. "Um den Arbeitsfrieden und die Arbeitsfähigkeit des Instituts wiederherzustellen", sprach Prandtl nunmehr seine Entlassung aus, obwohl er sich dadurch vollends die Feindschaft des SS-Hauptmanns Weniger zuzog. Die Versuche des SS-Geheimdienstmannes, dem Professor zu 
schaden, blieben jedoch folgenlos. Trotz des Ärgers, den der Fall des Dr. Nikuradse für den Institutschef gebracht hatte, sorgte Prandtl dafür, daß jener an der Breslauer Hochschule eine entsprechende Stelle bekam.

Ähnlich war sein Verhalten im März 1934. Ich übernehme die Darstellung dieses anderen Personalfalles aus dem Text "Institutsgeschichte" von Kurt Kraemer [17]:

"Im März 1934 mußte das Gesetz zur Wiederherstellung des Berufsbeamtentums (das schon zur Begründung der Entlassung der Juden an der Universität gedient hatte) auch im KWI für Strömungsforschung durchgeführt werden, folgendermaßen: Der Generaldirektor der KWG, Glum, forderte am 10.3. (vertraulich!) Loyalitätserklärungen derjenigen Institutsangehörigen an, die ehemals Sozialdemokraten waren, und verlangte die Entlassung eines angeblichen Kommunisten. Prandtl antwortete am 13.3. '.. Man kann mich von der Leitung des hiesigen Instituts entfernen, wenn man der Ansicht ist, daß ich dafür nicht mehr tauge, man kann aber von mir nicht verlangen, daß ich einen wertvollen Facharbeiter bloß deshalb entlasse, weil er als junger Mensch einmal eine Zeit lang in eine den kommunistischen Ideen nahestehende Jugendorganisation geraten ist.' Eine Rückfrage der Generalverwaltung beim Reichsminister des Inneren ergab, daß eine Ausnahme im Prinzip nicht gemacht werden darf, es sei denn ...

Darauf schrieb der Präsident Planck am 10.4. selbst (vertraulich!), daß der fragliche Kupferschmied nur weiterbeschäftigt werden darf, wenn Prandtl persönlich die volle Verantwortung übernimmt und durch den Obmann der NSBO (Zelle des Instituts) Beanstandungen nicht erhoben werden. So geschah es."

Prandtl lebte zwar weitgehend in der abstrakten Gedankenwelt seiner Forschung, war aber dennoch immer bereit, sich die Zeit zu nehmen, um sich der Angelegenheiten und Nöte seiner Mitmenschen und Mitarbeiter anzunehmen und wirksame Hilfe anzubieten.

Professor F. Schultz-Grunow schreibt in seiner Schrift [46], die er "Das geistige Erbe Ludwig Prandtls" nennt: "Auch Prandtls Hilfsbereitschaft darf nicht vergessen werden. Er kümmerte sich buchstäblich um Leib und Leben seiner Mitarbeiter. In der Wirtschaftskrise der dreißiger Jahre verzichtete er auf sein Gehalt als Institutsdirektor 
zugunsten notleidender Mitarbeiter, und als der Krieg ausbrach, waren wir alle freigestellt."

Zwischen Max Planck und Ludwig Prandtl bestand eine ganz persönliche Beziehung. Seine zweite Frau war die Münchner Schulfreundin meiner Mutter (sie wurde meine Patentante), und die beiden vertrauten Jugendgefährtinnen standen auch nach ihrer Eheschließung brieflich in enger Verbindung.

Auch im privaten Zusammensein mit Max Planck war man beeindruckt von seinem Ethos strengster Pflichterfüllung. Man durfte es als ein großes Glück ansehen, diesen integren, bedeutenden Mann, der in jeder Hinsicht ein Vorbild war, während der ersten Jahre des totalitären Regimes im Amt des Präsidenten der KWG verantwortlich zu wissen.

In Prandtls Institutsbereich wuchsen die Aufgaben. Je mehr sich die führenden Männer der Technik die Gedankengänge des Aerodynamikers zu eigen machten, desto stärker erweiterte sich das Arbeitsgebiet. Als im Sommer 1933 das 25. Jubiläum der Aerodynamischen Versuchsanstalt gefeiert wurde, hatte sich eine große Zahl namhafter Gelehrter und Industrieller in Göttingen eingefunden. Bei einer Besuchsbegehung in den Institutshallen konnte man sehr verschiedene Modelle bewundern: Neben Flugzeugmodellen standen dort Modelle von Stromlinienautos, Schnelltriebwagen sowie nachgebildete Funktürme, bei denen der Winddruck ermittelt worden war. Auch die Öffentlichkeit nahm regen Anteil an der neusten Forschung.

Sehr begrüßt wurde das Entgegenkommen der Stadt Göttingen, die zur Jubiläumsfeier ein Stück Land auf dem Flugplatz freigab, auf dem man eine Flughalle speziell für die Zwecke der AVA errichten wollte. Der Staatssekretär des Luftfahrtministeriums hatte ebenfalls den Zeitpunkt dieser Feier gewählt, um die Bewilligung eines neuen Bauabschnitts persönlich bekanntzugeben. Ein moderner, großer Windkanal sollte auf dem Gelände der Bunsenstraße erbaut werden, der zu Forschungszwecken dringend benötigt wurde. Ein Jahr später, 1934, wurde das Bauvorhaben spektakulär mit dem ersten Spatenstich begonnen; und in der Folge, nach zweijähriger Bautätigkeit, konnte 1936 der neue Windkanal in Betrieb genommen werden. 


\section{Ehrendoktor von Cambridge und Trondheim}

Anfang Juli 1934 reiste Prandtl in Begleitung seiner älteren Tochter nach Cambridge, um dort an einer Tagung des Kongresses für technische Mechanik teilzunehmen. Er war zu Gast bei seinem englischen Kollegen Prof. G. I. Taylor und hielt auf dem Kongreß einen Vortrag [20].

1936 wurde er erneut nach Cambridge eingeladen, weil ihm dort die Ehrendoktorwürde verliehen werden sollte.

9.6.1936, Cambridge: "Soeben habe ich die erste freie Stunde, nachdem ich gestern meinen Vortrag absolvierte. Er ist gut vonstatten gegangen. Die Tage bei Taylors waren sonst sehr gemütlich, nur mit Gesprächen aller Art ausgefüllt. In zwei Stunden wird die Zeremonie vor sich gehen. Ich brauche selbst gar nichts zu sagen, das ist auch gut so, da ich heute stockheiser bin."

10.6.36: "Die Sache gestern war sehr feierlich. Lord Baldwin, der Ministerpräsident, ist Kanzler der Universität und hat die Promotion vollzogen. - Ich erzähle Euch später Näheres. Morgen bin ich in Farnborough und abends in Berlin."

Notiz vom 3. Juli 1936 im Berliner Lokalanzeiger:

"Englischer Ehrendoktor für Ludwig Prandtl. Die Universität Cambridge hat den Vorsitzenden der Gesellschaft für angewandte Mathematik und Mechanik zum Ehrendoktor ernannt."

Zum 15. September 1935 war Prandtl nach Trondheim in Norwegen eingeladen worden, da man ihm auch dort bereits ein Jahr zuvor die Ehrendoktorwürde an der Trondheimer Technischen Hochschule verleihen wollte. Er konnte aber nicht persönlich bei der Feierlichkeit anwesend sein. Man sandte ihm dann das Diplom und den verliehenen Ring zusammen mit der Urkunde. Erst zwei Jahre später, im September 1937, konnte eine Begegnung mit den norwegischen Kollegen dort in Trondheim stattfinden. Prandtl hatte einen Vortrag angekündigt, um somit seinerseits nachträglich seinen Dank für den Ehrendoktortitel zum Ausdruck zu bringen. Er wurde daraufhin auch nach Oslo eingeladen. 
Die Freundschaften zu den Trondheimer Kollegen waren seitdem besonders herzlich. In den Hungerjahren nach dem Krieg hat uns Professor Brün aus Trondheim durch privaten Überbringer mehrere Flaschen wertvollen Dorschlebertrans geschickt, obwohl er sich selbst während der Besatzungszeit gegen die Deutschen gestellt und im Untergrund gewirkt hat. 


\section{Das Gebirgshaus}

An dieser Stelle möchte ich noch aus dem Jahr 1935 von einem Ereignis privater Natur berichten, das vor allem der Initiative meiner Mutter zuzuschreiben war. Meine Eltern erwarben in Österreich, im Kleinen Walsertal, ein Grundstück und ließen darauf ein bescheidenes Holzhaus erbauen. Sie hatten es immer abgelehnt, in Göttingen den Besitz eines eigenen Hauses anzustreben wie die meisten ihrer Kollegen in jenen dreißiger Jahren. Für sie war es weit verlockender, im süddeutschen Raum ein kleines Eigentum zu erlangen. Den Ort Mittelberg kannten wir schon seit einigen Jahren. In einem der Kinderheime dort hatte meine Schwester eine längere Erholungszeit verbracht. Später war dann dieses hochgelegene Tal noch mehrmals das Ziel für unsere Winterferien gewesen. Aus dem Tagebuch meiner Mutter:

"Als wir im Jahre 1934 das Weihnachtsfest wieder in Mittelberg im Hause Schaule verbrachten und Ludwig sich von einer schweren Grippe so glänzend erholte, wurde in mir der deutliche Wunsch lebendig, an diesem schönen und gesunden Fleckchen Erde ein kleines eigenes Heim zu erwerben. Ostern 1935 verhandelte ich bereits über Lage und Bau des Hauses, das dann schon im Sommer langsam aus der Erde herauswuchs."

Mein Vater hat selbst die Pläne für den Hausbau gezeichnet, nach denen dann die Arbeiten ausgeführt wurden. Im Dezember 1935 verbrachten wir bereits unseren ersten Winterurlaub in dem Häuschen. Aus dem Tagebuch:

"Mit der Gemütlichkeit war es in den ersten Tagen noch nicht weit her, wenn der Zentralheizofen nicht recht funktionierte. Später aber war der Hausherr so weit erfahren, ihm das abgewöhnt zu haben. Er kümmerte sich in liebevollster Weise um sein Haus und meinte einmal, es wäre doch ein wunderschönes Spielzeug. Man sah ihn viele Male am Tage mit Säge und Hammer herumlaufen und Ordnung schaffen."

Die Vorstellung, daß man nach der Pensionierung dort in das Haus übersiedeln wolle, beschäftigte damals meine Eltern, und sie steckten voller Pläne. Allerdings kam alles ganz anders. 
Verwandte und Freunde fanden den Weg zu uns in das entlegene Tal und teilten mit uns die Freuden des Skilaufens und Bergsteigens. Die köstliche, klare Bergluft erfrischte jung und alt, und die gemütlichen Abende mit Spielen, Geplauder und nützlichen Beschäftigungen, meist unter Mitwirkung des gemütvollen Gastgebers, sind allen in bestem Angedenken geblieben.

Es konnte vorkommen, wenn meine Mutter dort gerade ein Strickzeug in Händen hatte, dessen Garn aber in fatale Unordnung geraten war, daß sie von meinem Vater beobachtet wurde, wie sie ungeduldig daran herumzupfte. Es war anscheinend hoffnungslos verheddert. Er schaute von seinem Brief auf, den er zu schreiben im Begriff war, guckte eine Weile zu und sagte dann: "Laß mich einmal versuchen, die Sache wieder in Ordnung zu bringen." Meine Mutter fand dann allerdings, er solle sich die Mühe sparen. Doch nun ließ er sich von seinem eben gefaßten Vorhaben nicht abbringen und sagte nur: "Es macht mir doch Spaß!" Der Schwierigkeitsgrad des zu lösenden Problems übte einen unwiderstehlichen Reiz auf ihn aus. Er ging nun sachgerecht an die Aufgabe. Er wickelte, steckte durch und knüpfte die Knoten behutsam auf, und alle verfolgten aufmerksam seine Manipulationen. Er widmete sich dieser einfachen Beschäftigung mit Geduld und stillem Eifer, und indem man zuschaute, war man bestens unterhalten. Gespannt beobachtete man das allmähliche Gelingen, das er zuletzt wie ein Spiel zu Ende führte.

Meiner Schilderung möchte ich noch eine Briefstelle aus viel späterer Zeit zur Seite stellen. Prandtl schreibt am 17.4.1952 an Professor Marguerre, von dem er offensichtlich eine Buchsendung erhalten hatte: "Die Verpackung des Buches ist, wie mir scheint, Ihr eigenes Werk. Ich fand sie dadurch bemerkenswert, daß der Bindfaden, der durchaus zuverlässig verschlossen war, sich so hat auflösen lassen, daß er schließlich als eine einzige unverletzte Schnur wiedergewonnen werden konnte. Dies ist eine Art Sport von mir (man könnte auch Geduldspiel sagen). Die Lösung ergab sich ohne Suchen in eindeutiger Form, und der Bindfaden wurde für weitere Benützung in Reserve gestellt."

Eine Begebenheit möchte ich erwähnen, die für einen meiner kleinen Vettern unvergeßlich geblieben ist. Ferienbesuch! Die Betten für die verschiedenen Gäste waren so verteilt, daß mein Vater mit seinem Neffen ein Zimmer teilte. Nachts um vier Uhr 
wurde mein Vetter sanft von ihm geweckt. Er wies ihn an, aufzustehen und führte ihn an das geöffnete Fenster. Dort zeigte er auf einen Stern, der am Himmel in leuchtender Helle über den Bergen stand, und erklärte ihm, daß es die Venus sei, ein Planet des Sonnensystems. Beide genossen gemeinsam in dieser stillen Nacht die Schönheit des überaus klaren Sternenhimmels und vertieften sich in sinnender Betrachtung in den Anblick des mit funkelndem Licht herübergrüßenden Morgensterns.

Auch eine unserer Freundinnen erinnert sich noch jetzt im Alter an einen bemerkenswerten Ausspruch Prandtls. Als sie ihn damals in Mittelberg auf einem Spaziergang begleitete, sahen sie am Wiesenrand eine kleine Heuschrecke ihre zierlichen Sprünge vollführen. "So etwas wie dieses originelle Tierlein kann der Mensch trotz ständigen technischen Fortschrittes niemals nachbilden. - Es ist ein Wunder der Schöpfung."

Von den vielen Besuchern, die in den folgenden Jahren in dem Häuschen Quartier nahmen, möchte ich doch wenigstens eine Familie erwähnen. Im Herbst 1936 überlieBen meine Eltern ihr neues Feriendomizil einem befreundeten Kollegen, dem Philosophen Georg Misch, dem der Lehrauftrag an der Göttinger Universität aufgrund des "Arierparagraphen" entzogen worden war. Man hatte ihnen auch die Wohnung gekündigt, so daß sie gern auf das Angebot meines Vaters eingingen. Österreich war noch nicht an Nazi-Deutschland angeschlossen, so daß man dort keinerlei Ermittlungen zu befürchten hatte. Mischs erwachsene Kinder sahen sich gezwungen, Deutschland zu verlassen, und ehe sie ins Ausland emigrierten, haben sie dort ihre Eltern noch einmal aufgesucht.

Der Sohn Peter hatte eine Professur in Kanton (China) angenommen. Er schrieb in unser Fremdenbuch: "19. September 1936: Unmittelbar vor der Abreise nach Canton zum letzten Mal in unseren deutschen Bergen, zum Abschied von den Eltern, die hier im behaglichen Prandtl-Hause so gut aufgehoben zu wissen, ich froh bin. Es war schön, gerade für die letzten Tage zusammen zu sein." Die Tochter Lore (später Frau des Nobelpreisträgers Felix Bloch), die von Dänemark kam, fuhr über Mittelberg in die Schweiz; die jüngste Tochter, meine Freundin Lilli, reiste von dort nach England. Später lebten alle drei Geschwister in Amerika. 
Professor Misch schrieb am 7. März ins Fremdenbuch:

September, Oktober, November

und fast den ganzen Dezember, dann wiederum im neuen Jahr

bis über Ende Februar.

So lebten wir 6 Monat lang

in Prandtls Haus am Bergeshang,

selbander in der Einsamkeit;

die Berge ragen über Freud und Leid.

Und manche kommen und klopfen an,

ob man denn hier nicht wohnen kann?

Jawohl mit Behagen! Doch nicht jedermann.

Die Herrin des Hauses, auf die kommt es an!

Sie ließ es Freunden so lange Zeit.

Ist sie doch stets zum Guttun bereit."

Misch verließ Deutschland Ende 1937 und ging nach England, während seine Frau, die Tochter Wilhelm Diltheys, wegen ihrer zarten Gesundheit in Göttingen blieb, wohin ihr Mann nach sieben Jahren der Trennung im Mai 1945 zurückkehrte.

Aus der Universitätszeitung Nr. 2 aus dem Jahr 1946:

"Zur Rückkehr des Göttinger Philosophen aus der Emigration: Mit Georg Misch ist eine der bedeutendsten Gestalten der deutschen Philosophie aus der Emigration zurückgekehrt, und wenn er jetzt sein altes Lehramt wieder aufgenommen hat, so haben wir allen Grund, ihm dafür dankbar zu sein."

Im Februar 1938 hatte sich meine Schwester Hilde mit dem Gerichtsreferendar Wolfgang Weber verlobt. Meine Eltern haben sich über diese Verbindung sehr gefreut. Das Familienoberhaupt, Rudolf Weber, war ein kritischer, charaktervoller Mann, der als Minister in Oldenburg seinen Dienst quittiert hatte, weil er keine Kompromisse mit der nationalsozialistischen Regierung einzugehen gewillt war. Wolfgangs Schwester, Dr. Sophie Weber, war Kinderärztin, später die vertraute Ärztin meiner Kinder, die uns allen beratend zur Seite stand. Das Schicksal, das heraufzog, nahm 
der Braut aber bald wieder dieses Glück, für uns alle eine tiefe Bekümmernis. Am 16. September 1939 hatte die Kriegstrauung in unserem Hause stattgefunden, und es folgten alsdann mit der Einziehung des jungen Ehemanns die schmerzlichen Trennungen. Am 29. Juni 1941 ist Wolfgang Weber vor Riga als Oberleutnant gefallen. 


\section{Eintreten für W. Heisenberg}

In der Physik gab es seit längerer Zeit eine schlimme Kontroverse zwischen Anhängern einer sogenannten arischen Physik - von Alfred Rosenberg unterstützt - und jenen der modernen Physik. Die Vertreter der ersten Gruppe, die der Quantenmechanik und Einsteins Relativitätstheorie ablehnend gegenüberstanden, verlangten, daß die Physik mehr "pragmatischen Charakter" haben sollte. Da diese Experimentalphysiker (zu ihnen gehörten Johannes Stark und Philipp Lenard) sich überdies als politische Bewegung verstanden, versuchten sie, durch ihre Machenschaften die Gesamtheit der Physiker im Nazi-Deutschland zu beherrschen. Ihre Angriffe richteten sich 1937 massiv gegen den jungen Professor für theoretische Physik, Werner Heisenberg.

Viele seiner Kollegen, die Heisenberg hochschätzten, wagten daraufhin eine Verteidigung, die in Form von schriftlichen Protesten an das Ministerium gingen. Auch Heisenbergs Vorgehen - er selbst verfaßte einen Brief "zur Wiederherstellung seiner Ehre", den er an den Reichsführer der SS, Heinrich Himmler, sandte - hatte zunächst nicht zu dem gewünschten Ergebnis geführt. Die eingehend genaue Darstellung dieser Begebenheit, wie sie sich im Ablauf eines Jahres ereignet hat, finden wir in dem Buch von Elisabeth Heisenberg "Erinnerungen an Werner Heisenberg" [12]. Hier sei nur noch kurz bemerkt, daß auch Prandtl sich unmittelbar eingesetzt hat, um Heisenberg in dieser bedrängenden Lage tatkräftige Hilfe zu leisten, indem er sich dem Angriff entgegenstellte, wodurch er ihm letztlich zu seiner Rehabilitation verhelfen konnte.

In dem Buch "Wissenschaftler unter Hitler" [7] befaßt sich der Autor Alan D. Beyerchen ausführlich mit der "Affäre Heisenberg" sowie mit ihrer ganzen Geschichte. In welcher Weise nun Prandtl versucht hat, dem jüngeren Kollegen aus dieser Situation herauszuhelfen, berichtet A. D. Beyerchen:

"Der Fall Heisenberg blieb bis zum Hochsommer (1938) ungelöst. Im Juli kam wichtige Unterstützung von Ludwig Prandtl, dem Göttinger Fachmann für Aerodynamik, der bei einem von der Deutschen Akademie für Luftfahrtforschung schon vor einiger Zeit veranstalteten Festessen neben Himmler saß. Prandtl hatte gewartet, bis er den SS-Führer von seinen aus der Annexion Österreichs entstandenen, dringenden Ver- 
pflichtungen befreit wähnte, um seiner Verteidigung von Heisenberg Gehör zu verschaffen."

Am 12. Juli 1938 erinnerte Prandtl Himmler in einem Brief an ihr Gespräch. "Als ich gelegentlich der Festsitzung der Deutschen Akademie der Luftfahrtforschung am 1. März des Jahres Ihr 'Tischnachbar war, brachte ich das Gespräch auf gewisse Schwierigkeiten, in die die deutschen Vertreter des Faches 'Theoretische Physik' durch ungerechtfertigte Angriffe seitens einer Gruppe von Experimentalphysikern gebracht worden sind, und erwähnte besonders die persönlichen Nöte des Herrn Heisenberg ... Ich möchte im Anschluß daran noch über die theoretische Physik ein paar Worte sagen. Die Schwierigkeiten, die diesem Fach gemacht werden, sind hauptsächlich dadurch hervorgerufen, daß eine an sich kleine Gruppe von Experimentalphysikern, die mit den Forschungen der Theoretiker nicht haben Schritt halten können, sich mit Heftigkeit gegen die neuere Entwicklung der theoretischen Physik aufgelehnt haben, in der Hauptsache aus dem Grunde, daß in dem Lehrgebäude der heutigen Physik erhebliche Bestandteile stecken, die von nichtarischen Forschern stammen.

Aber es gibt auch unter den Nichtariern Forscher allerersten Ranges. Ich erinnere da nur an den früh verstorbenen Heinrich Hertz, der mit mühevollen und geistreich angeordneten Versuchen zum ersten Mal das Vorhandensein der elektrischen Wellen nachwies, derselben Wellen, die heute in der drahtlosen Telegraphie und dem Rundfunk die große technische Bedeutung gewonnen haben. Der Physiker Einstein ist durch und durch erstklassig.

Die Wissenschaft steht einfach vor der Tatsache, daß Gesetze entdeckt worden sind, die ihrerseits wieder den Anlaß zu weiteren Entdeckungen geliefert haben und die man nicht weglassen kann, ohne das auf ihnen weiter aufgebaute Lehrgebäude zu zerstören. Es wird immer neben den theoretischen Physikern die Experimentalphysiker geben müssen, deren Stärke in der Ausführung von Versuchen liegt, zu denen sie sich die Theorie von den Theoretikern machen lassen. Es ist aber unerhört, wenn solche experimentell eingestellten Leute nun die Theorien, weil sie ihnen nicht zu folgen vermögen, einfach als verderblich oder verwerflich erklären und die Vertreter der Theorie deshalb glauben mit Schmutz bewerfen zu können. Ich möchte, um Ihnen die Auffassung des bekannten theoretischen Physikers Max Planck vor Augen zu führen, den Auszug aus einer Ansprache dieses Gelehrten übersenden.

Was nun Herrn Heisenberg selbst betrifft, so ist er von Stark ja noch viel schwerer 
beleidigt worden, und es ist dringend nötig, daß in irgendeiner wirksamen Form die Beschimpfung von ihm genommen wird und deutlich gemacht wird, daß die zentralen Behörden sowohl wie die obersten Parteistellen nicht der Meinung von Herrn Stark sind. Es ist dies einfach deshalb nötig, weil bei dem Weiterbestehen des Schimpfes die Wirksamkeit von Herrn Heisenberg als akademischer Lehrer schwer gehemmt wäre, indem den Studenten, zum Schaden ihrer späteren fachlichen Wirksamkeit, die Meinung beigebracht würde, daß das, was sie hier lernen könnten, für sie wertlos, vielleicht sogar schädlich sei.

Für sehr geeignet würde ich es halten, wenn es möglich wäre, Herrn Heisenberg in der 'Zeitschrift für die gesamte Naturwissenschaft', die als Organ der Reichsfachgruppe Naturwissenschaft der Reichsstudentenführung erscheint, persönlich mit irgendeinem geeigneten Beitrag aus seinem Fachgebiet zu Worte kommen zu lassen. Für die geeignete Wahl dieses Fachgebietes wäre ich gerne bereit, mich mit Herrn Heisenberg ins Benehmen zu setzen."

Ich zitiere nun noch einmal Alan Beyerchen: "Es besteht kaum ein Zweifel, daß Prandtls scharf formulierte Verteidigung Heisenbergs und der theoretischen Physik in der Angelegenheit eine entscheidende Rolle gespielt hatte. Nicht ganz zwei Wochen später schrieb Himmler an Heydrich, daß er Prandtls Brief zustimme und der Meinung sei, daß der Studentenbund Heisenberg in seiner Zeitschrift publizieren lassen sollte."

Der Münchner Lehrstuhl für Physik, der schon 1935 von Sommerfeld für Heisenberg vorgesehen war, ging dann allerdings an einen Physiker namens Wilhelm Müller, über den sich Prandtl wiederum mit einer Deutlichkeit, die nichts zu wünschen übrig läßt, äußerte: "Herr Müller bringt für die theoretische Physik nichts, aber auch rein gar nichts mit. Statt dessen hat er in polemischer Form ein Arbeitsprogamm veröffentlicht, das nur als Sabotage eines für die technische Weiterentwicklung unentbehrlichen Faches bezeichnet werden kann." (Memorandum vom Mai 1941, zitiert bei E. Heisenberg [12].) 


\section{Stimmen zur Situation jener Zeit}

An dieser Stelle drängt sich vielleicht für jüngere Leser die Frage auf: Wie konnte sich Prandtl an Himmler wenden, der für die größten Verbrechen im Naziregime verantwortlich gemacht werden muß? Sie kann nur in Unkenntnis jener Zeitumstände gestellt werden. Mehr Gewicht als eine eigene Antwort, die ich geben könnte, haben da gewiß die Worte des Historikers Christian Maier, der auf das Phänomen der deutschen Gutgläubigkeit und Arglosigkeit hinweist. Zum Verständnis dieser Probleme trägt ein Vortrag, in Tel-Aviv gehalten, in seiner differenzierten Betrachtungsweise bei. Ich zitiere aus dem Vortrag "Verurteilen und Verstehen", der in der FAZ vom 28. Juni 1986 abgedruckt wurde.

"Sie [ein Teil der Deutschen ist gemeint] konnten zwar von vornherein allerhand Unrecht am NS-Regime ausmachen, aber deswegen noch nicht schon wissen, zu welch riesigen, einmaligen Verbrechen ihr Land unterwegs war. Hätte man ihnen den Holocaust vorausgesagt, hätten sie ihn kaum für möglich halten können. Und das nicht nur, weil sie zumeist unpolitisch und mit besonderem Respekt vor dem Staat erzogen waren.- ... Wann wird einer ganzen Generation nachträglich zugemutet, sie hätte ihre beruflichen Chancen nicht wahrnehmen dürfen, da sie dadurch oft notwendig in enge Berührung mit den Herrschenden kommen mußte? Was eigentlich hätten wir Heutigen in solcher Lage getan? Nur wenn wir wüßten, daß wir es besser gemacht hätten, unter den damaligen Verhältnissen und mit dem Wissensstand der damaligen Zeit, könnten wir die damaligen Deutschen - immer abgesehen von denen. die Vergehen und Verbrechen begingen - verurteilen. ... Wir haben auch allen Anlaß, uns vorzunehmen, es besser zu machen; zumal wir heute wissen können, was ein totalitäres Regime ist und wie es entsteht. Doch gibt es keinen Grund, daß wir uns in unserer so viel glücklicheren Lage als Pharisäer aufspielen."

Ich möchte hier noch eine Erinnerung anfügen, eine Unterhaltung aus dem Jahr 1943. Mein Vater kam von einem Spaziergang zurück, den er in Gesellschaft einer guten Bekannten gemacht hatte. Er berichtete: "Weißt Du, was mir die Frau X. erzählt hat? Im Osten würden jüdische Menschen zusammengeholt und umgebracht! Wie kann man nur so einen Unsinn glauben! Im vorigen Krieg haben die Franzosen auch solche Märchen ausgestreut, daß die Deutschen in Belgien Greueltaten an Frauen und Kin- 
$-143-$

dern verübt hätten." Er war seiner ganzen Natur nach überhaupt nicht in der Lage, derartiges für möglich, ja auch nur für denkbar zu halten. 


\section{Kongreß in Amerika}

Am 1. September 1938 trat Prandtl eine Reise nach Amerika an, um an der Tagung des 5. Internationalen Kongresses für angewandte Mechanik in Cambridge, Massachusetts, teilzunehmen. Er war damals bereits 63 Jahre alt. Er fuhr in Begleitung von Professor Blenk, Dr. Schultz-Grunow, Professor Schlichting und vieler anderer Kongreßteilnehmer. Man traf auf dem Dampfer "Bremen" zur Überfahrt über den Atlantik zusammen. Meine Mutter nutzte die Abwesenheit ihres Gatten für einen erneuten Kuraufenthalt in Kissingen, der ihr vom Arzt dringend angeraten worden war. Dort erreichten sie die folgenden Briefe ihres Mannes:

\section{September 1938:}

"Die Reise ist bis jetzt recht glatt und auch angeregt verlaufen. Das Schiff ist sehr schön, das Essen königlich, unsere Gesellschaft sehr behaglich. Jeden Morgen reite ich auf einem Kamel und einem Pferd (beide mit Elektromotor als Lebensprinzip) und schwimme dann. Das Wetter ist oft sehr schön gewesen, ab und zu auch ein Nebeltag und im Golfstrom etwas steiferer Wind. Morgen, zwei Uhr, sollen wir in New York sein. Von der Landung aus werden wir ins Hotel gebracht und brauchen uns zwölf Tage um nichts zu kümmern. Auf dem Kongreß sollen 130 Vorträge sein, drei immer gleichzeitig. Aber auch 43 ist noch viel ..."

In Cambridge angekommen, traf Prandtl unter den ausländischen Fachkollegen auch gute Bekannte, wie z. B. Professor von Kármán, Professor G. I. Taylor, mit denen unter anderem auch manche persönlichen Gedanken ausgetauscht wurden. Über die Gespräche 1938 in Cambridge hat von Kármán in seiner Biographie [15] seinem Mitverfasser Lee Edson einiges berichtet. Jener hat dann aber das Buch erst nach Kármáns Tod allein herausgebracht. Es wurde dabei sicherlich nicht sorgfältig genug unterschieden zwischen dem, was wirklich gesagt wurde, und dem, was Kármán zurückblickend von sich aus noch hineininterpretiert hat.

In Fachkreisen, in denen Kármáns Buch "Die Wirbelstraße" bekannt wurde, ist man zu dem Schluß gekommen, daß diese Biographie kritisch betrachtet werden muß. Professor Blenk hat sich bei einem Treffen der Ludwig-Prandtl-Ringträger am 9. Mai 1972 wie folgt dazu geäußert: "Die Autobiographie von Kármán kann keinen An- 
spruch auf historische Richtigkeit erheben, was jeder Leser dieses sonst interessanten Buches beachten sollte."

Prandtl, der vom Berliner Ministerium ersucht worden war, eine Empfehlung für einen Kongreß in Deutschland auszusprechen, hatte sich bereitgefunden, den ausländischen Kollegen eine Einladung der deutschen Regierung vorzulegen, und hoffte, dadurch den wissenschaftlichen Austausch mit den anderen Ländern in friedlicher Koexistenz weiterhin pflegen zu können. Daß daraufhin dort in Cambridge unter den Kollegen der verschiedenen Nationen erregte politische Gespräche stattgefunden haben, ausgelöst durch die Einladung, die durch Prandtl bekanntgemacht worden war, ist den noch lebenden Teilnehmern durchaus im Gedächtnis geblieben.

Professor Blenk schrieb am 9. Juli 1987 an Dr. Rotta: "Ich erinnere mich gut an die gespannte, teilweise recht unfreundliche Stimmung auf dem Kongreß, die zwischen uns Deutschen und den anderen Teilnehmern herrschte. Es gab viele Einzeldiskussionen über die Notwendigkeit oder Wahrscheinlichkeit des 2 . Weltkrieges, wobei wir deutschen diese Notwendigkeit wohl meistens nicht einsahen. Dabei verteidigten wir die Politik, aber nicht die Ideologie oder gar die Verbrechen Hitlers, soweit solche damals überhaupt schon bekannt waren. Was wir mit Recht verteidigen zu müssen glaubten, war 1. die Aufhebung des Diktats von Versailles, 2. die Wiedererlangung der Wehrhoheit, 3. die Vereinigung mit Österreich zum Großdeutschen Reich. Es ist interessant, was ein Historiker wie Sebastian Haffner in seinem Buch 'Anmerkungen zu Hitler' zu diesem Fragenkomplex schreibt."

Auch Prandtl hatte in den Diskussionen mit den ausländischen Kollegen versucht, sein Land gegen die abwertenden Beurteilungen des gegenwärtigen Deutschlands zu verteidigen. Er glaubte damals, ohne im mindesten kritisch zu sein, an die guten Absichten und die Aufrichtigkeit seiner Regierung.

Männer, die wie er im kaiserlichen Deutschland aufgewachsen waren, in deren Denken sich Loyalität gegenüber der Obrigkeit und Patriotismus eng verbanden, fühlten gerade Ausländern gegenüber die Verpflichtung, die politischen Ereignisse daheim zu rechtfertigen, indem sie ihr Land vor vermeintlichen Verunglimpfungen in Schutz nahmen. Diese Haltung wird auch in seiner ausländischen Korrespondenz sichtbar. 
Bald nachdem die deutsche Gruppe verabschiedet worden war, schrieb G.I. Taylor im Rückblick auf diese Gespräche unter anderem:

\section{September 1938 (drei Tage vor der Sudetenlandkrise):}

"Now I must ask you to believe that, whatever happens between our countries, the friendship and admiration which $I$, in common with aerodynamical people in all other countries, feel for you, will be unchanged. I realized that you know nothing of what the criminal lunatic, who rules your country, has been doing, and so you will not be able to understand the hatred of Germany which has been growing for some years in every nation, which has a free press."

Die Übersetzung: Nun muß ich Sie bitten, mir zu glauben, daß, was auch immer zwischen unseren Ländern geschieht, die Freundschaft und Bewunderung, die ich im Verein mit aerodynamischen Forschern aus aller Herren Länder für Sie hege, unverändert bleiben wird. Es ist mir klar geworden, daß Sie nichts wissen, von dem, was der verbrecherische Irre, der Ihr Land beherrscht, getan hat, und so werden Sie nicht in der Lage sein, den Haß auf Deutschland zu verstehen, der seit einigen Jahren in all den Ländern gewachsen ist, die eine freie Presse haben."

Prandtl hat später freilich seine politischen Irrtümer, die Taylor hier anspricht, erkennen müssen.

Nach dem Schluß des Kongresses war für die Teilnehmer noch die Besichtigung der Weltausstellung in New York vorgesehen, die gerade erst im Aufbau begriffen war.

Bei der Überfahrt über den Atlantik, die die deutsche Wissenschaftlergruppe auf dem amerikanischen Schiff "New York" angetreten hatte, ereilte die Passagiere die Nachricht von Hitlers bevorstehender Besetzung des Sudetenlandes, was die Schiffsleitung zu einem Ausweichmanöver veranlaßte, um einem eventuellen Kriegsgeschehen zu entgehen. Man steuerte die Küste Norwegens an; aber da sich inzwischen die politische Lage wieder beruhigt hatte, und zwar durch das Münchner Abkommen die Krise überwunden worden war, konnten die Schiffsgäste, mit einiger Verspätung allerdings, auf deutschem Boden an Land gebracht werden. 
Es schien nun bestätigt, daß man die friedlichen Absichten der deutschen Regierung richtig beurteilt hatte und $\mathrm{zu}$ Recht die schlimmen Voraussagen zurückgewiesen hatte. In einer Antwort an Taylor gab Prandtl zu verstehen, daß er seinen vormaligen Standpunkt, nämlich die bestehenden deutschen Verhältnisse verteidigen zu wollen, nicht aufgegeben hatte. Seine Argumente bleiben aber mehr oder weniger unverständlich. Daß man sich aber schon ein Jahr später wirklich im Kriegszustand befinden würde, das konnte Prandtl, der, wie gesagt, gutgläubig den Nachrichten in den Zeitungen vertraute, sich damals unmöglich vorstellen.

Als dann am 1. September 1939 der Krieg mit dem Überfall auf Polen eröffnet wurde, bewegten meinen Vater kummervollste Gedanken, wußte doch diese Generation genug von den Schrecken eines Krieges. "Es wird wie bisher weitergearbeitet", war seine lakonische Weisung an die Belegschaft.

Der erste Kriegswinter brachte für die Göttinger manche Einschränkung. Im Februar 1940 hatte man Familien aus dem Saarland evakuiert, um sie vor der kriegerischen Auseinandersetzung mit Frankreich in Sicherheit zu bringen. Den Bewohnern der großen Etagen in unserem Haus wurden einige Flüchtlinge zugeteilt, in jedem Stockwerk zwei oder drei Personen. Zu uns kam die Familie eines Grubenarbeiters mit sieben Mitgliedern ins Haus, die auf die drei Mietparteien verteilt wurden. Meine Mutter war voll Anteilnahme und stellte ihnen für das abendliche Zusammensein der Großfamilie unsere geräumige Küche zur Verfügung. Und auch mein Vater nahm sich mitunter die Zeit, sich dort einzufinden, um sich mit ihnen einmal länger zu unterhalten. Manche anderen Wohnungsbesitzer stöhnten nur über die Belastung der Einquartierung. Die Saarländer blieben etwa drei Monate in ihren Quartieren, bis sie in ihre Heimatdörfer zurückreisen konnten.

Unsere Familie trafen im Jahr 1940 und 1941 mehrere traurige Schicksalsschläge. Ende Juli starb gleich nach der Geburt das Baby meiner Schwester. Im Dezember verstarb meine Mutter. Von dem Tod meines Schwagers, der Ende Juli 1941 bei Riga gefallen ist, habe ich schon berichtet.

Für uns alle war es eine schwere Zeit. Meine Schwester wohnte seit ihrer Verheiratung nicht mehr bei den Eltern, so daß nach dem Tod meiner Mutter nur mein Vater 
und ich in der großen Wohnung zurückblieben. Mein Vater vermißte die Fürsorge und die erfrischende Lebhaftigkeit meiner Mutter, mit der sie an allem teilgenommen hatte. Es war nun oft sehr still bei uns. Ich setzte meine philologischen Studien fort und konzentrierte mich nach besten Kräften auf die Lehrveranstaltungen. Der Haushalt war durch ein verläßliches Mädchen gut versorgt. Im übrigen versuchte ich, mich nach Vaters Gewohnheiten zu richten, damit ihm im Täglichen nichts fehlen sollte.

Wie üblich nahm sich mein Vater jedes Wochenende einen größeren Spaziergang vor, auf dem ich ihn begleitete. In den Osterferien 1941 reisten wir dann gemeinsam zu unseren süddeutschen Verwandten nach München sowie zu seinen Cousinen nach Schleching. Mit Hilfe dieser lieben Menschen gelang es uns schließlich, von den jüngsten Ereignissen mehr Abstand zu gewinnen.

Ingenieur Müller erinnert sich an einen Ausspruch Prandtls aus jener Zeit: "Wissen Sie, es ist schwer, einen solchen Verlust zu tragen, aber das Leben geht weiter; also arbeiten wir." Die Arbeit nahm ihn wieder ganz in Anspruch. 


\section{Der Physikerstreit}

Obwohl Prandtl wie bisher mit Arbeitsproblemen überhäuft war, ergriff er im Frühjahr 1941 wiederum die Initiative zu einer entschiedenen Stellungnahme gegenüber der derzeitigen NS-Wissenschaftspolitik. Diesmal ging es darum, den Herrschenden seinen Standpunkt bei dem unseligen Streit der Physiker bekannt zu machen.

In dem Jahr nach Heisenbergs Rehabilitierung hatte sich der lange schwelende Kampf zwischen den Vertretern der sogenannten "arischen Physik" und denjenigen der theoretischen Physik neu radikalisiert. Die Hauptangreifer waren immer wieder die Professoren Philipp Lenard und Johannes Stark, denen es am 1. Dezember 1939 gelungen war, den Münchner Lehrstuhl für theoretische Physik, der ursprünglich für Werner Heisenberg vorgesehen war, mit einem ihrer Gesinnungsgenossen neu zu besetzen. Da er Aerodynamiker war, holte man Prandtls Rat ein. Er formulierte seine Meinung bemerkenswert deutlich: Wilhelm Müller sei kein schöpferischer Geist und die Münchner Professur eine Fehlbesetzung. Er nannte die Berufung einen Sabotageakt gegen die technische Weiterentwicklung.

Prandtl wollte sich der Macht dieser überlegenen Nazi-Gruppe widersetzen. Er verfaßte eine Verteidigungsschrift für die theoretische Physik, die er direkt an Hermann Göring in Berlin adressierte. Wieviel Mut damals zu einem solchen Schritt gehörte, nämlich Wahrheiten auszusprechen, die der NS-Führung ihre Unzulänglichkeit in der Beurteilung fachwissenschaftlicher Erkenntnisse aufzeigen mußten und die ihre treuen Anhänger als unfähige Nichtskönner brandmarkten - das ist heute nicht mehr vorstellbar!

Ein zeitgenössischer Kollege, der betagte Physiker Friedrich Hund, dem ich kürzlich begegnete, brachte das Gespräch darauf. Und er erinnerte sich mit größter Anerkennung der mutigen Schrift Prandtls.

Der Brief vom 28. April 1941 an den damaligen Reichsmarschall Hermann Göring lautet wie folgt:

"Abwendung einer schweren Gefahr für den Nachwuchs an deutschen Physikern.

Es dreht sich, kurz gesagt, darum, daß eine Gruppe von Physikern, die leider das Ohr 
des Führers besitzt, gegen die theoretische Physik wütet und die verdientesten theoretischen Physiker verunglimpft, ganz untragbare Besetzung der Lehrstühle durchzusetzen versteht usw., und zwar mit der Begründung, daß die moderne theoretische Physik eine jüdische Mache wäre, die man nicht schnell genug auszutilgen und durch eine 'deutsche Physik' zu ersetzen haben würde. Was es damit auf sich hat, habe ich in einer hier beigefügten Anlage des näheren ausgeführt. Unstreitig ist jedenfalls, daß die theoretische Physik ein gerade für die Ausbildung des Führernachwuchses in der Physik unentbehrliches Fach ist, ist es doch ihre Aufgabe, die Gesamtheit der physikalischen Tatsachen logisch zu ordnen und hieraus die Gesetzmäßigkeiten zu entwickeln, mit Hilfe derer dann der technische Physiker seine Neukonstruktion planmäßig entwerfen und ihre Wirksamkeit vorausberechnen kann. Eine Physikerausbildung ohne theoretische Physik kann gute Handlanger hervorbringen, niemals aber Führer, die das Gesamtgebiet in der erforderlichen Weise überblicken und beherrschen.

Das gemeinsame Merkmal der erwähnten, von Professor L e n a r d geführten Gruppe von Physikern ist, daß ihren Mitgliedern scharfes kritisches Denken auf mathematischer Grundlage ermangelt. Dadurch, daß diese nicht in der Lage sind, Arbeiten der modernen theoretischen Physik, die recht großes mathematisches Können erfordern, kritisch zu beurteilen, sind sie sich auch im unklaren über die Unentbehrlichkeit dieses Faches. Im Gegensatz zu ihnen wird von allen wirklich fachkundigen Physikern, die das notwendige mathematische Rüstzeug besitzen, einhellig die Notwendigkeit der theoretischen Physik anerkannt. Ich möchte Sie, hochverehrter Reichsmarschall, bitten, etwa auf Grund meiner Ausführungen zwei bekannte, in der Industrie stehende Physiker, Professor $\mathrm{R} \mathrm{a} \mathrm{m} \mathbf{s}$ a u e r, Leiter des Forschungslaboratoriums der AEG, und Professor J o o s, Chefphysiker der Zeiss-Werke, befragen zu lassen, die durch ihre Stellung gegenüber dem terroristischen Verhalten der LenardGruppe genügend unabhängig sind. Ich selbst möchte, da man gegen mich einwenden kann, ich sei kein Physiker vom Fach, in der Angelegenheit lieber im Hintergrund bleiben (ich habe allerdings in jungen Jahren das Doktorexamen in der Physik gemacht und die seitherige Entwicklung der Physik immer aufmerksam verfolgt, so daß mir das Sachverständnis nicht mangelt!).

Die erwähnte Gruppe der 'deutschen Physiker' hat bei ihrem Geschrei, daß die moderne theoretische Physik eine jüdische Mache wäre, nicht nur das Ohr des Wissenschaftsministeriums, sondern auch das der Studentenführung; wie schon ange- 
deutet, betätigt sie sich in wüsten Angriffen auf die verdientesten und angesehensten Vertreter der theoretischen Physik und macht auch die Studenten diesem Fach abspenstig. Sie hat in letzter Zeit auch eine geradezu unglaubliche Neubesetzung durchgesetzt, die man nicht anders als völlig sinnlos bezeichnen kann, wenn man nicht etwa den 'Sinn' darin sieht, daß zerstört werden soll ..."

Als Anlage zu diesem Brief, in dem er letztlich darum bat, die Sache auch Hitler zu unterbreiten, hatte Prandtl einen achtseitigen Aufsatz über theoretische Physik beigelegt zur Erläuterung der wissenschaftlichen Grundlagen. Er erscheint hier ungekürzt im Anhang. In Physikerkreisen wurden Exemplare des Manuskriptes an verschiedene Adressen geschickt. Hier eine Rückantwort:

Professor Dr. Joos, Chef-Physiker der Zeiss-Werke, Jena, schrieb am 5. Mai 1941: "Seit langem habe ich keine solche Freude erlebt wie die, die Sie durch Ihr Schreiben, dessen Durchschlag Sie mir sandten, mir bereiteten! Endlich hat man die Hoffnung, daß doch höchste Stellen die Gefahr sehen werden. Sie haben ein ganz großes Verdienst um die Physik erworben, gleichgültig, ob es sofort wirkt oder nicht! Ich finde übrigens die Darstellung der theoretischen Physik ganz wundervoll!"

Prandtls Angriffsschrift war gewissermaßen ein Signal geworden. Der in seinem Brief genannte Physiker, Carl Ramsauer, der zum Vorstand der physikalischen Gesellschaft gewählt worden war, unterbreitete am 20. Januar 1942 dem Reichserziehungsministerium eine umfangreiche, klug angelegte Schrift, um so gegen die Machenschaften der begünstigten "Lenard-Gruppe" vorgehen zu können. Seine Argumente wurden respektiert und brachten in der Tat den Erfolg:

A. Beyerchen [7], der darüber berichtet, schreibt: "Seit dem Sommer 1942 unterstützte Görings Ministerium die fachorientierten Physiker gegen weitere politische Einmischung." 


\section{Rumänienreise}

Vom 29. April bis zum 14. Mai 1941 unternahm Prandtl auf Einladung seines früheren Doktoranden, Professor Valcovici, eine Reise nach Rumänien, um dort mehrere Vorträge zu halten.

Aus Prandtls Bericht: "Im Hinblick darauf, daß durch die Rumänienreise notwendigerweise alle zum Teil recht dringenden Arbeiten in Rückstand kommen werden, hatte ich vor dem Antritt der Reise erhebliche Bedenken gegen diese und fürchtete, daß das Ergebnis den Verlust an Zeit nicht aufwiegen würde."

Trotz dieser Bedenken trat er die Reise am 29. April 1941 an. Von Berlin aus gelangte er per Flug nach Bukarest.

Aus dem Flugzeug an die Tochter: "Wir reisen sehr behaglich über eine zauberhafte Landschaft aus weißer Watte, mit unregelmäßig darin verstreuten Wolkentürmchen; über uns blauer Himmel. Jetzt kommen wieder Berge, hinter denen die Wolkendecke aufreißt. Jetzt ohne Wolken, Elbe, Gebirge, dann Prag, freundliche Landschaft, Talsperre mit romantischen Burgen, welliges Land, lange Dörfer."

Auf dem Flugplatz in Bukarest wurde er von Professor Valcovici abgeholt.

Aus dem Bericht: "1. Mai: Heute ist erster Mai. Alle Läden sind geschlossen; dafür gibt es aber Straßenverkäufer mit Blumen, Apfelsinen und dergleichen (sitzen auf dem Pflaster oder stehen barfuß). Das Straßenbild ist nicht einheitlich: Staatsgebäude in europäischem Stil und Geschäftshäuser im amerikanischen ( 7 bis 10 Stockwerke), viele breite Straßen. Nachmittags, zur Bummelzeit, so viel Volk unterwegs, daß man nur ganz langsam vorwärts kommt. Daneben viele Autos (sie haben Überfluß an Benzin)."

Er schrieb nach seiner Rückkehr den erwähnten Bericht über diese Vortragsreise. Daraus teile ich nun in Auszügen mir interessant erscheinende Abschnitte mit:

"Meine auf Anordnung des Reichsministeriums für Wissenschaft und Erziehung unternommene Reise nach Rumänien hat vom 29. April bis 14. Mai stattgefunden. 
Die folgenden Vorträge wurden gehalten:

1.) An der mathematisch-naturwissenschaftlichen Fakultät ein allgemeiner Vortrag 'Über Strömungsforschung'.

2.) Drei Vorträge von je zwei akademischen Stunden für Studenten über die Themata 'Kompressible Strömung', 'Kleine Reibung, besonders Grenzschichten' und 'Turbulenz'. Sämtliche Vorträge wurden durch zahlreiche Lichtbilder und zwei auch durch einen Film unterstützt.

3.) An der Technischen Hochschule in Temeschburg ein allgemeiner Vortrag am 9. Mai.

Am 10. Mai war der rumänische Nationalfeiertag (Tag der nationalen Einigung) mit großem Schüleraufmarsch und Militärparade, dem ich auf dringenden Wunsch der Rumänen beiwohnte.

Die Vorträge, die durch Plakate und Zeitungsartikel wie auch durch Einladungskarten angekündigt waren, sind an beiden Orten sehr stark besucht gewesen. Ansprachen in deutscher Sprache vorweg, in Bukarest eine des Dekans der naturwissenschaftlichen Fakultät und eine meines alten Doktoranden Professor Valcovici.

Begrüßungsworte des Dekans, Professor San Jonescu:

'Meine Damen und Herren, die naturwissenschaftliche Fakultät der Universität Bukarest hatte bis nun die Ehre, zwei der angesehensten deutschen Professoren als Gäste zu empfangen.

Es waren die Herren Professoren August Sieberg und Adolf Butenandt, deren überaus interessante Ausführungen einen nachhaltigen Eindruck zurückgelassen haben.

Nun hat Herr Dr. Ludwig Prandtl, Doktor honoris causa, Direktor des Kaiser-Wilhelm-Institutes für Strömungsforschung und Professor an der Universität Göttingen, die Liebenswürdigkeit gehabt, unserer Einladung Folge zu leisten.

Herr Professor Prandtl wird während seines Bukarester Aufenthaltes eine Reihe von Vorträgen aus seinem Forschungsgebiete halten.

Heute wird das Thema über Strömungsforschung behandelt werden. Sehr geehrter Herr Professor und Kollege!

Ihr Vortrag interessiert nicht nur Mathematiker und Ingenieure, sondern auch uns Biologen, denn dieselben Prinzipien und Gesetze, die die Bewegung in der leblosen Natur leiten, beherrschen auch viele Lebenserscheinungen des tierischen und pflanzlichen Körpers. Mehr noch, ich könnte sogar behaupten, daß letzten Endes diese Prinzipien auch hinsichtlich der Siedlung und Einrichtung der Glieder einer Gesell- 
schaft oder Nation ihre Anwendung finden. Deshalb bin ich überzeugt, da $B$ ihre wichtigen Ausführungen mit viel Interesse und Aufmerksamkeit vom Auditorium verfolgt werden. Als Dekan der naturwissenschaftlichen Fakultät habe ich die Aufgabe, mit einigen Worten auf die Notwendigkeit einer immer engeren deutsch-rumänischen wissenschaftlichen Zusammenarbeit hinzuweisen. Wie ich schon des öfteren bei derartigen Gelegenheiten erwähnt habe, wiederhole ich mit derselben Überzeugung, daß wohl in erster Linie wissenschaftliche Mitarbeit die verschiedenen Völker und Nationen miteinander verbindet."

\section{Bericht über Temeschburg:}

"In Temeschburg waren neben weltlichen sogar auch geistliche Würdenträger, u.a. der orthodoxe Bischof, anwesend, der nachher auch noch zu dem Empfang kam und mir seine Freude über das Gehörte und Gesehene zum Ausdruck brachte.

Professor Valcovici hat mich während meines Bukarester Aufenthaltes dauernd in liebenswürdiger Weise betreut. Er zeigte mir auch die Stadt und die Universität, auch sein eigenes, recht ansehnliches Institut für reine und angewandte Mathematik. Am Nachmittag des 1. Mai veranstaltete er in seinem sehr hübschen Hause einen TeeEmpfang zu meinen Ehren, bei der sich ein großer Kreis von Herren und Damen einfand, nach meinem Eindruck die besten Kreise der Bukarester Gesellschaft (sehr viele Hochschullehrer, verschiedene gewesene Minister, rumänische Offiziere). Daneben war auch die Deutsche Botschaft vertreten, letztere durch Prinz Solms. Die Herren in Temeschburg haben sich ebenfalls sehr um mich bemüht. Ich wurde vom Dekan und einigen Professoren sowie auch von einer Abordnung der Volksdeutschen am Bahnhof empfangen und zu einer kleinen Pension begleitet, weil die großen Hotels sämtlich von der deutschen Wehrmacht in Anspruch genommen waren ... Man sieht sehr viele deutsche Mannschaften (Militär) und auch Offiziere auf den Straßen und auch in den Lokalen."

"Im Straßenbild von Bukarest war nichts von Unruhe irgendwelcher Art festzustellen. Es soll aber sehr gehamstert werden. Die Verpflegung in den Eßlokalen, auch das Bier und der Wein, der im Lande selbst wächst, ist sehr gut und genügt auch verwöhnten Ansprüchen. Es sind fleischlose Tage eingeführt, aber Schinken, geräuchterte Zunge und dergleichen werden dabei nicht als Fleisch gerechnet. Wegen der auch dort vorhandenen Mehlknappheit war man auf den bemerkenswerten Ausweg verfal- 
len, daß nur alte Brötchen verkauft werden dürfen (von denen natürlich weniger gegessen wird als von frischen). Außerdem sind zwei Maisbrottage eingeführt.

Bei Gesprächen mit Rumänen kommt vielfach der große Kummer zum Ausdruck darüber, daß sie verschiedene Landesteile haben abgeben müssen, und vor allem wird betont, daß alles andere eher erträglich wäre als die Abgabe einer so großen rumänischen Bevölkerung an Ungarn (1940 durch den 2. Wiener Schiedsspruch wird von den Ungarn ein Gebiet in Siebenbürgen, das ihnen 1920 verlorenging, mit einer Million Bewohnern zurückgenommen). Man hofft, daß durch Umsiedlung eine andere Lösung gefunden wird. Auf der Rückfahrt durch Ungarn hatte ich eine Unterhaltung mit einem Ungarn aus diesem an Ungarn zurückgegebenen Gebiet, der seinerseits natürlich der Ansicht war, auch der übrige Teil des früheren Ungarn müßte noch an Ungarn zurückkommen."

Die Rückreise mit der Bahn ermöglichte Prandtl noch einen Aufenthalt sowohl in Budapest wie in Wien. Am 15. Mai kam er, beträchtlich ermüdet, nach Göttingen zurück.

Im Jahr 1942, am 10. November, wurde Prandtl von der Universität Bukarest der Ehrendoktor verliehen. 


\section{Aus der Zeit der letzten Kriegsjahre}

An dieser Stelle scheint es mir nicht unwichtig, Prandtls Haltung gegenüber Auszeichnungen zu charakterisieren:

Wer der Meinung ist, Prandtl, dem Ehrungen und Preise auch von der NS-Regierung verliehen wurden, hätte sich dadurch dem Regime sehr verbunden gefühlt, vermag mit dererlei Vermutungen nicht diejenigen zu überzeugen, die Prandtl genau gekannt haben, seien es Kollegen, Mitarbeiter oder Freunde. Er legte keinen besonderen Wert auf diese Ehrendiplome. Sie kamen ins Haus und wurden dort in Schubladen abgelegt, ohne daß er sie später jemals erwähnte.

Wie wenig ihm Ehrungen solcher Art bedeutet haben, mag ein Wort aus jenen Jahren bekräftigen, an das ich mich noch gut erinnere. Für Schüler, die sich im Flugmodellbau hervortaten, war der "Ludwig-Prandtl-Preis" geschaffen worden, der dann jährlich dem fähigsten jungen Konstrukteur verliehen wurde, mit einer Summe von 3000 RM als Prämie. $\mathrm{Zu}$ Hause aber ist niemals von diesem Preis die Rede gewesen. Und so konnte es geschehen, daß ich von anderer Seite darauf aufmerksam gemacht wurde: "Ihr Vater ist ja bei der Göttinger Bevölkerung recht populär geworden durch den Ludwig-Prandlt-Preis, der jedes Jahr vergeben wird. Wußten Sie das gar nicht? So etwas steht doch auch hier in der Zeitung."

Die Forschung weiter voranzubringen, unabhängig von der politischen Lage in Deutschland, war der einzig wesentliche innere Antrieb seiner Wirksamkeit. Zudem war es ihm auch am Herzen gelegen, endlich eine große Arbeit abschließen zu können: Im Jahr 1942 war die dritte erweiterte Auflage seines Lehrbuchs "Abriß der Strömungslehre" erschienen, das unter dem Titel "Führer durch die Strömungslehre" im Vieweg-Verlag herauskam [27]. Diesen Titel haben später seine einstmaligen Schüler, Professor K. Oswatitsch und Professor K. Wieghardt, beibehalten, die in jüngster Zeit eine erweiterte Neubearbeitung fertigstellten.

So sehr ihn auch sein ständig wachsender Aufgabenkreis in Anspruch nahm, so blieb er doch der schlichte, gütige Mensch, der immer bereit war, sich für eine gute Sache einzusetzen. So hat er, um nur ein Beispiel zu nennen, trotz seiner vielen Beanspru- 
chungen, sich um die Doktorarbeit eines an der russischen Front stehenden Doktoranden gekümmert. Es liegt von dem Dissertanten, Hans Böhm, das Antwortschreiben vor.

\subsubsection{3:}

"Sehr geehrter Herr Professor!

Soeben kam ich von der Wache. Eine herrliche, sternklare und mondhelle Nacht, wie man sie nur in Rußland erleben kann, verkürzte mir die Stunden und brachte meine Gedanken richtig in Gang. Ich ging nochmals den Inhalt Ihres lieben Briefes durch und freute mich ganz besonders darüber. Ihr Buch ist nun fertig, und ich soll ein Exemplar davon erhalten! Sie werden mir wohl glauben, Herr Professor, wie sehr ich mich darüber freue! Ich möchte Sie bitten, das Buch nach meiner Heimat zu senden, da ich Anfang Februar endlich Urlaub bekomme. Das Buch kommt dann natürlich mit nach Rußland - muß eben was anderes raus aus dem Tornister.

Meine Dissertation wollen Sie vornehmen! Darüber bin ich wohl am meisten erfreut, denn ich brauche wohl nicht zu betonen, wie sehr ich an dieser Arbeit hing. Sie wollen sie überarbeiten, hoffentlich braucht nicht allzuviel verbessert zu werden. Ich denke eigentlich sehr oft daran, was ich anders hätte machen sollen. Aber Fehler und Verbesserungen sieht man ja immer erst nachher."

\subsubsection{4:}

"Das fortwährende Wandern und das unstete Leben an der Front ließen mich einfach nicht zu einem Antwortschreiben auf Ihren lieben Brief kommen, und ich beeile mich nun, Ihnen für die Bemühungen meiner Reklamation zu danken. Kaum wage ich an den Erfolg zu denken und warte schon sehr auf die Entscheidung ...

Ihr Hans Böhm."

Im Jahr 1943 berichtet mein Vater in einigen Briefen mehrmals von seinen Fahrten nach Berlin, wo er immer wieder einmal seine vorgeordnete Dienststelle, die KaiserWilhelm-Gesellschaft, aufsuchte, da mündliche Unterredungen bevorzugt wurden. Am 4. März erlebte er dort einen Bombenangriff mit. Der Weg in einen Luftschutzkeller über eine unbeleuchtete Treppe wurde ihm zum Verhängnis, er stürzte und schlug sich eine Kopfwunde. Darauf wurde er zu einem Arzt gebracht, der die Wunde sofort ohne Betäubung nähen mußte und ihm dann einen großen Kopfverband an- 
legte. Als er so mit verbundenem Kopf nach Göttingen zurückkam, erschraken wir zuerst. Aber er lachte nur ein wenig und meinte, es sei kein Grund mehr, die Verletzung jetzt noch wichtig zu mehmen. Allerdings empfand er eine gewisse Genugtuung darüber, daß die Ärzte, nachdem er genäht worden war, ihm ihre Bewunderung über seine Tapferkeit ausgedrückt hatten, die sie bei einem Mann seines Alters nicht erwartet hätten.

Trotz seines vorgeschrittenen Alters war er noch voll in seinem Beruf tätig. Seine Maxime war es, im gleichen Maße wie bisher seine Arbeitskraft für den Fortschritt der Wissenschaft einzusetzen, obwohl man sich damals in ständig wachsender Ungewißheit über die nähere und fernere Zukunft befand.

Noch hatten wir die letzten Kriegsmonate zu bestehen, natürlich auch mit häufigem nächtlichem Fliegeralarm. Wenn auch Göttingen weitgehend vor Zerstörungen verschont geblieben war, so brachten doch die vielen Stunden, die wir uns in der Nacht im Keller aufhielten, viel Unruhe in unser Leben. Im November 1944 waren die ersten Bomben in das Göttinger Stadtgebiet gefallen, und die Vorschrift, den Luftschutzkeller bei Alarm aufzusuchen, wurde seitdem selbstverständlich ernst genommen. Jeder weitere Angriff war eine neue Mahnung.

Mit dem Optimismus der Jugend, die nicht das Ungewisse der Zeitläufe abwägt, wenn einmal ihre Begegnungen schicksalhaft erscheinen, beschlossen mein Studienfreund, Helmut Vogel, und ich, eine feste Bindung einzugehen. So gab es dann im Jahr 1944 wieder eine Hochzeit in unserem Haus. Schon in der Verlobungszeit hatte sich zwischen Schwiegervater und Schwiegersohn ein herzliches Verhältnis entwickelt. Ebenso freundschaftlich gestaltete sich bald auch die Beziehung zu der Mutter meines Mannes und seiner Schwester, einer sehr begabten Malerin, die beide oft aus Bremen zu uns zu Besuch kamen. Ich sehe noch meine Schwiegermutter mit meinem Vater zusammen an unserem Flügel sitzen, wo sie mit Erfolg probierten, ein Musikstück vierhändig zu spielen. Er schätzte die lebensfrohe Heiterkeit und Liebenswürdigkeit der Bremerin, die so viel teilnehmendes Verständnis für jeden von uns hatte. 
Wie unmittelbar mein Vater Musik aufnehmen konnte, zeigt ein kleines Erinnerungsblatt, das er aufgehoben hat. Er hatte sich die Noten nach dem Hören am Radio schnell notiert, um den ganzen Satz im Gedächtnis zu behalten.

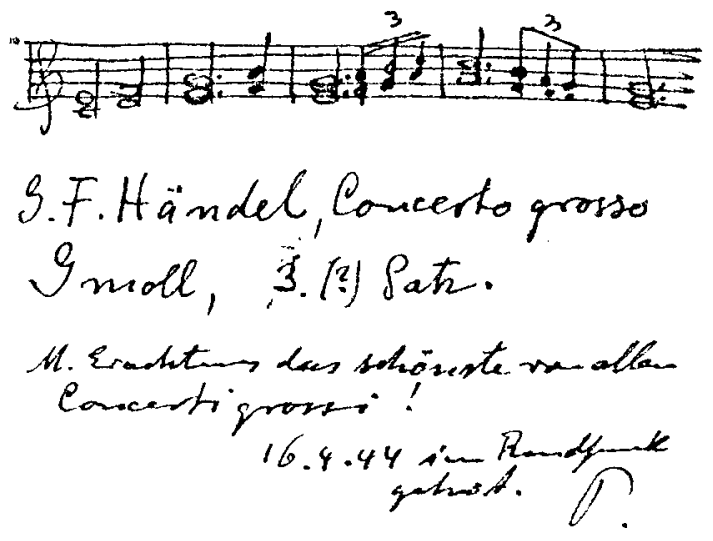

In dem letzten Kriegsjahr 1945 unternahm man kaum noch Besuchsreisen. Als Prandtl am 4. Februar 1945 seinen siebzigsten Geburstag feierte, waren nur wenige Gratulanten gekommen, um ihre Glückwünsche persönlich auszusprechen. Ich erinnere mich, daß Professor F. Schultz-Grunow nicht die Umstände und damaligen Gefahren einer Reise gescheut hatte, um meinem Vater zu gratulieren, der ihn in freudiger Überraschung sehr herzlich bei uns begrüßte.

Mehrere frühere Schüler und Kollegen ehrten den alten Lehrer mit einer Festschrift [51], die 20 Fachbeiträge aus den Gebieten der angewandten Mathematik und 
Mechanik enthält. Bedingt durch die Kriegsumstände konnte das Heft erst verspätet ausgeliefert werden. Einleitend schrieb Professor W. Tollmien, Dresden, einen Artikel, der nur auszugsweise wiedergegeben werden kann:

"In Ehrerbietung und Liebe gilt es am 4. Februar eines Mannes zu gedenken, dessen Wirken in der langen und ruhmvollen Geschichte der Mechanik wahrhaft Epoche gemacht hat. An diesem Tage vollendet Ludwig Prandtl sein 70. Lebensjahr ...

Das Werk Prandtls hätte sich nicht so glanzvoll und folgenreich entfalten können, wenn er nicht aus der eigenen wissenschaftlichen Besessenheit die Kraft entwickelt hätte, in einer großen Zahl von Schülern und Mitarbeitern eine ähnliche entsagungsvolle und leidenschaftliche Hingabe an die Forschung zu wecken. Nicht das geistreiche Aperçu, sondern die systematische Aufhellung ganzer Fragenkomplexe war sein Ziel, das sich eben nur durch Bildung einer Schule erreichen ließ. $\mathrm{Zu}$ den vielen Doktoranden, die im Lauf der Jahre bei Prandtl promovierten, kamen mit dem fortschreitenden Ausbau der Göttinger Institute zahlreiche Mitarbeiter, die im persönlichen Verkehr seiner Anregungen teilhaftig wurden. Dabei hat Prandtl es bewußt aufs sorgfältigste vermieden, angehende Forscher durch die Übermacht seiner wissenschaftlichen Persönlichkeit in ihrem Wachstum zu hemmen. Eine sinnvolle Frage wurde aufgeworfen, deren Beantwortung bei dem derzeitigen Stande der Forschung nicht ausgeschlossen schien, einige Lösungsmöglichkeiten wurden zur Diskussion gestellt; im übrigen ließ Prandtl mit der Geduld eines echten Erziehers die Eigenart des Bearbeiters sich entfalten, so bereitwillig er die bei rechten Forschungsaufgaben unvermeidlichen schweren Sorgen durch Ermutigung und Rat mittrug und dem Festgefahrenen durch neue Anregungen weiterhalf. Die Forderungen, die Prandtl an wissenschaftliche Arbeiten erhob, waren getreu der Tradition der Georgia Augusta sehr hoch. Dafür war eine knappe Anerkennung aus seinem Munde die höchste Belohnung, die einem jungen, unter ihm arbeitenden Forscher zuteil werden konnte. Jeder, der wie der Schreiber dieser Zeilen das Glück hatte, einige Zeit in einem Prandtischen Institut zu arbeiten, wird mit Dankbarkeit an die geistige Gemeinschaft denken, die durch den Dienst an der Sache und die Verehrung für die Persönlichkeit des Meisters geeint waren.

Widerspruchslos, aber auch neidlos wird Prandtl seit einem Vierteljahrhundert von der gesamten Fachwelt als der führende Forscher auf dem Gebiete der Mechanik anerkannt. Nicht weniger erstaunlich aber ist es, daß er nach so gewaltigen Leistungen 
an der Schwelle des achten Jahrzehnts sich nicht im mindesten von dem aktiven Wissenschaftsleben abgewandt hat. Im Gegenteil, in den letzten Jahren hat Prandtl in der Wissenschaftsorganisation neue verantwortungsvolle Führungsaufgaben für die Forschung seines Landes übernommen, und auch die eigene forschende Pionierarbeit ruht nicht.

Welchen besseren Wunsch können daher seine Fachgenossen und Freunde zum 4. Februar 1945 zugleich für sich selbst und für den Jubilar haben, als daß seine Schaffenskraft noch recht lange ungeschwächt erhalten bleibe!"

Professor J. Ackeret (ETH Zürich) hat zu dem gleichen Anlaß ebenfalls einen Artikel verfaßt [2]. Auch hier zitiere ich nur auszugsweise:

"Prandtl hat die technische Mechanik um ganz eigenartige neue Züge bereichert. ... Wenn man von Forschung spricht, so sieht der Laie gewöhnlich im Geiste einen Wirrwarr von komplizierten Apparaten und teuren Instrumenten. Prandtl aber hat seine größten Entdeckungen mit Einrichtungen von verblüffender Primitivität gemacht. Die Grenzschichttheorie, die mit einem Schlage den Alpdruck mathematischer Unlösbarkeit der Strömung mit Reibung beseitigte, fand Prandtl an einem Apparat, der vielleicht 40 Franken gekostet hat und mit Handbetrieb arbeitete. Wie recht hatte er, wenn er zu seinen Mitarbeitern bei einer Gelegenheit sagte: 'So ein großes Fernrohr ist ja ganz schön, die Hauptsache aber ist der Mann, der hindurchguckt.' ...

Hydro- und Aerodynamik waren vor Prandtl in einem Zustand beginnender Versteinerung; es schien, als ob die Natur sich hinter den Mauern mathematischer Schwierigkeiten verschanzt hätte. In ständiger Fühlungnahme mit dem Experiment fand Prandtl den Ausweg. Mit einem unglaublichen Tastgefühl ließ er von der Allgemeinheit der Probleme so viel weg, daß die wesentlichen Züge übrigblieben und die Mathematik gerade noch ausreichte, um nun das Übriggebliebene exakt und sauber zu lösen, und zwar in einer Weise, die zu praktisch brauchbaren Resultaten führte. ... Sein Ideenreichtum war seit jeher so groß, daß er ohne Prioritätsängstlichkeit nach links und rechts davon reichlich ausgab; und sein Werk kann nur ganz übersehen werden, wenn man die Arbeiten seiner zahlreichen Schüler aus aller Welt irgendwie mitrechnet. ...

... Diejenigen aber, die das Glück hatten, in seiner Nähe zu lernen und zu arbeiten, 
werden nicht nur das Bild des großen Forschers, sondern auch das des bescheidenen grundgütigen Menschen und väterlichen Freundes vor sich haben. ..."

In der Zeitschrift "Luffahrt-Forschung" wurde der Artikel "Ludwig Prandtl 70 Jahre" ohne Verfasserangabe gedruckt [19]. Daraus zitiere ich:

"Am 4. Februar begeht Ludwig Prandtl, nicht nur der bekannteste und erfolgreichste Wissenschaftler der Luftfahrtforschung, sondern seit einigen Jahren auch deren organisatorische Spitze, den 70. Geburtstag. Wird die Feier mit Rücksicht auf die Zeit und den Wunsch des Gefeierten gedämpfter ausfallen, als dies in Friedenszeiten angemessen wäre, so ist dies doch ein Tag für alle Angehörigen der Luftfahrtforschung, an dem man einen Augenblick rasten darf, um sich zu vergegenwärtigen, welche entscheidenden Gedanken er der jungen Luftfahrttechnik mit auf den Weg geben konnte. Daß Prandtl die Schwelle des biblischen Alters als tätiger Forscher überschreitet, ... erfüllt uns alle mit dankbarer Freude ...

Man würde wohl für das 7. Jahrzehnt erwartet haben, daß Prandtl die Pflichten des Berufslebens allmählich ganz jüngeren Schultern übergibt, um sich stärker den Lieblingsaufgaben oder besonders harten Nüssen, die früher liegengeblieben sind, widmen zu können und Zeit für alle diejenigen zu gewinnen, die ein besonderes Bedürfnis haben, sich an den erfahrensten Fachmann selbst zu wenden oder vielleicht mit ihm die Gedanken wieder auszugraben, die ihn bei der Geburt seiner Theorien erfüllt haben, welche heute, abgestempelt mit dem berühmten Namen, manchmal mehr schlagwortartig als mit tiefstem Verständnis gehandhabt werden. Trotz des brennenden Interesses aller luftfahrttreibenden Nationen blieb Prandtl während aller Jahrzehnte führend in der weiteren Vervollkommnung seiner im Jahre 1904 ausgesprochenen Theorie. Er hat daneben auch für die Luftfahrt noch zahlreiche weitere Fragen gelöst, die mit der Grenzschicht nicht unmittelbar zu tun hatten. Erwähnt sei nur die Tragflügeltheorie und die Profiltheorie bei hohen Unterschallgeschwindigkeiten, die sogenannte Prandtlsche Regel ...

Daneben arbeitet er an seinem Lehrbuch, das umgearbeitet in 3. Auflage den Titel "Führer durch die Strömungslehre" erhält. Auch hier, wo Prandtl keine großen Anforderungen an die Vorbildung des Lesers stellt, läßt er sich nicht auf Seitenwege ein, die nur zu beschränkten Höhen führen, sondern er benutzt Wege, die stets den Zugang zu den größten Höhen ermöglichen. Seine Veranschaulichungen und seine 
Vergleiche nehmen auch den Fortgeschrittenen gefangen, genau wie seine Vorlesung, besonders wenn er innehielt oder abschweifte, vielfach dem Fortgeschrittenen noch mehr bot als dem Anfänger. Sein Bestreben ist, stets auch bei anderen die Schärfe der Begriffsbildung und die kritische Einstellung zu wecken.

Sein Erfolg war vielfach darin begründet, $\mathrm{da} ß$ er seine Versuche gleichsam spielerisch in weiteren Grenzen durchführte, als die technische Fragestellung es erforderte; hierdurch wurde an oftmals einfachen Versuchseinrichtungen dank seiner aufmerksamen Beobachtung und seinem vorwärtstastenden Verstand ein undurchsichtiger Vorgang in seine Bestandteile zerlegt. Wo dagegen eine mühsame Versuchsdurchführung mit engen Schritten unumgänglich war, befreite er nach Möglichkeit die technische Aufgabe von allen Zufälligkeiten und behandelte den benachbarten Idealfall, der einer späteren theoretischen Aufklärung besser zugänglich erschien. Er trennte also das technische Bedürfnis von der Lücke im physikalischen Lehrgebäude, und bemühte sich mehr, diese Lücken zu schließen als jede technische Art zu untersuchen. Dieselbe Grundauffassung, in selbstloser Weise dem Ganzen zu dienen statt dem vielleicht sogar besser honorierten Einzelfall, finden wir in seiner ganzen Lebensführung wieder. Obwohl der anerkannte Fachmann, bleibt er stets einfach in seinen persönlichen Wünschen. Er bleibt der kleinen Universitätsstadt Göttingen treu, und wieviel Anregungen sind auf den gemütlichen gemeinsamen Heimwegen in dieser Stadt entstanden, die man in der Großstadt mit ihren zeitverschlingenden Verkehrsproblemen nicht kennt. Er könnte die Besetzung von Lehrstühlen bestimmen, und doch greift er nur dort ein, wo es gewünscht wird und wo offenbare Fehlbesetzungen zu befürchten sind. Diese Einstellung hat auch ihre Früchte getragen. Seine Versuchsanstalt lebte in den schlechtesten Zeiten nicht nur von ihrer Monopolstellung, sondern auch wesentlich von dem Ansehen, das die selbstlose Hilfsbereitschaft Prandtls und seiner Mitarbeiter ihr erworben hatte."

Außerdem schrieb Professor A. Betz zu dem gleichen Anlaß einen Artikel "Ludwig Prandtl zum 70. Geburtstag" [6], der allerdings erst im April 1947 in der Zeitschrift "Forschungen und Fortschritte" erschienen ist. Ich zitiere einen Absatz:

"Prandtl erstrebt immer die klare Durchdringung der von ihm gerade behandelten Aufgabe, wodurch fast immer das Ziel erreicht wurde, die Vorgänge wirklich zu verstehen und auf die physikalischen Grundgesetze zurückzuführen. Weiterhin hat 
Prandtl die Fähigkeit, Mitarbeitern und Fremden ein rückhaltlos anerkannter Führer $\mathrm{zu}$ sein und so die wissenschaftliche Arbeit der ganzen Welt richtungsgebend zu beeinflussen. Ungewöhnliche Klarheit des Denkens und selbstlose, von jedem eigennützigen Gedanken freie Hingabe an seine Aufgabe sind die Grundlagen, die diese Arbeitsweise und ihre großen Erfolge ermöglichten." 


\section{Kriegsende}

Von einem familiären Ereignis möchte ich hier noch berichten: Wenige Monate vor Kriegsende war unsere Tochter Agnes zur Welt gekommen. Die Entwicklung des Enkelkindes interessierte den Großvater überaus. Er versäumte nie, wenn er nach Hause kam, nach ihr zu schauen, und beobachtete liebevoll ihre charakteristischen Regungen. Er saß oft neben ihr mit einem Skizzenblock und zeichnete das kleine Babyköpfchen. Auch legte er eine Tabelle an, um ihre Gewichtszunahme zu überwachen. Der junge Vater konnte nur während eines kurzen Fronturlaubs an dem Familienglück teilhaben, und so übernahm der Großvater ein wenig seine Rolle. Er schrieb an meine Schwester in München: "Unser Kleines macht mir durch seine Lebhaftigkeit und Verständigkeit und sein zutunliches Wesen viel Freude."

Inzwischen befanden wir uns in der letzten Phase des Krieges. Wir beschränkten uns nunmehr auf einen der drei großen Wohnräume, um Heizmaterial zu sparen. Auf den Flügel, der im Salon stand, mochte mein Vater natürlich nicht verzichten, und so schafften wir ihn in das als Wohnraum eingerichtete Arbeitszimmer. Es gab wohl kaum einen Tag, ohne daß das schöne Instrument zum Klingen gebracht wurde. Alle, die Prandtl je zugehört haben, lauschten innerlich angerührt seinen musikalischen Einfällen. Als er einmal ganz besondere Harmonien klangvoll in verschiedenen Tonarten aufblühen ließ, kamen uns Worte der Anerkennung. Er wehrte unseren Beifall ab und sagte nur: "Ich habe eben für meine liebe Gertrud gespielt."

Der Krieg näherte sich nun seinem Ende. Als die Front der feindlichen Truppen näher heranrückte, plante die Kreisleitung Göttingens die Sprengung aller naturwissenschaftlichen Institute. Um dies zu verhindern, beschlossen einige verantwortungsbewußte Professoren, eine Unterredung mit dem Gauleiter Lauterbacher herbeizuführen. Man war sich einig geworden, daß man zu ihm fahren müsse, um mit ihm zu verhandeln. Noch aus anderem Grunde war Göttingen in einer besonders kritischen Lage. Im Laufe der Kriegsjahre war die Stadt vollbelegt mit Verwundeten, 24 Lazarettabteilungen waren eingerichtet worden, die unmöglich evakuiert werden konnten. Von dieser Mission, der Fahrt zum Gauleiter, wird in dem Buch "Göttingen 1945 - Kriegsende und Neubeginn" berichtet [11]: 
"Professor Plischke begab sich am 31. März 1945 nachmittags in Begleitung von Professor Prandtl und eines Königsberger Kollegen, Professor Baumgarten, sowie des Göttinger Rechtsanwaltes, Dr. Beyer, nach Lindau bei Katlenburg, wo Professor Osenberg von der Technischen Hochschule Hannover, Leiter des Vierjahresplaninstituts für Fertigungsverfahren war. Mit Osenberg fuhren die Herren am nächsten Morgen nach Rothenkirchen bei Einbeck zum Gauleiter, konnten ihn jedoch erst mittags sprechen und ihm die ernsten Bedenken wegen einer Verteidigung Göttingens und den daraus entstehenden Folgen vortragen. Lauterbacher versprach, sich mit der Reichskanzlei in Verbindung zu setzen wegen der Erklärung, daß Göttingen als Stadt der Wissenschaft aus dem Kampfgebiet ausgespart werden solle."

Als die Herren gleich bei ihrer Rückkehr den Kreisleiter aufsuchten, hatte dieser bereits die Weisung erhalten, den Vernichtungsbefehl nicht aufzuheben. Die Professoren wurden von ihm als "liberale Defaitisten" abgestempelt. Ich erinnere mich, daß mein Vater sehr müde und einsilbig von dieser Unternehmung heimkam.

Durch die Initiative mutiger Bürger und einsichtiger Beamter der Stadtverwaltung wurde zuletzt doch noch eine kampflose Übergabe der Stadt erreicht.

Der Tag des 8. April, ein strahlender Sonntag, ist mir noch lebhaft in Erinnerung. Wir hatten zuletzt die Weisung erhalten, uns in unseren Kellern aufzuhalten, nachdem der Plan, sich im Freien fern der Stadt zu versammeln, aufgegeben worden war. Am Abend zuvor kam eine Mitbewohnerin unseres Hauses zu uns, Frau E. Oesterheld, die vor einiger Zeit aus Berlin geflüchtet war. Sie hat in ihren Tagebuchblättern von diesem Besuch bei Prandtl berichtet, der am Vortag der Kapitulation stattfand.

7. April 1945: "Er saß in seinem Arbeitszimmer, das nichts von behaglicher Wohnlichkeit hatte. Es war nüchtern und fast büromäßig eingerichtet, mit großen Kartothekkästen an den Wänden. Nur ein großer Flügel und einige gute Ölgemälde verliehen dem Zimmer etwas Eleganz. Er saß an dem wachstuchbedeckten Tisch und hatte gerade die Radionachrichten gehört. Sein ausruckvolles, ehrwürdiges Gelehrtengesicht war von Kummer und Sorge erfüllt. Ich erzählte ihm von der Aufforderung der Partei, daß Frauen und Kinder sich morgen um fünf Uhr früh auf dem Rohns versammeln sollten, und fragte ihn, wozu er wohl raten würde. Ich bekam aber gar keine 
rechte Antwort. Er war offenbar durch die Ereignisse, die sich jetzt überstürzten, überfordert und gänzlich unfähig, für sich oder andere eine Entscheidung zu treffen. Seine Tochter, Frau Vogel, kam herein, und wir beschlossen schließlich, nach mancherlei Hin und Her, uns nicht dem Auszug der Frauen und Kinder anzuschlieBen, sondern in unserem Luftschutzkeller zu bleiben und in Ergebung abzuwarten."

\section{E. Oesterfeld berichtet vom 8. April wie folgt:}

"Feindalarm ertönte um die Mittagszeit; alle Hausbewohner begaben sich in den Keller. In banger Erwartung saßen wir eine lange Zeit, ohne daß sich irgendetwas ereignete. So war die Stadt doch wohl kampflos übergeben worden? Plötzlich krachte es, das Haus erzitterte, die Fensterscheiben stürzten scheppernd herab. Das Dröhnen ging immer noch weiter, deutlich waren die Einschläge zu hören. Plötzlich war es dann wieder still. Professor Prandtl sagte: 'Ich werde jetzt einmal nach oben gehen und sehen, wie es dort ausschaut. Und wenn mir etwas passiert - ich bin ja schon alt, auf mich kommt es nicht mehr an', meinte der Professor bescheiden.

Dann kam der alte Herr wieder herunter. 'Es sieht böse aus, gut, daß Sie nicht oben geblieben sind, sonst wären Sie jetzt alle unter den Trümmern begraben', sagte er zu der Familie, die im 2. Stock wohnte. 'Offenbar war es eine Granate, sie muß vorhin in den Giebel eingeschlagen haben; das ganze Treppenhaus liegt voller Trümmer."

Obwohl es, wie gesagt, wieder ganz ruhig geworden war, blieben wir auf den Schock hin noch längere Zeit im Keller sitzen. Von dort konnten wir durch die zur Erde gehenden Fenster die unaufhörlich vorbeirollende Kette von Panzern beobachten. $\mathrm{Ob}$ der Krieg für uns nun tätsächlich zu Ende war? Die Besetzung durch die Amerikaner sahen wir als ein glückliches Los an. Man schöpfte neuen Mut und ging wieder in seine Häuslichkeit zurück, um Essen zuzubereiten.

Am nächsten Tag war für meinen Vater der Gang zum Institut von größter Wichtigkeit. Was er allerdings an jenem und dem folgenden Tag dort erlebte, erfuhr ich nicht. Er war meist schweigsam und in sich gekehrt. Es fehlte ihm ja wie in all diesen Jahren seine Lebensgefährtin, um das Erlebte mitzuteilen.

Sehr viel später habe ich durch Berichte anderer doch noch erfahren, daß die Amerikaner, bevor sie das Institut besetzten, sich alle wissenschaftlichen Ergebnisse, die im Krieg geheimgehalten worden waren, herausgeben ließen. 
Sie übernahmen dann das Institut vollständig unter ihre Machtbefugnisse. Mein Vater hatte mehrere Wochen keinen Zutritt mehr. Einmal jedoch in der ersten Woche wurde er dort gebraucht. Man holte ihn zu Hause ab und ließ ihn auf einen offenen Militärwagen aufsteigen, unter der Bewachung von sechs amerikanischen Soldaten. Die Nachbarn, die dies beobachtet hatten, fragten besorgt, wohin der Professor wohl abgeführt worden sei. Nach einigen Stunden brachte man ihn im selben Fahrzeug wieder zurück. In einem eigenen Bericht aus dem Jahre 1949 teilt Prandtl diese Begebenheit mit [5]:

"Eines Morgens wurde ich von bewaffneten Soldaten in einem Mannschaftswagen nach dem AVA-Gelände gebracht. Der Führer der Soldaten, ein deutschsprechender jüdischer Offizier, wollte von mir Erklärungen über das, was sich auf dem Gelände befindet, haben und war zunächst über das, was ich ihm sagen konnte, höchst enttäuscht. Er fragte mich nämlich nach den Flugzeugmotorenmustern, die wir in Göttingen gebaut hätten. Ich mußte ihm sagen, daß wir nur über Einzelteile, z.B. Luftverdichter, Studien hinsichtlich der bestmöglichen Formgebung gemacht hätten."

Aber im übrigen waren mein Vater und ich in diesen ersten Wochen, wie alle Familien damals, ständig gefordert, uns Lebensmittel $\mathrm{zu}$ beschaffen, was viel Zeit in Anspruch nahm. Um Brot zu kaufen, das uns auf Marken zustand, mußte man sich möglichst gleich um sechs Uhr, bei Ende der Sperrzeit, auf den Weg machen, um sich beim Bäckerladen anzustellen, weil die Brote immer schon bald nach acht Uhr ausverkauft waren. Wie oft hat mein guter Vater für uns beide diesen frühen Gang unternommen, da ich mich um meine kleine Tochter kümmern mußte. Unsere Haushaltshilfe war noch vor der Besetzung durch die amerikanischen Truppen in ihr Dorf zurückgegangen. Die Weiterführung unserer kleinen Wirtschaft bedurfte nun mancher gemeinsamen Anstrengung. Da weder Gas noch Elektrizität vorhanden war und man dringend Brennholz brauchte, holte ich mit einem Leiterwagen einen ersten Holzvorrat aus dem nahen Waldgebiet des Hainbergs. Keiner kümmerte sich um die Probleme der anderen. In allen Haushalten mußte genauso wie bei uns dem Mangel durch äußersten Einsatz an Kraft und Zeit begegnet werden. Auf dem Hofplatz zersägten wir beide dann die Rundhölzer in gemeinsamer, mühevoller Arbeit. 
Verkürzte Ausgangsperre und regelmäßige Belieferung der Lebensmittelgeschäfte brachten schon im Mai einige Erleichterungen. Trotzdem war die Lage noch angespannt. Im Juni schrieb Bürgermeister Schmidt an die Militärregierung, die den Vorschlag gemacht hatte, Lautsprecher in der Stadt aufzustellen, um die Bevölkerung mit Nachrichten zu versorgen: "Die Menschen sind sehr in Eile und nicht in der Lage, genau zuzuhören oder die angeschlagenen Bekanntmachungen lesen zu können. Allein das Anstehen vor den Geschäften nimmt die Hausfrauen täglich mehrere Stunden in Anspruch."

Unerwartet erschien bei uns Professor Nikuradse, der uns eine Fuhre Holz ankündigte, die er besorgen wollte. Das Holz wurde wirklich schon am nächsten Tag bei uns abgeladen. Bald darauf kamen unbeschäftigte junge Leute aus dem KWI, die uns die Stämme nach und nach zersägten. Der Vorrat an Brennholz, der damals in unserm Hof aufgestapelt lag, war beachtlich.

Die Fortsetzung der bisherigen aerodynamischen Forschungen war streng untersagt. Statt aber zu resignieren, befaßte sich Prandtl nunmehr mit meteorologischen Problemen. Seit jeher war ja die Meteorologie eines seiner speziellen Interessengebiete. Die Wochen zu Hause nutzte er zu intensiver Arbeit. Hin und wieder kam einer der Kollegen auch privat zu ihm nach Hause, um über den Stand der Dinge zu berichten und über die Möglichkeiten eines Neuanfangs mit ihm zu beraten.

Ministerialdirigent A. Baeumker war auch unter diesen Besuchern. Es ergab sich ein stundenlanges, lebhaftes Gespräch. Der Gast nahm vorlieb mit einer Suppe zur Mittagszeit, die ich im gleichen Zimmer auf dem Ofen gekocht hatte. Baeumker, im ersten Weltkrieg Flugzeugbeobachter, dann Delegierter bei der Abrüstungskonferenz in Genf, später Referent für Forschungsangelegenheiten der Luftfahrt, hatte große organisatorische Erfahrung. Jetzt bewegten ihn schon neue Pläne für die fernere Zukunft der Gesellschaft für Luftfahrt.

1949 schrieben A. Betz und L. Prandtl aus der Erinnerung einen umfassenden Bericht über die Institutsangelegenheiten vom Frühjahr 1945 [5]. Hier einige Auszüge: 
A. Betz: "Ein wichtiges Ereignis war der Besuch von Professor v. Kármán am 14. und 15. Mai, der in Begleitung von einer Reihe angesehener Forscher in die AVA kam. Hierbei kam wohl zuerst die Möglichkeit zur Sprache, den Direktoren und ihren Angestellten die Institute wieder zugänglich zu machen. Da die Forschungsarbeit grundsätzlich verboten war, sah v. Kármán eine andere Möglichkeit, die Wissenschaftler wieder zu beschäftigen. Er schlug vor, sie im Dienst der Besatzungsmacht Berichte abfassen zu lassen über ihre Versuchsergebnisse während der Kriegsjahre." Diese Monographien wurden später ins Englische übersetzt.

L. Prandtl: "Es fingen nun ziemlich häufige Besuche von amerikanischen Fachleuten an, denen ich mein spezielles Institut, das Haus 3, zeigen und erklären mußte. ... Ich habe dabei um Vermittlung gebeten, daß uns erlaubt würde, uns in den eigenen Institutsräumen wieder freier bewegen zu können. Es blieb aber dabei, daß wir im Institut von bewaffneten Soldaten begleitet werden mußten."

Man berichtete mir später über einen Ausspruch Prandtls, der das Absurde dieser Situation, der er ausgesetzt war, kennzeichnet: Er wies lächelnd auf den ihm stets folgenden Soldaten mit Maschinenpistole hin, indem er ihn ansprach: "Hat der Soldat vielleicht Angst vor mir?" Verlegen erklärte ihm jener, daß es so die Vorschrift sei.

Prandtl: "Die gelehrten und fachmännischen Besuche kamen in immer größerer Zahl, und ich empfand meine neue Rolle mehr und mehr als die eines Museumsdieners, der in ungefähr immer denselben Worten dieselben Sachen zu erklären hatte (und natürlich je nach Sachlage auch immer dieselben kleinen Witzchen anbrachte)."

Nach der Aussage eines Mitarbeiters wurden dort eines Tages Dokumente gesucht, die ein junger Wissenschaftler an geheimem Ort vergraben hatte. Er war ziemlich bestürzt und hatte wohl allen Grund, sich die Folgen auszumalen, wenn er der Militärmacht sein Geständnis ablegen würde. "Das mit den Dokumenten nehme ich auf mich", sagte Prandtl zu ihm, "mir wird man nicht so leicht den Kopf abreißen wie vielleicht Ihnen."

Auch Professor Betz wurde ebenso häufig zu Führungen ins Institut geholt, um Fragen zu beantworten und Erläuterungen zu geben. 
Betz schreibt: "Die bei den Führungen gestellten Fragen boten öfters Einblick in uns überraschende Tatsachen. So konnten die meisten Amerikaner nicht verstehen, daB wir im wesentlichen Grundlagenforschung getrieben haben. Auch die großen Personal- und Materialschwierigkeiten während des Krieges waren ihnen häufig unvorstellbar. Mehrfach wurde die Frage gestellt, warum eine so wichtige Anlage wie der große Kältekanal nicht rasch fertiggestellt wurde.

Aus anderen Fragen ging wieder eine erstaunliche Unkenntnis vieler in Deutschland längst bekannter Dinge hervor, obwohl die Fragesteller durchaus den Eindruck fähiger Wissenschaftler machten. So kam immer wieder die Frage, warum wir Pfeilflügel bauten, und es erforderte lange und wiederholte Erläuterungen, bis die Vorteile dieser Flügelform bei Annäherung an die Schallgeschwindigkeit begriffen wurden. Jetzt werden Pfeilflügel als große amerikanische Erfindung aufgezogen."

Sehr erfreut war Prandtl, als die Besetzer ihm nach acht Wochen des Verbots erlaubten, sein Institut wieder regelmäßig zu betreten. Allerdings wurde verlangt, daß man sich einen Passierschein für die Stunde des Dienstantritts und wiederum einen für Dienstschluß ausstellen ließ. Eine groteske Forderung für den Institutsdirektor! Prandtl fragte eines Tages unschuldig: "Könnte ich nicht auch so einen Passierschein haben, der für den ganzen Tag gilt, wie der Bote unseres Instituts ihn hat?"

Am 8. Juni 1945 teilte er meiner Schwester in München mit:

"In meinem Institut hat jetzt die Arbeit in geringem Umfang wieder angefangen mit einem Drittel der Leute."

Einige der jüngeren begabten Wissenschaftler fanden bald einen neuen Arbeitsplatz in Amerika oder England, wo ihnen sehr gute Möglichkeiten geboten wurden, ihre wissenschaftliche Arbeit fortzusetzen.

Eine Kleinigkeit möchte ich noch erwähnen. Jede Woche wurde damals an die Mitarbeiter des Instituts ein Laib Brot ausgegeben. Das "Institutsbrot" schmeckte meinem Vater besonders gut; er legte Wert darauf, jeden Tag ein Stück davon abzuschneiden, das er gleichsam mit Andacht kostete. Natürlich teilte er auch aus. Aber ich beobachtete, daß es ihn besonders froh stimmte, wenn das Brot vor ihm auf dem Eßtisch lag. Es war bestimmt nicht die Vorstellung des reichlichen Mundvorrates, die ihn so 
befriedigte, vielmehr hatte dies "Institutsbrot" gewissermaßen einen symbolischen Wert für ihn. Nachdem er wochenlang ausgesperrt worden war, empfand er ein stilles Vergnügen, dort wieder in seiner geistigen Heimat, dem Strömungsinstitut, arbeiten zu können, wenn auch unter erschwerten Bedingungen.

Ausführlich berichtete Prandtl seinem englischen Kollegen G. I. Taylor über die Nachkriegsereignisse in seinem Institut.

28. Juni 1945: "Mein Institut ist unbeschädigt durch den Krieg gekommen, hatte dann aber, als es mehrere Wochen hindurch Quartier für amerikanische Soldaten war, viel Schaden erlitten. Seit Anfang Juni haben wir selbst wieder Zutritt. Was wir machen durften, war uns von der alliierten Kommission vorgeschrieben. Wir durften Reparaturen machen und Berichte schreiben, die die alliierte Kommission verlangte. Auch durften wir an einigen Aufgaben weiterarbeiten, die während des Krieges nicht mehr fertig geworden sind und über die ebenfalls Berichte erwartet werden. Neue Arbeiten anzufangen, ist bisher nicht erlaubt. Wir hoffen immer noch, daß wir die Probleme der Grundlagenforschung, die wir während des Krieges mehr und mehr zurückstellen mußten und von denen wir zur Zeit für ein Jahrzehnt genug haben, bald wieder aufnehmen können."

Am 10. Oktober 1945 an Taylor: "Jegliche Fortführung unserer Forschungsarbeiten ist uns jedoch von dem Director of Scientific Research in London verboten worden. Das ist für ein Forschungsinstitut, das seine Aufgabe darin sieht, die Erkenntnisse auf seinem Fachgebiet nach allen Kräften weiter zu fördern, eine sehr harte Forderung. Wir sehen noch viele Aufgaben, die der Lösung harren, einerseits auf dem Gebiet der Turbulenzforschung, andererseits auf dem Gebiet der Strömung in der Nähe der Schallgeschwindigkeit. Die meteorologischen und ozeanographischen Strömungsfragen, bei denen einerseits Dichteschichtung, andererseits turbulente Vorgänge eine wesentliche Rolle spielen, gehören auch hierher."

Obschon durch die strengen Maßnahmen der Militärbehörde die wissenschaftliche Fortentwicklung gänzlich unterbunden war und dadurch der Einflußbereich Prandtls eingeschränkt wurde, so bestand doch seine internationale Bedeutung unangefochten fort. Eine Chinesin, die Anfang der vierziger Jahre ihre Doktorarbeit bei Prandtl ge- 
schrieben hatte, weilte kurz nach Kriegsende, das sie in Berlin überlebte, trotz mißlicher Zeitumstände wieder einige Monate in Göttingen, um sich bei Prandtl Rat für ihre weitere wissenschaftliche Arbeit zu holen. Frau Lu Hsin Chen kehrte dann nach China zurück, wo sie später Professorin für Aerodynamik in Peking wurde. Einmal sagte sie im Rückblick auf die Göttinger Jahre, daß Professor Prandtl sich so gütig wie ein Vater um sie gekümmert habe. Das lebendige Andenken, das sie ihrem verehrten Meister bewahrte, hat sie bewogen, noch einmal mit ihrem Mann in Göttingen sein Grab aufzusuchen. Wir standen zusammen vor seinem Grabstein. Sie verbeugten sich dreimal ehrfurchtsvoll vor dem Toten, in der Weise, wie die Chinesen ihren Ahnen größte Hochachtung zollen. 1984 übersandte sie mir ihre Übersetzung der Strömungslehre ins Chinesische. In dem Begleitbrief schreibt sie:

16. November 1984:

"Bei der Gelegenheit, daß ein Kollege von meinem Institut nach Göttingen fährt und dort mit DFVLR wissenschaftlich zusammenarbeiten wird, bitte ich ihn, Ihnen ein Buch zu überreichen. Das ist eine Übersetzung des Buches 'Führer durch die Strömungslehre' von meinem hochverehrten Lehrer, Herrn Professor Ludwig Prandtl. Ich habe die Übersetzungsaufgabe übernommen als ein Andenken an den weltweit größten Lehrer der Strömungsmechanik.

Lu Schang (geb. Hsin Chen)." 


\section{Neuanfang an der Universität}

An der Universität war man bereits im Juli 1945 sehr bemüht, den Lehrbetrieb wieder in Gang zu bringen. Aufgrund des von der Militärregierung verordneten Entnazifizierungsverfahrens war eine Reihe von ehemaligen Professoren entlassen worden, so daß nur ein Teil der Hochschullehrer für einen Neubeginn zur Verfügung stand. (Aus dem "War Diary" der Miltärregierung Göttingens: 8. August 1945: "Von den $60 \%$ der entlassenen Universitätsprofessoren legte keiner Widerspruch ein.")

Es gab natürlich auch noch viele andere schwierige Probleme, die einer Lösung bedurften, z. B. die Erarbeitung der Aufnahmebedingungen für Studenten, die Wiedereinrichtung der Mensa, Maßnahmen, durch die Wohnraum für die Studenten beschafft werden sollte. So wurde an die Bevölkerung ein Aufruf erlassen, private Studentenzimmer anzumelden, indem jeder dazu aufgefordert war, auf entbehrliche eigene Räume zu verzichten. Auch wir, die wir damals nur zu dritt in unserer Wohnung lebten, meldeten zwei der leerstehenden Zimmer als "Studentenbuden" an und nahmen notgedrungen die Unruhe, die diese jungen Menschen mitbrachten, in Kauf. Es gab bald kein Haus mehr, wo nicht zumindest in einer Dachkammer ein Student untergebracht war.

Am 17. September 1945 war es soweit, daß die Georgia Augusta als erste Universität in Deutschland ihre Tore wieder für die Studierenden öffnen konnte. Die britische Militärregierung hatte die Zahl der Studenten auf 3500 festgesetzt, die aber bald überschritten wurde, da man den später entlassenen Kriegsteilnehmern ebenfalls den Studienanfang ermöglichen wollte.

Prandtl, obwohl siebzigjährig, hielt Vorlesungen wie bisher. Allgemein wurde der Lerneifer der Studenten wohlwollend anerkannt. Das Bild der Stadt hatte sich in wenigen Wochen gewandelt, ein neuer Geist der Freiheit war trotz der Besatzungsmacht zu spüren.

1946 teilten die Neuen Physikalischen Blätter mit: "Die Georgia Augusta steht mit 4775 Studenten, die im Sommersemester immatrikuliert waren, an der Spitze aller deutschen Universitäten." 
Nachdem nun die Wahrheit in ihrem ganzen Ausmaß offenbar geworden war, versuchte Prandtl, tief betroffen, sich mit den Geschehnissen der jüngsten Vergangenheit auseinanderzusetzen, und entschloß sich, die dabei gewonnenen Einsichten vor allem im Hinblick auf die Möglichkeiten wissenschaftlicher Weiterarbeit zusammenhängend schriftlich zu formulieren. Er richtete ein Schreiben an den Education Officer, Mr. Bird, dem er seine Reflexionen mitzuteilen wünschte. Er nannte seine Schrift "Gedanken eines unpolitischen Deutschen zur Entnazifizierung".

Prandtl selbst hatte, wie schon gesagt, jegliche Mitgliedschaft in der Partei durchweg abgelehnt und wurde somit in keiner Hinsicht bei dem Neuanfang belastet. Doch konnte er sich, seiner Wesensart entsprechend, des Mitgefühls nicht erwehren im Gedanken an manche derjenigen, die lediglich aufgrund ihrer Parteizugehörigkeit unterschiedslos verurteilt worden waren, ohne politisch interessiert und beteiligt gewesen zu sein. In seiner stets menschlichen Haltung hielt er es für notwendig, der Besatzungsmacht aufklärende Erläuterungen zu geben über die Entstehung und die konsequent entwickelten Mechanismen des NS-Staates. Durch diese Ausführungen konnte möglicherweise eine günstigere Beurteilung mancher Fälle von Schuldzuweisung erreicht werden.

Inzwischen gibt es ja viele Veröffentlichungen über dieses Thema, das vor allem uns Deutsche auch jetzt und in wachsendem Maße beschäftigt, obwohl über 40 Jahre vergangen sind.

Es folgt nun das Schreiben vom 14. März 1946:

"Sehr geehrter Mr. Bird!

Auf Ihre Anregung hin habe ich einen Text über die Frage der Entnazifizierung abgefaßt, wie er zur Veröffentlichung in einer englischen Zeitung geeignet sein möchte. ... Sollte Ihnen zu irgendeinem Punkt noch eine Aussprache mit mir erwünscht sein, so werde ich Ihnen gerne jederzeit zur Verfügung stehen.

Mit ausgezeichneter Hochachtung

Ihr sehr ergebener Ludwig Prandtl" 
Der Text hat folgenden Wortlaut:

\section{"Gedanken eines unpolitischen Deutschen zur Entnazifizierung}

\section{Vorbemerkung}

Die Frage der künftigen politischen Entwicklung in Deutschland und besonders auch diejenige des besten Verfahrens zur Ausschaltung aller Elemente, die diese Entwicklung stören könnten, beschäftigt zur Zeit in Deutschland sehrviele Gemüter. Der Schreiber dieser Zeilen ist Professor an einer deutschen Universität, seinem Fach nach Ingenieur und Physiker, er ist bei den englischen Fachleuten seines Spezialgebietes wohlbekannt. Er ist über 70 Jahre alt. Sein Alter und sein von wissenschaftlicher Arbeit erfülltes Leben schützt ihn wohl vor dem Verdacht, daß er in ingendeiner Weise Extremist sein könnte. Vielmehr hat er bisher niemals eine Rolle in der Politik spielen wollen, sondern sich nur an Hand der ihm zugänglichen Quellen ein Urteil zu bilden versucht.

\section{Die Lage von 1932}

Durch die Weimarer Verfassung wurde das deutsche Parlament nach "Reichslisten" gewählt, die von den einzelnen Parteien aufgestellt wurden; dies hatte zur Folge, daß eine ungeheure Zersplitterung in zahlreiche kleine Parteien eintrat, die bei Neuwahlen in der Hauptsache in fast gleicher Stärke wiederkehrte. Eine Mehrheit konnte immer nur durch Zusammenarbeit von Parteien mit sehr stark voneinander abweichenden Programmen gewonnen werden. Die Regierungen standen deshalb meist auf sehr schwachen Füßen und mußten sich dauernd durch irgendwelche Kompromisse vorwärtshelfen. Es ist deshalb zu verstehen, daß sie mit dem Problem der schließlich sieben Millionen Arbeitslosen, zu denen noch weitere etwa sieben Millionen Kurzarbeiter kamen, nicht fertig werden konnten. Ferner war die Landbevölkerung durch jahrelange Aufrechterhaltung von zu geringen Zwangspreisen im Zusammenwirken mit hohen Steuern für ihre Erzeugnisse stark verschuldet und durch harte Eintreibung dieser Steuern schwer bedrückt und konnte sich dagegen nicht wehren, da sie, selbst noch zersplittert, gegenüber der Industriebevölkerung und der sonstigen Städter in der Minoriät war.

Bei dieser wirtschaftlichen Misere in Stadt und Land war es kein Wunder, daß zum Schluß die extremen Parteien, die Kommunisten auf der linken Seite und die National- 
sozialisten auf der rechten, ständig an Stärke zunahmen, sich selbst dabei aufs heftigste bekämpfend. Die Landbevölkerung, der Hitler Entschuldung und Sicherung des Erbbesitzes versprach, schlo $\beta$ sich ihm in großen Scharen an; viele der Arbeitslosen, denen die kommunistischen Methoden mißfielen, wandten sich jetzt ebenfalls Hitler zu, da dieser ihnen Arbeit zu beschaffen versprach. Die Entwicklung drängte auf ein Duell zwischen den beiden extremen Parteien hin. Sehr viele Anhänger der Mittelparteien hielten gegenüber den Kommunisten, von deren Herrschaft man Bolschewismus nach nussischem Muster befürchtete, den Nationalsozialismus für das kleinere Übel, und so kam es, daß im Jahre 1933 Hitler eine Mehrheitsregienung bilden konnte. Daß der ehrwürdige Reichspräsident von Hindenburg ihm das Reichskanzleramt übertrug, entsprach zwar den Regeln der demokratischen Regierungsform, brachte aber doch Hitler auch noch die Sympathie von weiteren Wählern zu.

\section{Die psychologische Situation nach der Machtergreifung in der NSDAP}

Hitler hielt sich in der ersten Zeit, offenbar beeinflußt durch Hindenburg, ziemlich zurück, und viele, denen seine Art früher mißfallen hatte, hofften, daß die zahlreichen gemäßigten Elemente, die nun Hitler zu seiner Majorität verholfen hatten, einen guten Einfluß auf die Fortführung der Staatsgeschäfte haben würden. So ist die große Stimmenzahl bei dem Volksentscheid im März 1933 zu verstehen, die durch den dabei gelegentlich angewandten politischen Druck wohl kaum allzu stark verbessert worden ist.

Die Partei erhielt in dieser Zeit sehr viel Zuwachs. Man kann ihre Zusammensetzung in den ersten Jahren nach 1933 etwa so charakterisieren: Es gab in ihr

1. die langjährigen Parteimitglieder, die sogenannten "alten Kämpfer" (unter diesen waren viele, die in ihrem Beruf aus eigener Unzulänglichkeit gescheitert waren, aber auch viele Idealisten, die sich den Kampf gegen die bolschewistische Gefahr zum Ziele gesetzt hatten);

2. andere Unzufriedene, die auf diesem Wege, teils aus Geltungsbedürfnis, teils aus selbstsüchtigen Gründen, zu Einfluß kommen wollten;

3. Arbeitslose, die sich vom Eintritt in die Partei eine Besserung ihrer Lage erhofften, desgleichen zahlreiches Landvolk;

4. aber jetzt auch Männner ernster Lebensauffassung, die die Mängel des Hitlerschen Systems wohl erkannt hatten, die aber glaubten, die schädlichen Einflüsse, die hauptsächlich von den alten Kämpfern kamen, zu korrigieren; auch bei vielen von diesen 
spielte die Vorstellung mit, daß man Hitler unterstützen müsse, um Deutschland vor dem Bolschewismus zu bewahren.

Die unter Nr. 4 genannten Männer konnten auch im einzelnen manches Gute erreichen, auf die große Poltik konnten sie freilich, wie sich bald zeigte, keinen Einflu $\beta$ gewinnen. Der demonstrative Austritt aus der Partei, den einige Mutige vollzogen, belehrte die anderen, daß sie sich dadurch nur härtester Verfolgung aussetzten und sich aller weiteren Wirkung beraubten. Wer also glaubte, in seinem kleineren Kreis weiterhin Gutes wirken zu sollen, mußte deshalb in der Partei bleiben und es auf sich nehmen, daß er gezwungen war, manches Wort mitzusprechen, das seiner wirklichen Einstellung widersprach.

Mit dem Fortschreiten der Entwicklung nahm der Druck der Parteïnstanzen für einen Eintritt in die Partei und ihre Gliederungen stark zu. Von Beamten-Anwärtern wurde der Eintritt sogar kategorisch gefordert. Wer aus wirtschaftlichen oder anderen Gründen es sich nicht leisten konnte, auf die angestrebte Laufbahn zu verzichten, mußte sich beugen, auch wenn es seiner inneren Einstellung zuwider lief. Auch bei ängstlichen Leuten der älteren Generation spielten ähnliche Gesichtspunkte eine Rolle. Nicht selten haben auch private Arbeitgeber einen Druck in solcher Richtung auf ihre Untergebenen ausgeübt. Die ungeheure Zahl der "Mitläufer" wird so begreiflich.

\section{Folgerungen für das anzustrebende Entnazifizierungs-Verfahren}

Diese Buntheit der Zusammensetzung der Partei läßt es nicht geraten sein, ein rein schematisches Verfahren nach den Angaben des Parteibuches oder eines Fragebogens zu wählen. Es ist vielmehr nötig, der Beurteilung die Taten des einzelnen und seine Wirkung auf die Gesamtheit zugrunde zu legen. Natürlich ist dieses System umständlicher zu handhaben als das andere, aber es geht um Menschenschicksale, und hierfür lohnt sich wohl der größere Aufwand. Das neue Entnazifizierungsgesetz in Bayern geht bereits diesen Weg. Wenn die eigenen Landsleute maßgeblich an den Entscheidungen beteiligt werden, ist die Gefahr, daß einzelne sich herauszulügen versuchen, nicht allzu groß. Man kennt doch seine Leute und weiß zwischen "Mitläufern" und eigentlichen Nazis zu unterscheiden.

Jeder um die Zukunft seines Volkes besorgte Deutsche wird erwarten, daß diejenigen, die durch ihr Wirken in den letzten zwölf Jahren eine schwere Schuld auf sich geladen haben, eine schwere Strafe erleiden müsssen. Ebenso müssen diejenigen, die ihre Vorrechte als Mitglieder der Partei oder ihrer Organisationen zu ihrer Bereicherung und zu sonstigen Vorteilen benutzt haben, aber auch die, die durch Verleumdung oder Denunziation 
irgendwelchen Mitmenschen schweren Schaden zugefügt haben, hart bestraft werden. Die deutsche Volksgemeinschaft hat aber ein Anrecht darauf, die wertvollen Menschen unter den Parteimitgliedern für die ungestörte Weiterführung ihrer Tätigkeit in ihrer Mitte zu behalten, und wünscht sie von dem ihnen im Augenblick noch anhaftenden Odium, ein Nazi zu sein, freigesprochen zu sehen.

Über die zweckmäßigste Art der Bestrafung zu sprechen, erachte ich nicht als meine Aufgabe. Ich möchte nur erwähnen, daß man diese je nach der Schwere der Vergehen oder Verbrechen nach Strafort und Dauer wird abstufen müssen. Als geringste Strafe mag vielleicht die Entziehung des aktiven und des passiven Wahlrechts innerhalb einer gegebenen Bewährungsfrist genügen. Damit würden Störungen der neuen politischen Entwicklung durch unreife oder unbelehrbare Elemente wirksam vermieden werden können, und es würde damit auch dem Volksempfinden gegenüber den harmlosen Mitläufern Genüge geschehen.

\section{Entnazifizierung der Universitäten}

Der eigene engere Wirkungskreis des Schreibers dieser Zeilen liegt ihm, wie begreiflich, besonders am Herzen. Hier ist unter dem Nazi-Regime großer Schaden angerichtet worden, indem Leute, die für den Lehrer- und Forscherberuf gänzlich ungeeignet waren, sich in die Hochschulen eindrängten und sich die Herrschaft anmaßten. Diese Leute, vielfach in ihrer Laufbahn wegen Unfähigkeit gescheiterte Dozenten, verteilten unter sich die Führerstellen im NS-Dozentenbund und nahmen erheblichen Einflu $\beta$ auf alle Neuberufungen, bei denen sie tunlichst weitere "alte Kämpfer" unterzubringen versuchten. Von einigen ganz Hochbegabten abgesehen, konnte niemand, der ihnen nicht durch Eintritt in die Partei, in die SA oder dergleichen zu Willen war, von da ab noch Dozent werden. Die Reichsleitung des Dozentenbundes in München beherrschte auch die Hochschulabteilung des Erziehungsministeriums, die selber häufig über die zu treffende Auswahl von geeigneten Lehrkräften vernünftiger dachte; die Reichsleitung konnte aber, da ihr von Hitler ein Vetorecht gegeben worden war, jede ihr nicht genehme Benufung verhindern. Man kann sich vorstellen, daß alle jungen Anwärter, die nicht auf ihre wissenschaftliche Laufbahn verzichten konnten oder wollten, der Partei meist unter schwerem seelischen Druck in irgendeiner Weise Tribut zahlen mußten. Besonders ängstiche Leute ließen sich auf mehr als das Mindestmaß ein, wurden Blockleiter oder dergleichen und haben jetzt Schwierigkeiten, ihre nichtnazistische Gesinnung glaubhaft zu machen. 
Die Universitäten müssen fordern, daß alle menschlich wie fachlich wertvollen jungen Forscher und Lehrer, die keine Aktivisten waren, sondern nur dem Staat und ihrer Wissenschaft $z u$ dienen wünschten, jetzt wieder in Gnaden aufgenommen werden und nicht dadurch zu Schaden kommen, daß sie in den letzten Jahren keinen anderen Weg hatten als den über die Partei, die völlig mit dem Staate verschmolzen worden war. Von der Entscheidung in diesem Sinne hängt der ganze Nachwuchs der deutschen Hochschullehrerschaft ab.

Ich kann sehr wohl verstehen, daß die Engländer, die seit Jahrhunderten an die demokratische Regierungsform gewöhnt sind, viel Mühe haben werden, derartige Gedankengänge zu begreifen. Man muß unter einer Diktatur gelebt haben, um sie voll verstehen zu können."

Nach diesem offenen Bekenntnis, das zwar auf ein Fehlverhalten der unpolitischen Deutschen hinwies, empfahl Prandtl jedoch, Urteile über Entnazifizierung entsprechend seiner erläuternden Ausführungen zu überdenken. Er setzte sich auch wiederholt ein, um nun einzelnen Kollegen zu einer gerechteren Einschätzung ihrer Vergangenheit zu verhelfen, die wegen bloßer Mitgliedschaft von der Militärregierung als mitschuldig erkannt worden waren und eine dementsprechende Verurteilung erfuhren.

Prandtl versuchte wiederum, den britischen Besetzern verständlich zu machen, wie unterschiedlich solche Mitgliedschaften beurteilt werden müßten. So schreibt er z.B. am 14. April 1946 an Mr. Bird:

"Es handelt sich um Professor Osenberg von der Technischen Hochschule Hannover, der, wie Ihnen bekannt sein wird, während der letzten Kriegsjahre eine sehr erfolgreiche Tätigkeit durch die Leitung des Planungsamtes des Reichsforschungsrates entfaltet hat. Er hat in jahrelanger Arbeit gegen allergrößte Widerstände durchgesetzt, daß wichtige Wissenschaftler aus der Front gezogen und in planvoller Weise für die Forschungsarbeit freigemacht werden konnten ...

Wenn es einen Weg gibt, ihn und die anderen Professoren aus der Internierung zu befreien ... so würde damit im Sinne der Menschlichkeit und der Möglichkeit wissenschaftlicher Betätigung dieser Gelehrten ein sehr gutes Werk getan." 
Ein anderes Schreiben, in dem er sich als Fürsprecher einsetzte, möchte ich noch anführen. Prandtl stellte am 13. Januar 1946 eine Bescheinigung aus zu dem Spruchkammerverfahren gegen Professor H. Schaefer, Bad Nauheim, dessen politische Vergangenheit als früheres Parteimitglied untersucht wurde.

"Mit Professor Hans Schaefer bin ich in meiner Eigenschaft als Vorsitzender der Forschungsführung im Jahre 1943 in persönliche Berührung gekommen, weil es sich damals darum handelte, Herrn Professor Schaefer für eine neu zu gründende Stelle an der Luftfahrtforschungsanstalt München zu gewinnen. Er litt damals unter erheblicher Bedrückung seitens des Frankfurter Gauleiters, der alle Hebel in Bewegung setzte, um ihn aus Nauheim zu entfernen. Ich selbst hatte gelegentlich eines Besuches von Professor Schaefer in Göttingen eine längere Aussprache mit ihm. Er hat mir hierin auch ausführlich von den Bemühungen des Gauleiters berichtet, ihn von Nauheim zu entfernen.

Aus meinem Bericht an die Mitglieder der Forschungsführung:

8. Juni 1943: Professor Schaefer strebt von Nauheim fort, weil es dem Frankfurter Gauleiter nicht paßt, daß Schaefer ein die Kirche besuchender Katholik ist.

Der ganze persönliche Eindruck von Professor Schaefer auf mich war der eines ernsten und von wissenschaftlichen Ideen erfüllten Gelehrten. Ich zweifle deshalb nicht, daß man ihm in seinen Aussagen jedes Wort glauben kann."

In seiner Biographie "Erkenntisse und Bekenntnisse eines Wissenschaftlers" berichtet der Physiologe Professor Hans Schaefer selbst von dem oben erwähnten Besuch bei Prandtl in Göttingen [45]:

"Mein Versuch, den leichtesten Weg zu gehen, auf eine andere Stelle, mißlang im Krieg natürlich, trotz vieler Anläufe. Einen dieser Anläufe möchte ich schildern, weil er ein hohes Lied auf einen großen Gelehrten zu singen gestattet.

Ich hatte mich inzwischen mit Theo Benzinger angefreundet. Er meinte, daß die Übernahme in die Stellung eines Regierungsmedizinalrates möglich sei, und hatte schon alle Wege geebnet. Der letztlich maßgebende Mann war Professor Ludwig Prandtl, der große Pionier der Strömungsforschung in Göttingen. Ihn hatte ich zu besuchen beschlossen, um den Plan, an einem noch zu gründenden biologischen Institut der Luftfahrtforschungsanstalt München unter Benzingers Leitung zu arbeiten, 
voranzutreiben. Bei dem Besuch, der am 7. Juni 1943 stattfand, fand ich Prandtl erst ziemlich ablehnend. Er verstand nicht, warum ich jetzt noch zur Luftwaffe wollte, ob ich keine Zeitung läse? Mein Hinweis darauf, daß ich durch den Gauleiter gezwungen sei, eine Position zu suchen, und ich in ziemlichen politischen Schwierigkeiten stecke, verwandelten den alten brummigen Herrn in einen liebenswürdigen väterlichen Berater. Sein Rat: In Bad Nauheim festbeißen. Das riet mir auch mein Kollege Hermann Rein ... Also erreichte mich das Kriegsende in Bad Nauheim. Mit dem Einzug amerikanischer Panzer in unser Städtchen hatte der schlimmste Alptraum meines Lebens ein Ende."

Dr. Hans Schaefer schreibt am 17.11.1946:

"Sehr verehrter Herr Prandtl!

Ich habe Ihre Bescheinigung zu meiner Angelegenheit erhalten und möchte Ihnen meinen herzlichen Dank aussprechen. Der Brief wird mit Sicherheit eine durchschlagende Wirkung haben." 


\section{Erste Nachkriegsjahre}

Die britische Besatzungsbehörde hatte zwar die Fortsetzung jeglicher Forschungsarbeit in den einzelnen Instituten untersagt, doch die Kaiser-Wilhelm-Gesellschaft bestand zunächst noch als übergeordnete Organisation weiter. Dem Generalsekretär Dr. Ernst Telschow ist es dann gelungen, in mühevollen Einigungsgesprächen diese Gesellschaft als eingetragenen Verein zu erhalten. Dieser weitblickende Mann hatte schon vor Kriegsende einen Teil der Generalverwaltung aus Berlin in das unzerstörte Göttingen verlegt und hatte somit die Grundlage für eine Weiterarbeit geschaffen.

Auch für Dr. Telschow, dessen Bedeutung und Wirksamkeit in den folgenden Jahren gar nicht überschätzt werden kann, konnte Prandtl eine Unbedenklichkeitsbescheinigung erwirken (Brief von 7.6.1946 an die Besatzungbehörde).

Dr. Telschow führte Verhandlungen mit der Miltärbehörde in Hannover und berichtete dort mündlich über seine Besuche in den verschiedenen Instituten, die sich in den anderen Zonen, der amerikanischen, der französischen, der russischen befanden.

Noch fehlte allerdings eine einheitliche Führung. Als Max Planck im Juni 1945 in Göttingen als Flüchtling eintraf, um bei Göttinger Verwandten Aufnahme zu finden, war der Gedanke naheliegend, ihm den Vorschlag zu machen, sich für das Weiterbestehen der Forschungsgesellschaft einzusetzen. Man wußte, daß Planck durch seine unangreifbare, klare Haltung gegen Hitler von den Siegermächten hoch geachtet wurde. Von einem Komitee wurde er gebeten, trotz seines hohen Alters (87 Jahre) noch einmal die Präsidentschaft der Gesellschaft zu übernehmen. Sie sollte später auch seinen Namen tragen: Max-Planck-Gesellschaft. Planck willigte ein und erklärte sich bereit, sich nach besten Kräften der Aufgabe des Wiederaufbaus dieser Gesellschaft zu widmen, so daß die Verantwortung für die vielen deutschen Forschungsinstitute damit wieder in einer Hand lag.

Als im April 1946 Prof. Otto Hahn aus der Gefangenschaft nach Göttingen entlassen wurde, konnte er Planck durch seine Mitarbeit in den schwierigen Verwaltungsangelegenheiten entlasten. Hahn wurde dann zum neuen Präsidenten gewählt.

Das Strömungsforschungsinstitut konnte nun auf diese Weise weitergeführt werden, 
aber nicht die AVA, die Aerodynamische Versuchsanstalt. Sie wurde all ihrer Einrichtungen beraubt - die Windkanäle wurden teils zerstört, teils demontiert und nach England abtransportiert. Ich kann mich jedoch nicht erinnern, daß mich mein Vater zu diesem Zeitpunkt davon in Kenntnis setzte. Es muß ein großer Schmerz für ihn gewesen sein, zuzusehen, wie die Versuchsanlagen, die in langjähriger Planung entstanden waren, abgewrackt wurden - sein Lebenswerk durch Demontage vernichtet. Er hat es auch nicht mehr erlebt, daß ein großzügiges Vorhaben wieder neue Windkanäle in die alten Hallen brachte. Mein Vater hat sich manchmal als Stoiker bezeichnet; ein Bekenntnis zu der Philosophie einer ethischen Grundhaltung, die lehrt, sich von keinerlei Gemütsbewegungen bestimmen zu lassen.

Im gesamtwissenschaftlichen Bereich gab es hingegen Neuanfänge, zumal in den leerstehenden Gebäuden der AVA andere Institute eingerichtet werden konnten. W. Heisenberg hatte sein Kaiser-Wilhelm-Institut für Physik dorthin verlegt und teilte sich mit C.F. von Weizsäcker und K. Wirtz die Räumlichkeiten, die ihrerseits eigene Abteilungen aufbauten. So ist es nicht verwunderlich, daß die erste Physikertagung nach Kriegsende am 4. Oktober 1946 in Göttingen stattfand. Obwohl die Teilnehmerzahl im Hinblick auf Verpflegungsschwierigkeiten begrenzt bleiben mußte, fanden sich doch etwa 80 Physiker am Tagungsort ein. Man war glücklich, die schöne Gepflogenheit des wissenschaftlichen Gekankenaustausches wieder ins Leben gerufen zu haben, ungeachtet der kümmerlichen Versorgungslage.

Prandtls Interesse war nun auch ganz bewußt auf die Politik gerichtet. Er fühlte im Hinblick auf die Versäumnisse in der Vergangenheit eine Art Verpflichtung, sich über das politische Geschehen eigene Gedanken zu machen und daraus entsprechende Konsequenzen zu ziehen. Nachdem sich 1946 die Parteien neu etabliert hatten, trat er als Mitglied in die FDP ein.

Im privaten Bereich, in der Calsowstraße, erlebten wir einen neuen Aufschwung, als im Herbst 1945 meine Schwester zu uns nach Göttingen zurückkehrte. Sie hatte in München bei einem Bombenangriff alles verloren, und wir waren froh, sie gesund wiederzusehen. Sie selbst, glücklich, wieder bei ihrer Familie zu sein, setzte sich sofort hilfsbereit für unsere Haushaltung ein, und es lag ihr besonders am Herzen, den alten Vater nach bester Möglichkeit zu versorgen. Genügend Essen für eine 
Familie zu beschaffen, nahm damals viel Zeit in Anspruch. Für das wenige, was es auf Marken gab, stand man an, und zwar vor verschiedenen Geschäften; im Herbst sammelten wir Bucheckern, um etwas Öl zu gewinnen, und hielten Nachlese auf den abgeernteten Kartoffelfeldern, da Kartoffeln, das Hauptnahrungsmittel, nie ausreichend zu bekommen waren. Manchmal hatten wir das Glück, auf dem Land gegen Tauschware wertvolle Lebensmittel zu erwerben. Zusammen war dann alles leichter zu bewältigen.

Auch mein Vetter, Hermann Föppl, der nach seiner Entlassung aus der Gefangenschaft in Göttingen studieren wollte, konnte noch bei uns unterkommen. Er erinnert sich an die Abende, wo er sich gemeinsam mit seinem Onkel an den großen Küchentisch setzte und wie dieser bis in die Nacht über seinen Arbeiten saß. Der elektrische Stromverbrauch war in der Weise rationiert worden, daß abends ab zehn Uhr der Strom ganz abgeschaltet wurde. Aber in der Küche hatten wir außer dem elektrischen Anschluß noch eine altmodische Gasbeleuchtung. Der Lichtschein, der aus unserer Küche zu den anderen Häusern hinüber leuchtete, die sich in Dunkel hüllten, mag manchem Göttinger recht verwunderlich erschienen sein.

Im April 1946 wurde nun auch mein Mann aus der amerikanischen Gefangenschaft entlassen. Er war gesund geblieben; die Verpflegung bei den Amerikanern war zuletzt ausreichend gewesen. Unsere kleine Tochter, die damals anderthalb Jahre alt war, befreundete sich schnell mit dem jungen Vater.

Nun wohnten wir alle, ein wenig eingeschränkt, in der gleichen Wohnung. Doch ließ es sich einrichten, daß unser Vater zwei seiner Zimmer für sich behielt. Die Raumnot in Göttingen war ganz allgemein, so daß sich jeder daran gewöhnen mußte, nun mit weniger Wohnfläche auszukommen.

Die schmale Kost, von der wir uns alle schlecht und recht ernährten, war immer weniger ausreichend für eine ganze Familie. Wir erinnern uns noch an eine klägliche Mahlzeit, wo außer einigen gekochten Kartoffeln nichts auf den Tisch gebracht werden konnte. Und um sie aufzubraten, gaben wir etwas Dorschlebertran in die Pfanne. Das Resultat unserer Kochkunst mundete keinem. Man kann sich daher wohl unsere frohe Stimmung vorstellen, als wir am folgenden Tag aus Amerika von Professor Cou- 
rant ein Carepaket erhielten, mit dessen reichlichem Inhalt wir längere Zeit wirtschaften konnten.

Später dachten auch andere Kollegen, die in Amerika lebten, an ihren Lehrer und Freund Prandtl, so daß wir fast jeden Monat solch ein kostbares Paket aus Übersee empfingen. Damit waren wir reich beschenkt, und die bange Frage, ob wir anderntags vielleicht ganz ohne Vorräte bleiben würden, tauchte nicht mehr auf.

An unserem Familienleben nahm unser Vater herzlich gern teil. Der Schwiegersohn, der vor allem menschliche Probleme in die Unterhaltung einzubringen pflegte, brachte manche Anregung in die naturwissenschaftliche Atmosphäre unseres Hauses. Es ergaben sich dann Gespräche allgemeineren Charakters. Gelegentlich hat mein Mann mit einer kurzen Notiz festgehalten, was ihm bedeutsam erschien.

Er fragte seinen Schwiegervater eines Tages mit einer gewissen Unbekümmertheit, ob er die Relativitätstheorie verstehe, die ihm als Philologen nur dem Namen nach bekannt war. Darauf antwortete er, ein wenig lächelnd: "Eigentlich ja - sie hat mich sogar auf Anhieb so angesprochen, daß ich gleichfalls Relativist wurde. Als ich Einsteins ersten Aufsatz las, hatte ich sogleich das Gefühl, die Überzeugung: Das ist richtig."

Die Antwort war bezeichnend für Prandtls nachsichtige Haltung und hilfreiche Zuwendung, auch dem naturwissenschaftlich Unkundigen gegenüber, den er gleichwohl ernst genug nahm, um ihn einer für ihn faßbaren Antwort zu würdigen. Diese Haltung, dem Gegenüber in jedem Fall Achtung zu zollen, wird auch deutlich in einer grundsätzlichen Forderung an Autoren, die er wie folgt formulierte: "Der Leser muß, um die teilweise schwer verständlichen Darlegungen besser zu vertragen, zuvorkommend behandelt werden."

Mein Mann hat oft zugehört, wenn der Schwiegervater am Flügel "präludierte", wie er es selbst nannte. Als er ihn eines Tages fragte, ob seine Musik gewissermaßen als höhere Mathematik, als ein sublimes Spiel mit Proportionen und Zahlenverhältnissen getrieben werde, antwortete er: "Nein, ganz und gar nicht, keineswegs, sondern ich spiele rein gefühlsmäßig, lasse mich allerdings durch einen unversehens hineingerutschten Akkord, eine unbeabsichtigte Harmonie, dazu verleiten, ihre Richtung nun 
bewußt weiterzuverfolgen." Grundlegend sei stets die Abhängigkeit von Stimmungen gewesen. Nach seiner eigenen Aussage glückten ihm Improvisationen am besten, wenn ein bestimmter Anlaß vorhanden war, wie zum Beispiel Gedenktage oder ein Abschied. (In der Tat kann ich mich erinnern, daß er uns mit seiner Musik bei Familienfesten, den Geburtstagen oder den Tauffeiern jedesmal durch eine überraschend meisterliche Komposition zutiefst erfreute.)

Bei einem allgemeinen Gespräch über äußeren Erfolg sagte er, er sei besonders begünstigt gewesen, "indem dasjenige, was mir am Herzen lag, auch gerade diese Zeit interessierte. Man muß halt mit seinem Pfund wuchern, so gut man kann. Im übrigen habe ich auch meine Berufsethik, die mich danach streben läßt, ein möglichst vollkommenes Werk zu hinterlassen und einen Schülerkreis zu gewinnen, der dieses Werk dann auch fortsetzt." Hierhin gehört auch das, was er über sich selbst aussagte, als mein Mann ihm einmal erzählte, ein englischer Fachkollege habe ihn als "a marvellous sort of man" bezeichnet. "Der hat sich eben gewundert, daß ein Mann, von dessen wissenschaftlichen Erfolgen allerlei Leute reden, sich äußerlich so wenig darauf einbildet. Ich meine nämlich, von mir sagen zu können, daß ich trotz so vieler Anerkennungen in all den Jahren nicht eingebildet geworden bin." Aber nach einer kleinen Pause fügte er, gleichsam in gewissenhafter Selbsterforschung, hinzu: "Aber, wenn ich das sage, dann zeige ich ja eigentlich damit, daß ich doch eingebildet bin. Ich bin nämlich schon stolz auf das, was ich geschafft habe, aber ich mache keinen Gebrauch davon." Ein andermal äußerte er seine Meinung über seine Haltung in Konfliktsituationen: "Der Mensch muß eben sehr oft ein scheinbares Opfer bringen, indem er temperamentvolle Ausbrüche unterdrückt. Ich selbst habe das Glück, daß ich in solchen Überlegungen sehr langsam bin. Wenn ich die Situation überschaue, hat sich alles schon wieder so weit beruhigt, daß ich die Sache mit Gelassenheit nehme."

Diese Gelassenheit war für ihn Inbegriff einer angemessenen Grundhaltung. Auf die Frage, was ihn befähige, auch schmerzhafte Dinge zu ertragen, antwortete er wiederum: "Gelassenheit!" Nach einer Operation habe er eine sehr schwere Zeit durchgemacht. Schlaflosigkeit und innere Unruhe hätten ihn gequält. Da habe er sich gesagt: "Ich muß mir diese Gelassenheit wiedererwerben." Ob er sich dem stoischen Ideal verpflichtet fühle? "Ja, die stoische Lehre hat mich stets angesprochen - nicht nur im Tode nichts zu erwarten, sondern auch im Leben. Ich glaube nicht an Unsterblichkeit, 
aber ich glaube, daß man moralisch leben muß. Man muß sich nichts vorzuwerfen brauchen, dann wird einem diese Gelassenheit zuteil. Man soll Mitleid haben und gut zu anderen Menschen sein. Man soll helfen, aber sich nichts erwarten, also gewissermaßen eine stoische Moral." Auf die Frage, ob diese Einstellung durch seine humanistische Erziehung vorbereitet sei, sagte er: "Ja, das ist sehr gut möglich. Es gehört allerdings eine gewisse Stärke dazu, sich diese Haltung zu eigen zu machen." Diese Stärke wird auch spürbar in seiner gelassenen Einstellung zum Tod. Im Zusammenhang eines Gesprächs über die Frage des Fortlebens nach dem Tode sagte er: "Ich erwarte mir nichts. Ich weiß, daß mein Herz eines Tages aufhören wird zu schlagen und mein Atem stehenbleibt. Ich habe genug Zeit gehabt, mich daran zu gewöhnen, mich damit abzufinden." Durch die Beschäftigung mit den Naturwissenschaften sei er den katholischen Lebren, in denen sich der Unsterblichkeitsgedanke mit dem Gottesgedanken verbindet, allmählich ferngerückt. Schließlich auf den Schöpfungsgedanken angesprochen, antwortete er: "Ein Schöpfer der Welten? Ja, wie soll ich mir das vorstellen? Ich formuliere mir das nicht und habe auch kein Bedürfnis nach einer solchen Formulierung." In diesem Sinne bekannte er sich ausdrücklich zu dem Goethewort: "Das schönste Glück des denkenden Menschen ist, das Erforschliche erforscht zu haben und das Unerforschliche ruhig zu verehren."

In einem Gespräch über den vergangenen Krieg wurde wiederum der sehr ernste Untergrund seiner Lebensanschauung deutlich, und auch seine Kraft, mit schonungsloser Aufrichtigkeit der erkennbaren Wahrheit ins Auge zu schauen. "Es ist eine alte Weisheit: Die Welt ist eben ein Jammertal." Mein Mann fügt hier aus eigener Anschauung hinzu: "Es kennzeichnet Ludwig Prandtls zutiefst humane Wesensart, daß er bei der harten Entschiedenheit eines so konsequenten Realismus hinsichtlich der conditio humana gleichwohl im mitmenschlichen Bereich von großem Zartgefühl war, voller Nachsicht und Güte."

Im Wintersemester 1946 wurde Prandtl emeritiert, und anschließend trat er mit fast 72 Jahren als Institutsdirektor zurück. Professor Betz wurde sein Nachfolger. Allerdings sah man sich genötigt, drei Abteilungen zu schaffen, da das inzwischen so umfangreiche Gebiet nicht länger von einem einzelnen bearbeitet werden konnte. Eine Abteilung wurde weiterhin von Prandtl geleitet. Professor Tollmien, der Prandtls Nachfolger an der Universität geworden war, sowie Professor Betz waren 
ebenfalls für je eine Abteilung verantwortlich. Eine gute Zusammenarbeit dieses außerordentlichen Teams war von vornherein gewährleistet.

Da Prandtl nun von einigen Verpflichtungen befreit war, konnte er im März 1947 einer Einladung in die Schweiz Folge leisten. Dank der Initiative von Professor Ackeret in Zürich waren die Voraussetzungen dafür geschaffen worden, den Plan dieser Reise zu verwirklichen.

Ackeret schrieb an Prandtl am 30. Januar 1947:

"Nun muß ich wirklich einmal Ihnen genauen Bescheid geben über meine bisherigen Bemühungen, Ihnen und einer Ihrer Töchter einen Erholungsurlaub in der Schweiz zu ermöglichen.

Jetzt, da die Hauptsache, nämlich die Finanzierung und die alliierte Erlaubnis in Ordnung sind, sollten prinzipielle Hindernisse nicht mehr bestehen. Auf meine Anfrage hin haben sich die drei Firmen

Aktiengesellschaft Brown Boveri Cie., Baden

Escher Wyss Maschinenfabriken

Gebrüder Sulzer, Winterthur

mit großer Freude bereiterklärt, die Kosten für einen circa sechswöchigen Aufenthalt zweier Personen gemeinsam zu übernehmen. Nun möchte ich noch erfahren, welche speziellen Wünsche Sie bezüglich dieses Aufenthaltes haben."

Was es damals, 1947, bedeutete, plötzlich die Aussicht zu haben, in die Schweiz reisen zu können, ist heute kaum noch vermittelbar. Bei dem totalen Mangel jeglicher Art von Waren kämpfte man ständig um die elementarsten Dinge, um die Erhaltung des Bestehenden. In unserer Phantasie durften wir uns nun die Möglichkeit ausmalen, wie wir dort in einem vom Krieg verschonten Land leben würden. Anfang März konnte mein Vater die Reise antreten, und ich durfte ihn begleiten. Die Züge fuhren in dieser Nachkriegszeit nicht täglich, meistens nur dreimal in der Woche. Aber wir erreichten schließlich nach vielen Stunden Fahrt und einer Übernachtung in Freiburg in einem Bunker, der notdürftig als Herberge eingerichtet war, die Grenzstation Weil, wo wir abgeholt wurden. Es mußten nur einige Formalitäten erledigt werden, dann konnten wir zur Weiterfahrt in einen Zug nach Zürich einsteigen. So saßen wir in unseren abgetragenen Mänteln in einem komfortablen Schnellzug unter Schweizern, 
die im Gegensatz zu uns gut gekleidet waren und ohnehin eine natürliche Selbstsicherheit erkennen ließen, die uns begreiflicherweise nicht auszeichnete. Einige junge Leute, vom Skilaufen kommend, rotbackig und gebräunt, scherzten in fröhlicher Unterhaltung. Die aufgezwungenen Kriegsjahre und die folgende allgemeine Depression und Notlage hatten für uns Gedanken an solche sportlichen Vergnügungen in unerreichbare Ferne gerückt.

In Zürich wurde uns gleich großzügig die Möglichkeit gegeben, unsere Garderobe aufzubessern. Man hatte uns in einem sehr schönen Hotel untergebracht. So genossen wir den außerordentlichen, paradiesischen Zustand, ohne tägliche Sorgen in der unversehrten Schweiz zu Gast zu sein.

Herr Professor Ackeret und seine Frau kümmerten sich aufmerksam um meinen Vater. Es wurde selbstverständlich eine Besichtigung seines Instituts für Aerodynamik verabredet; eine Besichtigung der Fabrik der Gebrüder Sulzer in Winterthur folgte sowie ein Besuch in den Werkstätten und Laboratorien der Fabrik Escher Wyss. Auch wurde eine persönliche Verabredung mit Dr. H. Gygi getroffen, dessen Chauffeur uns nach Wildegg in sein gepflegtes Privathaus brachte, wo wir im Kreise der Familie einen besonders angenehmen Sonntag verbrachten. Herr Ing. Gygi, Direktor der Maschinenfabrik Escher Wyss, war außerordentlich daran interessiert, sich über seine fachlichen Probleme mit meinem Vater zu unterhalten. Ich bemerkte, ohne den eigentlichen Gedankenaustausch verfolgen zu können, wie Dr. Gygi den Lösungen, die mein alter Vater vorzuschlagen wußte, dankbar zustimmte.

Ich möchte noch erwähnen, daß ich damals in Zürich zu meiner großen Freude meine Freundin Lilli Misch wiedergetroffen habe, die in die Schweiz emigriert war und dort während der Hitler-Diktatur ihr Medizinstudium absolvieren konnte. Sie und ihr Mann, Dr. Walter Baum, luden meinen Vater und mich zu einem unvergeßlichen Theaterabend im Züricher Schauspielhaus ein: Es wurde "Der Tod im Apfelbaum" von P. Osborne gespielt, mit Albert Bassermann in der Hauptrolle.

In der Technischen Hochschule hielt Prandtl zuletzt noch einen Vortrag über Turbulenz im Rahmen eines Kolloquiums. Am 15. März reisten wir nach Ascona am Lago Maggiore zu einem längeren Aufenthalt. Diese drei Wochen dort brachten für mei- 
nen Vater nun wirklich eine Erholung. Wir machten täglich schöne Spaziergänge, ungeachtet des wenig freundlichen Wetters. Der Blick auf den verhangenen stillen See war immer wieder reizvoll. Auf der Rückreise Anfang April waren jedoch für meinen Vater neue Programmpunkte vorgesehen, die er unbedingt einhalten wollte. Sein Interesse an neuen Projekten sowie an Neuveröffentlichungen in der Wissenschaft hatte im Alter keineswegs nachgelassen.

Er besuchte die Wissenschaftsgruppe der Professoren Schardin und Sauer in Weil am Rhein, die im Begriff war, ein Laboratorium im Elsässischen aufzubauen. Von dort reiste er nach Karlsruhe zu einer Tagung für angewandte Mathematik und Physik, hörte sich den größten Teil der zahlreichen Vorträge an; auch die anschließenden Diskussionen mit den Kollegen ließ er nicht aus. Nach Göttingen heimgekehrt, stellte er zuletzt selbst fest: "Ich war recht angeregt, aber auch angestrengt und habe einen guten Teil meiner Erholung dort wieder verpulvert, aber es reut mich trotzdem nicht, an dieser Tagung teilgenommen zu haben."

Am 3. Juli 1947 besuchte Professor Courant, aus USA kommend, das altvertraute Göttingen. In seinem Tagebuch vermerkte er: "7 Uhr 30 in etwas wehmütiger Stimmung in Göttingen angekommen. Äußerlich wies die Stadt kaum Beschädigungen auf. Laut von Kármán war sie seinerzeit ausdrücklich von den alliierten Luftangriffen ausgenommen worden." Seine Notizen Prandtl betreffend: "Das Institut für Aerodynamik war zu einer wahren Festung ausgebaut worden. Prandtl war krank und deprimiert, doch geistig immer noch aktiv. Er hatte sich eingehend mit Analogrechnern befaßt, und zwar vor allem im Hinblick auf meteorologische Berechnungen. Die Dimensionen der Maschine, die er konstruierte, waren von der Größe der Kugellager, die er zufällig unter Kriegsüberschußware gefunden hatte, bestimmt worden."

Für die Sommerferien war mein Vater von seinem Schwager, Ludwig Föppl, nach Ammerland eingeladen worden. Das bedeutete Erholung in der vertrauten Ferienheimat und, je nach Bedarf, Gelegenheit zu wissenschaftlichem Austausch. Anfang Juli war unsere zweite Tochter Susanne zur Welt gekommen, und somit blieben wir natürlich vorerst in Göttingen. 
Aus diesen Ferien stammt wahrscheinlich Prandtls kleine Schrift [36]:

"Über Mammatuswolken

Ich habe diese Wolkenform gelegentlich von Urlaubsreisen auf der bayrischen Hochebene öfters beobachtet und aus den über das bezügliche Wettergeschehen gemachten Erfahrungen verhältnismäßig bald festgestellt, daß ein drohendes Gewölk, in dem sich Mammatusbeutel zeigen, einen auffällig harmlosen weiteren Verlauf nimmt. Ich habe später in einem längeren Gebirgstal, das sich von dem im Südwesten befindlichen Talabschluß nach Nordosten erstreckt, besonders schöne Mammatuswolken beobachtet, die sich dort bei einer Südwestströmung aus einer dickeren Wolke gebildet haben und die eilig talabwärts zogen. Daß eine Labilität vorliegt, war mir nach den ganzen Bewegungsformen, die gewisse Ähnlichkeit mit den Strömungsformen in einer von unten her erhitzten Flüssigkeit zutage treten ließen, völlig klar, und es bedurfte nicht allzu vielen Nachdenkens, um zu finden, daß offenbar eine Wolkenluftmasse über einer durchsichtigen Luftmasse liegen müßte und die Labilität durch eine Absinkbewegung geschaffen wird, bei der die Wolkenmasse sich langsamer erwärmt als die klare Luftmasse. Daß die Strömung hier talab verlief, gab in diesem Fall auch gleich die Erklärung für das Absinken an sich."

Es sollte dieser Anfang der Schrift genügen, um erkennen zu lassen, wie Prandtl durch Beobachten von Naturphänomenen zu spezifisch wissenschaftlichem Denken angeregt wurde.

Im Institut wurden mitunter auch wieder neue Fachkräfte angeworben, und jeder, der eingestellt wurde, betrachtete es als ein großes Glück, dort einen Arbeitsplatz bekommen zu haben.

Als Frau von Stutterheim mir davon erzählte, wie sie 1948 dort ihre Stellung als technische Assistentin bei Dr. Reichardt antrat, sprach sie auch mit innerer Anteilnahme von "dem sympathischen alten Professor Prandt1", der oft im Büro von Dr. Reichardt erschien. Sie hatte bald nach Beginn ihrer neuen Tätigkeit eine Fußoperation machen lassen müssen und konnte für eine längere Zeit nur mühsam ihren Weg zum Arbeitsplatz zurücklegen. Prof. Prandtl habe größtes Mitleid gezeigt wegen ihrer peinvollen Behinderung. Er versuchte, sie täglich mit seiner Unterhaltung aufzumuntern. Einmal 
erzählte er ihr, daß er seine Schritte von zu Haus bis ins Institut des öfteren zähle, um feststellen zu können, ob nach dem Verlauf einiger Zeit die Berechnung der Schritte eine höhere Zahl ergebe. Er wollte offenbar den Alterungsprozeß, den er im voraus akzeptierte, auf diese Weise sicher kontrollieren können.

Ähnliche Gedanken, die er in einem Brief an Dr. A. Baeumker ausspricht, sollen hier folgen.

An Dr. A. Baeumker, Fairfield, USA, 14.2.1949:

"Mit den Arbeiten für mein Buch bin ich noch lange nicht am Ende. Ich darf dazu bemerken, daß ich das Alter in verschiedenen Dingen stark zu spüren bekomme. Aber Ideen sind immer noch so reichlich vorhanden, daß ich noch lange nicht daran denken kann, meine Lebenserinnerungen zu schreiben, was meine Töchter so gerne haben wollen. Herr Sommerfeld ist jetzt über 80 und schreibt gerade wieder an einem neuen Buch. Bis ich so alt bin, werde ich hoffentlich das mit den Erinnerungen noch schaffen können, und wenn dies nichts wird, ist es auch kein sehr großer Schade.

Denn ich sehe es an der jungen Generation selbst, daß das, was uns seinerzeit interessiert hat, die jungen Leute nicht mehr interessiert. Erst wenn etwas sehr lange her ist, fängt es an, etwas interessanter zu werden."

Aus dem Brief vom 1.6.1949:

"Von Ihrer politischen Erörterung habe ich leider vieles nicht recht verstanden. Offenbar bin ich in politischen Dingen sehr schlecht unterrichtet und kann Ausführungen hierüber nur verstehen, wenn mit klaren direkten Worten gesagt wird, um was es sich dreht.

Ich möchte noch sagen, daß es ja recht interessant ist, daß man in Wrightfield meine Eingabe an Göring gelesen hat, in der ich mich über das greuliche Benehmen einiger nationalsozialistischer deutscher Physiker beschwert habe."

Prandtl beschäftigte sich, wie schon erwähnt, nun ausschließlich mit meteorologischen Problemen. Er arbeitete mit dem Meteorologen Dr. E. Kleinschmidt zusammen. 1949 veröffentlichte er seine Gedanken und Ergebnisse in einem Sonderdruck, der durch die Akademie der Wissenschaften publiziert wurde. Die allgemein verständliche Einleitung soll hier folgen. Inzwischen sind ja die Kenntnisse auf diesem Gebiet 
ganz enorm angewachsen, so daß es lohnend scheint, daß man sich die ersten Anfänge der wissenschaftlichen Betrachtungen von damals mittels dieses einführenden Textes bewußt macht.

Wettervorgänge in der oberen Troposphäre (vorgelegt in der Sitzung vom 17. Juni 1949) [39]:

"Die Voraussage von Schlechtwettergebieten (barometrischen Tiefdruckgebieten) an der atlantischen Küste von Europa war früher immer sehr schwierig gewesen, da diese Tiefdruckgebiete mit beträchtlichen Geschwindigkeiten von See her an Land kamen und daher - abgesehen von den Haupt-Schiffahrtskursen, von denen drahtlose Meldungen kommen - nicht rechtzeitig vor dem Eintreffen über Land beobachtet werden konnten. Durch die Einführung der Radiosonden, die die Wetterzustände bis in die Stratosphäre hinein an Bodenstationen meldeten und bei Doppelanpeilungen auch Angaben über Richtung und Stärke der Höhenwinde lieferten, konnten hierin erhebliche Fortschritte erzielt werden. Es zeigte sich, daß in der hohen Troposphäre auch in den unteren Stratosphärenschichten ein charakteristisches Windsystem mit Windgeschwindigkeiten bis weit über $100 \mathrm{~m} / \mathrm{s}$ auftritt, das einem neuen Tief vorausläuft und dieses sozusagen anmeldet, wobei die Höhe der Windgeschwindigkeit auch eine Angabe über die Stärke des Tiefs liefert.

Ein Grundgedanke sei noch erwähnt, der eine erste Voraussetzung der eigentlichen Berechnungen abgibt, $\mathrm{da} ß$ nämlich die bewegten Luftmassen über der rotierenden Erde als mitrotierende Atmosphäre mitdriften."

Die Zusammenarbeit mit Dr. E. Kleinschmidt, dem Meteorologen, führte Prandtl an neue ungelöste Probleme heran, mit denen er sich eindringlich beschäftigte und für die er in der Folge einige charakteristische Lösungen herausfand. Dank seines Reichtums an schöpferischen Ideen konnte er auch für das Gebiet der Meteorologie wesentliche Ergebnisse zur Veröffentlichung vorlegen.

Auf der Physikertagung vom 6. September 1948, bei der Prandtl zum Ehrenmitglied der Deutschen Physikalischen Gesellschaft in der Britischen Zone gewählt wurde, hielt er eine kleine Rede über seine Arbeitsweise. Er hatte sich später bereiterklärt, seine im freien Vortrag geäußerten Gedanken nachträglich schriftlich niederzulegen, um sie einem größeren Kreis zugänglich zu machen [31]. 
"Dem Wunsch von Herrn B. komme ich besonders gern nach, weil ich mich bisher noch nie näher über die Methoden geäußert habe, die es mir öfters ermöglicht haben, bei meinen Problemen neue Wege zu gehen, und besonders auch weil ich glaube, mit solchen Ausführungen gerade den jungen Fachgenossen nützliche Hinweise geben zu können.

Herr Heisenberg hatte in den mir gewidmeten freundlichen Ausführungen unter anderem behauptet, daß ich die Fähigkeit hätte, den Gleichungen ohne Rechnung anzusehen, welche Lösungen sie hätten. Ich mußte antworten, daß ich zwar diese Fähigkeit nicht hätte, daß ich mir aber von den den Aufgaben zugrunde liegenden D ingen eine möglichst eingehende A n chaung zu verschaffen strebe und die Vorgänge zu verstehen suche. Die Gleichungen kommen erst später dran, wenn ich die Sache glaube verstanden zu haben; sie dienen einerseits dazu, qu a n t i t a t ive Aussagen zu gewinnen, die natürlich durch Anschauung allein nicht zu erreichen sind; andererseits sind die Gleichungen ein gutes Mittel, um für meine Schlüsse Beweise beizubringen, die auch andere Leute anzuerkennen bereit sind."

Auf diesen besonderen Ansatz im wissenschaftlichen Denken Prandtls kam sein früherer Schüler Professor F. Schultz-Grunow zu sprechen, als er im Oktober 1980 zum Thema "Das geistige Erbe Ludwig Prandtls" einen Vortrag hielt [46]:

"Prandtl trachtete zunächst, Erscheinungen durch Anschauung zu verstehen und sich so in die Differenzialgleichungen einzufühlen. Er fand durch dieses Einfühlen eine Menge sich überlagernder Einflüsse. Er wußte die wesentlichen herauszufinden, er befreite sich von den unwesentlichen und sah, daß gerade sie die mathematische Lösung versperren. Eine wunderbare Einrichtung der Natur war aufgedeckt. Prandtl erklärt selbst: Durch planmäßiges Vereinfachen des Ansatzes, das je nach der gestellten Aufgabe verschieden weit gehen kann, wird eine Beweglichkeit der Methoden erreicht, die sich gegenüber der zwar strengen, aber auch starren Methode der exakten Theorie als großer Vorzug erweist. Er schuf damit eine neue eminent erfolgreiche Dimension des Denkens."

Wir wenden uns nochmals Prandtls eigener Rede zu:

"Die vorerwähnte Art von Anschauung läßt sich durchaus erlernen, wie ich an verschiedenen Schülern feststellen konnte. ... 
In dem altmodischen Mathematikunterricht, den ich um 1890 auf der höheren Schule genoß, gab es noch keine Funktionen, sondern nur konkrete Einzelbeispiele. Es war deshalb im ersten Studiensemester eine richtige Erleuchtung für mich, daß es 'Veränderliche' und 'Funktionen' einer Veränderlichen gab. Mit einer wahren Begierde habe ich mir damals den Verlauf der verschiedenen Funktionen $\mathrm{y}=\mathrm{x}^{\mathrm{n}}$, mit positivem und negativem n auf kariertem Papier aufgemalt. ... In Beispielen der Mechanik gewöhnte ich mich allmählich daran, die Kräfte und Beschleunigungen in den Gleichungen und Skizzen zu 'sehen' oder mit dem Muskelsinn nachzufühlen, ebenso die Spannungen im Inneren der belasteten festen Körper usw...

Stromlinien einer zweidimensionalen Strömung ließen sich als Höhenlinien einer 'Stromfunktion' auffassen und dadurch auch als räumliches Modell dieser Funktion veranschaulichen. So gab es eine Menge von Arten, sich Bilder von den zu suchenden Lösungen aufzumalen. Derartige 'Spielereien' führten mich unter anderem auf eine hübsche Beziehung zwischen Schubspannungsverteilungen und Seifenhäuten.

Was nun die speziellen Aufgaben betrifft, denen ich mich zugewandt habe, so erhielt ich mehrmals die Anregung dazu in veröffentlichten Arbeiten, die meinen Widerspruch erregten; aber auch eigene Mißerfolge haben mich gelegentlich zu heftigem Nachdenken veranlaßt."

Dazu soll eines seiner Beispiele folgen: "In der Zeit kurz nach 1900 stieß ich in mehreren Veröffentlichungen auf die Behauptung, daß ein ausfließender Druckluftstrahl keine größere Geschwindigkeit erreichen könne als Schallgeschwindigkeit, obwohl die Energie zu größeren Geschwindigkeiten ausreichte. ... Die Sache ließ sich aber leicht zurechtrücken. Die Eulerschen Gleichungen lieferten mit der Kontinuitätsgleichung für ein zusammendrückbares Medium stationäre Wellen mit Überschallgeschwindigkeit [34] ...".

Noch im selben Monat September 1948 fand vom 22. bis 24. in Göttingen die erste wissenschaftliche Tagung der Gesellschaft für Angewandte Mathematik und Mechanik in der britischen Zone statt. Prandtl, der erster Vorsitzender der GAMM war seit ihrer Gründung 1922, hatte sich mit Erfolg bei den Besatzungsbehörden um die Wiederzulassung der Gesellschaft bemüht. Der britische Scientific Adviser Dr. R. Frazer zeigte sich interessiert. Prandtl hatte einen eigenen Vortrag auf das Programm gesetzt: "Erzeugung von Zirkulationen beim Schütteln von Gefäßen". Auch für den Verlauf der Tagung war er verantwortlich. So ermutigte er einen jüngeren 
Teilnehmer, Julius Rotta ${ }^{1)}$, über ein eigenes Thema zu referieren. Es war sein erster öffentlicher Vortrag. Ein Nachmittag war noch vorgesehen für eine gemeinsame Wanderung nach Nikolausberg, wo eine lockere Gesprächsrunde bei Kaffee und Kuchen stattfand. Jener schon genannte Teilnehmer konnte mir berichten, daß der nunmehr dreiundsiebzigjährige Prandtl sich dort angeregt mit den jeweiligen Tagungsgästen unterhielt und danach auf dem Heimweg der Gruppe rüstigen Schrittes vorauseilte und die Teilnehmer zu den schönsten Aussichtspunkten führte.

Prandtl war auch als Emeritus immer noch im gewohnten Arbeitsrythmus eingespannt. Außer der Beschäftigung mit meteorologischen Fragen hatte er sich die Aufgabe gestellt, noch einmal eine Neuauflage seiner Strömungslehre herauszugeben, um sein Lehrbuch auf den neuesten Stand zu bringen.

Auch an den Universitätsangelegenheiten, die auf den Akademiesitzungen zur Sprache kamen, nahm er weiterhin teil. Bei einer Universitätsfeier, die zum hundertsten Geburtstag des Göttinger Gelehrten Felix Klein am 7. Mai 1949 stattfand, hielt auch Prandtl eine Ansprache [26]. Ich zitiere daraus:

"Es mag mir als einem von den 'jüngeren Leuten', denen Felix Klein damals Schicksal geworden ist, vergönnt sein, anhand meiner Erinnerung über meine Erlebnisse unter seiner Führung zu berichten. Es war die Zeit, als unter der Leitung Kleins das Riesenunternehmen der mathematischen Enzyklopädie in Gang gebracht wurde. Daß das Werk wirklich entsprechend seinem ursprünglichen Plane zu einem guten Ende gebracht werden konnte, ist das alleinige Verdienst von Klein, der durch die mitreiBende Wirkung seiner machtvollen, ja königlichen Persönlichkeit imstande war, Willige und Unwillige zu erstaunlichen Leistungen anzuspornen."

Es ist vielleicht erlaubt, hier aus dem Brief Prandtls vom 8.3.49 an Professor Dr. A. Sommerfeld zu zitieren, was ein Freund Kleins, der durch die industrielle Verflüssigung der Luft sehr bekannt gewordene Carl von Linde, ihm damals geraten hatte, als die Gelder für die Gründung eines Institutes für Technische Physik benötigt wurden, sowie in der Folge auch für das Projekt einer Modellversuchsanstalt: "Wenn Sie,

1) Dr. Julius Christian Rotta ist der Verfasser des Buches: "Die Aerodynamische Versuchsanstalt - ein Werk Ludwig Prandtls. Ihre Geschichte von den Anfängen bis 1925" [43]. 
Herr Klein, bei Industriellen Geld sammeln wollen, werden Sie nicht viel zusammenbekommen. Derartiges muß so gemacht werden, daß man den Reichsten von den Industrieleuten für sich gewinnt und diesen sammeln läßt ..."

Von Linde vermittelte ihm dann die Bekanntschaft mit dem kaufmännischen Leiter der Elberfelder Farbwerke, Henry Böttinger, dem es selbst ein Anliegen war, mit Kreisen der Wissenschaft in enge Beziehungen zu treten. Dank seines Interesses an Kleins Ideen und seines uneigennützigen, persönlichen Einsatzes für die große Sache konnten schließlich so viel Mittel aufgebracht werden, daß die technische Forschung an die Universität geholt werden konnte. So hatte er zweifellos entscheidenden Anteil an der Verwirklichung dieser neuzeitlichen Projekte. Durch Ministerialdirektor Althoff in Berlin, der eng mit Klein zusammenarbeitete, hat Böttinger den erblichen Adel und den Sitz im preußischen Herrenhaus erhalten.

1950 war das Jahr einiger Jubiläen, die Prandtl selbst betrafen. Er feierte seinen 75. Geburstag, sein goldenes Doktorjubiläum, seine 50jährige Mitgliedschaft im Verein Deutscher Ingenieure, und im Juli gedachte man der 25 Jahre der Institutsgeschichte, von der Einweihung des Strömungsforschungsinstitutes bis in diese Nachkriegszeit.

In der Zeitschrift "Forschungen und Fortschritte" veröffentlichte Professor Tollmien einen Artikel zum 75. Geburtstag Prandtls [49]. Sein Werdegang ist dem Leser ja genugsam bekannt, so daB ich hier nur den ersten und letzten Absatz dieser Schrift anführen möchte. Tollmien beginnt folgendermaßen: "Epochen in der Geschichte eines bedeutenden Mannes richten sich nicht nach runden Jahreszahlen, derartige ausgezeichnete Daten sind eine Mahnung für die Mitwelt, sich der Verdienste des Gefeierten zu vergewissern und das Errungene zu bewahren." Er beschließt den Artikel mit folgenden Worten: "Bei diesem knappen Überblick über das bisherige Wirken von Prandtl darf sein bedeutender EinfluB als wissenschaftlicher Erzieher nicht übergangen werden. Zu den vielen Doktoranden, die im Lauf der Jahre bei Prandtl promovierten, kamen mit dem fortschreitenden Ausbau der Göttinger Institute zahlreiche Mitarbeiter, die im persönlichen Verkehr seiner Anregungen teilhaftig wurden. Mit seiner Emeritierung im Jahr 1946 hat Prandtl freilich seine Vorlesungstätigkeit aufgegeben, doch beteiligt er sich mit der Fülle seines überlegenen Wissens 
und mit dem ihm eigenen entschiedenen Temperament an den Diskussionen in dem Kolloquium über Fragen der angewandten Mathematik und Mechanik. Im MaxPlanck-Institut für Strömungsforschung leitet Prandtl Forschungsarbeiten in einer eigenen Abteilung. Nicht zuletzt zeigen die Veröffentlichungen der allerletzten Jahre, von denen nur einige an dieser Stelle erwähnt werden konnten, daß Prandtl es nicht nötig hat, die Rolle einer 'historischen Figur' zu spielen, sondern daß er mitten in einem gesegneten, höchst anziehenden Altersschaffen steht.

Möge uns, Prandlts Schülern und Freunden, wie den Fachgenossen in aller Welt noch lange das Glück beschieden sein, den verehrungswürdigen Mann in unserer Mitte wirken zu sehen."

Auch vom Ausland erreichten ihn viele Glückwünsche seiner einstmaligen Schüler. 


\section{Allerletzte Lebensjahre}

Um nun von seinen letzten Lebensjahren zu berichten, vornehmlich über seine Tätigkeiten und Reflexionen von mancherlei Art, habe ich seine Korrespondenz aus dieser Zeit herangezogen. Ich werde mich aber nur auf die Mitteilungen beschränken, die ganz Persönliches aussagen.

In dem Briefaustausch mit früheren Mitarbeitern, die nun in England, Amerika, auch in Rußland einen neuen Wirkungsbereich gefunden hatten, wird das freundschaftliche Vertrauensverhältnis, das zwischen Prandtl und seinen Schülern bestand, noch einmal deutlich.

In einem Brief vom 1. März 1950 antwortet Prandtl Herrn Professor Bock in Moskau, dessen Rundbrief ihn erreicht hatte. Prof. G. Bock, der seit 1936 in Berlin in der Versuchsanstalt Adlershof eine leitende Stelle innehatte, wurde bei Kriegsende verhaftet und in die UdSSR gebracht. Nach einer sehr harten Zeit im Lubjanka-Gefängnis konnte er dann in Moskau wissenschaftlich arbeiten, und zwar im AeroHydronamischen Zentralinstitut. Er litt sehr unter der Trennung von seiner Familie.

Aus Prandtls Antwortbrief:

"Der Rundbrief gibt eine einigermaßen anschauliche Vorstellung von der Art, wie Sie dort leben. Er meldet leider auch, daß Sie durch den Weggang einer Arbeitsgruppe einsamer geworden sind. Wenn es so bald nicht anders werden sollte, so haben Sie doch das Bewußtsein, daß in der Ferne Ihre Gattin und Ihre Kinder leben und daß Sie für die letzteren sorgen.

Was mich betrifft, so habe ich vor nicht ganz 10 Jahren meine Gattin verloren, und wenn ich auch zwei Töchter habe, von denen die eine kinderlos ist und Kriegswitwe, die andere aber zwei muntere Töchterchen von 5 und 2 1/2 Jahren hat und einen munteren jungen Mann, so ist das doch kein Ersatz für die Gattin, mit der ich 31 Jahre lang alles, Freud und Leid, teilen konnte und die mir in der Folgezeit immer sehr gefehlt hat. Der Spruch, den Sie in Ihrem Briefe anführen, 'Gewohnheit ist uns von oben gegeben. Sie ist Ersatz für das Glück', trifft auch auf mich zu. Wie das in Deutschland jetzt so ist, wo durch die Vernichtung von Wohnungen und durch die aus östlichen Ländern vertriebenen Deutschen die Wohnungen doppelt belegt sind, leben 
meine Töchter in meiner Wohnung und halten den Haushalt in Gang. Aber das Glück war das andere gewesen.

Mit meiner Gesundheit bin ich, soweit man das von einem 75-jährigen verlangen kann, noch recht zufrieden.

Die Arbeitsrichtung des Instituts bedurfte natürlich gegen früher einer erheblichen Umstellung, die noch gar nicht beendet ist. Ich selbst tue auch nach Kräften noch mit und habe mich auf ein Steckenpferd, das ich schon früher ritt, umgestellt, die dynamische Meteorologie. Die meteorologische Wissenschaft ist besonders in Amerika, aber auch in Norwegen, Schweden, England in schönem Fortschreiten und scheint nachholen zu wollen, was bisher versäumt worden ist. Zum Teil sind es auch neue Forschungsmittel wie Radar, mit deren Hilfe man die Windgeschwindigkeiten, auch in großer Höhe messend, verfolgen kann. Man weiß jetzt über die Atmosphäre bis zu Höhen von $20 \mathrm{~km}$ recht gut Bescheid, so daß es sich wirklich lohnt, die Dinge dynamisch zu verfolgen.

Damit habe ich mich auf meine alten Tage also noch einmal einer jugendlichen Wissenschaft an den Hals geworfen, wo es wirklich Spaß macht, unerforschten Dingen nachzugehen. Wenn man diese Seite meiner Arbeit betrachtet, so hatte ich tatsächlich in puncto Wissenschaft noch einmal Glück!"

Auch in einem eigentlich formellen Antwortschreiben legte er Wert auf sehr persönliche Erwiderung:

16.12.1949: An die Indische Mathematische Gesellschaft, Madras: "Die Indische Mathematische Gesellschaft hatte die große Freundlichkeit, mir anzuzeigen, daß sie am 26. bis 29. Dezember dieses Jahres an der Universität in Madras ihre diesjährige Versammlung abhält. In Ihrem Einladungsschreiben nennen Sie mich 'an eminent mathematician'. Diese Bezeichnung kann ich für mich in keiner Weise in Anspruch nehmen. Ich bin Ingenieur, und wenn Sie wollen, Theoretiker des Ingenieurfaches und habe in verschiedenen Fällen Mathematik auf meine Probleme angewandt. Aber ich habe niemals die mathematische Wissenschaft durch irgendeinen Beitrag gefördert. Für Ihre guten Absichten spreche ich Ihnen meinen besten Dank aus und wünsche Ihnen für Ihre Tagung den besten Erfolg." 
Im April 1950 war unsere dritte Tochter Ruth zur Welt gekommen, und natürlich hatte der Großvater seine Freude daran, noch einmal ein Enkelchen in seiner Wohnung aufwachsen zu sehen. Aber es blieb mir seitdem noch weniger Zeit, mit dem Vater einen ungestörten Abend zu verplaudern. Hingegen sorgte meine Schwester treulich für sein Wohlergehen.

Aus Anlaß des 25jährigen Bestehens des Kaiser-Wilhelm-Instituts für Strömungsforschung, das nun schon Max-Planck-Institut hieß, fand am 15.Juli 1950 in Göttingen eine Feier statt, zu der erstmals nach dem Kriege viele frühere Mitarbeiter und Schüler Prandtls aus dem In- und Ausland gekommen waren; es war zugleich das letzte Mal, daß er seine älteren Mitarbeiter in größerer Zahl um sich versammeln konnte.

Im Spätherbst, am 19. November 1950, einem Samstag - es war der Geburtstag meiner Schwester -, machte er wie üblich einen Waldspaziergang, als ihn beim Bücken nach frischem Efeugrün plötzlich ein Gehirnschlag traf. Er hatte diesen anspruchslosen Schmuck aus dem nun schon eintönigen Herbstwald zur Tischdekoration mitbringen wollen.

Hier sein eigener Bericht von dem Vorfall: "Ich habe zwar etwas gespürt im Kopf, aber mit der mir eigenen Hartnäckigkeit habe ich doch noch weitergepflückt." Er kam hinkend nach Hause. Der Arzt, den wir sofort holten, stellte eine Lähmung von Bein und Arm fest und verordnete ihm absolut ruhiges Verhalten im Haus. Mehrere Wochen blieb er unser Patient, saß tagsüber in einem breiten Lehnstuhl sehr geduldig, aber doch traurig, daß seine Arbeit im Institut liegenbleiben mußte. Von den Besuchern, die ihn gut zu unterhalten wußten und ihn über Institutsangelegenheiten auf dem laufenden hielten, empfing er Anregung und Aufmunterung. An Herrn Dr. Rotta liegt ein Brief vor vom 27. November, der bekundet, daß er sich trotz seines Schwächezustandes mit fachlichen Problemen auseinandersetzte:

"Ich habe eine Arbeit von S... zur Beurteilung erhalten ... Ich habe sie von Anfang bis zum Ende durchgeschaut. Wenn Sie sich über den Inhalt und den Wert der Szablewskischen Arbeit orientiert haben werden, würde ich mich über einen Besuch von Ihnen in meinem Krankenzimmer freuen." 
Manches, was vorher an Schriftverkehr liegengeblieben war, konnte er nun endlich erledigen. Dabei gab es eine Angelegenheit von besonderer Dringlichkeit.

In einem Brief vom 29. November 1950 wandte Prandtl sich an den katholischen Kirchenvorstand mit der Erklärung, daß er beabsichtige, aus der Kirche auszutreten. In diesem Jahr hatte Papst Pius XII. die Himmelfahrt Mariä zum formellen Dogma erhoben.

"Verspätet durch Arbeitsdrang und schließlich durch Krankheit, wünsche ich meinen Austritt aus der katholischen Kirche hiermit zu erklären.

Aus den Zeitungen habe ich entnommen, daß die irdischen Überreste des Leibes der Mutter Maria in den Himmel versetzt worden seien. Dies ist ein für einen naturwissenschaftlich gebildeten Menschen ganz unvorstellbarer Sachverhalt und kann infolgedessen jemandem, der mit allem Ernste Naturwissenschaft treibt, nicht als Glaubenssatz vorgeschrieben werden. Ich bemerke dazu, daß ich mich bereits seit 1905, als es sich um den Anti-Modernisteneid drehte, innerlich von der Kirche gelöst habe.

Ich habe jedoch äußerlich trotzdem der Kirche die Treue gehalten, da mich viele wertvolle Jugenderinnerungen an sie gebunden haben. Wenn es sich damals um die Knebelung der Gedankenfreiheit der katholischen Priester gehandelt hat, die mir sehr wenig klug erschienen war, handelt es sich aber jetzt um meine eigene Einstellung.

Ich würde mir unehrlich vorkommen, wenn ich durch Verbleiben in der katholischen Gemeinschaft meine formelle Zustimmung zu dem neuen Glaubenssatz geben würde, der der Kirche wahrscheinlich noch sehr viel Schaden zufügen wird.

Es kann sich nicht bewähren, wenn die Kirche dauernd die Vorstellungen der Naturwissenschaft ignoriert ..."

Besuche im Krankenzimmer waren, wie gesagt, immer höchst willkommen. Einmal besuchte ihn der Kunstmaler Wolfgang Willrich. Als mein Vater im Laufe des Gesprächs von ihm erfuhr, daß er auch Klavierspieler sei und die Gewohnheit habe, sich zur freien Improvisation an das Instrument zu setzen, bat er ihn, den Flügel zu öffnen und ihm etwas vorzuspielen. Der kraftvolle Wohlklang einer eigenen musikalischen Schöpfung erfüllte alsbald das Krankenzimmer. Mein Vater war sehr bewegt. 
Ich sah Tränen der Rührung in seinen Augen. Diese Art des Musizierens beglückte ihn in ihrer Ursprünglichkeit. Und der Gedanke, daß er nun seit vielen Tagen nicht in der Lage gewesen war, selbst am Klavier eine musikalische Eingebung zu gestalten, mag ihm dabei wohl schmerzlich bewußt geworden sein.

Welches Glück hatte es ihm doch immer bedeutet, seine Innenwelt durch das Spiel auszudrücken. Er bedankte sich mit vielen Worten für das Vorspiel, lobte die Begabung des Gastes, dem die Ausgestaltung eines reizvollen musikalischen Themas so wohl gelungen war, und hielt dagegen sein gegenwärtiges Versagen.

Der Zuspruch Herrn Willrichs, daß er die Hoffnung auf Besserung nicht fallen lassen möge, klang jedoch recht tröstlich. Es trat tatsächlich im Laufe von Tagen des geduldigen Zuwartens eine Besserung ein. Durch allmähliche Resorption ging die Lähmung zurück. Sobald es ihm möglich war, begab er sich ins Institut. Anfänglich wurde er im Dienstwagen der AVA abgeholt, aber bald zog er es doch vor, unabhängig zu sein, indem er sich wieder wie eh und je zu Fuß auf den Weg machte. Es drängte ihn, mit der Neuauflage der Strömungslehre voranzukommen. Allerdings hatte seine Arbeitskraft spürbar nachgelassen, er ermüdete viel schneller als früher.

Er schrieb am 7. Januar 1951 an Professor Grammel:

"Die Lähmung meines rechten Beines ist inzwischen schon recht weit zurückgegangen. Ich hinke zwar noch ein wenig, aber ich habe schon wieder angefangen, auf dem Göttinger Hainberg kleinere Spaziergänge zu machen."

19. Januar 1951 an Professor Busemann:

"Inzwischen bin ich dabei, für eine neue Auflage meines Buches den Stoff durchzusehen und mich darum zu kümmern, was etwa Wichtiges in der Welt passiert ist."

2. März 1951 an Professor Grammel:

"Ich stelle mit gewisser Betrübnis fest, daß man eben doch nicht ungestraft 76 Jahre alt werden darf und bezüglich des Ruhestandes sich auf kommende Zeiten vertrösten muß." 


\section{Juni 1951 an Professor G. Bock:}

"Daß ich erst heute antworte hat seinen Grund hauptsächlich darin, daß ich mit den Vorbereitungen der neuen Auflage der Strömungslehre in letzter Zeit ziemlich angestrengt zu arbeiten habe. Das Tempo, in dem sich die Strömungslehre weiterentwickelt, ist, hauptsächlich durch die amerikanischen Publikationen, so heftig geworden, daß man gar nicht daran denken kann, einen wirklichen Überblick über alle einzelnen Teilgebiete zu bringen. Meine Arbeitskraft läßt doch ziemlich nach, und vor allem wäre ich gar nicht imstande, die heutige Fachliteratur wirklich zu verfolgen. Wenn ich dieses vorausgesehen hätte, so hätte ich vielleicht das Programm etwas bescheidener gesteckt. Denn von einem 'Führer', der das Buch sein soll, verlangt man schließlich, daß alle wichtigen Dinge darin erwähnt sein müssen. Ich lasse mir jetzt natürlich schon von meinen früheren Schülern kräftig helfen, sonst wäre die Sache hoffnungslos. Es ist für mich ein wahrer Segen, daß ich nicht Russisch verstehe, sonst wäre die Menge des zu Referierenden eben noch größer ... Wenn die Russen den Zustand, daß ihre Arbeiten nicht bekannt geworden sind, ändern wollen, dann müssen sie eben selbst Übersetzungen in eine westliche Sprache anfertigen und werden dadurch schon bekannt werden!"

In jenem Frühjahr 1951 schaffte sich mein Mann ein kleines Auto an, einen Zweisitzer; aber man konnte auch zu viert darin Platz finden. Für meinen Vater gab es nun manche nette Spazierfahrt, die er fröhlich mit uns genoß. Einmal, auf einem Ausflug in den Harz, als uns ein Regenschauer überraschte, fiel meinem Mann auf, wie an der linken Kante der Windschutzscheibe erhebliche Mengen von Regenwasser statt abzulaufen, langam emporstiegen. Da er gern fragte, machte er meinen Vater auf dieses Phänomen aufmerksam. Der schaute sich die Sache an und sagte mit Nachdruck nur ein Wort: "Stimmt!" Wobei sein leises Lächeln eine gewisse humorvolle Distanz erkennen ließ, da er mit diesem Wort ja die Genugtuung zum Ausdruck brachte, daß sich das feuchte Element nach den Regeln richtet, die die Strömungswissenschaft ihm "vorschreibt".

Für den Sommer 1951 hatte er einen längeren Ferienurlaub eingeplant, um gründlich auszuspannen. Meine Schwester begleitete ihn auf dieser Reise nach Bayern. Es waren seine letzten Sommerferien. 
Am 10. November 1951 feierte man in Göttingen wiederum ein Jubiläum: das 200jährige Bestehen der Akademie der Wissenschaften, die 1751, 14 Jahre nach der Gründung der Georgia Augusta, ins Leben gerufen worden war. Lehre und Forschung sollten sich von nun an wechselseitig befruchten können. Und wie ich mir habe sagen lassen, ist es sicher, daß "die Göttingsche Art" an der Gestaltung der modernen Hochschulen andernorts mitgewirkt hat.

$\mathrm{Zu}$ diesem bedeutenden Anlaß war der Bundespräsident, Theodor Heuß, für einige Tage zu Besuch nach Göttingen gekommen, was die ganze Stadt in freudige Stimmung versetzte. Der damalige Präsident der Akademie der Wissenschaften, Professor Werner Heisenberg, hat der besonderen Feier vorgestanden. Der Festakt in der Aula am 10. November fand unter stärkster Teilnahme in- und ausländischer Gelehrter statt.

Am Tag zuvor, am 9. November, war Heuß mit dem Präsidenten der Max-PlanckGesellschaft, Otto Hahn, zusammengetroffen und hatte auch das Max-Planck-Institut für Strömungsforschung mit seinem Besuch beehrt. Im Rahmen einer Feierstunde verlieh er Prandtl das Bundesverdienstkreuz.

Es sei hier noch ein Wort aus einer Ansprache wiedergegeben, die Heuß zum Abschluß seines Besuches im Rathaus gehalten hat: "Göttingen ist eine kleine Stadt, durch die aber die Ströme der Welt gehen."

Zur bleibenden Erinnerung an seinen Besuch pflanzte der Bundespräsident im Beisein der ganzen Belegschaft der dortigen Institute eine junge Linde auf einem Rondell nahe der Eingangspforte. Sie ist inzwischen ein stattlich hoher Baum geworden und wird unter Eingeweihten heute noch die "Heuß-Linde" genannt.

Das wenige, was mir noch zu berichten bleibt, ehe mein Vater Anfang August 1952 einen erneuten Schlaganfall erlitt, sind wiederum einige persönliche Mitteilungen über sein Befinden, die er dem fachlichen Briefinhalt anzufügen pflegte, wenn er an die ihm befreundeten Kollegen schrieb.

22. April 1952 an Professor Blenk:

"Meine eigenen Kräfte haben in letzter Zeit leider ziemlich nachgelassen, so daß Sie 
von mir wohl nicht mehr sehr viel aktive Tätigkeit in dieser Richtung (er war zum Ehrenmitglied der neubegründeten WGL ernannt worden) werden erwarten dürfen."

18. März 1952 an Professor Tietjens, Bangalore:

"Ich selbst will diesmal mit meiner Tochter Hilde nach Bad Gastein gehen, um allerhand Anzeichen des Alters hier wieder in eine mildere Form überzuführen."

Am 1. Mai 1952 reiste er also in Begleitung meiner Schwester für drei Wochen nach Bad Gastein. Sie waren dort in dem Haus des emeritierten Kollegen Pröll bestens untergebracht. Die Kuranwendungen jedoch haben ihn letztlich zu sehr angestrengt, und er fühlte sich bei seiner Rückkehr nicht erholt. Es bekümmerte ihn, daß er seine frühere Energie und Ausdauer nicht hatte wiedererlangen können.

30. Juni 1952 an Dipl.-Ing. R. Langer, einen früheren Mitarbeiter:

"Daß es mir in jeder Beziehung gut ginge, kann ich leider nicht sagen. Ich habe mich aufgrund besonders guter Erfahrungen von Kollegen dazu entschlossen, eine Kur in Bad Gastein zu machen. Aber die Badekur hat mir nicht gut zugesagt, so daß ich nachträglich nötig hätte, mich von der Gasteiner Kur zu erholen. Man redet in Gastein viel davon, daß die eigentliche Erholung ein halbes Jahr später käme. Wollen wir also das Beste hoffen!"

Von dem plötzlich eintretenden Gehirnschlag Anfang August erholte sich mein Vater nun nicht mehr. Die erneute Hinfälligkeit führte zu einem langen Krankenlager. Wir nahmen eine Pflegerin ins Haus. "Schwester Lenchen" war sich ihrer besonderen Aufgabe bewußt und sorgte gewissenhaft und liebevoll für ihren Patienten. Sie blieb bis zu seinem Tod bei uns. Wie oft hörte ich sie sagen: "Der Herr Professor ist so geduldig und anspruchslos, er hat gar keine Wünsche oder Forderungen, sondern ist mit allem zufrieden und dankbar für jede Handreichung. Rücksichtsvoll bedenkt er sogar, inwiefern er mir manche kleinen Arbeiten erleichtern könnte. Noch niemals habe ich einen so bescheidenen, sanftmütigen Patienten gepflegt."

Die einzige Verlegenheit, die er uns anfangs bereitete, waren seine eigenwilligen Versuche, trotz seiner Schwäche wie eh und je den Weg ins Institut zu nehmen. Aber dort angekommen, fehlte ihm gänzlich die geistige Konzentration. Seine Erschöpfung war nicht zu verbergen, und man brachte ihn nach Haus. Die Aerodynamische 
Versuchsanstalt war durch all die Jahre das eigentliche Zentrum seines Daseins gewesen, von dem zu scheiden er sich nur zögernd und betrübten Herzens anschickte.

Der Krankheitszustand verschlimmerte sich, und er wußte, daß er sich nun nicht mehr erholen würde. Klaglos fügte er sich in das Unabänderliche. Am 15. August 1953 starb er. Bis zuletzt blieb er in seiner gewohnten Umgebung.

Es ergaben sich Schwierigkeiten, seine Trauerfeier zu gestalten, da die Theologen der Universität es ablehnten, dem Kollegen, der kürzlich aus der Kirche ausgetreten war, ein christliches Geleitwort zu sprechen. Ungeachtet dieser Tatsache hielt jedoch der Pfarrer der Reformierten Kirche, Pastor Th. Kamlah, die Grabrede. Ich zitiere einen Satz daraus.

20. August 1953: "Die letzten, tiefsten Fragen des Lebens machte er mit sich selbst ab und pflegte nicht darüber zu reden. Es war eine der teuersten Stunden meines Amtslebens, als er beim Tod seiner Frau zu mir kam und mir, davon tief bewegt, einen Einblick in seine feine Seele schenkte."

In seiner Einleitung zu "Ludwig Prandtls Gesammelten Abhandlungen" erinnert sich sein früherer Schüler und späterer Nachfolger, Professor Walter Tollmien [50]:

"Es war im November 1950, daß ihn ein leichter Schlaganfall traf, von dem er sich nicht zuletzt dank einer großen Willensanstrengung sehr bald erholte. Jedoch beobachtete seine Umgebung mit Sorge die einige Monate später einsetzende ständige Abnahme seiner Kräfte. Im August 1952 trat der gefürchtete Zusammenbruch ein, wonach ihm ein geordneter Ausdruck seiner Gedanken nicht mehr möglich war. Auch dann noch schimmerte aus seinem Verhalten seine Herzensgüte hervor. Ich wurde an den greisen Immanuel Kant erinnert, der in ähnlicher Weise verlosch.

Während meines letzten Besuches bei Prandtl sprachen nur seine Augen, bis er mir beim letzten Händedruck die beiden Worte sagte: 'Wir danken'. Ich weiß, daß ich im Sinne des Verewigten handele, wenn ich diesen Dank an alle seine Mitarbeiter, an alle Helfer seines Werkes und an seine wissenschaftlichen Freunde weitergebe." 


\section{Schlußbemerkung}

Vier Jahre nach Prandtls Tod wurde zur Ehrung und Erinnerung an seine Pionierleistung in der Flugwissenschaft eine Auszeichnung für die nachfolgenden Aerodynamiker geschaffen, die seinen Namen festhalten sollte. Man wählte zum Symbol einen goldenen Ring, der in hervorgehobener Schrift seinen Namen trägt, und nannte ihn LUDWIG-PRANDTL-Ring. In den großen Stein aus Bergkristall ist die Figur eines Adlers geschnitten, der die Freiheit des Geistes versinnbildlichen soll.

Zum Datum der erstmaligen Verleihung wählte man den 4. Februar, seinen Geburtstag, im Jahr 1957. Die Wissenschaftliche Gesellschaft für Luftfahrt verlieh diese höchste Auszeichnung dem Aerodynamiker Theodore von Kármán. Und da er nicht persönlich in Göttingen anwesend sein konnte, schickte er ein Schreiben, das bei der Feierstunde verlesen wurde: "Ich betrachte es als eine große Ehre, daß der Ludwig-Prandtl-Ring bei der ersten Verleihung mir zuerkannt wurde ... Prandtls Einfluß war entscheidend für meine wissenschaftliche Entwicklung, und ich gedenke seiner stets in Dankbarkeit und Verehrung."

Seitdem wurde der Ludwig-Prandtl-Ring an viele verdiente Aerodynamiker verliehen, die einst als seine Schüler neben ihm gearbeitet haben. Es waren Wissenschaftler von besonderem Rang, die die Forschung weiter vorangetrieben haben und ihr neue Impulse gaben.

Nachdem sich der Geburtstag Ludwig Prandtls am 4. Februar 1975 zum 100. Male gejährt hatte, wurde am 3. April in der Göttinger Stadthalle eine Gedächtnisfeier im Rahmen der wissenschaftlichen Jahrestagung der Gesellschaft für Angewandte Mathematik, deren erster Vorsitzender Prandtl über 20 Jahre lang gewesen war, veranstaltet [9]. Sie war verbunden mit der Ludwig-Prandtl-Vorlesung, die hier zum 18. Male stattfand; diese wurde von Fritz Schultz-Grunow gehalten. Im gleichen Jahr brachte das Max-Planck-Institut für Strömungsforschung aus Anlaß seines 50jährigen Bestehens eine Festschrift heraus [18]. 


\title{
Anhang
}

Prof. Dr. L. Prandtl

\author{
Anlage zum Brief vom 28.IV.1941 - Pp.314/41 - \\ an Herrn Reichsmarschall Hermann Göring
}

\section{I. Über die theoretische Physik}

Die Aufgabe der theoretischen Physik ist es, ein logisch widerspruchsfreies Gedankengebäude aufzuführen, durch das in die Beobachtungstatsachen eine Ordnung derart hereingebracht werden kann, daß selbst weitauseinanderliegende Tatbestände eine gemeinsame und dabei möglichst exakte Erklärung finden. Die aus dieser Arbeit resultierenden Gesetze können dann umgekehrt wieder zur Voraussage neuer Versuchstatsachen dienen. Von einer Theorie muß verlangt werden, daß sie in sich ohne logische Widersprüche ist und daß sie in ihren Ergebnissen den Tatsachen gerecht wird. Je nach den Hypothesen, die man der Theorie zugrundelegt, kann es zu ein und derselben Gruppe von Tatsachenbeständen auch mehrere zulässige Theorien geben. Wird nun eine neue Tatsache beobachtet, die mit einer dieser Theorien in Einklang ist, mit einer anderen dagegen nicht, so muß diese andere Theorie verlassen werden. Dieser Fall ist um die Jahrhundertwende eingetreten durch die experimentellen Feststellungen, die der sogenannte Michelsonsche Interferenzversuch geliefert hat. Dieser Versuch hätte aufgrund der bis dahin als unumstößlich richtig geltenden Newtonschen Raum-Zeit-Anschauung eine Aussage über die Relativgeschwindigkeit der Erde gegenüber dem Weltäther erweisen müssen, gab aber trotz mehrfacher verfeinerter Wiederholung immer ein negatives Resultat (statt einer Verschiebung der Interferenzstreifen keine Verschiebung). Damit war die Newtonsche Raum-ZeitAnschauung als grundsätzlich unrichtig nachgewiesen. Die Abweichungen für alle irdischen Vorgänge sind allerdings so gering, daß man diese alte Raum-Zeit-Anschauung immerhin praktisch weiterbenützen könnte. H.A. Lorentz in Leiden hat damals zeigen können, daß die Maxwellschen Gleichungen der Elektrodynamik zu keinem Widerspruch mit den neuen Versuchstatsachen führen, man also nicht in Widersprüche kommt, wenn man die Erscheinungswelt als aus elektrodynamischen Vorgängen bestehend auffaßt. Vom exakten Standpunkt war jetzt die Forderung nach 
einer klaren Formulierung einer Raum-Zeit-Anschauung zu erheben, die den neuen Tatsachen mit voller Exaktheit gerecht wird. Eine solche ist erstmalig von A. Einstein geliefert worden. Sein System ist ohne innere Widersprüche, dabei nach dem Vorgesagten natürlich nicht die einzig mögliche Lösung, aber wohl die einfachste.

Gegenüber diesem Tatbestand steckt die Lenard-Gruppe heute noch wie der Vogel Strauß den Kopf in den Sand und hält an der Newtonschen Raum-Zeit-Anschauung fest, obwohl diese an dem Michelsonschen Experiment längst zerbrochen ist. Die Einsteinsche Raum-Zeit-Anschauung, die von den klar denkenden Physikern in der ganzen Welt als zur Zeit beste Lösung anerkannt ist und die längst zu einem unverlierbaren Fundament der Weiterentwicklung der Physik geworden ist, durfte nach Ansicht der Lenard-Gruppe einfach nicht wahr sein, weil ihr Schöpfer Jude war. Alle weitreichenden Untersuchungen, die seitdem von Ariern mit Hilfe des neuen Instrumentes durchgeführt worden sind, sind also in den Augen der Lenard-Leute "jüdische Physik".

Etwas anders liegt es mit der Quantentheorie, deren Anfänge ebenfalls aus dem Anfang dieses Jahrhunderts stammen. Das physikalische Denkvermögen der Menschen hat sich an der sichtbaren Umwelt entwickelt. Diese besteht nach heutiger gesicherter Kenntnis aus kleinen Teilchen (Atomen), die auch selbst wieder aus noch kleineren Bestandteilen aufgebaut sind. Bei allen sichtbaren Vorgängen hat man es auch auf kleinstem Raum noch mit ungeheuer großen Zahlen solcher Teilchen zu tun, und man hat in allen Vorgängen eine strenge Gesetzmäßigkeit von Ursache und Wirkung zu sehen geglaubt, aus der man ein "Kausalitätsprinzip" ableitete. Die ganze ältere theoretische Physik ist auf solchen kausalen Verknüpfungen der einzelnen Größen miteinander aufgebaut. Heute, wo die Forschung längst in das Innere der Atome eingedrungen ist und man es sozusagen mit den Urbestandteilen der Materie zu tun hat (vermittels gewisser Methoden werden diese Einzelobjekte getrennt wahrnehmbar), hat sich gezeigt, daß hier der Kausalitätsbegriff versagt und durch einen statistischen Wahrscheinlichkeitsbegriff ersetzt werden muß. (Bei zerfallenden Radiumatomen z. B. kann man auf keine Weise angeben, wann ein bestimmtes Radiumatom zerplatzen wird. Man kann aber die durchschnittliche Zahl angeben, die von einer gegebenen Menge Radium in einer Stunde oder in einem Jahr zerplatzt. Derartige Dinge sind nicht auf das Radium beschränkt, sondern spielen bei allen Atomprozessen herein). Die alte Kausalität erweist sich hiernach einfach als das "Gesetz der großen Zahlen", wie es in Fragen über statistische Gesamtheiten jeder 
Art auftritt. Je größer die Zahl, desto geringer sind die zufälligen Abweichungen von dem, was "kausal" zu erwarten wäre. Die Energieumsetzungen in den Atomen, von denen man im einzelnen also nicht weiß, wann und wo sie im Einzelfall auftreten, haben ferner die Eigenschaft, daß je nach der Art der Umsetzung immer ganz bestimmte Energiequanten auf einmal umgesetzt werden (daher der Name Quantentheorie). Mit derartigen Anschauungen war man in der Lage, eine ungeheure Fülle von alten und neuen Beobachtungstatsachen in ein logisch einheitliches System zu bringen. Auch das gilt den Lenard-Leuten als "jüdische Physik", vielleicht nach dem Grundsatz, den ich gelegentlich erwähnt hörte: "Was ich nicht verstehen kann, sehe ich als jüdisch an". Es gibt natürlich auch Beiträge von Juden zu diesem Teil der wissenschaftlichen Entwicklung, aber der überwiegende Teil ist von Männern wie Planck und Sommerfeld bis zu Heisenberg und Schrödinger geschaffen worden.

\section{Einzelheiten über den Lenard-Kreis}

1. Lenard selbst hat sich durch experimentelle Untersuchungen, bei denen er seinerzeit wahrscheinlich auch die Röntgenstrahlen entdeckt hätte, wenn Röntgen ihm nicht zuvorgekommen wäre, verdientermaßen einen bedeutenden Namen geschaffen. Mathematische Theorie hat ihm allerdings nie gelegen, und es wäre alles gut, wenn er nicht über mathematische Dinge zu streiten angefangen hätte. In seinen alten Tagen hat er ein mehrbändiges Lehrbuch geschrieben, dem er den Titel "Deutsche Physik" gegeben hat. Dieses läßt schon bei den einfachen Gesetzmäßigkeiten der gewöhnlichen Mechanik die nötige Klarheit und Strenge vermissen, mag aber als ein Lehrbuch für die Unterstufe einigermaßen hingehen, für die Oberstufe genügt es auf keinen Fall.

2. Ein anderer Exponent der Gruppe ist Johannes Stark, der verflossene Präsident der Physikalisch-Technischen Reichsanstalt. Herrn Stark kenne ich aus seiner Göttinger Privatdozentenzeit als einen reichlich leidenschaftlichen und sonderlichen Mann. Dabei ist er ein ganz glänzender Experimentator und hat zwei Entdeckungen ersten Ranges gemacht, von denen die eine, die in der ganzen Fachwelt "Stark-Effekt" heißt, seinen Namen unsterblich gemacht hat. Mit Theorie hat er sich, soviel mir bekannt, nie abgegeben, was ihn aber nicht hinderte, in unglaublich gehässigen Artikeln, deren einer vor einer Reihe von Jahren im "Schwarzen Korps" erschienen ist, die Herren Planck und Heisenberg maßlos zu beschimpfen. 
3. Die Gruppe hat eine Anzahl Mitläufer, die im wesentlichen experimentell eingestellt sind und die auf ihre Weise verdienstliche Arbeit machen. Daneben finden sich aber auch in ziemlicher Zahl Leute, die sich für verkannte Genies halten, die aber wegen ihrer unzureichenden Leistungen in älteren Zeiten nicht vorwärtskommen konnten und natürlich seit dem national-sozialistischen Umbruch Morgenluft gewittert haben. Von diesen betätigen sich einige sehr ausgiebig in Reformierung der philosophischen Grundlagen der Physik, besonders der RaumZeit-Anschauung, wobei aber für diese ganzen Leute das Michelsonsche Experiment keinerlei Rolle spielt, sie mit anderen Worten der Newtonschen RaumZeit-Anschauung nach wie vor verhaftet bleiben 1 ).

4. Eine besondere Sache ist es mit dem Nachfolger des weltbekannten Münchener Theoretikers Sommerfeld, dem man neben vielem anderen eine klare Ordnung der Gesetze der Spektrallinien verdankt. Dieser Nachfolger mit Namen Wilhelm Müller ist früher Assistent und später Professor der technischen Mechanik gewesen, ersteres in Hannover, letzteres in Prag und Aachen, und hat sich bisher hauptsächlich mit Strömungslehre und Flugmechanik befaßt, auch über Teilgebiete davon Lehrbücher geschrieben. Für die theoretische Physik bringt er aber nichts, rein nichts mit. Statt dem, was die Physiker für ihre Ausbildung nötig hätten, also Elektrodynamik, Elektronentheorie, Optik und Strahlungslehre, Thermodynamik, mathematische Statistik und partielle Differentialgleichungen der Physik, liest er nach eigenen Angaben über Flugmechanik und andere Ingenieurmechanik. Es ist nicht zu leugnen, daß es nützlich ist, daß auch Universitätshörer etwas von diesen Dingen erfahren, aber wenn ihnen deshalb ein ganz wesentlicher Teil der Physik vorenthalten wird, so erzeugt dies eine Sachlage, die man nur als Sabotage des notwenigen Unterrichts bezeichnen kann. Herr Müller hat sich in der "Zeitschrift für die gesamte Naturwissenschaft", Heft vom November-Dezember 1940, S. 281-298 ausführlich über sein Programm geäußert. In diesem Aufsatz, der den Titel trägt "Die Lage der theoretischen Physik an den Universitäten", hat er dabei nicht versäumt, den deutschen Vertretern der theoretischen Physik viel Unfreundliches zu sagen. Im übrigen kommt das physikalische

1) Vgl. verschiedene z.T. gehässige Artikel von Kubach, Thüring, Dingler u.a. in der "Zeitschrift für die gesamte Naturwissenschaft", die sich im Untertitel als "Organ der Reichsfachgruppe Naturwissenschaft der Reichsstudentenführung" bezeichnet. (Auf der Innenseite des Titelblatts Verzeichnis des Redaktionskollegiums!). 
Glaubensbekenntnis der Lenard-Gruppe ausgiebig zum Wort; man kann da lesen, da $\beta$ auf seiten der Theoretiker "eine geheimnisvolle Gruppe von Autoritäten" ... "in fast magischer Weise eine Verpflichtung auf ein bestimmtes Programm" erzwinge, "die jeden bedroht, der es wagt, eine eigene Meinung unabhängig von der Zunft auszusprechen". (Ich habe dazu zu bemerken, daß die "geheimnisvollen Autoritäten" nichts anderes sind als die experimentellen Tatsachen und $\mathrm{da} B$ es sich bei der Bedrohung Andersdenkender um nichts weiter handelt als um die berechtigte Zurückweisung von Querköpfen, die die Tatsachen nicht sehen wollen.) Von den Herren Stark und Müller kündigt übrigens zur Zeit die Helingsche Verlagsanstalt, Leipzig, eine Broschüre "Jüdische und deutsche Physik" an, in der schärfster Kampf angesagt wird: "Gegenüber einem noch immer dem jüdischen Geiste verhafteten Dogmatismus, der nicht der Wahrheit und Erkenntnis dient, sondern die Natur zu vergewaltigen und zu einer bloßen Dienerin der Formel zu erniedrigen strebt." Es soll darin auch der "grundlegende Unterschied zwischen dieser jüdischen oder jüdisch beeinflußten theoretischen Willkür und der deutschen pragmatischen Theorie" an Beispielen dargelegt werden, "die sich nicht an der gegebenen Ordnung auf ein einfachstes anschaulich faßbares System kausaler Gesetzmäßigkeiten zurückzuführen sich bemüht".

Ich glaube, daß diese Textproben genügen, um die Einstellung des Lenard-Kreises hinreichend zu kennzeichnen.

\section{Prandtl}




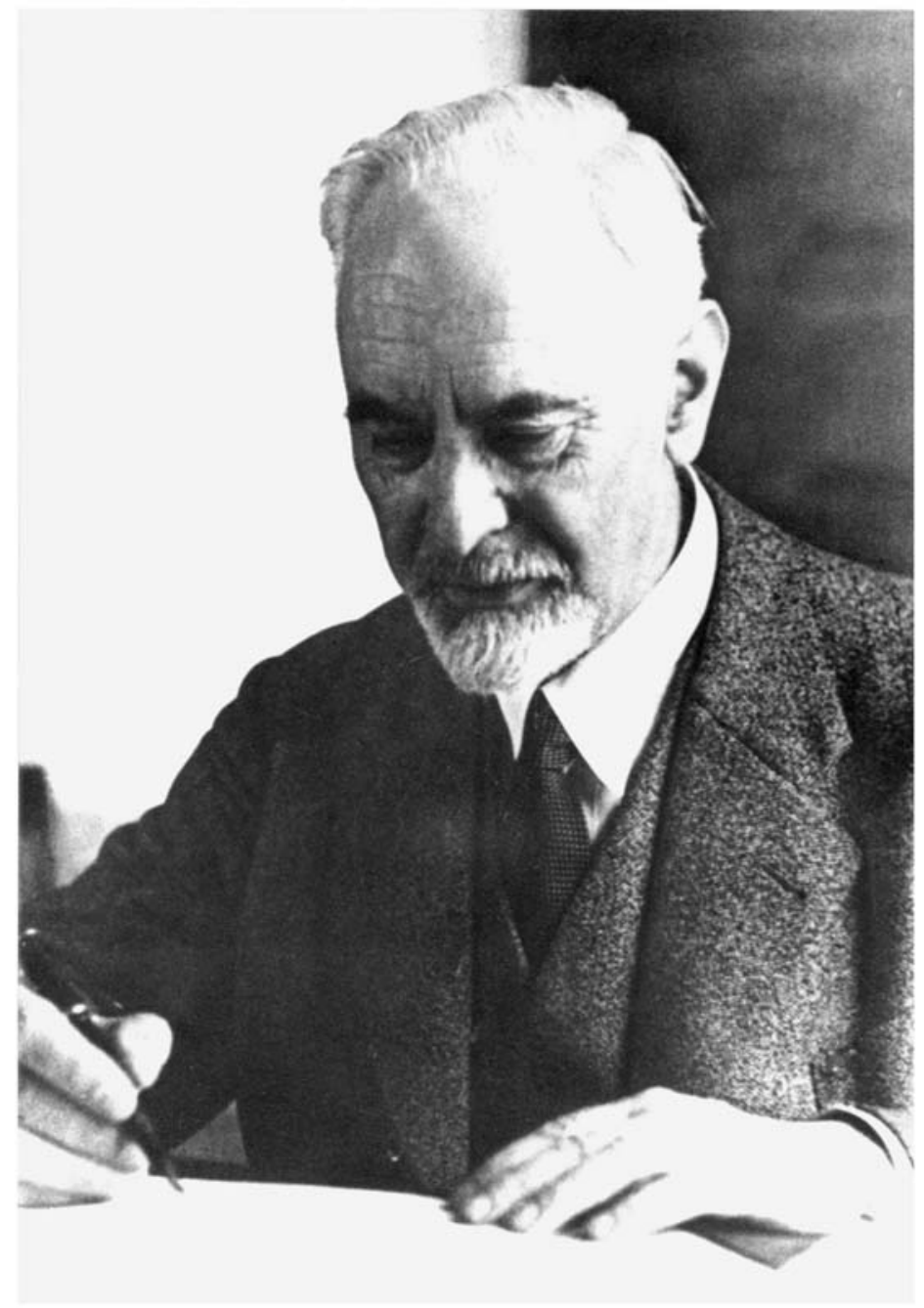

Am Schreibtisch 



\section{Literatur}

[1] Ackeret, J., Das Rotorschiff und seine physikalischen Grundlagen. Verlag Vandenhoeck \& Ruprecht, Göttingen 1925

[2] Ackeret, J., Ludwig Prandtl siebzigjährig. Neue Zürcher Zeitung, 166 Jg, Sonntag 4. Febr. 1945

[3] Betz, A., Aus der Geschichte der Aerodynamischen Versuchsanstalt Göttingen. Jahrb. 1957 d. Max-Planck-Gesellschaft zur Förderung d. Wissenschaften e.V., S. 40 - 59

[4] Betz, A., Das Lebenswerk von L. Prandtl. Neue Zürcher Zeitung Nr. 1953, 11. August 1954

[5] Betz, A., Die AVA und das Max-Planck-Institut für Strömungsforschung. Mit einer Ergänzung von L. Prandtl. In: Die Geschichte der KWG und MPG 1945-1949. Aus Anlaß d. 70. Geburtstages ihres Präsidenten, Otto Hahn, 8.3.1949, S. 20 - 40

[6] Betz, A., Ludwig Prandtl zum 70. Geburtstag. Forschungen und Fortschritte 21/23, 1947, S. 31

[7] Beyerchen, A. D., Wissenschaftler unter Hitler. Titel der Originalausgabe: Scientists under Hitler, Yale University 1977. Deutsch von Erica und Peter Fischer, Verlag Kiepenheuer und Witsch, Köln 1980

[8] Föppl, O., Windkräfte an ebenen und gewölbten Platten. Jahrb. d. Motorluftschiff.Studiengesellschaft 4, 1910-1911, Verlag J. Springer, Berlin 1911, S. 51-119

[9] Gedächtnisveranstaltung für Ludwig Prandtl aus Anlaß seines 100. Geburtstags, verbunden mit der 18. Ludwig-Prandtl-Gedächtnis-Vorlesung. Zeitschr. f. Flugwiss., 23, 1975, S. 149-183

[10] Göttingen unterm Hakenkreuz. Stadt Göttingen, Kulturdezernat 1983

[11] Göttingen 1945, Kriegsende und Neubeginn. Stadt Göttingen, Kulturdezernat 1985

[12] Heisenberg, E., Das politische Leben eines Unpolitischen, Erinnerungen an Werner Heisenberg. R. Piper \& Co. Verlag, München, Zürich 1980

[13] Hergesell, H., Prandtl, L., Das Projekt einer Reichsversuchsanstalt für Luftschiffahrt. Jahrb. Dtsch. Versuchsanst. Luftf. Bd1, 1912/13, Verlag G. Stilke, Berlin, S. 39-52 (In [50]: S. 1412)

[14] v. Kármán, Th., Aerodynamik, Ausgewählte Themen im Lichte der historischen Entwicklung. Interavia Genf 1956

[15] v. Kármán, Th. mit Lee Edson, Die Wirbelstraße. Hoffmann und Campe Verlag, Hamburg 1968 
[16] v. Kármán, Th., Ludwig Prandtl. Zeitschr. Flugt. und Motorl. 16, 1925, S. 37 - 39

[17] Kraemer, K., Geschichte der Gründung des Max-Planck-Instituts für Strömungsforschung in Göttingen, In [18]: S. 16 - 34

[18] Max-Planck-Institut für Strömungsforschung Göttingen, 1925-1975, Festschrift zum 50-jährigen Bestehen des Instituts. Hrsg. MPI f. Strömungsforschung Göttingen, Hubert \& Co. Göttingen 1975

[19] N.N., Ludwig Prandtl 70 Jahre. Luftfahrt-Forschung 21, Febr. 1945, Lfg 2, S. 1-3

[20] Prandtl., L., Anwendung der turbulenten Reibungsgesetze auf atmosphärische Strömungen. Proc. IV. Intern. Congress Appl. Mech., Cambridge/England 1934, S. 238239 (In [50]: S. 1098)

[21] Prandtl, L., Bemerkungen über den Segelflug. Zeitschr. Flugt. Motorl. 12, 1921, S. 209-211 (In [50]: S. 520)

[22] Prandtl, L., Der Luftwiderstand von Kugeln. Nachr. d. Ges. d. Wiss. zu Göttingen, Math.-phys. Kl., 1914, S. 177-190 (In [50]: S. 597)

[23] Prandtl, L., Die Aerodynamische Versuchsanstalt der Kaiser-Wilhelm-Gesellschaft und ihre Bedeutung für die Technik. Die Naturwissenschaften 10, 1922, S. 169-176 (In [50]: S. 1294)

[24] Prandtl, L., Eine neue Darstellung von Torsionsspannungen bei prismatischen Stäben von beliebigem Querschnitt. Jahresber. Math. Ver., 13 , 1904, S. 31-36 (In [50]: S. 81)

[25] Prandtl, L., Erste Erfahrungen mit dem rotierenden Laboratorium. Die Naturwissenschaften 14, 1926, S. 425-427 (In [50]: S. 1304)

[26] Prandtl, L., Felix Klein und die Anwendungen der Mathematik. Universitätsbund Göttingen e.V., Mitteilungen, 26, 1949, H.1, S. 7-11

[27] Prandtl L., Führer durch die Strömungsiehre. Verlag F. Vieweg \& Sohn, Braunschweig 1942 (1944 und 1949 sind 2 von Prandtl bearbeitete Auflagen erschienen, die letztere ist 1956 und 1957 unverändert nachgedruckt worden wegen der großen Nachfrage. Zwischen 1965 und 1990 haben K. Oswatitsch und K. Wieghardt 4 Neuauflagen bearbeitet, an denen weitere Bearbeiter mitgewirkt haben. Insgesamt hat das Buch also 9 Auflagen erfahren)

[28] Prandtl, L., Kipp-Erscheinungen. Ein Fall von instabilem elastischem Gleichgewicht. Inaugural Dissertation d. Phil. Fakultät, Sekt. IId. Ludwigs-Maximilians-Universität München 1899 (In [50]: S. 10)

[29] Prandtl, L., Lehren des Röhnflugs 1922. Zeitschr. Flugt. Motorl. 13, 1922, S. 274-275 (In [50]: S. 526) 
[30] Prandtl, L., Magnuseffekt und Windkraftschiff. Die Naturwissenschaften 13, 1925, S. 93-108 (In [50]: S. 1503)

[31] Prandtl, L., Mein Weg zu hydrodynamischen Theorien. Phys. Blätter 4, 1948, S. 8992. (In ]50[: S. 1604)

[32] Prandtl, L., The Generation of Vortices in Fluids of Small Viscosity. Jo. Roy. Aeron-Soc., 31, 1927, pp 720-743 (In [50]: S. 752)

[33] Prandtl, L., Tragflügeltheorie I. Mitteilg.. Nachr. Ges. Wiss. Göttingen, Math. phys. Kl., 1918, S. 151-177 (In [50]: S. 322)

[34] Prandtl, L., Über die stationären Wellen in einem Gasstrahl. Phys. Z. 5, 1904, S. 599-601 (In [50]: S. 891)

[35] Prandtl, L., Über Flüssigkeitsbewegung bei sehr kleiner Reibung. Verhandlungen d. III. Internat. Math. Kongr. Heidelberg, 8.-13. Aug. 1904. B. G. Teubner, Leipzig 1905, S. 485-491 (In [50]: S. 575)

[36] Prandtl, L., Über Mammatuswolken. Ann. Meteor. 3, 1950, S. 119-120 (In [50]: S. 1179)

[37] Prandtl, L., Verhandlungen der Versammlung von Vertretern der Flugwissenschaft am 03. bis 05. Nov. 1911 zu Göttingen. Verlag R. Oldenbourg, München und Berlin 1912

[38] Prandtl, L., Vorträge an der Kaiserl. Universität in Tokio: Über Turbulenz, J. aeron. Res. Institut, Tokyo Imp. Univ., 5, No. 65, 1930 pp. 12-24 (In [50]: S. 788). Über Gasdynamik, ebenda, pp. 25-34 (In [50]: S. 998). On the Role of Turbulence in Technical Hydrodynamics. World Eng. Congr. Tokyo 1929. Proc. Tokyo, 5, 1931, pp. 495-507 (In [50]: S. 798)

[39] Prandtl, L., Wettervorgänge in der oberen Troposphäre. Nachr. Akad. Wiss. Göttingen. Math.-phys. Kl., 1949, S. 13-18 (In [50]: S. 1173)

[40] Prandtl, L., Zur Torsion von prismatischen Stäben. Phys. Zeitschr. 4, 1903, S. 758 (In [50]: S. 79)

[41] Prandtl, L., Zur Vorgeschichte der Wissenschaftlichen Gesellschaft für Luftfahrt. Zeitschr. Flugt. Motorl. 13, 1922, S. 156-157 (In [50]: S. 1497)

[42] Reid, C., Courant in Göttingen and New York. Springer Verlag Berlin, Heidelberg, New York 1979

[43] Rotta, J.C., Die Aerodynamische Versuchsanstalt in Göttingen, ein Werk Ludwig Prandtls. Verlag Vandenberg \& Ruprecht, Göttingen 1990

[44] Runge, I., Carl Runge und sein wissenschaftliches Werk. Vandenhoeck \& Ruprecht, Göttingen 1949

[45] Schaefer, H., Erkenntnisse und Bekenntnisse eines Wissenschaftlers. Verlag für Medizin Dr. Ewald Fischer GmbH, Heidelberg 1986 
[46] Schultz-Grunow, F., Das geistige Erbe Ludwig Prandtls. Jahrb. 1980 d. Deutsch. Ges. f. Luft- und Raumfahrt, S. $37-9$ bis $37-27$

[47] Staatsbibliothek Berlin (Hrsg), Max Born, James Franck, Physiker in ihrer Zeit. Der Luxus des Gewissens. Ausstellungsexemplar, Stiftung Preussischer Kulturbesitz Berlin 1982

[48] Stamer, F., Zwölf Jahre Wasserkuppe. Hobbing Berlin 1933

[49] Tollmien, W., Ludwig Prandtl zum 75. Geburtstage. Forschungen und Fortschritte, 26, 1950, S. 103-105

[50] Tollmien, W., Schlichting, H., Görtler, H. (Hrsg.), Ludwig Prandtl. Gesammelte Abhandlungen zur angewandten Mechanik, Hydro- und Aerodynamik, 3 Bde. SpringerVerlag Berlin, Göttingen, Heidelberg 1961

[51] Willers, Fr. A. (Hrsg.), Festschrift zu Prandtls 70. Geburtstag. Zeitschr. Angew. Math. Mech. 24, 1944, S. 185-300 